DEPARTAMENTO DE ELECTRÓNICA, TECNOLOGÍA DE COMPUTADORAS Y PROYECTOS

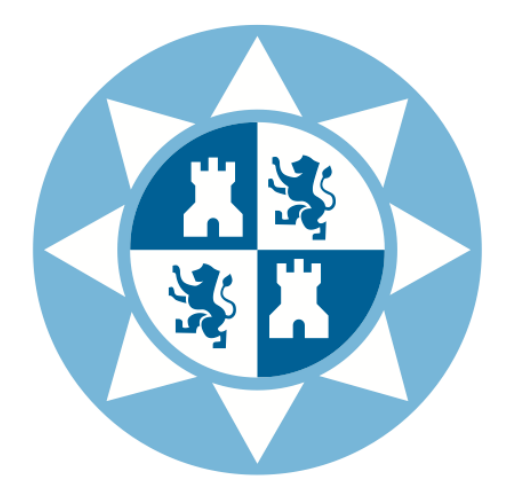

\title{
Estudio y realización de un neuroprocesador biológico: métodos de aprendizaje
}

\section{TESIS DOCTORAL}

Autor: Víctor Lorente Sánchez Director: José Manuel Ferrández Vicente Codirector: Francisco Javier Garrigós Guerrero

Cartagena, Febrero 2014 
El presente documento presenta una Tesis por compendio de publicaciones. Se sustenta sobre cuatro artículos publicados en revistas que se encuentran indexadas en el Journal Citation Reports (JCR), sumando un total de 12 puntos, de los que se requieren 12 por normativa. Una copia íntegra de estas publicaciones ha sido incluida en la memoria, así como un resumen extendido de cada una de ellas. Todo, según las regulaciones aplicables: Artículo 33 del Reglamento de estudios oficiales de máster y doctorado de la Universidad Politécnica de Cartagena, aprobado por Consejo de Gobierno el 13 de abril de 2011 y modificado en Consejo de Gobierno el 11 de julio de 2012.

Los artículos se citan a continuación:

a. Daniel de Santos, Víctor Lorente, Félix de la Paz, José Manuel Cuadra, José R. Álvarez-Sánchez, Eduardo Fernández, José M. Ferrández. A client-server architecture for remotely controlling a robot using a closed-loop system with a biological neuroprocessor. Robotics and Autonomous Systems, 58:12231230, 2010. (JCR-ISI, IF 1.313, Q2).

b. J.M. Ferrández, V. Lorente, F. de la Paz, J.M. Cuadra, José Ramón ÁlvarezSánchez, E. Fernández. A biological neuroprocessor for robotic guidance using a center of area method. Neurocomputing 74:1229-1236, 2011. (JCRISI, IF 1.580, Q2).

c. J.M. Cuadra, J.R. Álvarez-Sánchez, D. De Santos, V. Lorente, J.M. Ferrández, F. de la Paz, E. Fernández. Response calibration in neuroblastoma cultures over multielectrode array. Neurocomputing 75:98-105, 2012. (JCR-ISI, IF 1.634, Q2).

d. J.M. Ferrández, V. Lorente, F. de la Paz, E. Fernández. Training biological neural cultures: Towards Hebbian learning. Neurocomputing 114:3-8, 2013. (JCR-ISI, IF 1.634, Q2).

Las publicaciones anteriores cubren todos los sub-objetivos definidos, logrando así el cumplimiento del objetivo global de la misma. Además, se incluyen una serie de contribuciones que no podían ser incluidas como artículos publicados y que amplían y profundizan los sub-objetivos marcados. Estas contribuciones adicionales fueron publicadas en diferentes congresos nacionales e internacionales y se incluyen en el capítulo referente al trabajo complementario. 
D. José Manuel Ferrández Vicente, Profesor Titular de Universidad del Departamento de Electrónica, Tecnología de Computadoras y Proyectos de la Universidad Politécnica de Cartagena y D. Francisco Javier Garrigós Guerrero, Profesor Titular de Universidad del Departamento de Electrónica, Tecnología de Computadoras y Proyectos de la Universidad Politécnica de Cartagena.

\section{INFORMAN:}

Que los artículos [1], [2], [3] y [4] incluidos en la tesis doctoral titulada "Estudio y realización de un neuroprocesador biológico: métodos de aprendizaje", presentada por D. Víctor Lorente Sánchez, bajo la dirección de los Doctores D. José Manuel Ferrández Vicente y D. Francisco Javier Garrigós Guerrero engloban satisfactoriamente el trabajo de investigación relacionado con la mencionada tesis.

El objetivo general es la realización de un neuroprocesador biológico empleando como plataforma redes neuronales biológicas cultivadas sobre matrices de microelectrodos. Para alcanzar este objetivo general se han debido alcanzar una serie de subobjetivos, que se enumeran a continuación:

O1) Definición y construcción de una plataforma para el soporte en tiempo real de los sistemas de adquisición de registros neuronales, y estimulación eléctrica de los mismos, que se comunique remotamente con un dispositivo robótico.

O2) Estudio y propuesta de un método de guiado robótico basado en una plataforma de lazo cerrado que integre la información de los sensores del robot en el neuroprocesador $\mathrm{y}$, en función de la respuesta de éste, direccione el sistema robótico.

O3) Normalización y calibración estadística de los registros del neuroprocesador para su adecuación a los distintos algoritmos de guiado robótico y aprendizaje en los cultivos neuronales.

O4) Estudio y definición de técnicas de aprendizaje en cultivos neuronales para la realización de conectividad funcional dirigida con objeto de proporcionar nuevos paradigmas de programación en neuroprocesadores biológicos.

Estos subobjetivos han sido alcanzados en su totalidad a través de los cuatro artículos que conforman esta Tesis. El primer artículo [1] propone un sistema de experimentación con cultivos neuronales en lazo cerrado y tiempo real que proporciona las herramientas de filtrado, visualización, procesamiento y estimulación de la respuesta de poblaciones neuronales y su comunicación con un sistema robótico remoto, cubriendo de esta forma el primero de los objetivos. 
El segundo objetivo se realiza en la segunda publicación [2], al adaptar el algoritmo de centro de área para guiado robótico a las respuestas funcionales de las poblaciones de neuronas, e identificando aquella neurona que incrementa más su disparo, winner-takeall, como el objetivo para el direccionamiento del robot.

El tercer artículo [3] cubre el tercer objetivo al proporcionar técnicas de calibración y normalización estadística de los registros de poblaciones de neuronas que conforman el neuroprocesador, con objeto de suprimir la variabilidad intrínseca a las mismas y a las distintas características de no-homogeneidad tanto en la densidad del cultivo como en las propiedades eléctricas de los distintos electrodos.

Por último, el cuarto objetivo se recoge en el artículo [4], al proponer un paradigma de aprendizaje natural, como es el aprendizaje Hebbiano, para la conformación de conexiones funcionales entre electrodos que no se encontraban enlazados previamente y conseguir de esta forma el modelado del cultivo para la implementación en su estructura de las funciones a implementar, en este caso las estructuras de Braitenberg.

Adicionalmente a los artículos principales, se han presentado un número destacado de contribuciones a diferentes congresos nacionales e internacionales que profundizan los sub-objetivos indicados. Algunos de estos artículos son recogidos en la presente tesis como trabajo complementario.

Por tanto, atendiendo a la calidad y contenido de estas publicaciones, consideramos oportuno presentar esta tesis doctoral en la modalidad de "compendio de publicaciones".

[1] Daniel de Santos, Víctor Lorente, Félix de la Paz, José Manuel Cuadra, José R. Álvarez-Sánchez, Eduardo Fernández, José M. Ferrández. A client-server architecture for remotely controlling a robot using a closed-loop system with a biological neuroprocessor. Robotics and Autonomous Systems, 58:12231230, 2010. (JCR-ISI, IF 1.313, Q2). DOI: 10.1016/j.robot.2010.09.003 (http://www.sciencedirect.com/science/article/pii/S0921889010001569)

[2] J.M. Ferrández, V. Lorente, F. de la Paz, J.M. Cuadra, José Ramón ÁlvarezSánchez, E. Fernández. A biological neuroprocessor for robotic guidance using a center of area method. Neurocomputing 74:1229-1236, 2011. (JCRISI, IF 1.580, Q2). DOI: 10.1016/j.neucom.2010.07.018 (http://www.sciencedirect.com/science/article/pii/S0925231210003772)

[3] J.M. Cuadra, J.R. Álvarez-Sánchez, D. De Santos, V. Lorente, J.M. Ferrández, F. de la Paz, E. Fernández. Response calibration in neuroblastoma cultures over multielectrode array. Neurocomputing 75:98-105, 2012. (JCR-ISI, IF 1.634, Q2). DOI: 10.1016/j.neucom.2011.04.038 (http://www.sciencedirect.com/science/article/pii/S0925231211004073)

[4] J.M. Ferrández, V. Lorente, F. de la Paz, E. Fernández. Training biological neural cultures: Towards Hebbian learning. Neurocomputing 114:3-8, 2013. (JCR-ISI, IF 1.634, Q2). DOI: 10.1016/j.neucom.2012.09.031 (http://www.sciencedirect.com/science/article/pii/S0925231212008016) 
En Cartagena, a 21 de Enero de 2014

LOS DIRECTORES DE LA TESIS

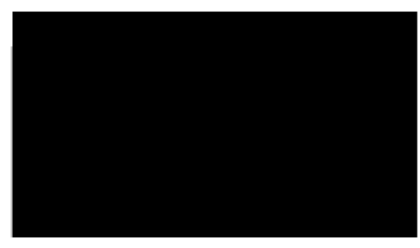

Fdo.: José Manuel Ferrández

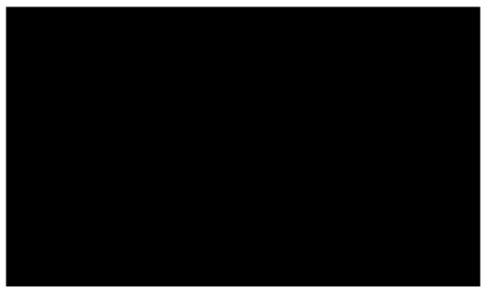

Fdo.: Francisco Javier Garrigós Guerrero

\section{COMISIÓN DE DOCTORADO}




\section{Universidad \\ Politécnica \\ de Cartagena}

\section{CONFORMIDAD DE DEPÓSITO DE TESIS DOCTORAL POR LA COMISIÓN ACADÉMICA DEL PROGRAMA}

D. Fernando Quesada Pereira, Presidente/a de la Comisión Académica del Programa Tecnologías de la información y las comunicaciones.

\section{INFORMA:}

Que la Tesis Doctoral titulada, "Estudio y realización de un neuroprocesador biológico: métodos de aprendizaje", ha sido realizada, dentro del mencionado programa de doctorado, por D. Víctor Lorente Sánchez, bajo la dirección y supervisión de los directores D. José Manuel Ferrández Vicente y Francisco Javier Garrigós Guerrero.

En reunión de la Comisión Académica de fecha , visto que en la misma se acreditan los indicios de calidad correspondientes y la autorización del Director de la misma, se acordó dar la conformidad, con la finalidad de que sea autorizado su depósito por la Comisión de Doctorado.

La Rama de conocimiento por la que esta tesis ha sido desarrollada es:

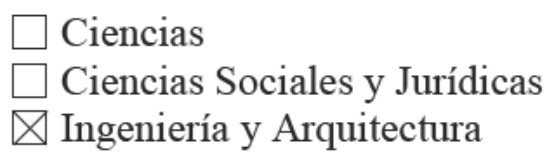

En Cartagena, a 24 de Enero de 2014

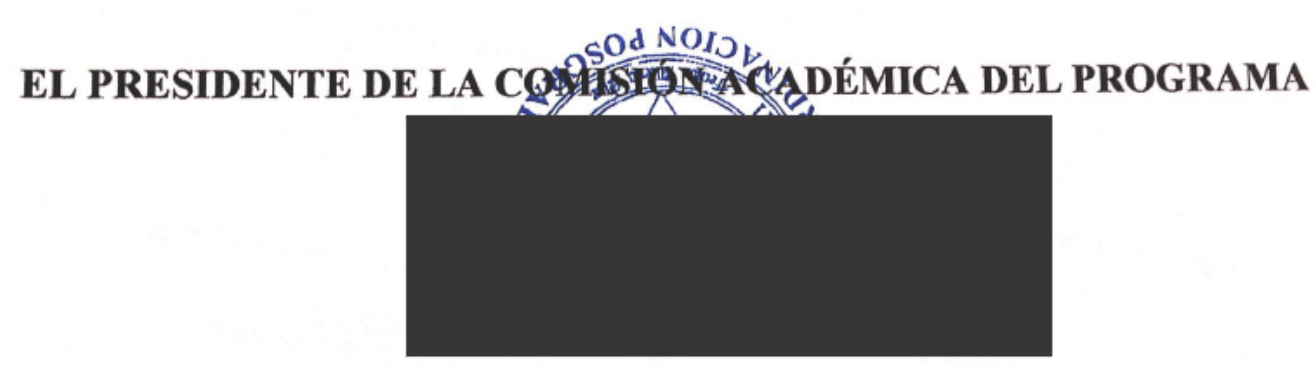

Fdo.: Fernando Quesada Pereira

COMISIÓN DE DOCTORADO 


\section{Víctor Lorente Sánchez}

Vistos los informes favorables de los Directores de Tesis y el $\mathrm{V}^{\circ} \mathrm{B}^{\circ}$ de la Comisión Académica para la presentación de la Tesis Doctoral titulada: "Estudio y realización de un neuroprocesador biológico: métodos de aprendizaje" en la modalidad de "compendio de publicaciones" solicitada por D. Víctor Lorente Sánchez, la Comisión de Doctorado de la Universidad Politécnica de Cartagena, en reunión celebrada el 31 de enero de 2014, considerando lo dispuesto en el artículo 33 del Reglamento de Estudios Oficiales de Máster y Doctorado de la UPCT, aprobado en Consejo de Gobierno el 13 de abril de 2011 y modificado el 11 de julio de 2012,

\section{ACUERDA}

Autorizar la presentación de la Tesis Doctoral a D. Víctor Lorente Sánchez en la modalidad de compendio de publicaciones.

Contra el presente acuerdo, que no agota la vía administrativa, podrá formular recurso de alzada ante el Sr. Rector-Magnífico de la Universidad Politécnica de Cartagena, en el plazo de un mes a partir de la notificación de la presente.

Cartagena, 31 de enero de 2014

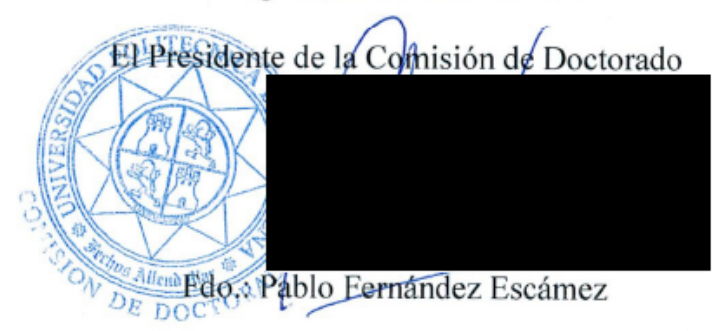


A mi familia, por su gran apoyo. 


\section{Agradecimientos}

El trabajo realizado para dar lugar a esta tesis ha sido fruto de los esfuerzos realizados durante aproximadamente cuatro años. Sin embargo, la magnitud de este aporte no hubiese sido posible sin la participación y apoyo de personas e instituciones que han facilitado las cosas para que este trabajo llegue a un feliz término. Por ello, es para mi un placer poder utilizar este espacio para ser justo y consecuente con ellas, expresándoles mis agradecimientos.

Quiero agradecer de manera especial y sincera al Dr. José Manuel Ferrández Vicente, por aceptarme para realizar esta tesis doctoral bajo su dirección. Su apoyo y confianza en mi trabajo y su capacidad para guiar esta tesis ha sido un aporte invaluable, no solamente en el desarrollo de la misma, sino también en mi formación como investigador. Le agradezco también el haberme facilitado siempre todos los medios a su alcance para llevar a cabo todas las actividades necesarias durante el desarrollo de esta tesis. Continúo mostrando mi agradecimiento al Dr. Francisco Javier Garrigós Guerrero, codirector de la tesis, por sus aportaciones en el campo de la computación, su disponibilidad y su apoyo.

Deseo expresar también mi más sincero agradecimiento al Dr. Eduardo Fernández Jover, director de la Unidad de Neuroprótesis y Rehabilitación Visual del Instituto de Bioingeniería de la Universidad Miguel Hernández de Elche, por aceptarme en su laboratorio en mis diferentes estancias en este centro, por su calidez y apoyo, y por poner todo lo que estaba a su alcance para el buen desarrollo de esta tesis.

Agradezco también a mis compañeros de laboratorio del Instituto de Bioingeniería, Daniel de Santos, Lawrence, Saeid, Andrés y Cristina, por su inestimable ayuda y su disponibilidad. También agradezco a Desi, nuestra técnica de laboratorio, por su gran trabajo realizado con los cultivos neuronales y por estar siempre ahí para lo que necesitemos.

Para mis compañeros de doctorado, sólo tengo palabras de agradecimiento, especialmente a aquellos que me instaron a realizar esta tesis doctoral y con los que compartía numerosas charlas. Ellos son Alejandro Ortuño, Francisco Javier Clemente y Pedro Piñero. Muchas gracias.

Y, por supuesto, el agradecimiento más profundo y sentido va para mi familia. A mis padres, Francisco y Ángeles, por su gran apoyo y ayuda; a mi hermana Ana, por su paciencia y ánimos. Y a Lydia, mi compañera, mi apoyo incondicional; mil gracias por estar siempre ahí en este trayecto aguantando inquebrantable mi lucha. 
Finalmente, debo agradecer a la Fundación Séneca, Agencia de Ciencia y Tecnología de la Región de Murcia, por haber financiado mis estudios doctorales, otorgándome una beca-contrato de Formación Personal Investigador en el año 2010. 


\section{Resumen}

La presente tesis se enmarca dentro de dos campos diferentes pero intrínsecamente unidos entre sí en este caso: neurociencia y computación. El objetivo global de esta tesis es la realización de un neuroprocesador biológico empleando como plataforma redes neuronales biológicas cultivadas sobre matrices de microelectrodos. Este objetivo global resulta en una serie de sub-objetivos:

(1) Definición y construcción de una plataforma para el soporte en tiempo real de los sistemas de adquisición de registros neuronales, y estimulación eléctrica de los mismos, que se comunique remotamente con un dispositivo robótico.

(2) Estudio y propuesta de un método de guiado robótico basado en una plataforma de lazo cerrado que integre la información de los sensores del robot en el neuroprocesador $\mathrm{y}$, en función de la respuesta de éste, direccione el sistema robótico.

(3) Normalización y calibración estadística de los registros del neuroprocesador para su adecuación a los distintos algoritmos de guiado robótico y aprendizaje en los cultivos neuronales.

(4) Estudio y definición de técnicas de aprendizaje en cultivos neuronales para la realización de conectividad funcional dirigida con objeto de proporcionar nuevos paradigmas de programación en neuroprocesadores biológicos.

Con respecto al sub-objetivo (1), se ha propuesto un sistema de experimentación con cultivos neuronales en lazo cerrado y tiempo real que proporciona las herramientas de filtrado, visualización, procesamiento y estimulación de la respuesta electrofisiológica de poblaciones neuronales y su comunicación con un sistema robótico remoto.

Para alcanzar el objetivo (2), se ha adaptado el algoritmo de centro de área para guiado robótico a las respuestas funcionales de las poblaciones de neuronas, identificando aquellos electrodos de la matriz cuyas neuronas incrementan en mayor medida sus disparos, como objetivo para el direccionamiento del robot.

El cumplimiento del sub-objetivo (3) se ha conseguido al proporcionar técnicas de calibración y normalización estadística de los registros de poblaciones de neuronas que conforman el neuroprocesador, con objeto de suprimir la variabilidad intrínseca de las mismas y a las distintas características de no-homogeneidad tanto en la densidad del cultivo como en las propiedades eléctricas de los distintos electrodos. 
Finalmente, atendiendo al sub-objetivo (4), se ha propuesto un paradigma de aprendizaje natural, como es el aprendizaje hebbiano, para la conformación de conexiones funcionales entre electrodos que no se encontraban enlazados previamente y conseguir de esta forma el modelado del cultivo para la implementación en su estructura de las funciones a implementar, en este caso las estructuras de Braitenberg. 


\section{Abstract}

This thesis deals with two different fields, inherently related to each other in this case: neuroscience and computation. The overall objective of this thesis is the development of a biological neuroprocessor with cultured biological neural networks using microelectrode arrays as platform. This objective results in a set of specific subobjectives:

(1) Define and build a platform for real time support of acquisition systems and electrical stimulation systems of neural registers, which remotely communicates with a robotic device.

(2) Study and propose a robotic guidance method based on a close-loop platform which includes the sensory robot information in the neuroprocessor and, according to its response, guides the robotic system.

(3) Normalization and statistic calibration of the registers of the neuroprocessor in order to adapt them to different algorithms of robotic guidance and learning in cultured neural networks.

(4) Study and define learning techniques in neural cultures for the development of functional connectivity which allows new programming paradigms in biological neuroprocessors.

Regarding objective (1), a real-time close-loop experimentation system with neural cultures has been proposed, which provides a complete solution for filtering, visualization, processing and stimulation of electrophysiological response from neural population and communication with a robotic system.

In order to reach objective (2), centre of area algorithm for robotic guidance has been adapted to the functional response of neural populations, identifying those electrodes from the array whose neurons increase the most its firing rate, as target for robotic guidance.

Objective (3) has been met giving statistic calibration and normalization techniques of neural population registers that conform the neuroprocessor having in mind the goal of supressing the intrinsic variability of those populations and the different nonhomogeneity characteristics, both in culture density and electrical properties of the electrodes.

Finally, regarding objective (4), a natural learning paradigm has been proposed, Hebbian learning, to conform functional connections between previously not connected 
electrodes. In this way, the cultures can be modelled for implementing the desired behaviour in the biological structure, in this case Braitenberg behaviour. 


\section{Índice}

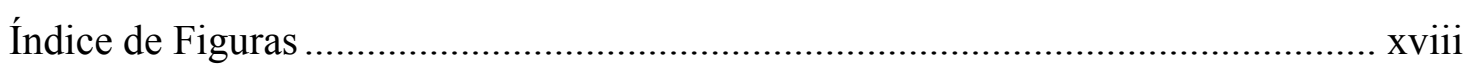

Índice de Tablas ................................................................................................ $\mathrm{xx}$

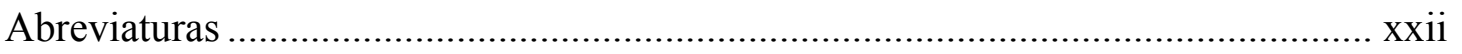

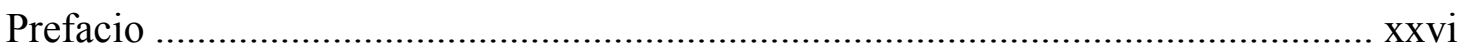

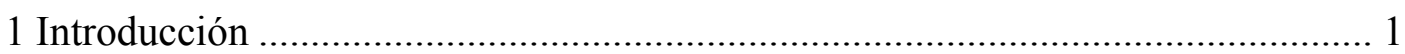

1.1 Aprendizaje y memoria en psicología ................................................... 2

1.2 Aprendizaje y memoria en neurociencia ................................................ 3

1.3 Mecanismos tras la plasticidad sináptica................................................... 4

1.4 ¿Por qué cultivos in-vitro? ................................................................. 5

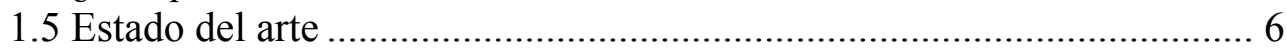

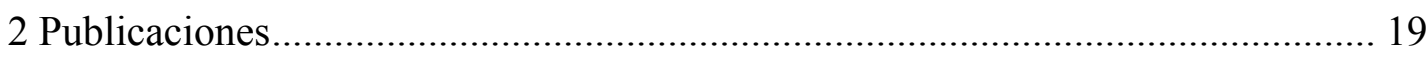

2.1 A client-server architecture for remotely controlling a robot using a closed-loop system with a biological neuroprocessor ................ 21

2.2 A biological neuroprocessor for robotic guidance using a center

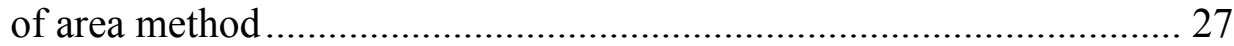

2.3 Response calibration in neuroblastoma cultures over

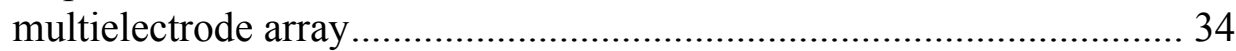

2.4 Training biological neural cultures: Towards Hebbian learning.............. 40

2.5 Artículos publicados .............................................................................. 44

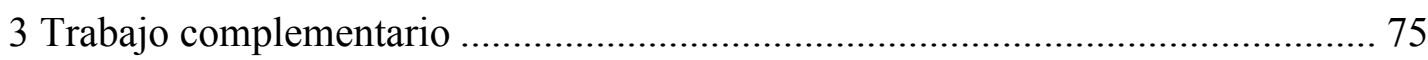

4 Conclusiones, aportaciones y líneas futuras............................................................ 77

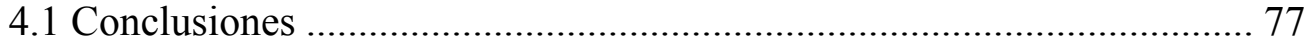

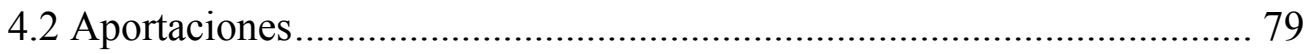

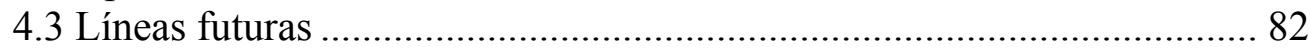

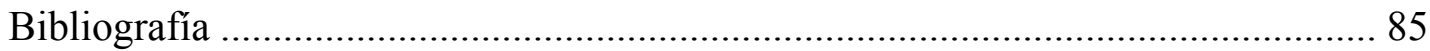

A Documentos que sustentan las publicaciones....................................................... 93

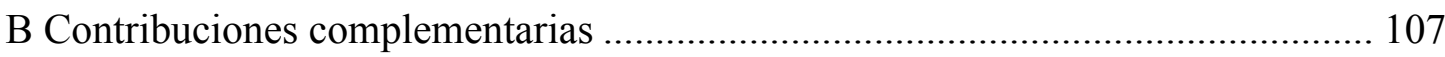




\section{Índice de Figuras}

1.1: Estudios del cerebro en diferentes niveles ................................................. 1

1.2: Esquema de la parte postsináptica de una sinapsis excitatoria ....................... 4

1.3: Matriz de microelectrodos estándar producida por el Centro Nacional

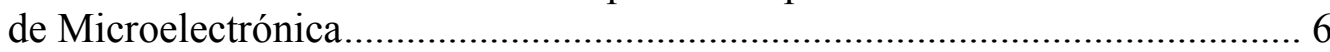

1.4: Configuración básica para la medida y el análisis de señales neuronales

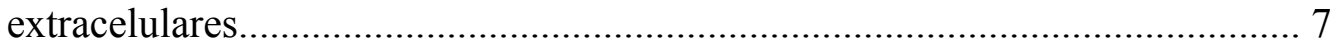

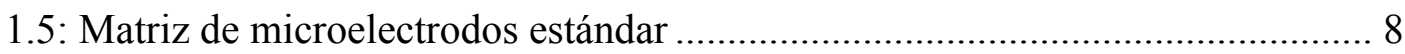

1.6: Registros de cuatro electrodos en un experimento de estimulación tetánica..... 9

1.7: Cambios en el retardo inducidos por la estimulación tetánica ......................... 10

1.8: Potenciales de acción con un pequeño retardo en respuesta a diferentes

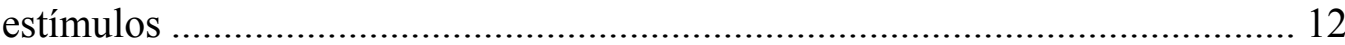

1.9: Aprendizaje en una red neuronal de neuronas corticales ............................... 13

1.10: Curvas de aprendizaje de un experimento de aprendizaje selectivo............... 14

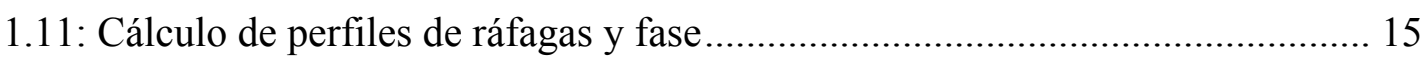

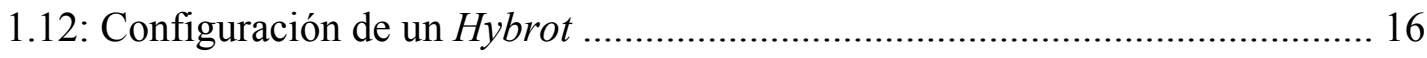

1.13: Esquema de una realimentación en bucle cerrado en un experimento de entrenamiento adaptativo ...................................................................... 17

2.1: Arquitectura de comunicación remota cliente-servidor para el robot................ 23

2.2. Representación del espacio libre sobre una matriz de electrodos .................... 23

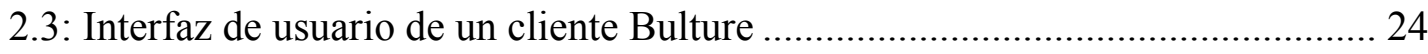

2.4: Potenciales de acción de retina y ampliación de la señal en MeaBench............ 25

2.5: Configuración experimental para el guiado robótico........................................ 28 
2.6: Evasión de obstáculos empleando el centro de área 30

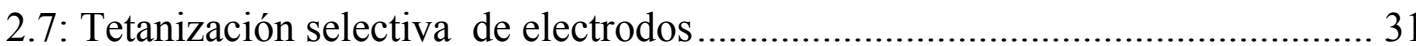

2.8: Actividad neuronal espontánea detectada previamente a la estimulación ......... 32

2.9: Actividad neuronal espontánea detectada durante y tras la estimulación .......... 32

2.10: Valores medios de actividad por canal en los experimentos......................... 37

2.11: Valores medios de actividad normalizada por canal en los experimentos....... 37

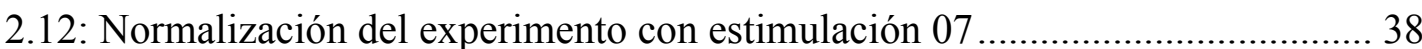

2.13: Normalización del experimento con estimulación 08 .................................... 38

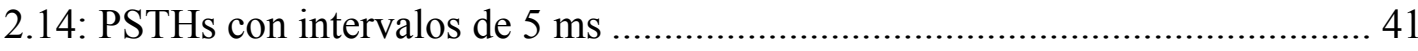

2.15: Diagrama de conectividad basado en la correlación cruzada entre los electrodos antes de la estimulación

2.15: Diagrama de conectividad basado en la correlación cruzada entre los electrodos después de la estimulación 


\section{Índice de Tablas}

1.1: Resumen de los estudios realizados sobre los cambios producidos en la actividad de la red causados por una estimulación eléctrica.

2.1: Media y desviación estándar del cálculo de potenciales de acción en una ventana de $500 \mathrm{~ms}$ por electrodo en toda la matriz de microelectrodos para cada experimento considerado.

2.2: Tests de homogeneidad para medias y varianzas del número total de potenciales de acción en la matriz de microelectrodos, calculados en ventanas de $500 \mathrm{~ms}$, en cada experimento 


\section{Abreviaturas}

\begin{tabular}{|c|c|}
\hline ASCII & American Standard Code for Information Interchange \\
\hline AMPA & $\alpha$-amino-3-hydroxy-5-methyl-4-isoxazolepropionic acid receptor \\
\hline ANOVA & ANalysis Of Variance \\
\hline AWSR & Array-Wide Spiking Rate \\
\hline $\mathrm{BP}$ & Burst Profile \\
\hline BRAVE & Biosignals Recorder And Visualization interfacE \\
\hline BT & Burst Type \\
\hline BT & BlueTooth \\
\hline CaMKII & Calmodulin-Dependent Protein Kinase II \\
\hline CAT & Center of Activity Trajectory \\
\hline $\mathrm{CM}$ & Connectivity Matrix \\
\hline $\mathrm{CNS}$ & Central Nervous System \\
\hline CPS & Context-Control Probing Sequences \\
\hline DAQ & Data Acquisition \\
\hline DIV & Days In Vitro \\
\hline DMEM & Dulbecco's Modified Eagle Medium \\
\hline EEG & Electroencephalography \\
\hline EPSC & Excitatory Post-Synaptic Current \\
\hline FIFO & First In, First Out \\
\hline FMRI & Functional Magnetic Resonance Imaging \\
\hline GUI & Graphical User Interface \\
\hline
\end{tabular}


IPI Inter-Pulse Interval

ISI Inter-Spike Interval

ITI Inter-Train Interval

LTD Long Term Depression

LTP Long Term Potentiation

MAC Media Access Controll

MCS MultiChannel Systems

MEA Microelectrode Array

mGLUr metabotropic glutamate receptors

NB Neuroblastoma

NDMA N-methyl-D-aspartate receptor

PBS Phosphate-Buffered Saline

PC Personal Computer

PCA Principal Component Analysis

PEI Polyethyleneimine

PI Potentiation Index

PP Phase Profile

PSTH Post-Stimulus Time Histogram

PTS Patterned Training Stimulation

RFCOMM Radio Frequency Communication

RS232 Recommended Standard 232

SBS Shuffled Background Stimulation

SMD Surface Mounted Device

STDP Spike-Timing Dependent Plasticity 
STG Stimulus Generator

TCP-IP Transmission Control Protocol - Internet Protocol

TiN Titanium Nitride

TTX Tetrodotoxin

USB Universal Serial Bus

VDCC Voltage-Dependent Calcium Channel 


\section{Prefacio}

\section{Motivación}

El uso de los sistemas nerviosos biológicos como elementos de cómputo convencional es un fascinante problema que permite la hibridación entre la Neurociencia y la Computación. Este enfoque sinérgico puede proporcionar una comprensión más profunda de los procesos de percepción y puede ser utilizado para el diseño de nuevos dispositivos basados en paradigmas computacionales naturales. Los paradigmas computacionales clásicos se basan en procesadores de silicio serie y supervisados, con relojes de alta frecuencia, con un consumo moderado de energía, y circuitos de estructura fija.

Sin embargo, el cerebro utiliza millones de procesadores biológicos, con estructura dinámica, conmutaciones lentas en comparación con los circuitos de silicio, bajo consumo de energía y sin aprendizaje supervisado. Este tipo de computación se relaciona más con la percepción y el reconocimiento, debido a la variación natural de los patrones perceptivos y a la falta de conocimiento a priori acerca del dominio a percibir.

Existen muchos enfoques de investigación basados en la imitación de este procesamiento paralelo bioinspirado, no sólo desde la perspectiva del algoritmo [1], sino también desde el diseño de circuitos de silicio [2]. Estos enfoques bioinspirados son útiles para aplicaciones de reconocimiento de patrones, como la visión artificial o la robótica y, sin embargo, se realizan en procesadores serie y artificiales con estructuras de silicio fijo y estático. Un procesador biológico con millones de neuronas y un gran número de interconexiones, poseería mucho más rendimiento computacional a pesar de sus bajos índices de transición, debido a la gran cantidad de elementos de computación en red y la extraordinaria capacidad de adaptación y reconfiguración a entornos desconocidos. Esta extraordinaria capacidad de adaptación está relacionada con el aprendizaje sin supervisión natural.

El aprendizaje es un proceso natural que requiere la creación y la modulación de conjuntos de asociaciones entre estímulos y respuestas. Para entender el proceso de aprendizaje, es necesario definir los mecanismos fisiológicos que apoyan la creación y la modulación de las asociaciones y determinar la relación entre las asociaciones de estímulos y respuestas. Estos mecanismos de relación se han estudiado por multitud de aproximaciones neurofisiológicas a diferentes niveles, principalmente, experimentación con células aisladas.

Desde el comienzo de la neurofisiología, los neurocientíficos han registrado y estimulado las células neuronales aisladas para estudiar su papel en el funcionamiento del sistema nervioso. Un número considerable de estudios se ha centrado en las 
respuestas de una única célula [3], [4]. Tradicionalmente, la tasa de disparo, o incluso la tasa espontánea de disparo se han utilizado como portadoras de información debido a la estrecha correlación con la intensidad del estímulo en todos los sistemas sensoriales. Sin embargo, las neuronas solo producen pocos disparos en respuesta a las distintas presentaciones y deben codificar un enorme espectro de estímulos en sus disparos. Además, el concepto de tasa implica un cierto promedio temporal, y la decodificación debe ser lo suficientemente rápida e inequívoca, de modo que el sistema sea capaz de responder en unos pocos milisegundos. La dimensión temporal, esto es, la exacta secuencia temporal de potenciales de acción, puede servir para la codificación de las principales características de los estímulos [5], como ocurre en algunos sistemas (por ejemplo, la codificación auditiva [6]), proporcionando precisión, rápida decodificación y una gran dimensión para representar todo tipo de estímulos. Una combinación de estrategias espacio-temporales en la red proporcionarán robustez al sistema.

Hay, sin embargo algunos inconvenientes en el uso de la actividad de células individuales. En primer lugar, la respuesta de una sola célula no puede describir de manera inequívoca el estímulo. La respuesta a partir de repeticiones de una única célula de los mismos estímulos tiene una considerable variabilidad para diferentes presentaciones. La secuencia temporal difiere no sólo en el momento de los acontecimientos, sino también en el número de disparos, aspecto que produce incertidumbre en la decodificación. Y en segundo lugar, la misma respuesta, la misma secuencia de eventos neuronales, se puede obtener proporcionando diferentes estímulos, lo que presenta ambigüedad en la respuesta neuronal. Por lo tanto, es una compleja tarea "comprender" la respuesta neuronal sólo analizando células neuronales aisladas. De esta manera, el cerebro requiere de la combinación de la actividad de millones de neuronas interconectadas y células gliales asociadas con ellas.

Nuevas técnicas de registro neuronal, y la aparición de nuevas tecnologías, como las matrices de microelectrodos (MEAs), proporcionan la capacidad de estimular y registrar de forma simultánea poblaciones de células neuronales. Esta tecnología permite analizar las interacciones entre las poblaciones neuronales de células y describir las propiedades emergentes, resultado de la computación en la población neuronal.

\section{Antecedentes}

La Universidad Politécnica de Cartagena (UPCT) se estableció en 1998, como la universidad técnica más joven de España. Sin embargo, los estudios de ingeniería han tenido una larga tradición en Cartagena debido a las numerosas escuelas fundadas a principios del pasado siglo. La unión entre juventud y tradición proporcionan un carácter dinámico e innovador pero también una fundación sólida. La UPCT es una institución académica española pública, muy centrada en la investigación y la transferencia de tecnología.

Los investigadores que han apoyado el desarrollo de esta tesis son miembros del grupo I+D denominado DETTS (Diseño Electrónico y Técnicas de Tratamiento de la Señal), perteneciente al Departamento de Electrónica, Tecnología de Computadores y Proyectos (DETCP). Este grupo integra 15 profesores, 9 de ellos doctores en diferentes disciplinas, y tiene una amplia experiencia en sistemas de bioingeniería, hardware digital basado en microcontroladores, DSP y dispositivos lógicos reconfigurables, redes 
neuronales bioinspiradas, procesamiento de la señal, control inteligente, dispositivos de realidad aumentada y prótesis de ayuda a la baja visión. El grupo es también coorganizador, junto con la UNED, del Congreso Internacional IWINAC, International Work Conference on the Interplay between Natural and Artificial Computation, y de Spanish and Iberomerican Networks on Natural and Artificial Computation.

El grupo de investigación ha publicado más de 30 artículos conjuntamente en la temática propuesta, algunos de los más destacados se reseñan en las referencias. Asimismo, se han solicitado diversos proyectos regionales, nacionales y europeos en el área de los neuroprocesadores biológicos.

\section{Descripción de la Tesis}

La parte principal de este documento se encuentra en los artículos publicados que componen la tesis como una tesis por compendio de publicaciones. Estos artículos alcanzan el objetivo global fijado, cumplimentando cada uno de ellos su respectivo subobjetivo, como se describe en el resumen de este documento.

El Capítulo 1 introduce el trabajo presentado en esta tesis a través de la descripción del aprendizaje y la memoria, así como de los mecanismos envueltos en estos procesos. Posteriormente, describe la plataforma básica para el estudio de dichos procesos en redes neuronales biológicas cultivadas, es decir, las matrices de microelectrodos o MEAs. Finalmente, se presenta el estado del arte relacionado con este trabajo.

El Capítulo 2 contiene resúmenes ampliados de cada una de las publicaciones que conforman esta tesis. Estos resúmenes incluyen la metodología propuesta, los resultados conseguidos y unas conclusiones finales. Seguidamente, se incluye una copia completa de los artículos citados y, finalmente, en el Apéndice A se recogen los documentos referentes a las declaraciones de co-autoría e información sobre el índice de impacto de las revistas en que han sido publicados los artículos, según la normativa vigente.

El Capítulo 3 recoge una breve descripción de algunas de las contribuciones relacionadas con esta tesis que amplían y/o profundizan en los objetivos marcados, pero que no han podido ser incluidas como artículos publicados según la normativa vigente. Una copia completa de cada una de las contribuciones mencionadas en este capítulo puede encontrarse en el Apéndice B.

Finalmente, en el Capítulo 4 se proporcionan unas conclusiones globales de este trabajo de investigación, las aportaciones realizadas durante este periodo, y posibles líneas futuras de investigación.

Víctor Lorente Sánchez. Cartagena, Enero 2014. 


\section{Capítulo 1 Introducción}

El sistema nervioso hace posible que humanos y animales puedan interaccionar con el entorno. Las señales de entrada proceden de neuronas especializadas que son sensibles a diferentes estímulos: químicos, luz, calor, presión, etc., y las señales de salida serían las contracciones musculares. Entre las señales sensoriales y actuadoras se ha de realizar un gran procesamiento de información. Una de las características más sorprendentes de este procesamiento es reconocer y memorizar regularidades en el entorno, y cambiar el comportamiento si es necesario. El reconocimiento, o aprendizaje y memoria, es el sujeto de estudio de varios campos. En el nivel más alto está la psicología del comportamiento (Figura 1.1) que trata la modificación del comportamiento en respuesta a estímulos, recompensa y castigo, pero no trata tradicionalmente con el aspecto neurofisiológico. Sin embargo, los modelos psicológicos han sido muy influyentes en el estudio del aprendizaje y la memoria en todos los niveles. En los niveles más bajos, el campo de la neurofisiología estudia las propiedades de unidad básica de procesamiento de información, la neurona. De interés particular en este campo es la comunicación entre dos neuronas, lo que es regulado por la sinapsis.

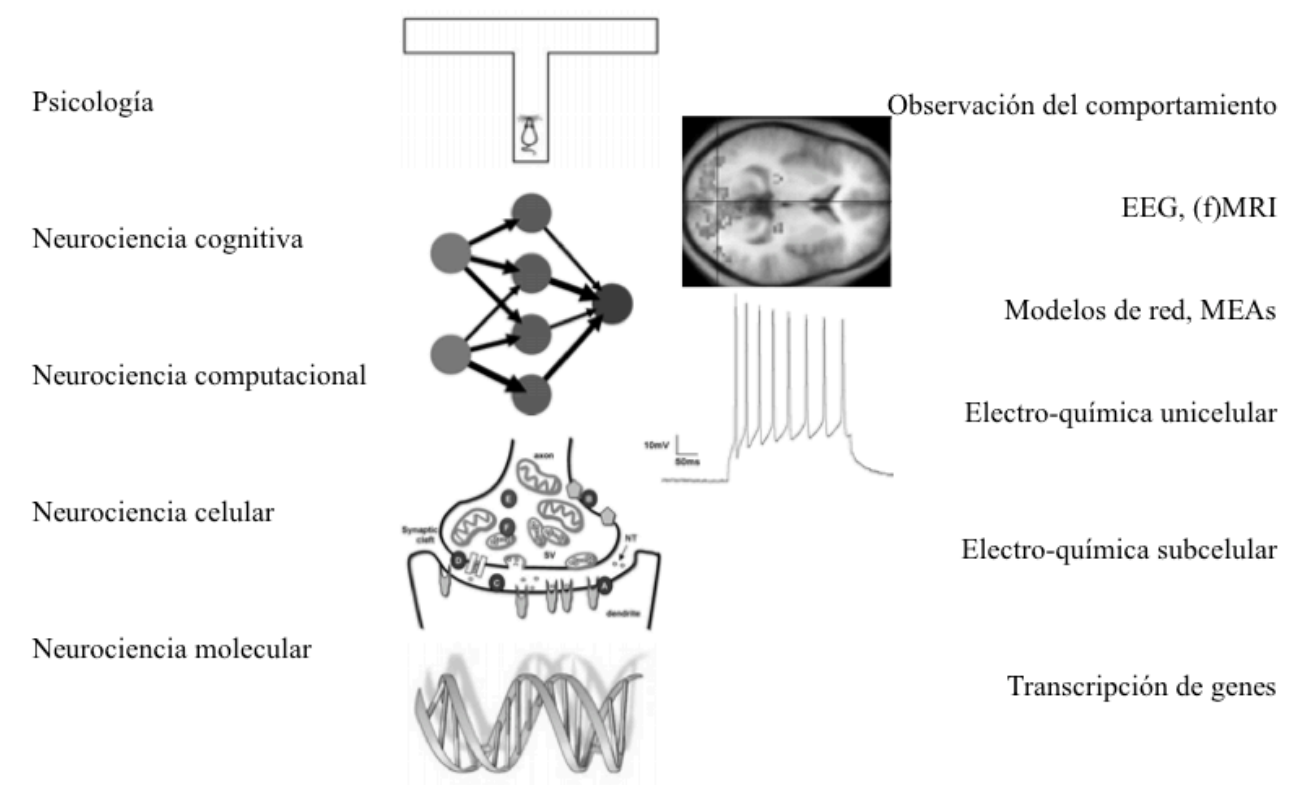

Figura 1.1: Estudios del cerebro en diferentes niveles. Debido a los avances en los sistemas de medida, los bordes entre las diferentes áreas se están difuminando rápidamente. 
En los niveles intermedios, se utilizan modelos de neuronas y sinapsis para estudiar el procesamiento de información en redes neuronales. Los experimentos in-vivo en este nivel usan técnicas no invasivas como la electroencefalografía (EEG) y las imágenes por resonancia magnética funcional (FMRI). En experimentos animales, también se utilizan técnicas invasivas como el implante de electrodos. Los electrodos implantados tienen la ventaja de ser mucho más precisos a la hora de tratar con el origen temporal y espacial de la actividad registrada. Como alternativa a los experimentos in-vivo, se pueden emplear cultivos primarios de neuronas disociadas o rebanadas organotípicas. A partir de ahí es posible medir la actividad de forma precisa, así como la observación a través del microscopio.

\subsection{Aprendizaje y memoria en psicología}

En la psicología del comportamiento, los sujetos son colocados en un entorno controlado y se estudia su comportamiento. Los estímulos consisten en señales audiovisuales y táctiles. Para alterar el comportamiento en animales, éstos pueden ser recompensados (comida) o castigados, y un instinto o reflejo de supervivencia puede ser activado. El experimento más conocido es la asociación que los perros de Pavlov hicieron entre el sonido de una campana y la comida después de que la campana fuera sonada de forma repetida mientras estaban comiendo. Después de un tiempo, los perros salivaban con sólo el sonido de la campana. A esto se le denomina condicionamiento clásico: un comportamiento ya existente se asocia con cualquier otro estímulo neutral. La estimulación podía cortarse no sonando la campana (o inmediatamente antes) durante la comida. Curiosamente, no se producía salivación cuando la campana se sonaba después de la comida. En otros experimentos, la presencia de un estímulo neutral después de la respuesta natural tenía un efecto inhibitorio. Por tanto, la causalidad y la proximidad temporal eran factores importantes para el tipo y la fuerza de la asociación.

El condicionamiento operativo se concentra en la modificación del comportamiento bajo condiciones ya existentes. Aquí, se aplica una realimentación del rendimiento en forma de refuerzo (recompensa) o castigo. La realimentación puede ser aplicada por un supervisor (en el sentido más amplio), haciendo que el condicionamiento operativo sea aplicado en la práctica. El condicionamiento operativo también resulta en un aprendizaje dirigido por objetivo cuando el supervisor aplica la realimentación con un determinado objetivo en mente.

Los estudios psicológicos de aprendizaje y memoria no terminaron en estas dos formas de condicionamiento, pero desde entonces se han desarrollado dentro de un amplio campo con muchas relaciones cercanas a la neurociencia cognitiva. Las definiciones de aprendizaje que se emplean difieren ligeramente, dependiendo del aspecto que se estudie. Dos definiciones que cubren los aspectos fundamentales son las siguientes:

- La alteración del comportamiento como resultado de la experiencia individual. Cuando un organismo puede percibir y cambiar su comportamiento, se dice que ha aprendido (Encyclopedia Brittanica).

- Se dice que un organismo ha aprendido cuando éste ha incrementado sus opciones de aplicar, bajo un conjunto circunstancias especificas, un 
comportamiento nuevo o diferente que el organismo cree que será para su beneficio. (Mike Willis Learning Services).

Solo la segunda definición menciona explícitamente un objetivo, lo que es especialmente útil en configuraciones experimentales. En ambas definiciones el entorno juega un papel importante, pues un organismo solo obtiene experiencia a través de la interacción con el entorno.

\subsection{Aprendizaje y memoria en neurociencia}

El cerebro puede dividirse en diferentes regiones, cada una con un grado de especialización diferente. El hipocampo es de particular interés en el estudio del aprendizaje y la memoria ya que se ha demostrado que encuentra envuelto en la acción de recordar información espacial [7-10]. En 1973, Bliss y Lomo realizaron una serie de experimentos fundamentales en los que estimulaban neuronas de hipocampo en conejos anestesiados y registraban potenciales postsinápticos en otra neurona [11]. Mostraron que la estimulación con trenes de pulsos $(100 \mathrm{~Hz} ; 1 \mathrm{~s})$, conocida como tetanización, daba lugar a un incremento de la amplitud de los potenciales postsinápticos que podía durar hasta días. Estas células, o más bien sus sinapsis, eran capaces de memorizar a corto (minutos) y largo (de horas a días) plazo. A este fenómeno se le llamó potenciación a largo plazo (Long Term Potentiation, LTP). Posteriormente se descubrió que la LTP podía ser inducida por otros dos protocolos. En la estimulación theta-burst, las neuronas eran estimuladas con cortas ráfagas de 4 o 5 pulsos a $100 \mathrm{~Hz}$, espaciadas aproximadamente $200 \mathrm{~ms}$ [12]. El llamado ritmo theta se observaba en el EEG del hipocampo durante el comportamiento exploratorio y la recuperación de información. Fue después cuando se demostró que cuando los estímulos seguían la oscilación natural theta, la aplicación del estímulo en el pico de la oscilación resultaba en LTP $[9,13]$. De forma inversa, la aplicación del estímulo entre la oscilación resultaba en el debilitamiento de los potenciales postsinápticos o depresión a largo plazo (Long Term Depression, LTD). El emparejamiento del estímulo fue la tercera aproximación descubierta para evocar cambios duraderos en la eficacia sináptica $[12,14-18]$. La upregulation podía conseguirse estimulando la neurona presináptica inmediatamente antes $\left(\begin{array}{llll}0 & \text { a } & 20 & \mathrm{~ms}\end{array}\right)$ que la neurona postsináptica. La downregulation se inducía estimulando la neurona postsináptica antes que la presináptica. No existía ningún efecto de estas manipulaciones en otros pares de neuronas, por lo que las modificaciones eran específicas de la sinapsis. A este mecanismo se le denominó plasticidad dependiente del tiempo de los potenciales de acción (Spike-Timing Dependent Plasticity, STDP). La STDP, y también los mecanismos de LTP y LTD, cumplen el conocido postulado de aprendizaje realizado por Donald O. Hebb en 1949 [19]:

Supongamos que la persistencia de una actividad repetitiva (o "señal") tiende a inducir cambios celulares duraderos que promueven su estabilidad. ... Cuando el axón de una célula $A$ está lo suficientemente cerca como para excitar a una célula $B y$ repetidamente toma parte en la activación, ocurren procesos de crecimiento o cambios metabólicos en una o ambas células de manera que tanto la eficiencia de la célula $A$, como la capacidad de excitación de la célula B son aumentadas.

La regla de Hebb es de gran importancia pues une las observaciones de las capas superiores de las investigaciones en neurociencia con las capas inferiores. Tras esta regla, se ha investigado en los mecanismos y en cómo ésta se usa para dar lugar a la 
memoria en redes neuronales. Encontrar conexiones funcionales que se adhieren a la regla de Hebb (por ejemplo cambios en la funcionalidad de entrada-salida) es equivalente a demostrar que la red tiene la habilidad de aprender y memorizar [20]. Más estrictamente, el aprendizaje y la memoria envuelve cierta forma de control por parte del experimentador sobre las relaciones de entrada-salida [21, 22]. Sin embargo, relaciones de entrada y salida útiles requieren más una red de células que un par de ellas.

\subsection{Mecanismos tras la plasticidad sináptica}

Hay 2 principales receptores envueltos en el STDP: el receptor AMPA (ácido alfaamino-3-hidroxi-5-metil-4-isoxazolpropiónico) y el NDMA (N-metil-D-aspartato), Figura 1.2. El receptor AMPA es permeable a $\mathrm{K}+\mathrm{y}$ a $\mathrm{Na}+$ cuando se activa por glutamato, y proporciona una transmisión normal de potenciales de acción. La activación del STDP depende de la activación de los receptores NMDA $[12,17]$. Los receptores NMDA son canales activos por glutamato y glicina conjuntamente que permiten la circulación iónica $(\mathrm{Na}+, \mathrm{K}+\mathrm{y} \mathrm{Ca} 2+)$, bloqueándose ante determinados iones $(\mathrm{Mg} 2+)$ alcanzando su potencial de equilibrio. Cuando las dendritas postsinápticas se despolarizan, o bien por una activación persistente de los receptores AMPA o a través de los potenciales de acción dendríticos, el bloqueo de $\mathrm{Mg} 2+$ se libera. El influjo resultante de $\mathrm{Ca} 2+$ en la célula post-sináptica activa una multitud de sistemas mensajeros secundarios [12]. Uno de estos es el la fosforilación de los receptores AMPA por Ca2+ (Calcio Calmodulina Kinasa II activada, CaMKII), lo que resulta en una conductancia superior por canal.

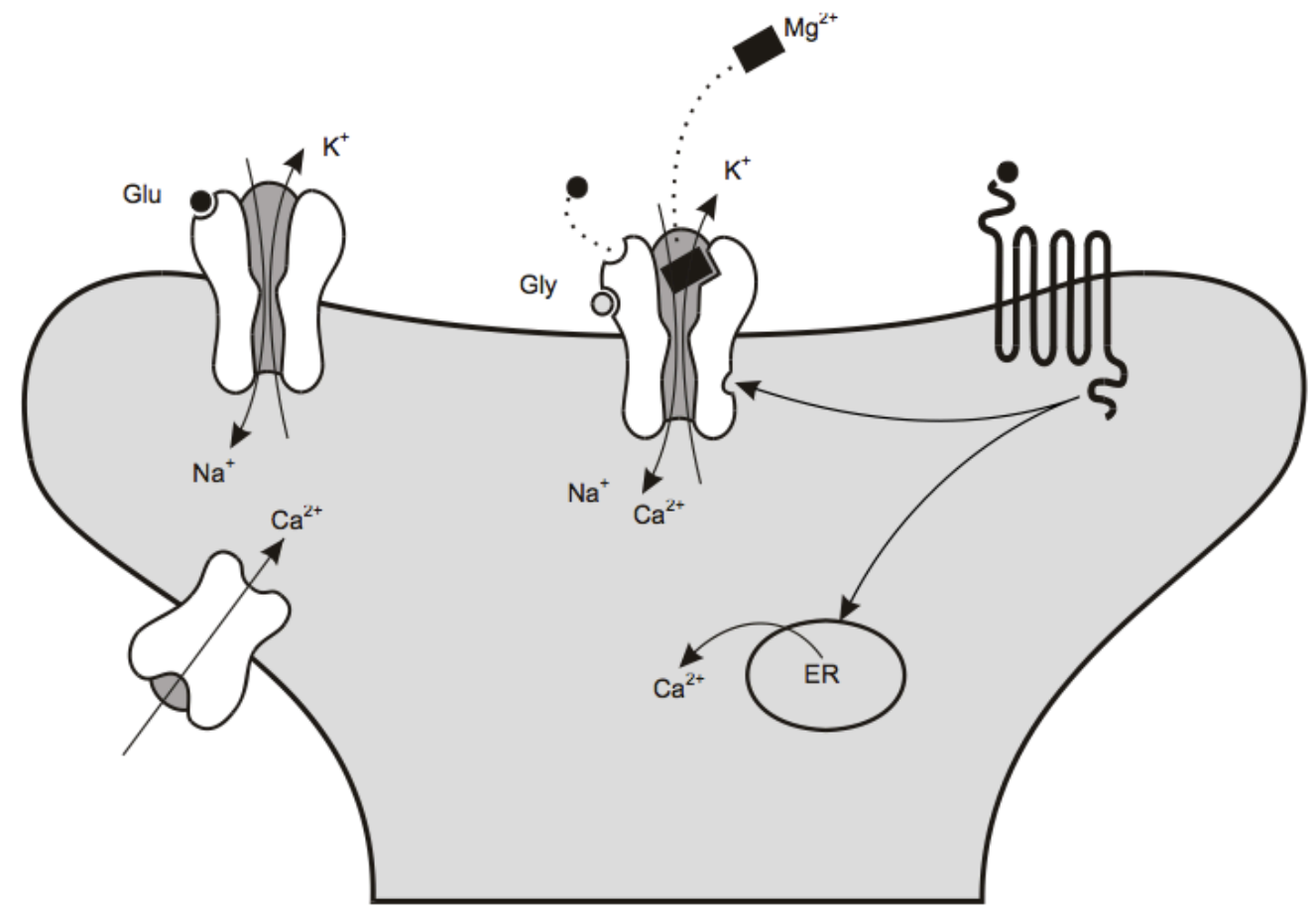

Figura 1.2: Esquema de la parte postsináptica de una sinapsis excitatoria. El receptor más a la izquierda (AMPA) gobierna la transmisión normal de potenciales de acción, despolarizando la membrana cuando el glutamato se une a el. El receptor intermedio (NDMA) se activa por glutamato con la condición de que la despolarización de la membrana es suficiente para limpiar el ion de magnesio que normalmente bloquea el canal. El receptor de glutamato metabotrópico (mGLUr) activa sistemas mensajeros 
secundarios que influencian la conductancia del canal NMDA y el retículo endoplásmico, causando el incremento de la concentración de calcio intracelular $\left([\mathrm{Ca}]_{\mathrm{i}}\right)$. Los cambios en $[\mathrm{Ca}]_{i}$ están unidos a la eficacia sináptica. Los canales de calcio dependiente de voltaje amplifican el incremento de $[\mathrm{Ca}]_{\mathrm{i}}$ durante la despolarización, y son necesarios para el mantenimiento de la eficacia sináptica.

Se han hecho hipótesis de que la presencia de mensajeros retrógrados, indicando a las células presinápticas la liberación de más neurotransmisores, juega un papel en el LTP y el LTD. Uno de los candidatos es el óxido nítrico. Sin embargo, la mayoría de los fenómenos pueden ser explicados por mecanismos que tienen lugar en la célula postsináptica.

Otro mecanismo de las células para modular la despolarización postsináptica es incrementar o decrementar el número de receptores AMPA. Cuanto más permanente sea el incremento de la concentración de $\mathrm{Ca} 2+$, más energía se emplea por la potenciación. Por tanto, Ca2+ puede ser también liberado a través de otros mecanismos, como la liberación del Retículo Endoplásmico (ER) o a través del influjo de canales de calcio dependientes de voltaje (VDCCs). Incrementando el número de VDCCs, el Ca2+ puede incrementarse de una forma más permanente y así mantener la potenciación por largos periodos de tiempo (LTP) [23].

\section{4 ¿Por qué cultivos in-vitro?}

Muchos de los resultados discutidos hasta ahora se han conseguido empleando técnicas de fijación de membranas, también denominadas patch-clamp, ya sea in-vivo o in-vitro. Los métodos patch-clamp son intracelulares, por lo que proporcionan gran nivel de detalle hasta en un régimen sub-umbral, pero son imprácticos para medir muchas neuronas en paralelo. Las matrices de microelectrodos (MEAs, Figura 1.3) han sido desarrolladas como plataforma para dar solución a esto. Algunas ventajas de los sistemas MEA son:

1. Las redes pueden aislarse de la actividad de otras regiones. El cerebro es demasiado complejo para estudiarlo en su conjunto. In vitro, es posible aislar una región del cerebro, controlar las entradas que recibe y estudiar las salidas que genera.

2. Es posible realizar registros de larga duración de muchas neuronas. Los contactos neurona-electrodo son estables durante el tiempo de vida del cultivo que puede ser de hasta varios meses. En contraste, los registros patch-clamp dañan la membrana celular de la neurona lo que limita los registros a varias horas. Además puede alterar procesos basados en la concentración de químicos.

3. Las redes pueden ser observadas en el microscopio. Las redes neuronales se mantienen esencialmente en dos dimensiones, por la práctica razón de que las sustancias necesarias para el metabolismo son transportadas por difusión desde el medio. Para cultivos disociados, la capa de neuronas y células glía no supera las 3 células de grosor $(15-30 \mu \mathrm{m})$.

4. Las manipulaciones se aplican con mayor control. El efecto de los químicos en la supervivencia y actividad de los cultivos puede ser estudiado simplemente al añadirlo a la solución del medio. 


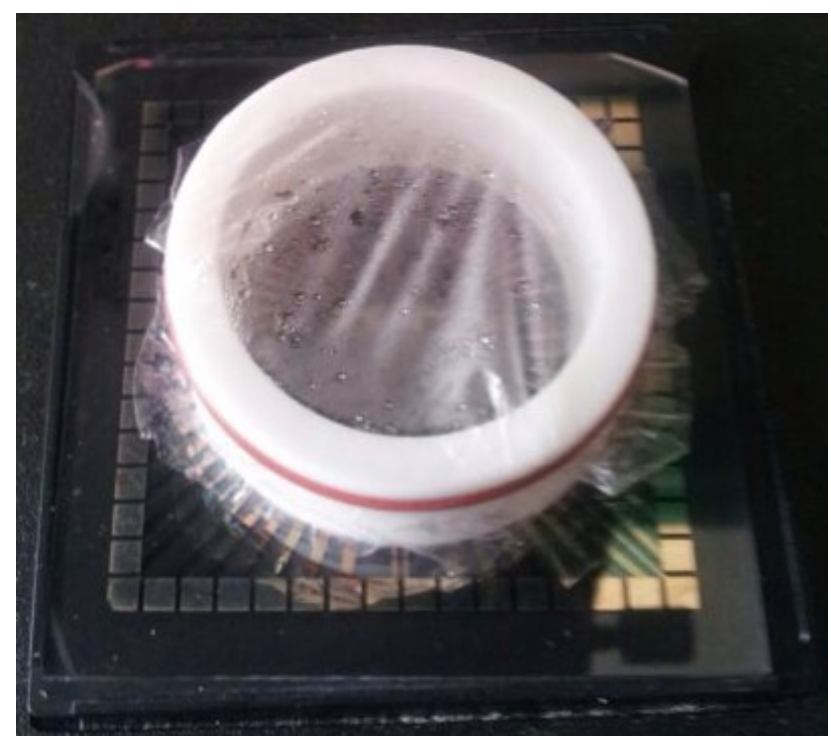

Figura 1.3: Matriz de microelectrodos estándar producida por el Centro Nacional de Microelectrónica.

Algunas desventajas son:

1. La falta de entradas aferentes en la red puede llevar a cambios en el procesamiento de la red.

a. En un organismo son necesarios la acumulación de experiencias para funcionar con normalidad. El cerebro está fuertemente conectado solo a las tareas más básicas. El resto lo aprende mediante las interacciones con el entorno.

b. Ninguna región del cerebro funciona por sí sola. Recibe químicos a través de la sangre y de otras zonas del cerebro así como actividad en forma de potenciales de acción. Estas entradas son difíciles de reproducir in-vitro, pero pueden ser esenciales para un funcionamiento adecuado.

2. Para redes disociadas, la falta de estructura. Al crecer in-vitro las redes están conectadas de forma un tanto aleatoria.

3. Actualmente, sólo pueden medirse potenciales de acción con fiabilidad debido al tamaño de los electrodos en los MEAs convencionales y al limitado espacio entre electrodos y neuronas. Con los métodos patch-clamp también puede monitorizarse actividad sub-umbral.

\subsection{Estado del Arte}

El primer enlace entre la comunicación neuronal y señales eléctricas fue realizado por Luigi Galvani en 1791 cuando mostró que los músculos de las ranas podían ser estimulados por electricidad. Sin embargo, no fue hasta la década de 1920 cuando los impulsos nerviosos llegaron a ser medidos directamente por la amplificación de señales eléctricas registradas por microelectrodos. El circuito eléctrico básico se muestra en la Figura 1.4. Este circuito amplifica el potencial entre tierra (generalmente medido 
colocando un cable debajo del cuero cabelludo) y el extremo del microelectrodo. Los cambios de potencial medidos en el extremo reflejan el flujo de corriente en el medio extracelular. Las componentes principales de esta corriente son las generadas por el potencial de acción, pero puede haber muchas otras componentes menos prominentes. De las fibras axónicas, también llamadas fibras de paso, también se pueden recoger señales mucho más localizadas y que son muy parecidas a los potenciales de acción celulares, aunque más pequeñas. Otra fuente de señal es el potencial de campo, que suele verse habitualmente en estructuras basadas en capas y resulta del flujo sincronizado de corriente en un conjunto paralelo de dendritas. Esta señal suele tener un ancho de banda suficientemente bajo como para ser filtrada de los potenciales de acción neuronales.

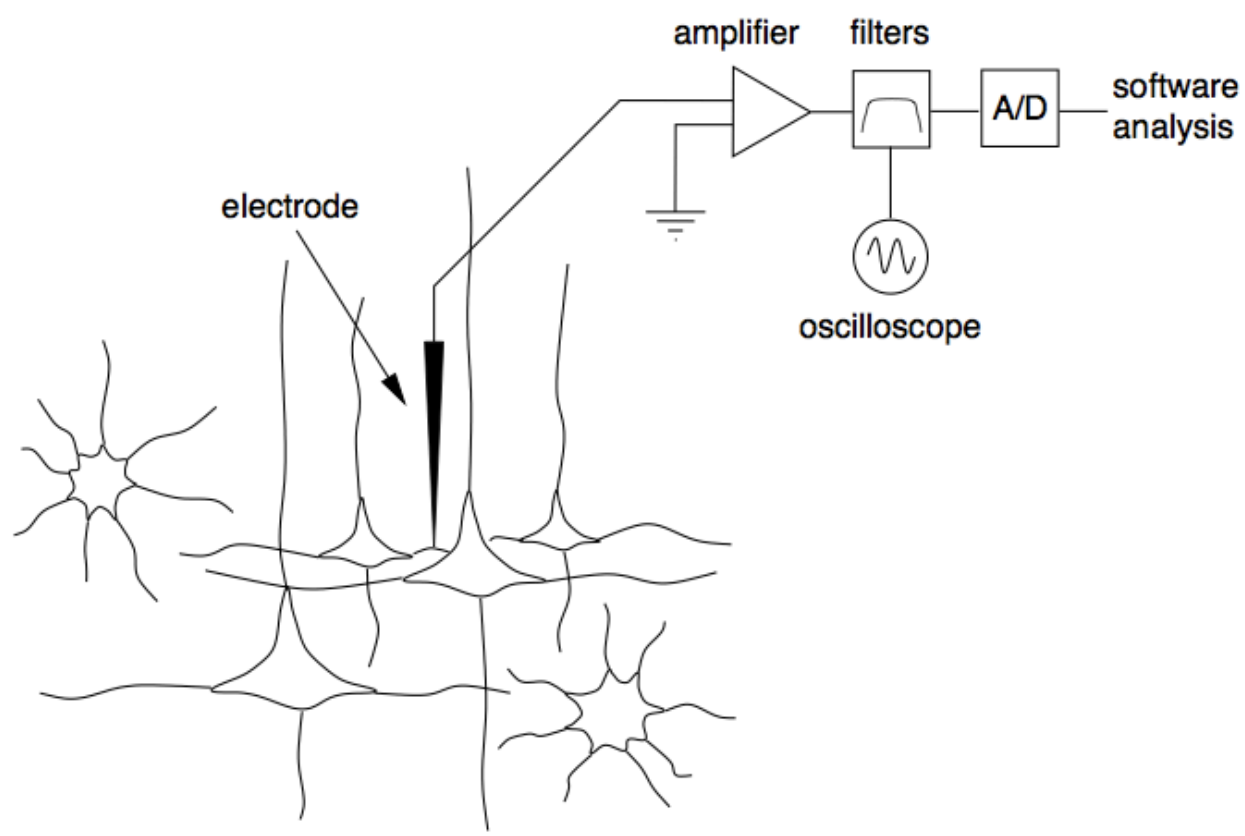

Figura 1.4: Configuración básica para la medida y el análisis de señales neuronales extracelulares. Figura extraída de [25].

La forma del electrodo tiene cierto efecto sobre qué tipos de señales son medidas hasta el punto de que cuanto más grande es el extremo del electrodo mayor es el número de señales registradas. Si el extremo del electrodo es muy grande será imposible aislar una neurona en particular. Si el extremo es muy pequeño puede ser difícil incluso detectar alguna señal. Adicionalmente, la configuración del extremo puede ser un factor importante para determinar qué señales pueden medirse. En [24], se puede encontrar una interesante discusión sobre temas relacionados con el registro eléctrico.

La aparición de las matrices de microelectrodos supuso todo un avance en neurofisiología. Una matriz de microelectrodos (MEA) es un conjunto de, típicamente, 60 electrodos que permite el registro y estimulación de varios lugares de forma paralela, Figura 1.5. Un MEA tiene un área de registro típica de $700 \mu \mathrm{m}$ a $5 \mathrm{~mm}$ de longitud. En esta área los 60 electrodos se alinean en una cuadrícula de 8x8 separados entre sí una distancia de 100, 200 o $500 \mu \mathrm{m}$. Los electrodos pueden ser de varios materiales, pero se emplea de forma extendida el TiN (Nitruro de Titanio) en su fabricación. El TiN es un material muy estable que se emplea en numerosas aplicaciones, entre las que destaca el aislamiento de equipo pesado. Los MEAs fabricados con este material se caracterizan por poseer una tiempo de vida largo y pueden ser reutilizados muchas veces si se 
manipulan con cuidado. La impedancia de los electrodos oscila entre los 30 y $400 \mathrm{k} \Omega$ y éstos se encapsulan en un material de transporte, generalmente cristal. Las pistas están eléctricamente aisladas por nitruro de silicio ( $\mathrm{SiN}$ ). La muestra biológica puede situarse directamente sobre el área de registro y su actividad puede detectarse hasta una distancia de $100 \mu \mathrm{m}$ de una neurona en una muestra de tejido cerebral. Típicamente, las fuentes de señal se encuentran dentro de un radio de $30 \mu \mathrm{m}$ alrededor del centro del electrodo. A menor distancia, mayores son las señales extracelulares. Cuanto mayor es la resolución espacial, menor es el número de unidades que son recogidas por un solo electrodo, y menor será el esfuerzo que será necesario poner en la clasificación de señales. Para un conocimiento técnico más profundo sobre los MEAs se puede consultar [26].

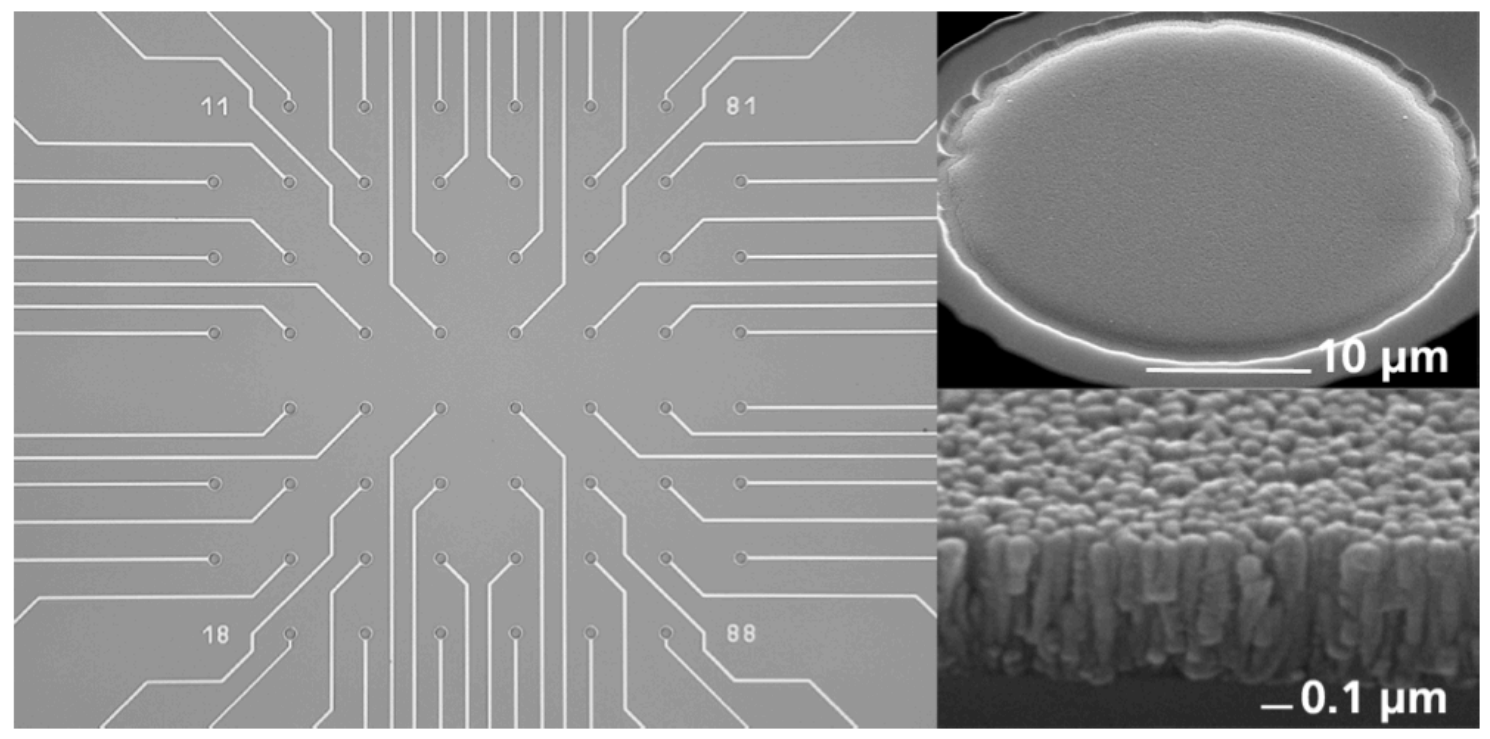

Figura 1.5: Matriz de microelectrodos estándar. Imagen extraída de [26].

Los controles de calidad y los procesos de producción han mejorado mucho en los últimos años, por lo que los MEAs se han convertido en un elemento indispensable en neurofisiología dada su gran calidad a unos precios razonables. Así pues, el registro de un gran número de electrodos se ha convertido en algo común en los últimos 30 años y las matrices de microelectrodos han sido empleados para estudiar muchas preparaciones in vitro incluyendo cultivos corticales (e.g. [27-30]), cultivos de médula (e.g. [31]) así como cultivos de retina (e.g. [32]).

La modificación de la plasticidad sináptica juega un papel central en la plasticidad de los sistemas neuronales. El mecanismo mejor caracterizado para cambiar la eficacia sináptica es la potenciación a largo plazo o LTP. Este mecanismo ha sido estudiado extensivamente por diversos grupos científicos, que han estudiado sus efectos en células de hipocampo procedentes de rata [33], así como en la corteza cerebral de estos animales [34-36].

La estimulación eléctrica ha sido empleada de forma habitual por los investigadores para inducir plasticidad de forma artificial y así estudiar los mecanismos de aprendizaje y la memoria. Dentro de los diferentes patrones de estimulación, se ha demostrado que la estimulación tetánica, consistente en una secuencia de alta frecuencia de estimulaciones, induce cambios de actividad en los cultivos, en forma de transiciones 
intracelulares sincronizadas de calcio [37] y actividad espontánea en forma de ráfagas [38]. Yasuhiko Jimbo y su grupo midieron los efectos de una tetanización focal en cultivos corticales sobre las propiedades de las ráfagas sincronizadas, iniciadas por un estímulo de "test" [39].

Jimbo probó que la estimulación tetánica producía dos efectos claros en respuesta a un estímulo de "test". El primero era un incremento en el número de potenciales de acción en cada ráfaga. Antes de la tetanización, la red producía ráfagas extendidas en respuesta a solo dos de los seis estímulos de test aplicados. Durante las grandes ráfagas, las células generaban potenciales de acción y durante las cortas ráfagas extracelulares, solo se observaban potenciales postsinápticos subumbrales . En contraste, después de la tetanización se evocaban ráfagas extendidas y disparos intracelulares en respuesta a casi cada estímulo de test. La Figura 1.6 ilustra estos efectos.
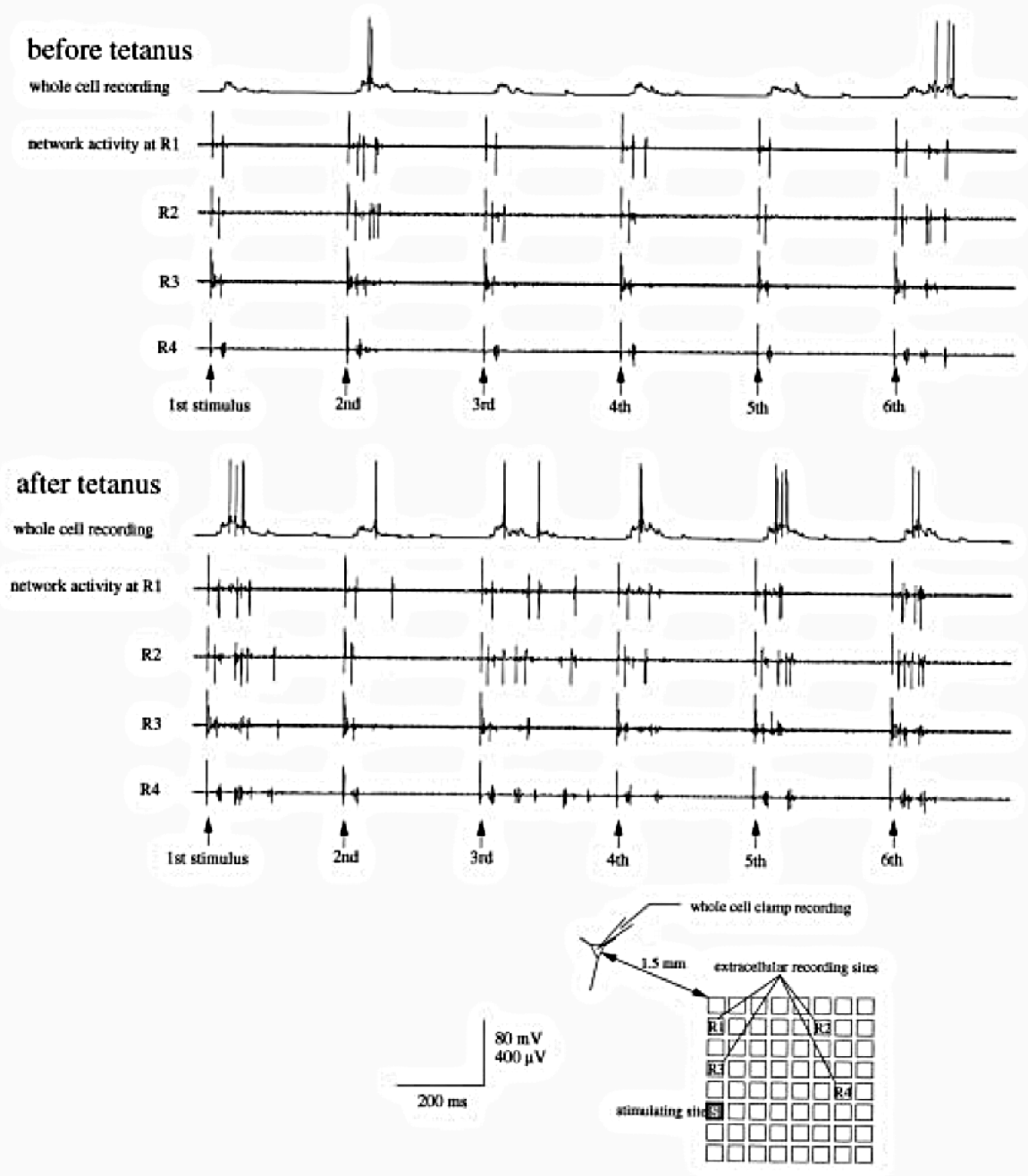

Figura 1.6: Registros de cuatro electrodos en un experimento de estimulación tetánica. En la parte inferior se muestran los lugares de registro y estimulación empleados por Yasuhiko Jimbo en su estudio sobre estimulación tetánica. Las gráficas de la parte superior ilustran la actividad registrada antes y después de la estimulación tetánica. Figuras extraídas de [39]. 
Además, se observaron cambios en la distribución del retardo en la respuesta, Figura 1.7, de forma que se obtuvo una disminución tanto en la media como en la dispersión del mismo. Todos estos cambios estaban asociados con un marcado incremento en el número de componentes tardías en las corrientes sinápticas.

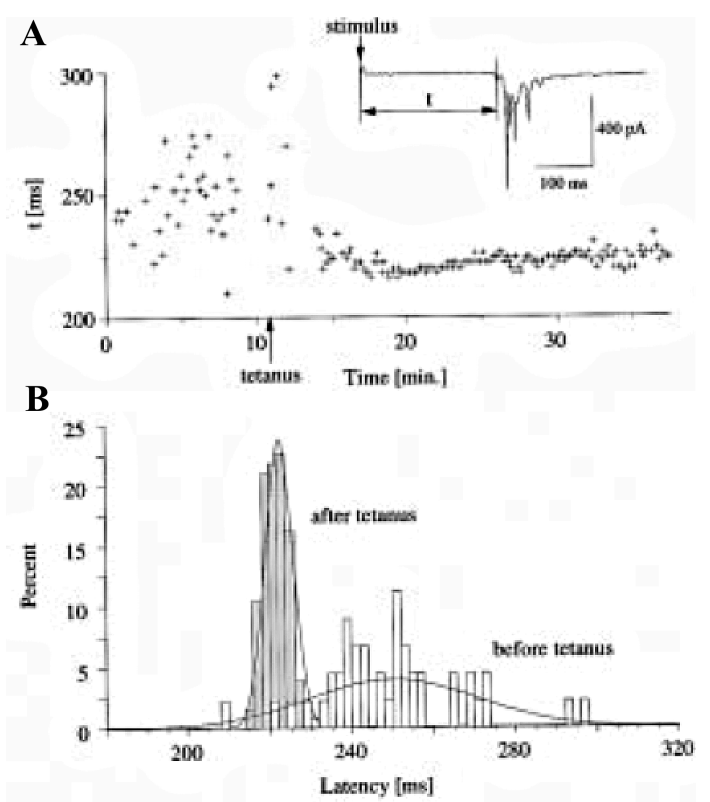

Figura 1.7: Cambios en el retardo inducidos por la estimulación tetánica. A. Diferencia de tiempo entre el estímulo de test y la respuesta del cultivo. Tras la tetanización, el retardo se estabilizaba gradualmente. B. Histograma de retardos antes y después de la tetanización. La varianza se reducía tras la estimulación tetánica. Figuras extraídas de [39].

La investigación realizada por el grupo de Yasuhiko Jimbo fue de vital importancia, pues demostró que los cultivos podían ser influenciados por estímulos externos y abrió el camino a nuevas investigaciones en el aprendizaje y la memoria. La estimulación tetánica, aunque efectiva, es solo un patrón más de estimulación de la gran variedad empleada por los investigadores para evocar actividad neuronal a través de matrices de microelectrodos [40, 41], empleando tanto pulsos controlados por voltaje y por corriente. Sin embargo, es de vital importancia hacernos la siguiente pregunta: ¿Cómo un investigador decide qué estimulación usar? El grupo del investigador norteamericano Steve M. Potter investigó la eficacia de ambos tipos de estímulos como una función de amplitud y anchura del pulso [42]. Se descubrió que en la mayoría de los casos los pulsos de corriente negativos son lo que excita a las neuronas para disparar potenciales de acción. Esto no quiere decir que los pulsos controlados por voltaje no sean útiles. De hecho, los pulsos bifásicos controlados por voltaje en los que el pulso positivo iba en primer lugar fueron los más efectivos de su repertorio.

Los investigadores han preferido tradicionalmente pulsos controlados por corriente porque su eficacia parece más sencilla de modelar [43], ya que el campo eléctrico y el potencial resultan de una estimulación que es directamente proporcional a la corriente que pasa a través de un electrodo. Existen, sin embargo, ventajas significativas para usar control por voltaje: no solo el circuito necesario para controlar el voltaje es simple, sino que utilizar éste hace posible evitar reacciones electroquímicas. Los estímulos controlados por corriente pueden exceder fácilmente voltajes que pueden dañar 
electrodos y a las neuronas; esto se convierte en significativo cuando los voltajes de electrodo superan un voltio. Mientras que el daño puede reducirse empleando pulsos de carga balanceados, es deseable evitarlo. Bajo el control por corriente, esto es solo posible si el espectro de impedancia de todos los electrodos es conocido. Además, la ventaja clave del control por corriente - la habilidad de calcular el campo eléctrico resultante en el medio que rodea al electrodo - se ve comprometida en MEAs debido a que las corrientes de fuga a través de la capa aislante pueden reducir la corriente que pasa a través del electrodo hasta un 30\% dependiendo de la integridad y grosor del aislante. En consecuencia, Potter y su grupo empleaban pulsos bifásicos controlados por voltaje de menos de un voltio.

Por otra parte, la amplitud de los pulsos es el principal determinante de la eficacia del estímulo, Figura 1.8. El número de células directamente estimuladas por un pulso controlado por voltaje dado crece linealmente con la amplitud de ese pulso. Las redes neuronales no son tan sensibles a la anchura de los pulsos de voltaje. Evidentemente, el pulso debe ser lo suficientemente ancho como para permitir que la membrana celular y todas sus capacidades parásitas en el sistema se carguen, aproximadamente 400 microsegundos. Incrementar el ancho por encima de ese valor tiene muy poco efecto sobre la respuesta neuronal.

Como se ha comentado, el objetivo de la estimulación eléctrica es servir de base en el estudio de ese complejo proceso conocido como aprendizaje. Aprender un nuevo comportamiento es un proceso de exploración que comprende la formación $\mathrm{y}$ modulación de un conjunto de asociaciones entre estímulos y respuestas. En un esfuerzo por entender el fenómeno del aprendizaje, se plantean dos preguntas. (1) ¿Cuáles son los mecanismos neuronales que envuelven la formación y modulación de asociaciones? (2) ¿Cuáles son los principios que rigen la selección de asociaciones "apropiadas" sobre aquellas "inapropiadas"? La naturaleza de los mecanismos que dan lugar a la formación y modulación de asociaciones ha sido tema de muchas investigaciones. Aunque hay aún mucho por descubrir, muchos mecanismos han sido descritos, en varios niveles de organización neuronal, como capaces de la modificación de asociaciones dependientes de la actividad entre estímulos y respuestas. Actualmente, la mayor parte de las investigaciones relacionadas con aprendizaje y estimulación eléctrica intentan dar respuesta a la segunda pregunta. Uno de los primeros referentes en el estudios de los mecanismos de aprendizaje fue un grupo de investigadores israelís formado por Goded Shahaf y Shimon Marom [29].

Shahaf y Marom fueron los pioneros en aplicar una estimulación condicionada para conseguir que la red neuronal fuera instruida para seleccionar y estabilizar una o varias conexiones de entre un conjunto amplio de ellas. Previamente, era necesario comprobar que las redes de neuronas, corticales en este caso, mostraban propiedades generales que se esperaban de los sistemas con capacidad de aprendizaje: numerosas conexiones, estabilidad en las conexiones y modificabilidad a partir de un estímulo externo. Posteriormente, procedían a una estimulación condicional basada en la simple idea de estimular la red hasta que se obtenía una determinada respuesta $y$, una vez que esto ocurría, retirar el estímulo. 


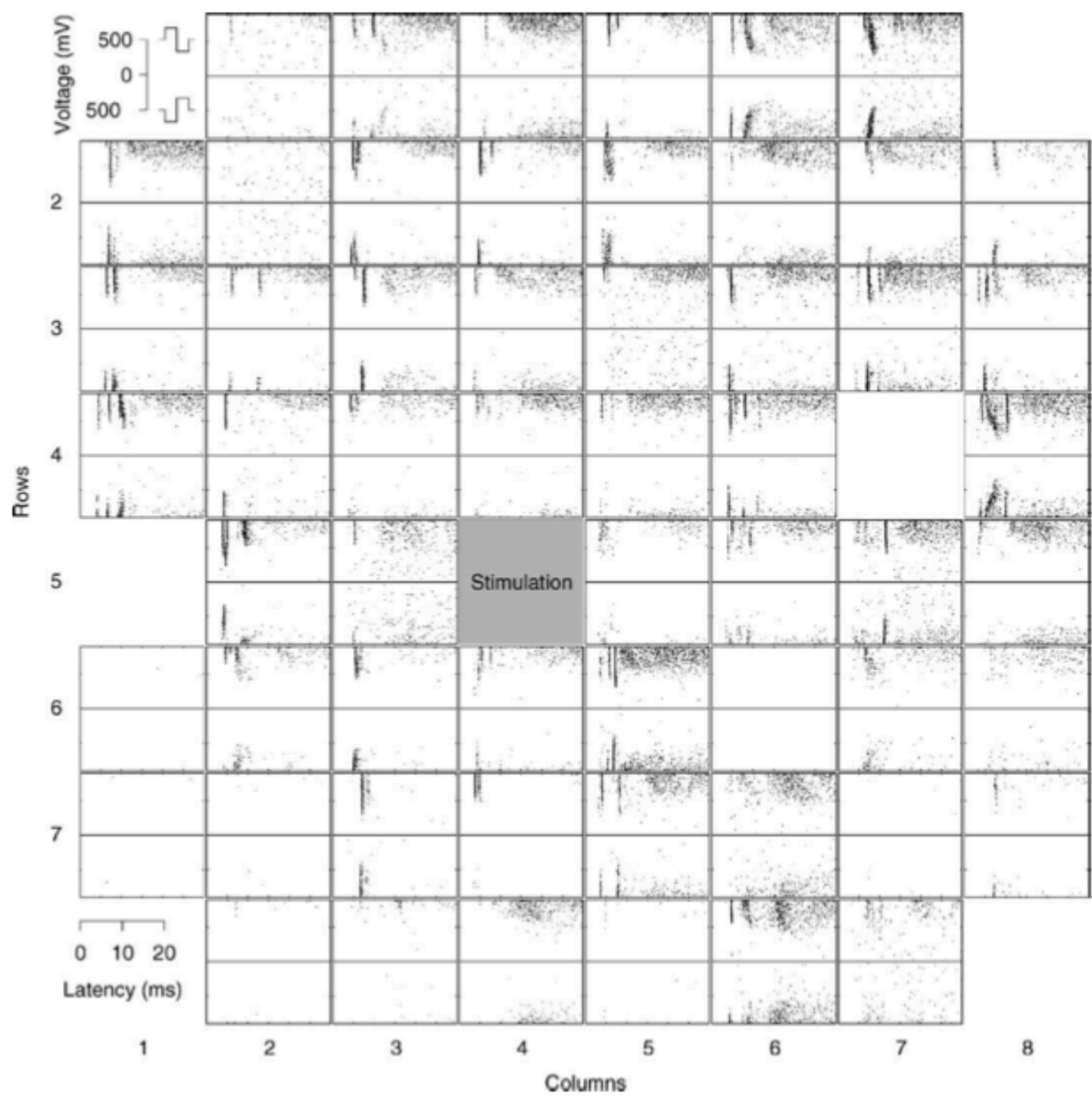

Figura 1.8: Potenciales de acción con un pequeño retardo en respuesta a diferentes estímulos. Cada punto de cada gráfica es un potencial de acción inducido por un pulso bifásico enviado al electrodo 45 en el tiempo cero. Cuando el voltaje se incrementaba de 0 a 1 Voltio, se observaban más respuestas a lo largo de la red. Figura extraída de [42].

Cada experimento comenzaba estimulando la red a través de un par de electrodos y observando su capacidad de respuesta en el resto de electrodos. Se seleccionaba un electrodo que respondía en $50 \pm 10 \mathrm{~ms}$ después del estímulo con una relación respuesta/estímulo (R/S) de 1/10 o menos. En otras palabras, antes del entrenamiento, eran necesarios al menos 10 estímulos para evocar un potencial de acción en el electrodo seleccionado dentro del tiempo designado. Durante la fase de entrenamiento, la tarea de aprendizaje consistía en incrementar la tasa $\mathrm{R} / \mathrm{S}$ del electrodo seleccionado en $2 / 10$ o superior en la ventana temporal $50 \pm 10 \mathrm{~ms}$ tras el estímulo. Los dos electrodos estimulados se estimulaban a una frecuencia constante de 1/3, 1/2 o 1 estímulo por segundo. Un ordenador recogía constantemente la relación $\mathrm{R} / \mathrm{S}$ del electrodo seleccionado y una vez que el criterio $\mathrm{R} / \mathrm{S} \geq 2 / 10$ se cumplía de forma que, por ejemplo, dos respuestas cualesquiera se observaran en cualquiera de 10 ciclos consecutivas, el ordenador paraba automáticamente la estimulación. Después de 5 min, 
la red era estimulada otra vez con la misma baja frecuencia hasta que se cumplía el mismo criterio en el mismo electrodo. El ciclo de estimulación, que se componía de 5 min sin estimulación seguidos de estimulación de baja frecuencia hasta que se cumplía el criterio se repetía varias veces. Como regla, si el criterio no se cumplía en $10 \mathrm{~min}$ la estimulación se paraba durante $5 \mathrm{~min}$. Un ejemplo del resultado de este proceso de aprendizaje se muestra en la Figura 9. La figura muestra la respuesta de un electrodo seleccionado antes (columna izquierda) y después (columna derecha) del entrenamiento. Las 11 trazas de cada columna representan 11 pulsos de estimulación consecutivos. Nótese que la actividad en la ventana temporal $50 \pm 10 \mathrm{~ms}$ se ha incrementado de forma considerable tras el entrenamiento.

Before training After training
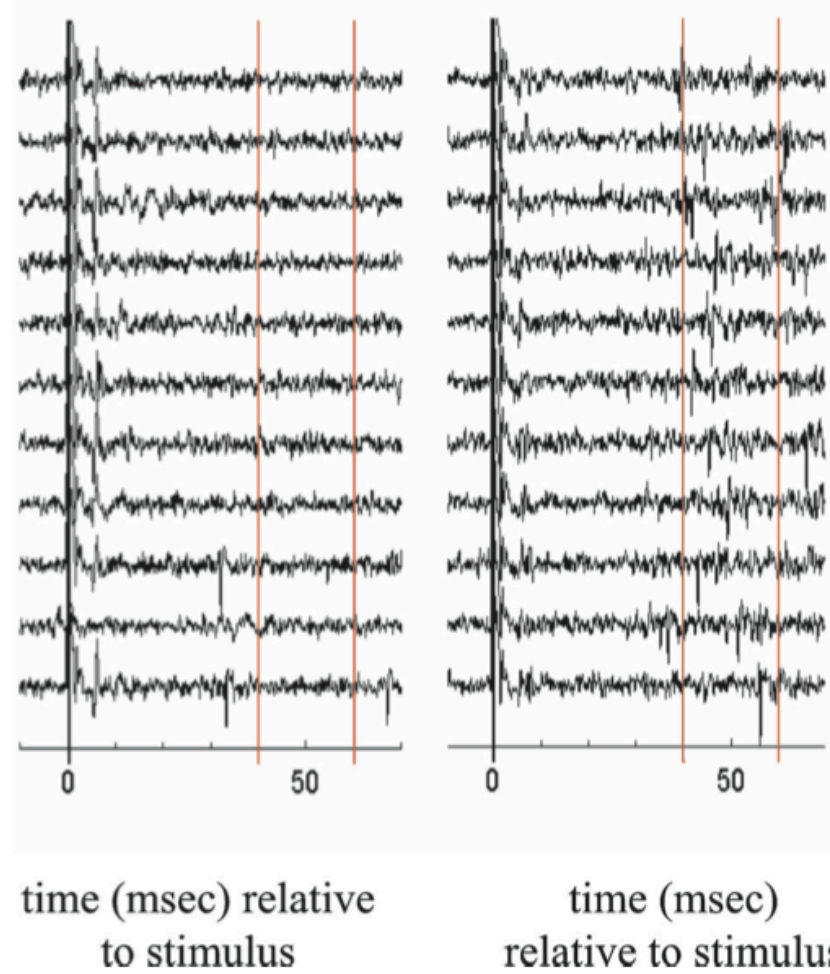

\section{time (msec) \\ relative to stimulus}

Figura 1.9: Aprendizaje en una red neuronal de neuronas corticales. Cada traza de cada gráfica muestra un registro obtenido $10 \mathrm{~ms}$ antes del estímulo a $70 \mathrm{~ms}$ después del estímulo, antes (izquierda) y después (derecha) del proceso de aprendizaje. Figura extraída de [29].

La Figura 1.10A muestra ocho curvas de aprendizaje, que difieren en la forma del aprendizaje. En estas curvas, el tiempo de respuesta (tiempo requerido para que el electrodo seleccionado cumpla el criterio $\mathrm{R} / \mathrm{S} \geq 2 / 10$ ) se muestra frente al ciclo de estimulación. Las curvas se caracterizan por una respuesta decreciente en tiempo y una estabilización a valores inferiores comparados con los valores iniciales. La Figura 1.10B muestra la importancia de dejar de estimular una vez se ha alcanzado el criterio deseado. En ella se observa que si esto no ocurre, el tiempo de respuesta presenta grandes fluctuaciones y una tendencia a disminuir la capacidad de respuesta con el tiempo. 


\section{$A$}
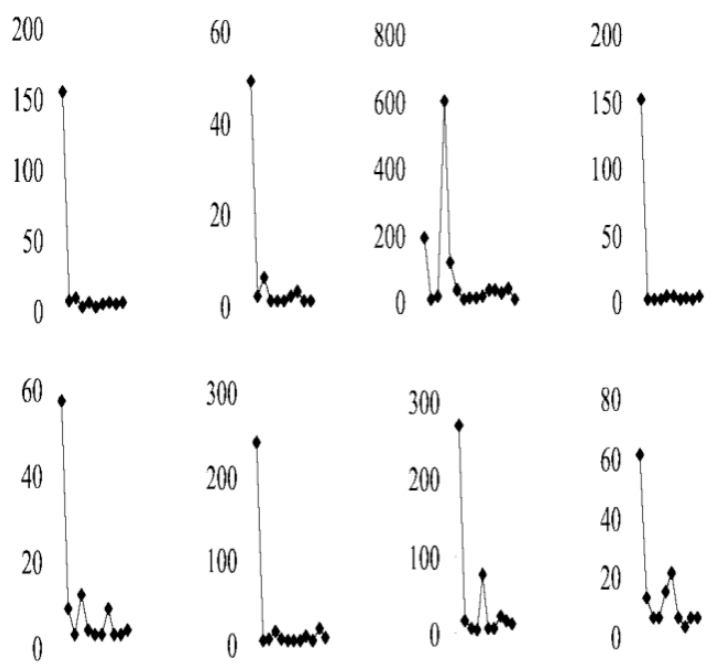

\section{$B$}
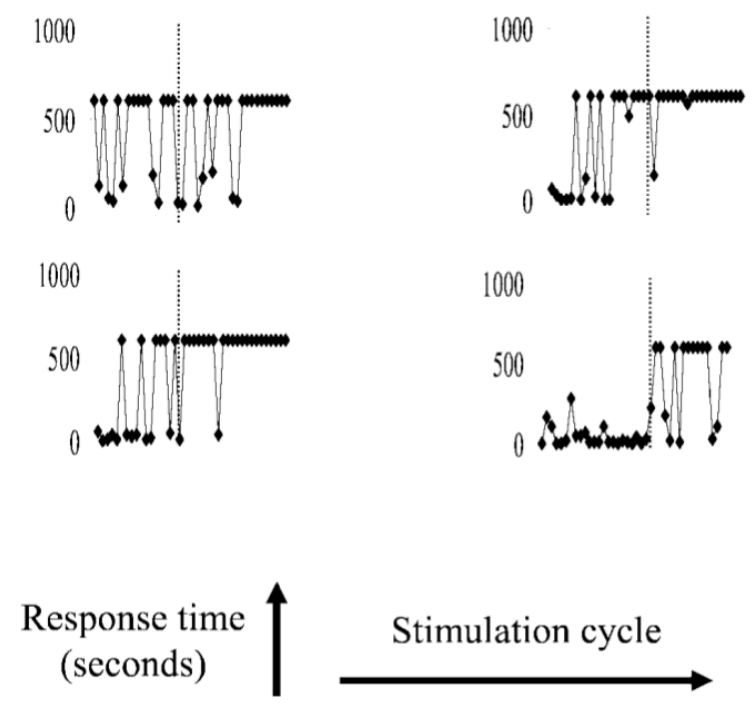

Figura 1.10: Curvas de aprendizaje de un experimento de aprendizaje selectivo. A. Ocho curvas de aprendizaje exitoso, que difieren en su forma de aprendizaje. El tiempo de respuesta se muestra frente al ciclo de estimulación. Cada punto representa el tiempo (en segundos) para completar la tarea en un ciclo. B. Cuatro curvas de control de un protocolo en el que cada ciclo consiste en $10 \mathrm{~min}$ de estimulación y $5 \mathrm{~min}$ sin estimulación, independientemente de la respuesta. Figura extraída de [29].

Tras los experimentos de Shimon Marom y Goded Shahaf las investigaciones se han dirigido en varias vertientes. Por un lado, algunos investigadores centran sus experimentos en el análisis de la actividad espontánea y de las ráfagas de los cultivos neuronales como base para entender los mecanismos de aprendizaje y memoria [44, 45]. Entre ellos, cabe destacar al investigador de los Países Bajos Wim Rutten, que emplea métodos para el análisis de las ráfagas basados en los perfiles de las frecuencias instantáneas de disparo [46]. Durante el desarrollo de los cultivos se analizan las formas típicas y los cambios de estos perfiles. Además, Rutten realiza una conexión matemática para análisis basados en las correlaciones de trenes de potenciales de acción electrodo- 
electrodo. La estabilidad de los perfiles y el nivel de detalle que proporcionan hacen que el análisis por perfiles de ráfagas y fase un candidato excelente para futuros estudios en plasticidad y aprendizaje. La Figura 1.11 muestra un ejemplo del cálculo de estos perfiles. En primer lugar se obtienen los potenciales de acción y con ellos se construye la tasa global de disparo o AWSR (Array-Wide Spiking Rate), Figura 1.11A. El AWSR se binariza y se compara con un umbral, Figura 1.11B. Si el número de potenciales de acción por intervalo por cruza el umbral, el perfil se calcula mediante la convolución del AWSR binarizado con una gaussiana, Figura 11C. Finalmente, la Figura 11D denota que un conjunto de datos está formado por una serie de perfiles de ráfagas (BP) y fase (PP).

$\mathbf{A}$

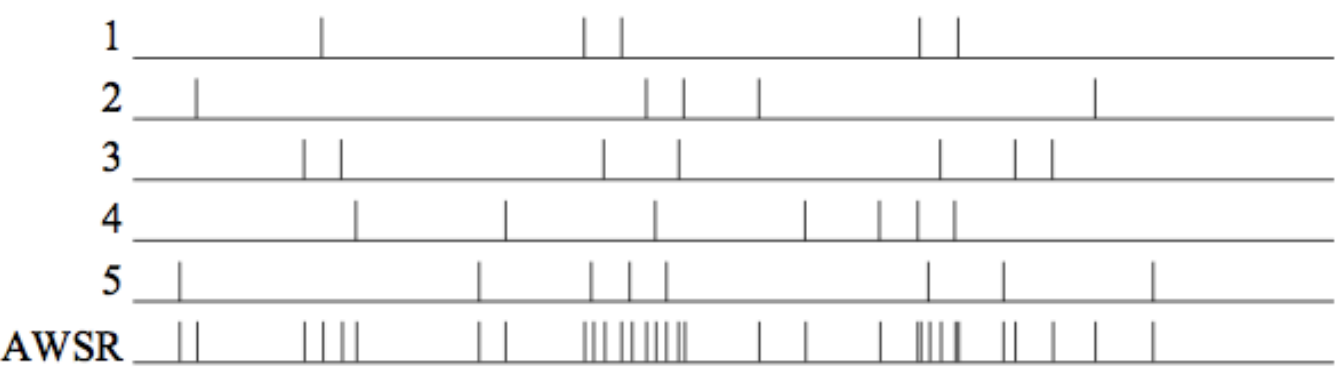

B

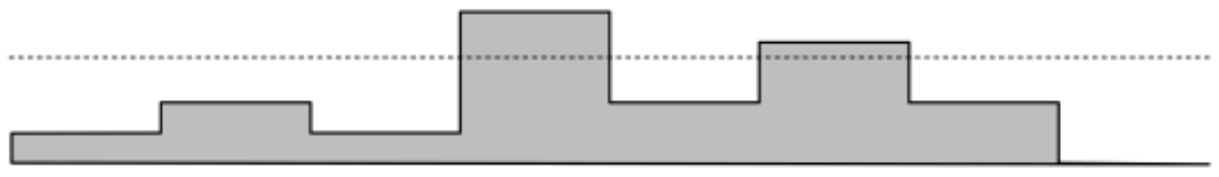

$\mathbf{C}$

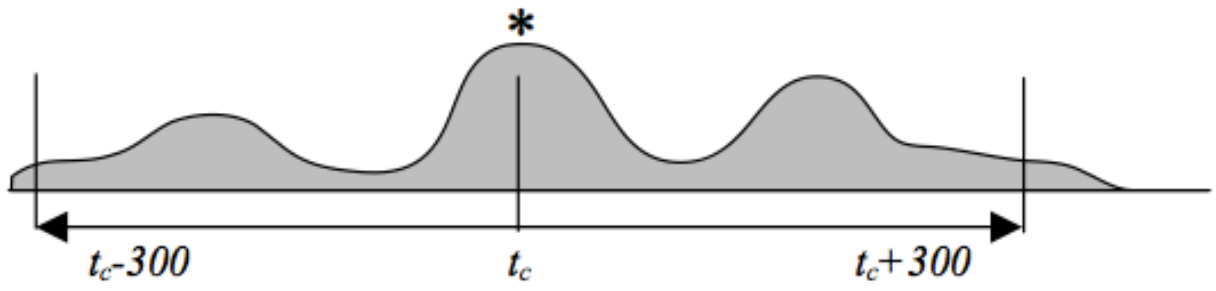

D

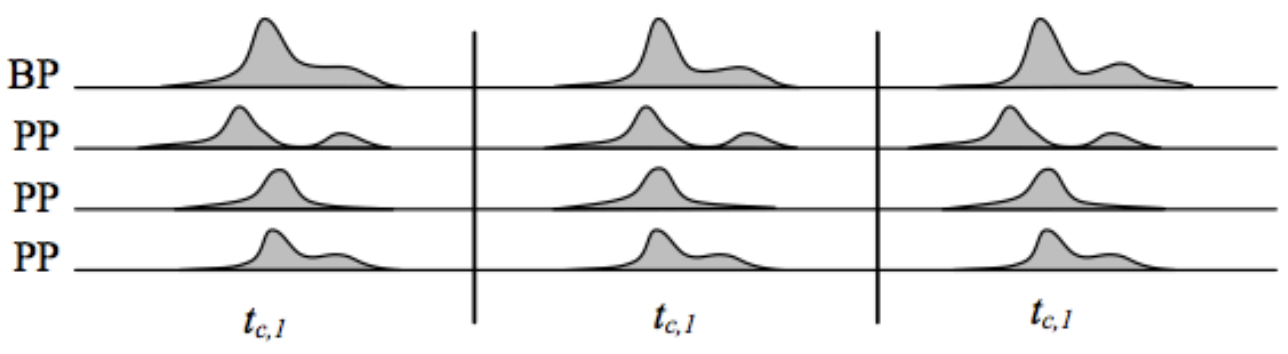

Figura 1.11: Cálculo de perfiles de ráfagas y fase. Figuras extraídas de [46].

Una vez obtenidos los diferentes perfiles, éstos se emplean en diferentes paradigmas de estimulación para inducir plasticidad sináptica [47].

Paralelamente, las investigaciones relacionadas con el aprendizaje y la memoria han intentado reproducir las condiciones de un estado in-vivo, ya que de esta forma se evitarían algunos comportamientos que dificultan inducir y observar cambios en los cultivos. El grupo de Rutten trató de prevenir el comportamiento de ráfagas y promover la actividad dispersada de dos formas diferentes: mediante alteración química y proporcionando estímulos de forma incorrelada a diferentes electrodos [48]. Esta idea se 
basa en la hipótesis de que los estímulos incorrelados mantienen a las neuronas en un estado en el que los mecanismos de plasticidad ni están inactivos ni sobrecargados [4950].

Por su parte, otros investigadores creen que la mejor manera de reproducir las características in-vivo de los cultivos es mediante la interacción de los mismos con el entorno, un concepto al que se le denomina embodiment [51]. Este concepto se basa en la idea de que la experiencia es el elemento fundamental en el aprendizaje pues permite que se establezcan las conexiones neuronales adecuadas. La forma de añadir una interacción con el entorno en los cultivos se consigue mediante una realimentación. Los estímulos actúan como entradas sensoriales y las señales registradas en el cultivo pueden ser empleadas como comandos motores.

Wilson [52] acuñó el término animat (animal robótico o simulado que tiene un determinado comportamiento sobre un entorno) en sus estudios sobre inteligencia en las interacciones con animales artificiales. El primer animat controlado neuralmente fue realizado por el grupo de Steve M. Potter (Figura 1.12) [53-55]. Potter y su grupo introdujeron el término hybrot para referirse a un robot biológico híbrido. Por su parte, el grupo de Mussa-Ivaldi creó el primer hybrot en bucle cerrado controlando un robot Khepera con tejido cerebral procedente de lampreas marinas [56].
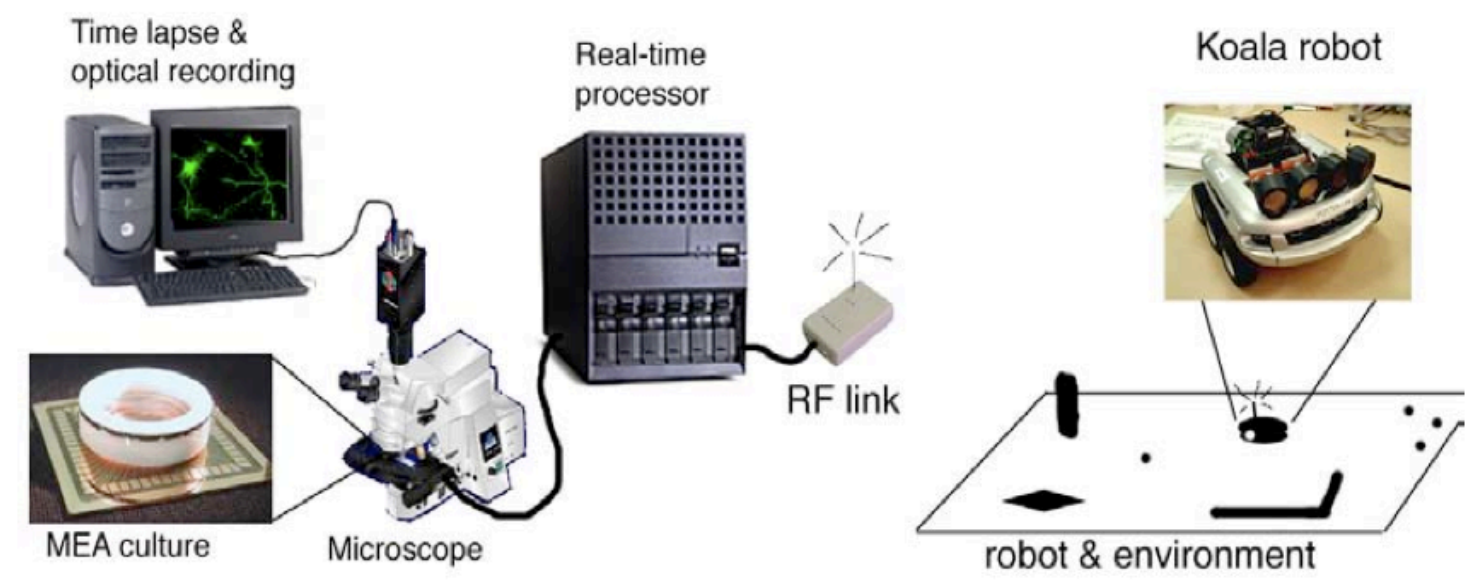

Figura 1.12: Configuración de un Hybrot. Los datos eléctricos y ópticos de las neuronas en un MEA son analizados y utilizados para controlar varios dispositivos robóticos, mientras que el proceso de imagen se emplea para hacer secuencias de la plasticidad neuronal. Figura extraída de [51].

Investigaciones recientes por parte del grupo de Steve M. Potter han conseguido que, a través de un sistema en bucle cerrado y la aplicación de un algoritmo adaptativo, un animat sea capaz de moverse en una dirección previamente establecida [57]. Dicho algoritmo, Figura 1.13, muestrea la actividad del cultivo mediante un protocolo de estimulación llamado CPS (Context-Control Probing Sequences). Ésta actividad se transforma en un vector de dirección que será comprobado con la dirección deseada. Si, con un cierto grado de error, el vector de dirección satisface la dirección deseada, se emplea otro protocolo de estimulación, SBS (Shuffled Background Stimulation), que tiene como fin estabilizar la plasticidad. En caso contrario, se empleará PTS (Patterned Training Stimulation) para inducir plasticidad. De esta forma se irá entrenando al 
cultivo neuronal hasta que satisfaga la dirección deseada, habiendo conseguido de forma exitosa el aprendizaje.

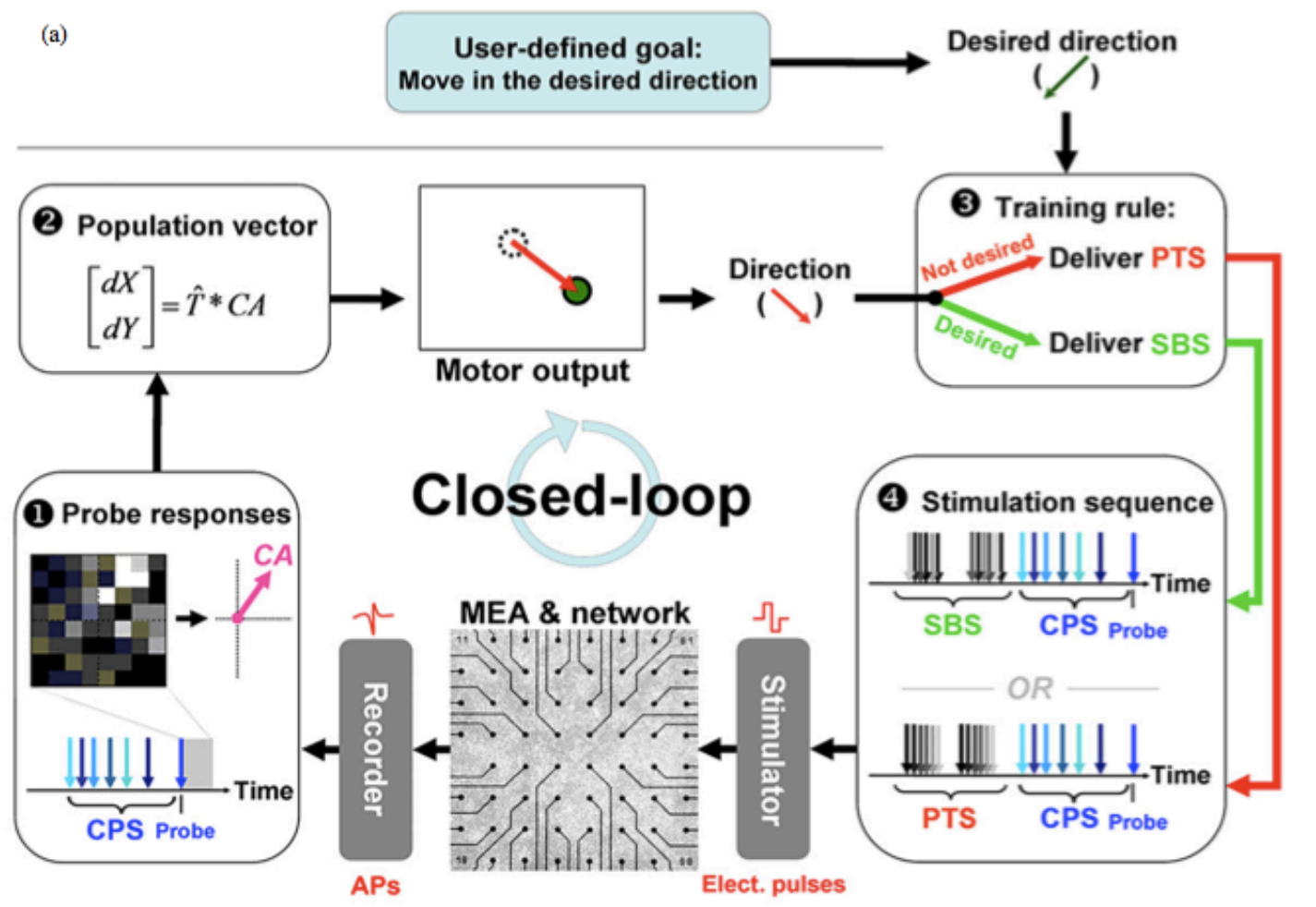

Figura 1.13: Esquema de una realimentación en bucle cerrado en un experimento de entrenamiento adaptativo. Figura extraída de [49].

Las investigaciones que hacen uso de realimentación han demostrado que cuando ésta se utiliza, los estímulos pueden alterar las relaciones de entrada-salida de las redes. Por tanto, los experimentos haciendo uso de realimentación son actualmente el eje central de los estudios sobre aprendizaje en redes neuronales cultivadas.

Finalmente, otros investigadores se han centrado en cambiar algunos parámetros de estimulación (voltaje vs. corriente, frecuencia, amplitud, etc.) con el fin de conseguir muestras de aprendizaje. El grupo de Brewer utilizó una estimulación de muy baja frecuencia y larga duración, que llamó estimulación crónica, para obtener un incremento en el número de potenciales de acción evocados por estímulo así como en la tasa de disparo [64]. Los resultados que obtuvieron sugieren que los cambios inducidos en la red por esta estimulación mejoran la fiabilidad de la transmisión de información y la eficiencia de la comunicación multisináptica de la red. Por su parte, el grupo de investigación de Sergio Martinoia aplicó estimulación de baja frecuencia, generalmente basada en voltaje, de forma constante durante semanas [65]. Descubrieron que la estimulación tenía un efecto retardante modulando así la capacidad de respuesta de la red sin afectar directamente a su desarrollo intrínseco in-vitro. La tabla 1.1 recoge una visión global de los protocolos de estimulación empleados en los estudios más destacados, además de los resultados obtenidos en cada uno. 


\begin{tabular}{|c|c|c|c|c|}
\hline Estudio & $\begin{array}{c}\mathrm{N}^{\mathbf{0}} \\
\text { electr. }\end{array}$ & $\begin{array}{l}\text { Parámetros de } \\
\text { estimulación }\end{array}$ & $\begin{array}{c}\text { Características } \\
\text { evaluadas }\end{array}$ & Efecto \\
\hline $\begin{array}{l}\text { Maeda et al. } \\
(1998)[58]\end{array}$ & 5 & $\begin{array}{l}\text { Tetanización: }(20 \mathrm{x}, 20 \mathrm{~Hz} \\
\text { ITI } 10-15 \text { s) } 5-10 \mathrm{x} .\end{array}$ & $\begin{array}{l}\text { Tasa de ráfagas y } \\
\text { duración, espontánea } \\
\text { inducida por un estímulo } \\
\text { de análisis. }\end{array}$ & $\begin{array}{l}\text { Incremento de la tasa de ráfagas } \\
\text { y potenciales por ráfaga, tanto } \\
\text { espontánea como inducida por } \\
\text { un estímulo de análisis. }\end{array}$ \\
\hline $\begin{array}{l}\text { Jimbo et al. } \\
(1998)[39]\end{array}$ & $1 \circ 8$ & $\begin{array}{l}\text { Tetanización: } \quad(11 x, \quad 20 \mathrm{~Hz} \text {; } \\
\text { ITI 5s) 10x. }\end{array}$ & Voltaje celular. & $\begin{array}{l}\begin{array}{l}\text { Incremento en las corrientes } \\
\text { excitatorios } \\
\text { (EPSC). }\end{array} \\
\text { post-sinápticas }\end{array}$ \\
\hline $\begin{array}{l}\text { Jimbo et al. } \\
(1999)[27]\end{array}$ & 1 & $\begin{array}{l}\text { Tetanización: } \quad(11 x, \quad 20 \mathrm{~Hz} \text {; } \\
\text { ITI 5s) 10x. }\end{array}$ & $\begin{array}{l}\text { Número e información } \\
\text { temporal de los } \\
\text { potenciales inducidos } \\
\text { por neurona en respuesta } \\
\text { a un estímulo de } \\
\text { análisis. }\end{array}$ & $\begin{array}{l}\text { Incremento o decremento de las } \\
\text { EPSCs y del número de } \\
\text { potenciales inducidos. }\end{array}$ \\
\hline $\begin{array}{l}\text { Tateno et al. } \\
(1999) \text { [59] }\end{array}$ & 1 o 2 & $\begin{array}{l}\text { Tetanización: }(10 x, 20 \mathrm{~Hz} \\
\text { ITI 5s) 20x pulsos } 100 \mu \mathrm{s} .\end{array}$ & $\begin{array}{l}\text { Fiabilidad de los } \\
\text { potenciales de acción } \\
\text { tras estímulo de análisis, } \\
\text { tiempo entre el estímulo } \\
\text { de análisis y el primer } \\
\text { potencial. }\end{array}$ & $\begin{array}{l}\text { Reducción de la latencia y del } \\
\text { jitter del primer potencial en } \\
\text { algunas neuronas. Incremento } \\
\text { del efecto en } 1 \text { o dos electrodos. }\end{array}$ \\
\hline $\begin{array}{l}\text { Shahaf et al. } \\
(2001) \text { [29] }\end{array}$ & 2 & $\begin{array}{l}\text { Estimulación bipolar, ISI 1- } \\
3 \text { s hasta respuesta deseada, } \\
10 \text { min. Máx. }\end{array}$ & $\begin{array}{l}\text { Incremento del número } \\
\text { de potenciales en un } \\
\text { electrodo de evaluación. }\end{array}$ & $\begin{array}{l}\text { Incremento de los potenciales } \\
\text { inducidos en una ventana } \\
\text { temporal. }\end{array}$ \\
\hline $\begin{array}{l}\text { Ruaro et al. } \\
(2005)[60]\end{array}$ & 15 & $\begin{array}{l}\text { Tetanización: }(100 x, 250 \mathrm{~Hz} \text {, } \\
\text { ITI 2s) 40x. }\end{array}$ & $\begin{array}{l}\text { Respuestas a estímulo de } \\
\text { análisis. }\end{array}$ & $\begin{array}{l}\text { Incremento en la tasa de disparo } \\
\text { establecida entre } 1 \text { y } 50 \mathrm{~ms} \text {. }\end{array}$ \\
\hline $\begin{array}{l}\text { Wagenaar et al. } \\
(2006)[61]\end{array}$ & 2 & $\begin{array}{l}\text { Tetanización: 20x, } 20 \mathrm{~Hz} \text {; ITI } \\
6 \mathrm{~s}, 150 \mathrm{x}, \text { desplazamiento } \\
5 \mathrm{~ms} .\end{array}$ & $\begin{array}{l}\text { Respuestas a estímulo de } \\
\text { análisis tras } 10-50 \mathrm{~ms} .\end{array}$ & $\begin{array}{l}\text { Incremento del número de } \\
\text { potenciales inducidos para un } \\
\text { electrodo destacado } r \\
\text { decremento para el siguiente } \\
\text { electrodo. }\end{array}$ \\
\hline $\begin{array}{l}\text { Madhavan et } \\
\text { al. (2007) [62] }\end{array}$ & 2 & $\begin{array}{l}\text { Tetanización: } 18000 x, 20 \mathrm{~Hz} \\
(15 \text { min), desplazamiento } 10 \\
\text { ms }\end{array}$ & $\begin{array}{l}\text { Expresión de la tasa } \\
\text { espontánea de los tipos } \\
\text { de ráfagas (BT). }\end{array}$ & $\begin{array}{l}\text { Generación de nuevos BTs e } \\
\text { incremento o decremento en la } \\
\text { tasa de BTs. }\end{array}$ \\
\hline $\begin{array}{l}\text { Chao et al. } \\
(2007)[63]\end{array}$ & 2 & $\begin{array}{l}\text { Tetanización: } 18000 x, 20 \mathrm{~Hz} \\
(15 \text { min), desplazamiento } 10 \\
\text { ms. }\end{array}$ & $\begin{array}{l}\text { Centro de la trayectoria } \\
\text { de actividad (CAT) de la } \\
\text { actividad evocada. }\end{array}$ & $\begin{array}{l}\text { Cambio significativo del CAT } \\
\text { en algunos electrodos de } \\
\text { análisis. }\end{array}$ \\
\hline $\begin{array}{l}\text { Stegenga et al. } \\
(2009)[48]\end{array}$ & 1 & $\begin{array}{l}\text { SESP: un solo pulso, } 0.1 \text { a } \\
1 \mathrm{~Hz} \text {. }\end{array}$ & $\begin{array}{l}\text { Perfiles de ráfagas (BPs) } \\
\text { y perfiles de fase (PPs). }\end{array}$ & $\begin{array}{l}\text { No se produce un efecto } \\
\text { medible en los BPs. } \\
\text { Incremento del efecto en PPs no } \\
\text { estimulados. }\end{array}$ \\
\hline $\begin{array}{l}\text { Brewer et al. } \\
(2009)[64]\end{array}$ & 30 & $\begin{array}{l}\text { Pulsos bifásicos pareados, } \\
50 \mathrm{~ms} \text { ISI, } 5 \mathrm{~s} \text { ITI, } 0-3 \text { horas } \\
30 \mu \mathrm{A} \text {, fase } 100 \mu \mathrm{s} \text {. }\end{array}$ & $\begin{array}{l}\text { Respuestas evocadas, } \\
\text { actividad de potenciales } \\
\text { de acción. }\end{array}$ & $\begin{array}{l}\text { Incremento de las respuestas } \\
\text { evocadas y de la frecuencia de } \\
\text { los potenciales de acción. }\end{array}$ \\
\hline $\begin{array}{l}\text { Martinoia et al. } \\
(2010)[65]\end{array}$ & 8 & $\begin{array}{l}\text { Pulso bifásico } 36 \mathrm{x}, 0.2 \mathrm{~Hz} \\
\text { secuencialmente a cada } \\
\text { electrodo, } 200 \mu \mathrm{s} / \text { fase, } 1.5 \\
\text { Vpp. }\end{array}$ & $\begin{array}{l}\text { Tasa de disparo } \\
\text { espontánea, tasa de } \\
\text { ráfagas. }\end{array}$ & $\begin{array}{l}\text { Cambios significativos en la } \\
\text { tasa media de disparo de las } \\
\text { redes. }\end{array}$ \\
\hline
\end{tabular}

Tabla 1.1: Resumen de los estudios realizados sobre los cambios producidos en la actividad de la red causados por una estimulación eléctrica. 


\section{Capítulo 2 Publicaciones}

Este capítulo contiene resúmenes extendidos de las publicaciones que componen la tesis, citadas a continuación. Estos resúmenes incluyen la metodología propuesta, los resultados obtenidos, las principales contribuciones y unas conclusiones finales. Seguidamente, se ha incluido una copia íntegra de los artículos citados, cuya documentación referente al índice de impacto de las revistas donde han sido publicados se puede encontrar en el Apéndice A, de conformidad con la normativa vigente: Artículo 33, epígrafe 3, del Reglamento de estudios oficiales de máster y doctorado de la Universidad Politécnica de Cartagena, aprobado por Consejo de Gobierno el 13 de abril de 2011 y modificado en Consejo de Gobierno el 11 de julio de 2012.

a. Daniel de Santos, Víctor Lorente, Félix de la Paz, José Manuel Cuadra, José R. Álvarez-Sánchez, Eduardo Fernández, José M. Ferrández. A client-server architecture for remotely controlling a robot using a closed-loop system with a biological neuroprocessor. Robotics and Autonomous Systems, 58:12231230, 2010. (JCR-ISI, IF 1.313, Q2).

b. J.M. Ferrández, V. Lorente, F. de la Paz, J.M. Cuadra, José Ramón ÁlvarezSánchez, E. Fernández. A biological neuroprocessor for robotic guidance using a center of area method. Neurocomputing 74:1229-1236, 2011. (JCRISI, IF 1.580, Q2).

c. J.M. Cuadra, J.R. Álvarez-Sánchez, D. De Santos, V. Lorente, J.M. Ferrández, F. de la Paz, E. Fernández. Response calibration in neuroblastoma cultures over multielectrode array. Neurocomputing 75:98-105, 2012. (JCR-ISI, IF 1.634, Q2).

d. J.M. Ferrández, V. Lorente, F. de la Paz, E. Fernández. Training biological neural cultures: Towards Hebbian learning. Neurocomputing 114:3-8, 2013. (JCR-ISI, IF 1.634, Q2).

Las publicaciones referenciadas cubren en su totalidad los objetivos de la tesis, descritos en el resumen y enumerados a continuación:

1. Definición y construcción de una plataforma para el soporte en tiempo real de los sistemas de adquisición de registros neuronales, y estimulación eléctrica de los mismos, que se comunique remotamente con un dispositivo robótico. 
2. Estudio y propuesta de un método de guiado robótico basado en una plataforma de lazo cerrado que integre la información de los sensores del robot en el neuroprocesador $\mathrm{y}$, en función de la respuesta de éste, direccione el sistema robótico.

3. Normalización y calibración estadística de los registros del neuroprocesador para su adecuación a los distintos algoritmos de guiado robótico y aprendizaje en los cultivos neuronales.

4. Estudio y definición de técnicas de aprendizaje en cultivos neuronales para la realización de conectividad funcional dirigida con objeto de proporcionar nuevos paradigmas de programación en neuroprocesadores biológicos.

Específicamente, el artículo (1) cubre completamente el objetivo (1). El objetivo (2) se encuentra cubierto en su totalidad por el artículo (2) y ha sido ampliado en otras contribuciones. El artículo (3) se encarga de cubrir el objetivo (3). Finalmente, aunque el objetivo (4) se completa con el artículo (4), son varias las contribuciones adicionales que amplían este objetivo, algunas de las cuales se pueden consultar en el Capítulo 3. 


\subsection{A client-server architecture for remotely controlling a robot using a closed-loop system with a biological neuroprocessor}

\section{Introducción}

Este artículo introduce un sistema en tiempo real de código abierto que controla remotamente un robot utilizando cultivos de neuroblastoma humano y una arquitectura cliente-servidor. Las configuraciones de matrices de microelectrodos han sido diseñadas para cultivar directamente células neuronales sobre sustratos de silicio o cristal, proporcionando la capacidad de estimular y registrar simultáneamente poblaciones de células neuronales. Sin embargo, es realmente complicado unir estas poblaciones de células a la estructura de un robot debido a las características particulares del material biológico. El principal objetivo de esta investigación es construir un sistema clienteservidor para controlar remotamente un robot empleando un cultivo neuronal en un experimento en bucle-cerrado. Los sensores del robot alimentarán el neuroprocesador biológico, mientras que la actividad neuronal será empleada para el guiado del robot, controlando de esta manera el comportamiento robótico.

La función fisiológica de las células neuronales se modula por los mecanismos de adaptación y reconfiguración en respuesta a la actividad neuronal. El aprendizaje Hebbiano describe un mecanismo básico para la plasticidad sináptica donde un incremento en la eficacia sináptica de la célula pre-sináptica proviene de la estimulación repetida y persistente de la célula post-sináptica. Esta teoría se evoca comúnmente para explicar algunos tipos de aprendizaje asociativo en los que una activación simultánea de células lleva a un incremento pronunciado de la fuerza sináptica.

La línea celular SH-SY5Y de neuroblastoma humano expresa receptores de dopamina y NDMA clones a los humanos y, a pesar de su naturaleza cancerígena, estas células muestran respuestas electrofisiológicas similares a las neuronas humanas, como los potenciales de acción sensibles a la tetrodoxina y acetilcolina. Esta línea celular será la plataforma biológica para el estudio del aprendizaje en células cultivadas.

\section{Metodología}

\section{Configuración experimental: hardware}

La configuración experimental comprende una solución completa para estimulación, registro, calentamiento celular y adquisición de datos de 64 canales. Los componentes básicos son los siguientes:

1. Una matriz de microelectrodos estándar (MEA) de 60 electrodos útiles, que permite la selección de varios emplazamientos para la estimulación y el registro extracelular.

2. Una placa de preamplificadores basada en tecnología Surface Mounted Device (SMD) de MultiChannel Systems (MCS), que permite amplificar y filtrar los datos con una ganancia y ancho de banda personalizados. El diseño compacto de la placa reduce los picos de línea y mantiene el nivel de ruido bajo. Estos amplificadores se encuentran montados sobre un microscopio invertido. 
3. Una tarjeta de adquisición de MCS, preinstalada en un ordenador con tareas de adquisición. La tarjeta permite adquirir los datos en formato RAW y el ordenador suple de potencia a los amplificadores así como establece patrones para un estimulador.

4. Un robot que envía información sobre su entorno, detectando obstáculos por medio de sus sensores de infrarrojos al ordenador a través de un enlace remoto.

\section{Configuración experimental: software}

A nivel de software, se emplean los siguientes elementos:

1. Un software de adquisición de datos y análisis para sistemas operativos Windows denominado MC_Rack, proporcionado por MCS.

2. Una suite de programas de código abierto para la adquisición de datos de matrices de microelectrodos diseñada para Linux denominada MeaBench [66]. Esta suite se comunica directamente con el hardware de adquisición de datos y proporciona visualización en tiempo real.

La arquitectura cliente-servidor descrita en este artículo ha sido diseñada para establecer una conexión remota entre un robot y un neuroprocesador biológico. El servidor se comunica directamente con el cultivo neuronal a través de la tarjeta de adquisición, mientras el cliente envía comandos remotamente al servidor, recibiendo los datos neuronales de éste. Las funciones principales han sido implementadas en un set de librerías de forma que cualquier tarea cliente pueda comunicarse con el servidor. La arquitectura propuesta se muestra en la Figura 2.1. Se pueden observar tres posibilidades diferentes para la comunicación con el servidor. En la primera de ellas (parte superior de la figura), la aplicación cliente se emplea como puente entre el robot y el servidor, permitiendo al usuario visualizar el flujo de datos entre cada agente. La segunda (parte media), representa el caso preliminar de estudiar el comportamiento del neuroprocesador biológico antes de conectar el robot al cultivo. Finalmente, en la parte inferior de la figura, el control robótico emplea la librería cliente directamente.

Con tal fin, se han desarrollado las librerías LinkLib, LibPulseGenerator y LibPolar2Script, sobre las cuales se ha implementado la aplicación Bulture, desarrollada en $\mathrm{C}++$ empleando las librerías gráficas Qt4. Las librerías implementadas son capaces de utilizar las diferentes herramientas de MeaBench, configurar la tarjeta de adquisición y seleccionar los electrodos para la estimulación. 


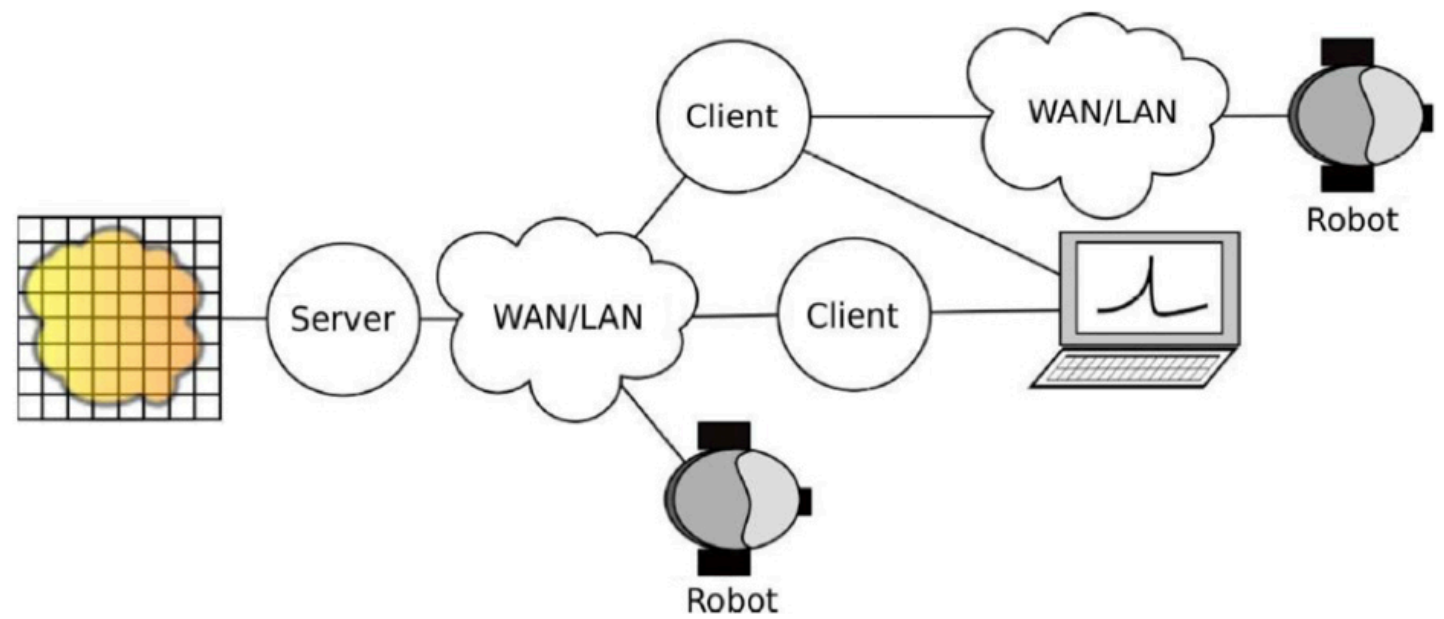

Figura 2.1: Arquitectura de comunicación remota cliente-servidor para el robot.

LinkLib es la librería responsable de la comunicación entre cliente y servidor. El objetivo principal es que un desarrollador pueda usar una herramienta para comunicarse con la matriz de electrodos sin conocer ningún detalle de la implementación de la comunicación. Sus funciones principales son cuatro: (1) seleccionar la fuente de datos, (2) pedir datos, (3) ejecución de programas y (4) configuración del estimulador.

LibPulseGenerator permite la configuración de secuencias de pulsos para ser enviadas al cultivo neuronal. Toma como parámetros los voltajes inicial y final, así como la duración del pulso. Ha sido diseñada para ser empleada con el estimulador STG1002 de MCS y puede, además, cargar y guardar formas de onda predefinidas.

LibPolar2Script es responsable de codificar el espacio libre que el robot ha obtenido de sus sensores como una representación equivalente en la matriz de electrodos. Esta limitada representación es necesaria debido a que el espacio libre alrededor del robot es un área circular de $180^{\circ}$ o $360^{\circ}$, mientras que la matriz de electrodos es sólo una representación cuadrada de $8 \times 8$, Figura 2.2. La librería se ha implementado tanto en el lado del servidor como del cliente.

\begin{tabular}{|c|c|c|c|c|c|c|c|}
\hline 0 & 0 & 0 & 0 & 0 & 0 & 0 & 0 \\
\hline 12 & 0 & 0 & 0 & 0 & 0 & 0 & 0 \\
\hline 10 & 0 & 0 & 0 & 0 & 0 & 0 & 0 \\
\hline 8 & 8 & 0 & 0 & 0 & 0 & 0 & 0 \\
\hline 8 & 6 & 6 & 6 & 6 & 6 & 0 & 0 \\
\hline 8 & 6 & 4 & 4 & 4 & 4 & 6 & 0 \\
\hline 8 & 6 & 4 & 2 & 2 & 4 & 6 & 8 \\
\hline 8 & 6 & 4 & 2 & 2 & 4 & 6 & 8 \\
\hline
\end{tabular}

Figura 2.2: Representación del espacio libre sobre una matriz de electrodos.

Las librerías comentadas anteriormente han sido empleadas como base para el desarrollo de la aplicación Bulture, que actúa como front-end de LinkLib y cuyo fin es 
el estudio de la actividad neuronal del cultivo cuando se produce la estimulación. Bulture se compone de tres herramientas:

1. PulseGenerator, que permite crear pulsos según el protocolo del estimulador STG-1002.

2. Polar2Script, que genera las secuencias de pulsos para ser enviadas al estimulador, seleccionando además los electrodos según el espacio libre detectado por el robot.

3. La aplicación principal cliente-servidor, que incluye a los anteriores, denominada Bulture.

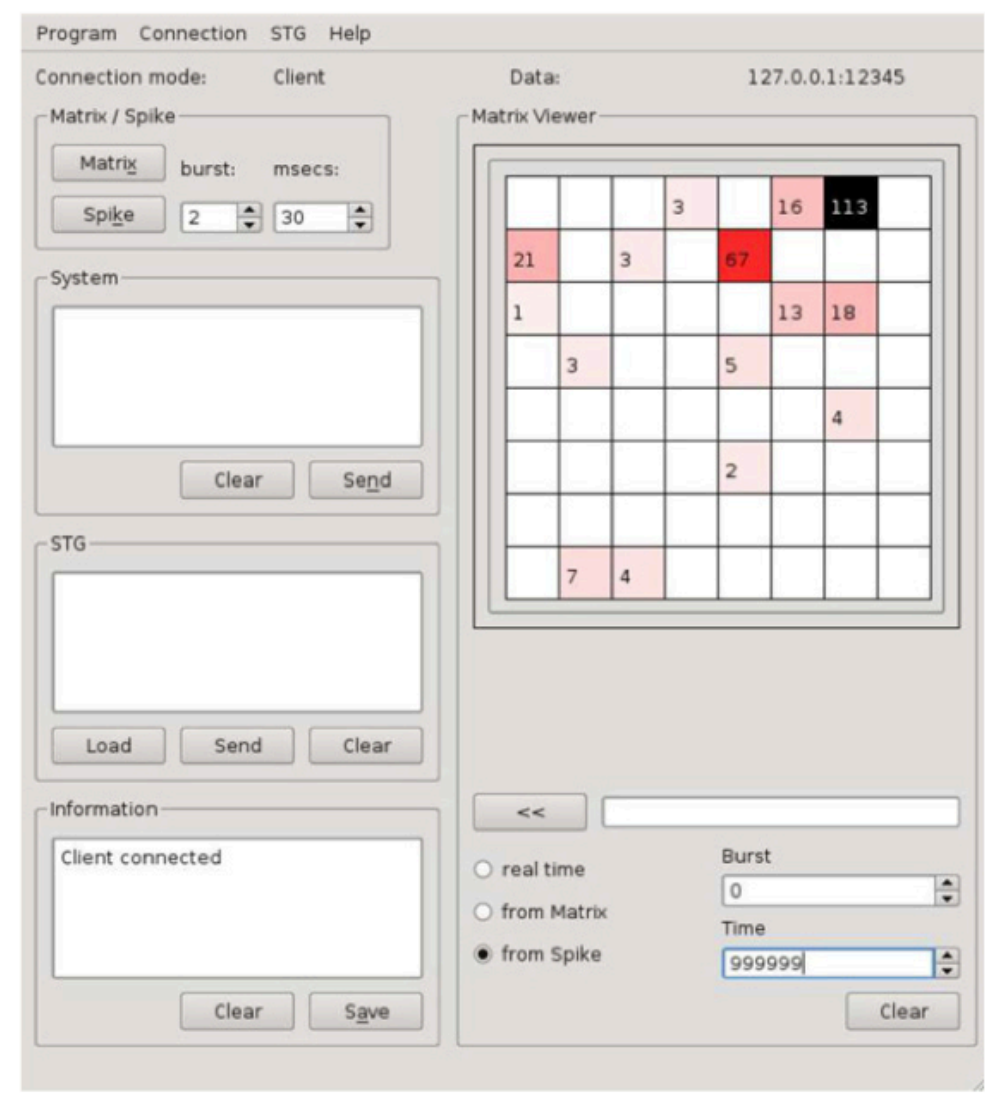

Figura 2.3: Interfaz de usuario de un cliente Bulture.

Bulture permite a diferentes clientes conectarse al servidor empleando hilos de ejecución y estableciendo diferentes permisos para los clientes en una estructura FIFO. La Figura 2.3 muestra la interfaz gráfica de un cliente Bulture que visualiza los datos relativos a los potenciales de acción de un cultivo.

Para realizar el control robótico, se ha desarrollado una plataforma robótica completa que incluye cinco herramientas gratuitas y de código abierto escritas en $\mathrm{C} / \mathrm{C}++$ para el control de aplicaciones robóticas en cultivos neuronales. El software comentado anteriormente hace uso de todas o algunas de estas herramientas para conseguir su propósito. Las herramientas son las siguientes:

- Cult2Robot: La herramienta principal. Desarrollado como un módulo de MeaBench, puede acceder a sus flujos de datos para obtener toda la información 
de un cultivo. Permite obtener un vector de dirección para el control robótico a partir de la actividad neuronal del cultivo.

- Stg_control: Controla un estimulador de propósito general STG 100X de MCS a través de un puerto serie.

- Electrode_select: Configura la placa de preamplificadores MEA1060BC de MCS posibilitando la selección de los electrodos a estimular, así como otras funciones.

- BT_server: Recibe información del entorno de un robot por medio de un enlace Bluetooth usando el protocolo RFCOMM. Se utiliza para detectar obstáculos.

- BT_client: Envía un vector de dirección a un robot empleando un enlace Bluetooth.

\section{Resultados}

Es realmente importante comprobar que el sistema de adquisición se encuentra funcionando correctamente con la configuración hardware antes de realizar estudios más específicos. Utilizando un generador de señales de MCS, se emplearon diferentes señales en el preamplificador.

La primera señal fue una señal sinusoidal básica, con una frecuencia de $1.25 \mathrm{~Hz}$ y valores de pico de 12 y $24 \mu \mathrm{V}$. La segunda señal generada consistía en potenciales de acción de células de retina con valores de 35 y $80 \mu \mathrm{V}$, dependiendo del electrodo. La Figura 2.4 muestra una ampliación de un potencial de acción de retina detectado en el electrodo 42 en MeaBench. El valor de pico fue de $140 \mu \mathrm{V}$ con un factor de escala de $4 \mathrm{x}$ y el nivel señal a ruido fue de 3.5:1. Es importante destacar que el valor de ruido es crucial en registros electrofisiológicos pues limita el análisis de datos al estar las señales de datos muy cercanas a los valores de ruido.

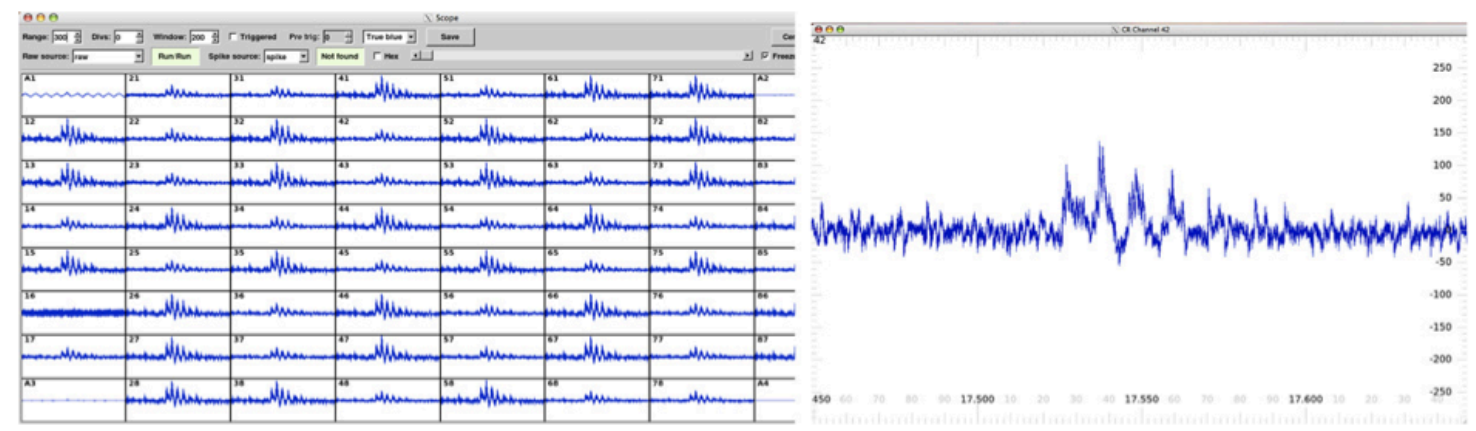

Figura 2.4: Potenciales de acción de retina y ampliación de la señal en MeaBench.

\section{Cultivos de neuroblastoma}

Las propiedades electrofisiológicas de los cultivos de neuroblastoma fueron analizadas a través de registros de actividad espontánea de la red. El curso de los experimentos fue de 15 días y los registros se realizaron empleando dos matrices de electrodos con cultivos de neuroblastoma.

Los cultivos mostraron actividad en forma de potenciales de acción y ráfagas, con despolarizaciones usualmente negativas. Durante el desarrollo del neuroblastoma, la actividad en forma de ráfagas se hizo más consistente y se podía observar su sincronía con claridad. 


\section{Guiado robótico}

Para controlar la dirección del robot, se propone calcular las neuronas ganadoras en términos de las características de disparo de las neuronas del cultivo, resultantes de registrar la actividad neuronal tras haber sido estimuladas empleando el concepto de centro de área. En mecánica, se denomina centro de masas de un sistema discreto al punto que dinámicamente se comporta como si en él estuviera aplicada la resultante de las fuerzas externas al sistema. Este concepto podría ser aplicado al ámbito de la robótica sustituyendo la masa por el área detectada El método de centro de área experimental ha sido probado como un mecanismo eficiente para el control robótico [67]. Fue inspirado en la orientación humana en un escenario complejo y dinámico, produciendo que el robot se moviera al centro de área más cercano del espacio libre percibido por sus sensores. Utilizando este concepto y la topología neuronal biológica se espera que, si estimulamos un área limitada, la neurona que reciba más actividad de sus vecinas será la que incremente más su tasa de actividad.

\section{Conclusiones}

En este artículo se presenta una nueva arquitectura cliente-servidor para control robótico remoto. El sistema comprende lo siguiente:

- Un control robótico bio-híbrido que incluye el desarrollo de toda una plataforma bio-híbrida hardware/software para guiado robótico.

- Un sistema de comunicación remota robótica con el cultivo neuronal a través de enlaces TCP-IP.

- La creación de un control robótico bio-híbrido: diseño de procesos neuromorfológicos como evasión de obstáculos, implementado sobre un sistema bio-híbrido.

El sistema permitirá el desarrollo de nuevas estrategias para el guiado robótico basadas en cultivos biológicos remotos. 


\subsection{A biological neuroprocessor for robotic guidance using a center of area method}

\section{Introducción}

Este artículo presenta un sistema neuroinformático que emplea cultivos de neuroblastoma humano y un sistema de aprendizaje basado en centro de área para el guiado robótico.

Nuestros experimentos de aprendizaje fueron realizados en cultivos neuronales que contienen 120.000 células de neuroblastoma humano SHSY-5Y, bajo la asunción de que este tipo de células son capaces de responder a estímulos externos y de modular sus respuestas neuronales al cambiar los parámetros de estimulación. Estas redes neuronales de neuroblastoma han mostrado configuraciones dinámicas, siendo capaces de crecer y adaptarse funcionalmente a la respuesta de estímulos externos bajo diferentes patrones de estimulación.

Las células de neuroblastoma humano muestran respuestas electrofisiológicas similares a las neuronas estándar, como los potenciales de acción sensibles a la tetrodoxina y acetilcolina, así como expresan receptores de domina y NDMA clónicos a los humanos. Poseen procesos de síntesis de neurotransmisores y además son capaces de tener un crecimiento neurítico en un medio de cultivo.

\section{Metodología}

\section{Configuración experimental}

Se propone una solución neurofisiológica completa que comprende estimulación, calentamiento del cultivo, registro y adquisición de datos de 64 canales. Los componentes básicos del sistema propuesto se muestran en la Figura 2.5. Estos componentes son:

1. Una matriz de microelectrodos (MEA) estándar compuesta por 64 electrodos, y que permite el registro y estimulación simultánea de varios electrodos. Las líneas celulares se colocan directamente sobre la matriz y pueden mantenerse hasta varios meses.

2. Los datos obtenidos en formato RAW de los electrodos de la matriz son amplificados y filtrados por una placa de preamplificadores MEA1060BC de MultiChannel Systems (MCS). Esta placa se sitúa sobre un microscopio invertido para un mejor seguimiento de la actividad experimental.

3. Las señales de entrada son adquiridas y digitalizadas por una tarjeta de adquisición de MCS preinstalada en un ordenador que realiza funciones de adquisición y análisis de datos.

4. El robot envía información sobre el entorno al ordenador a través de un enlace Bluetooth. Los sensores se basan en infrarrojos para detectar obstáculos. 


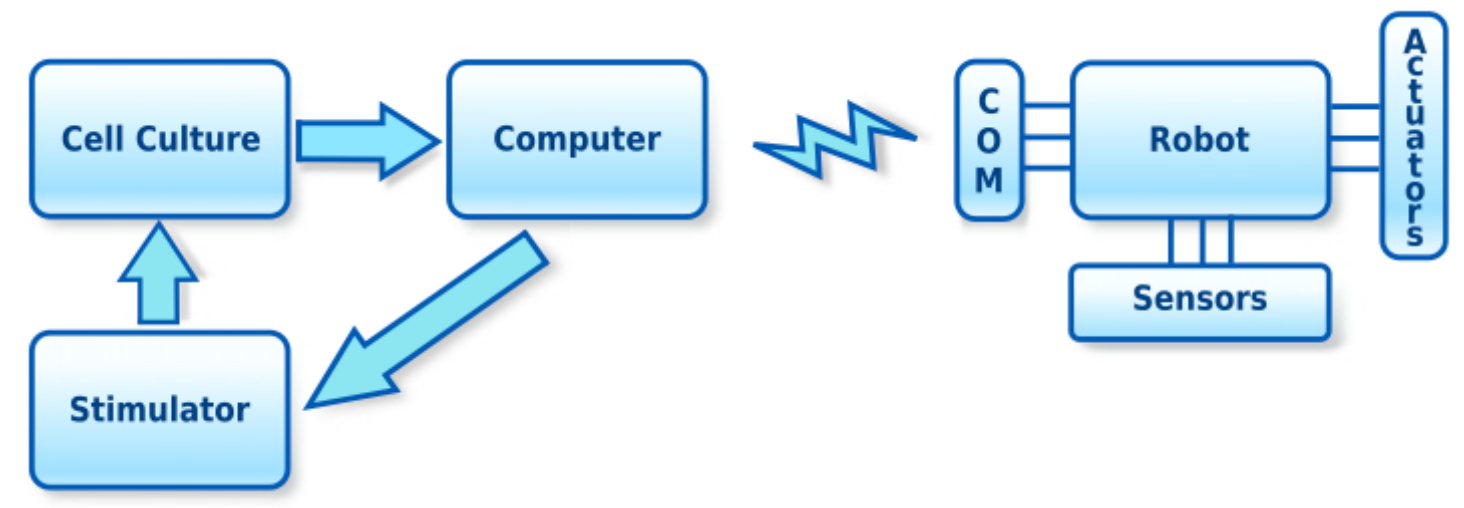

Figura 2.5: Configuración experimental para el guiado robótico.

Se ha desarrollado un sistema que proporciona una plataforma robótica completa sobre cultivos neuronales. El sistema incluye herramientas gratuitas y de código abierto desarrolladas en $\mathrm{C} / \mathrm{C}++$ para sistemas UNIX que permiten aplicaciones robóticas en tiempo real para redes neuronales cultivadas. Empleando estas herramientas con el hardware de MCS y en unión de la suite de adquisición de datos MeaBench de Daniel Wagenaar [66], se dispone de toda una plataforma para experimentos en bucle cerrado. Las herramientas software consisten en los siguientes programas:

1. Cult2Robot: Programa principal desarrollado como un módulo para MeaBench que se encarga de obtener los potenciales de acción de un cultivo neuronal y obtener un vector de dirección. Este vector de dirección se obtiene basándose en el número de potenciales de acción por electrodo en $t$ segundos y puede ser ponderado por la altura y anchura de éstos. Este vector de dirección puede ser enviado al robot para controlar su movimiento.

2. Stg_control: Controla un estimulador de propósito general de dos canales STG100X de MCS.

3. BT_server: Servidor Bluetooth no bloqueante que usa el protocolo RFCOMM para recibir la información procedente del robot en forma de caracteres ASCII.

4. Entorno remoto: el ordenador que se comunica directamente con el robot incluye facilidades TCP-IP para la lectura y envío de información a una plataforma biohíbrida.

Un cliente Bluetooth y un servidor es empleado con un robot humanoide (Robonova, Hitec Robotics) y un robot de dos ruedas (e-puck, www.epuck.org) para enviar y recibir información sobre los obstáculos.

El sistema comprende:

1. Control bio-híbrido del robot: Incluye el desarrollo de una plataforma hardware/software completa para el guiado robótico.

2. Sistema de comunicación remota con el cultivo neuronal a través de enlaces TCP-IP.

3. Creación del control robótico bio-híbrido: Diseño de procesos neuromórficos, como evasión de obstáculos, implementados sobre el sistema. 


\section{Cultivo celular}

Los cultivos de neuroblastoma humano fueron producidos empleando la línea celular $\mathrm{SH} / \mathrm{SY} 5 \mathrm{Y}$. Las células, congeladas inicialmente en nitrógeno, fueron inmersas en un baño de $37^{\circ} \mathrm{C}$ y centrifugadas a $1000 \mathrm{rpm}$ durante $5 \mathrm{~min}$. Cuando las células han crecido en un proceso uniforme monocapa, fueron lavadas con una solución salina amortiguada con fosfato (PBS) para mantener el $\mathrm{pH}$ aproximadamente constante. Posteriormente, se añadió $0.5 \%$ de tripsina a la solución para resuspender las células adheridas a las paredes del disco de cultivo durante el proceso de cultivo. Seguidamente, las células fueron colocadas en una incubadora durante 5 minutos, tras lo cual se trasladaron a un filtro de células para eliminar restos. Finalmente, las células fueron transferidas a un medio específico para desactivar la tripsina y fueron centrifugadas durante 5 min a 1000 rpm. Finalmente, las células fueron posteriormente situadas sobre matrices de microelectrodos.

Los cultivos de neuroblastoma se mantuvieron en una incubadora humidificada a $37^{\circ} \mathrm{C}$ con $5 \%$ de $\mathrm{CO} 2$ y $95 \%$ de $\mathrm{O} 2$ con un medio Neurobasal libre de suero. Bajo estas condiciones fue posible el registro estable de señales electrofisiológicas durante diferentes días in vitro (DIV). El 50\% del medio fue reemplazado cada 5 días.

\section{Control robótico}

Para controlar la dirección del robot se propone calcular las neuronas ganadoras, en términos de las características de los potenciales de acción de las mimas, resultantes de la actividad neuronal registrada en el cultivo de neuroblastoma estimulado mediante un método de centro de área $[68,69]$. Este método está inspirado en el concepto de centro de masas de la física mecánica, definido como el punto de un sistema discreto que dinámicamente se comporta como si en él estuviera aplicada la resultante de las fuerzas externas al sistema. El centro de masas sería la media ponderada de las partículas del sistema, cuyos pesos son la contribución relativa de cada partícula a la masa total del sistema. Este concepto podría ser aplicado al entorno de la robótica sustituyendo la masa por el área detectada.

El método de centro de área calcula el centro de área de un sector frontal, el sector de avance, del área percibida, y usa su posición para guiar al robot (Figura 2.6). La idea es que el centro de área es, normalmente, el lugar más seguro al que ir, pero cuando un obstáculo aparece cerca del camino del robot, el centro de área se convertiría en inaccesible dentro del obstáculo, siendo imposible llegar hasta él. En este caso, el sector de avance se divide en dos sectores más pequeños utilizando un punto del obstáculo como referencia. Si el centro de área de ambos sectores es accesible, se elige uno de ellos. Si ambos son inaccesibles, el método determina el centro de área de la zona trasera reducida y el robot gira en una maniobra de escape. Se pueden realizar divisiones sucesivas, si son necesarias, para que el robot circule a través de configuraciones complejas de obstáculos de forma segura. 


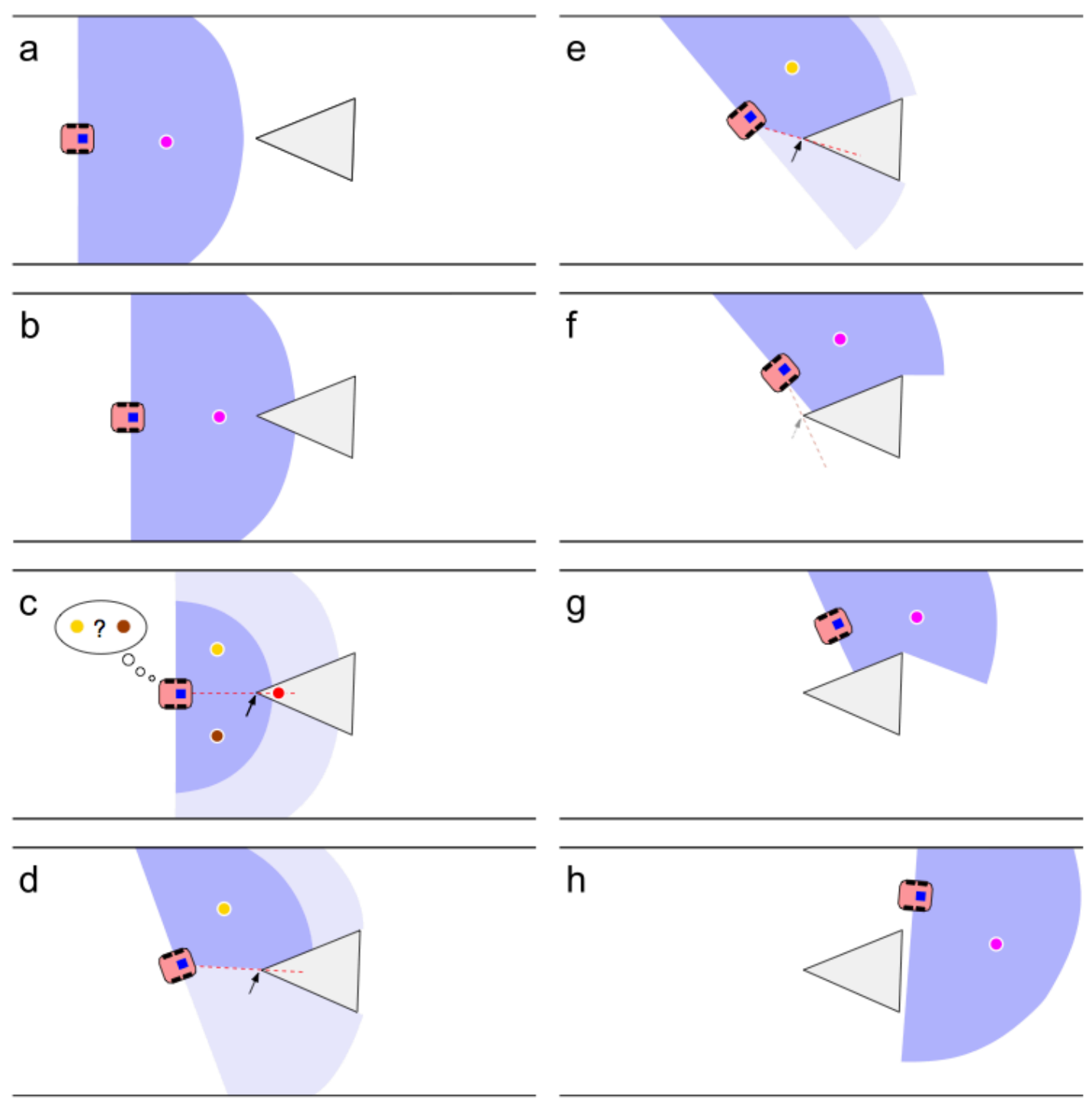

Figura 2.6: Evasión de obstáculos empleando el centro de área.

Para aplicar el método de centro de área con cultivos de neuronas se emplea estimulación tetánica. En neurobiología, una estimulación tetánica consiste en una secuencia de alta frecuencia de estimulaciones. Este tipo de estimulación está asociada con la potenciación a largo plazo o LTP y produce un incremento en la liberación de neurotransmisores causado por el influjo de calcio [70]. De artículos previos [71, 72], se demuestra que tras la aplicación de una estimulación tetánica, las células continúan incrementando su tasa de disparo, proporcionando un cambio persistente en el comportamiento del cultivo. Cuando estos cambios en la respuesta de la red perduran, se denomina aprendizaje. 
a

\begin{tabular}{|l|l|l|l|l|l|l|l|}
\cline { 2 - 7 } \multicolumn{1}{c|}{} & 21 & 31 & 41 & 51 & 61 & 71 & \multicolumn{1}{|c|}{} \\
\hline 12 & 22 & 32 & 42 & 52 & 62 & 72 & 82 \\
\hline 13 & 23 & 33 & 43 & 53 & 63 & 73 & 83 \\
\hline 14 & 24 & 34 & 44 & 54 & 64 & 74 & 84 \\
\hline 15 & 25 & 35 & 45 & 55 & 65 & 75 & 85 \\
\hline 16 & 26 & 36 & 46 & 56 & 66 & 76 & 86 \\
\hline 17 & 27 & 37 & 47 & 57 & 67 & 77 & 87 \\
\cline { 1 - 6 } & 28 & 38 & 48 & 58 & 68 & 78 & \multicolumn{1}{|c}{} \\
\cline { 2 - 6 } & & & & & &
\end{tabular}

b

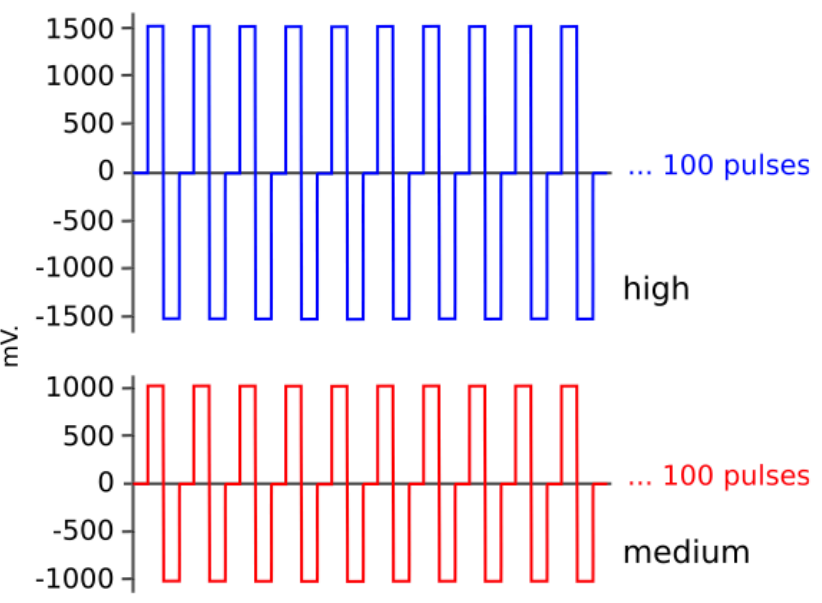

Figura 2.7: Tetanización selectiva de electrodos.

La configuración de estimulación empleada se ilustra en la Figura 2.7. Los electrodos representados en blanco no reciben estimulación, los electrodos en azul reciben una estimulación tetánica alta, en términos de amplitud de voltaje, y los electrodos en rojo reciben una tetanización media. La tetanización media consiste en cinco trenes de un centenar de pulsos bifásicos de $1 \mathrm{~V}$ de amplitud, comenzando por el pulso anódico, mientras que la tetanización alta consiste en pulsos bifásicos de $1.5 \mathrm{~V}$. De este ejemplo se espera que los electrodos 48 y 58 sean los que incrementen en mayor medida sus características.

\section{Resultados}

Se empleó la desviación estándar sobre las señales de cada canal para obtener el umbral de detección de potenciales de acción y así computar los potenciales por electrodo. La estimación de la desviación estándar se realizó empleando un intervalo de $500 \mathrm{~ms}$ y se estableció un umbral de desviación de -4 respecto a la desviación de cada canal para evitar falsas detecciones debido al ruido. La actividad espontánea fue registrada en intervalos de $5 \mathrm{~s}$ antes de la estimulación, y se extrajo el número de potenciales de acción por electrodo. La Figura 2.8 muestra el número total de potenciales de acción por cada canal, así como una visualización gráfica de seis electrodos localizados en diferentes posiciones del cultivo neuronal.

Cuando la configuración de estimulación tetánica mostrada en la Figura 2.7 fue aplicada, las características de disparo de los cultivos de neuroblastoma cambiaron. Los potenciales de acción computados por electrodo durante el proceso de tetanización se muestran en la Figura 2.9a. Se puede observar que el incremento más significativo se registra en el electrodo 58, que representa el centro de área de la configuración proporcionada. Se repitió nuevamente la configuración, y la actividad registrada cambió nuevamente. En la Figura $2.9 \mathrm{~b}$ se puede ver claramente un efecto de potenciación del electrodo 58 de unas 4 veces, mientras que en el resto de electrodos no se produjo un incremento significativo. 


\begin{tabular}{|c|c|c|c|c|c|c|c|c|c|c|c|c|c|c|}
\hline \multirow{8}{*}{$\begin{array}{c}\text { It. } \\
1\end{array}$} & \multirow{8}{*}{$\begin{array}{c}\text { E58 } \\
7 \\
7 \\
4 \\
6 \\
15 \\
8 \\
8 \\
12 \\
9\end{array}$} & \multirow{8}{*}{$\begin{array}{c}\text { E19 } \\
11 \\
7 \\
8 \\
12 \\
9 \\
6 \\
2 \\
2 \\
6\end{array}$} & \multirow{8}{*}{$\begin{array}{c}E 22 \\
4 \\
3 \\
5 \\
5 \\
10 \\
4 \\
3 \\
10 \\
6\end{array}$} & \multirow{8}{*}{$\begin{array}{c}\text { E26 } \\
7 \\
10 \\
9 \\
9 \\
6 \\
7 \\
14 \\
9 \\
8\end{array}$} & \multirow{8}{*}{$\begin{array}{c}E 29 \\
17 \\
12 \\
11 \\
11 \\
13 \\
8 \\
15 \\
12 \\
10\end{array}$} & \multirow{8}{*}{$\begin{array}{c}\text { E30 } \\
4 \\
9 \\
5 \\
5 \\
4 \\
1 \\
1 \\
4 \\
4\end{array}$} & 60 & 23 & 25 & 28 & 31 & 34 & 36 & 61 \\
\hline & & & & & & & 20 & 21 & 24 & 29 & 30 & 35 & 38 & 39 \\
\hline & & & & & & & 18 & 19 & 22 & 27 & 32 & 37 & 40 & 41 \\
\hline & & & & & & & 15 & 16 & 17 & 26 & 33 & 42 & 43 & 44 \\
\hline & & & & & & & 14 & 13 & 12 & 3 & 56 & 47 & 46 & 45 \\
\hline & & & & & & & 11 & 10 & 7 & 2 & 57 & 52 & 49 & 78 \\
\hline & & & & & & & 9 & 8 & 5 & 0 & 59 & 54 & 51 & 50 \\
\hline & & & & & & & 62 & 6 & 4 & 1 & 58 & 55 & 53 & 63 \\
\hline
\end{tabular}

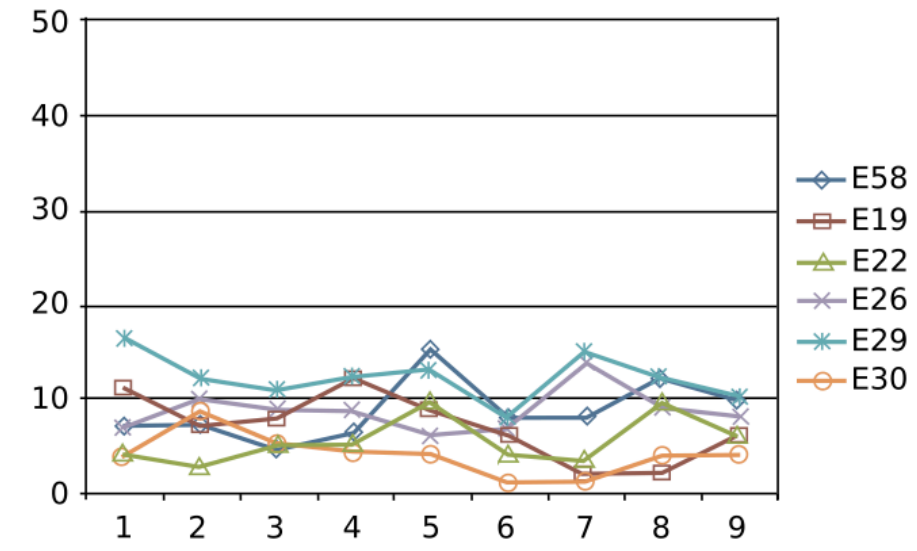

Figura 2.8: Actividad neuronal espontánea detectada previamente a la estimulación.

a

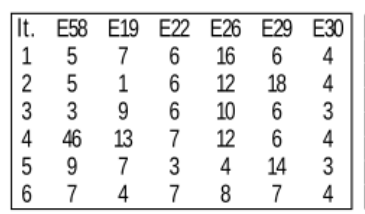

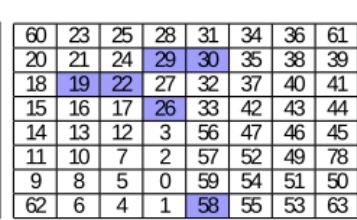

b
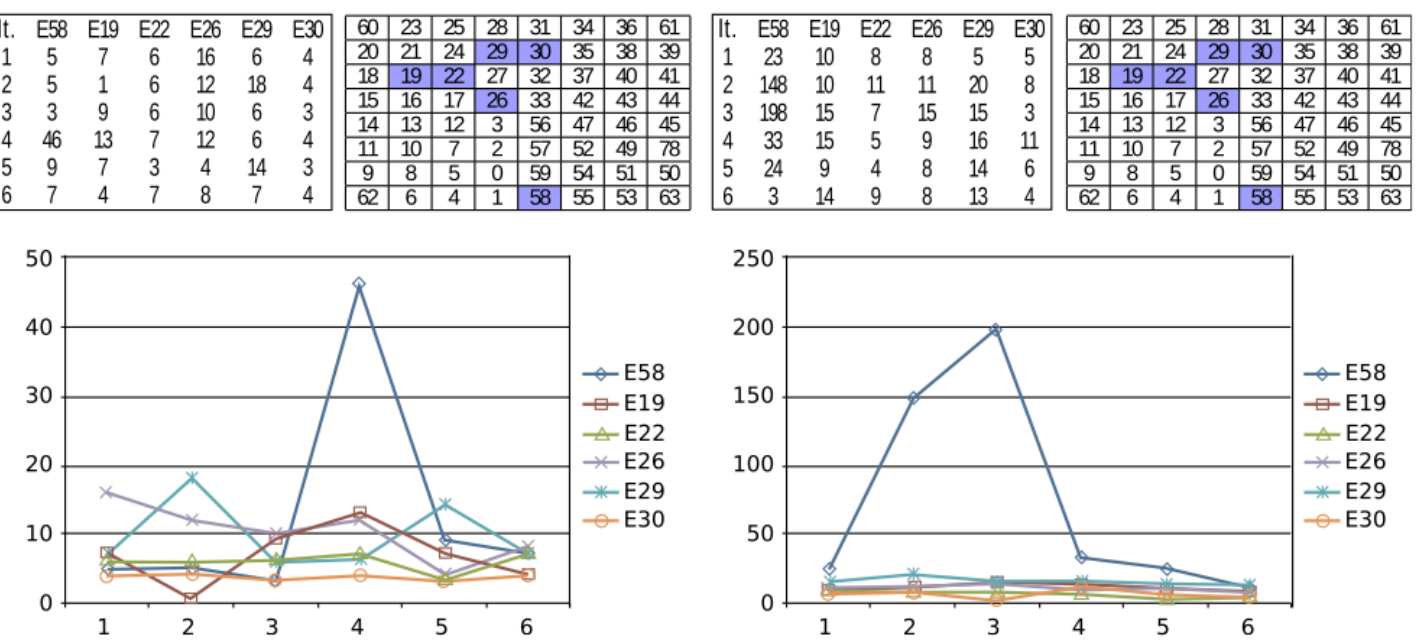

Figura 2.9: Actividad neuronal espontánea detectada durante (a) y tras (b) la estimulación.

\section{Conclusiones}

El aprendizaje en redes de neuroblastoma cultivadas a través de procesos de estimulación requiere identificar el estímulo correcto a proporcionar. La conectividad puede ser modulada por una estimulación externa, tal como se ha descrito en diversos estudios, pero también la actividad de la red puede ser modulada con un esquema de estimulación apropiado.

Los resultados de la estimulación tetánica indican la existencia de un mecanismo claro que facilita la respuesta a los estímulos tetánicos a diferentes edades del desarrollo celular. 
Es de gran importancia ajustar la frecuencia de los trenes de pulsos de la estimulación para suprimir el comportamiento de ráfagas de los cultivos. Además, para imponer un comportamiento deseado es necesario emplear una estimulación que pueda conseguir un efecto de activación sobre la zona estimulada, o emplear una estimulación que pueda producir el efecto contrario, una depresión de la actividad en la zona objetivo. Con este tipo de esquema de potenciación-inhibición local se puede controlar el comportamiento global del cultivo. 


\subsection{Response calibration in neuroblastoma cultures over multielectrode array}

\section{Introducción}

En trabajos anteriores [71, 73-74], se han llevado a cabo experimentos empleando cultivos neuronales de células de neuroblastoma humano SH-SY5Y, bajo la asunción de que estas células pueden responder eléctricamente a estímulos externos y modular sus disparos neuronales cambiando los parámetros de estimulación. El principal interés de estos experimentos fue analizar si las poblaciones de células de neuroblastoma eran capaces de procesar y almacenar información, y si el aprendizaje podía ser implementado en esta estructura biológica. El objetivo fue construir un sistema híbrido que integrara sistemas biológicos y electrónicos para conseguir una nueva estructura computacional capaz de, por ejemplo, realizar el guiado de un robot en un escenario de obstáculos.

Tras realizar una serie de experimentos con las características comentadas anteriormente, y empleando las herramientas desarrolladas para ellos, se pudo observar que la respuesta de los cultivos en términos de potenciales de acción presenta un nivel señal a ruido pequeño. Además, las poblaciones de células cercanas a cada electrodo pueden tener diferentes densidades, por lo que, aunque todos los canales de un cultivo responden a un estímulo, puede haber canales con un nivel muy diferente de activación. Para utilizar cultivos de neuroblastoma en conexión con otras estructuras computacionales, es necesario obtener respuestas repetibles y con el mismo significado en cualquier canal, en los diferentes cultivos, y en cualquier etapa del crecimiento. Esto puede obtenerse a través de la calibración, para detectar diferencias en el nivel señal a ruido, y a través de la normalización, para obtener niveles de respuesta para estimulaciones similares en diferentes canales.

\section{Métodos}

\section{Configuración experimental}

Al igual que en trabajos previos, la plataforma biológica para el estudio del aprendizaje fueron cultivos de células de neuroblastoma SH-SY5Y, que expresan receptores de dopamina clónicos humanos, así como receptores NDMA, que juegan un importante papel para la potenciación a largo plazo inducida al aplicar trenes de alta frecuencia de estimulaciones.

El estudio fue realizado por medio de la tecnología de matrices de microelectrodos embebidas en substrato (MEA) de MultiChannel Systems (MCS). Esta tecnología incluye matrices de 60 electrodos de Ti/Au/TiN, $30 \mu \mathrm{m}$ de diámetro por electrodo y 200 $\mu \mathrm{m}$ de espaciado entre electrodos. Se utilizó un amplificador comercial de 60 canales (MEA1060-BC; MCS) con frecuencia limitada en el rango 10-3000 Hz y una ganancia de 1024X. La estimulación se realizó por medio de un estimulador dedicado de dos canales (STG1002; MCS) capaz de multiplexar las señales para la estimulación de 60 electrodos en un proceso prácticamente paralelo. Los datos fueron digitalizados a través de tarjetas de adquisición de datos con interfaz analógico-digital de MCS. Cada canal 
fue muestreado a una frecuencia de 50000 muestras/s y preparado para el análisis por medio del software $M C_{-}$Rack, proporcionado también por MCS.

Los eventos de potenciales de acción neuronales, embebidos en la señal ruidosa, fueron detectados comparando las señales instantáneas de los electrodos con un umbral calculado para cada canal en base a un múltiplo de la desviación estándar. Un valor de entre -1 y -4 es apropiado para la mayor parte de las aplicaciones, por lo que para los experimentos se seleccionó un valor de -3. Para la clasificación de los potenciales de acción se empleó un software gratuito desarrollado por el grupo para todas las plataformas, NEV2lkit [75]. Este software es capaz de cargar archivos de datos de microelectrodos en varios formatos y clasificar los potenciales de acción de grandes cantidades de información. La clasificación fue realizada utilizando el análisis de componentes principales (PCA).

\section{Calibración del cultivo en respuesta a estímulos}

\section{Análisis estadístico}

El controlador robótico híbrido se basó en la respuesta a estímulos de las células en diferentes áreas del cultivo, representando el movimiento del robot a través de un escenario de obstáculos. La respuesta fue medida en términos de la actividad de potenciales de acción en las áreas correspondientes después de los diferentes trenes de estímulos pero, como se ha dicho anteriormente, la densidad celular y calidad del cultivo no es homogénea, así que las respuestas en los diferentes electrodos deben ser analizadas previamente a obtener una normalización.

Se realizaron una serie de experimentos consistentes en estimulación tetánica alternada con periodos de descanso. Los estímulos bifásicos consistían en 10 trenes de 100 pulsos de $1 \mathrm{~V}$ de amplitud comenzando por un pulso anódico y fueron enviados a los 60 electrodos para propagar la estimulación por el cultivo. El nivel de voltaje en cada electrodo fue registrado en secuencias de $5 \mathrm{~s}$ antes del estímulo y $15 \mathrm{~s}$ después de éste. La actividad de cada electrodo fue extraída contando los potenciales de acción que se encontraban por encima del nivel de ruido.

\begin{tabular}{lcccc}
\hline & Exp. 05 & Exp. 08 & Exp. 11 & Exp. 14 \\
\hline Sin estimulación & & & & \\
Media & 3.03 & 2.66 & 2.61 & 2.55 \\
Desv. Estándar & 2.45 & 2.20 & 2.17 & 2.13 \\
\hline & Exp. 07 & Exp. 10 & Exp. 13 & Exp. 16 \\
\hline Con estimulación & & & & \\
Media & 2.69 & 2.63 & 2.61 & 2.61 \\
Desv. Estándar & 2.18 & 2.19 & 2.17 & 2.18 \\
\hline
\end{tabular}

Tabla 2.1: Media y desviación estándar del cálculo de potenciales de acción en una ventana de $500 \mathrm{~ms}$ por electrodo en toda la matriz de microelectrodos para cada experimento considerado.

Para realizar la calibración primero debemos identificar la actividad espontánea de cada canal. Se analizaron los últimos 10 s de cada registro (9860 valores). La Tabla 2.1 resume los valores medios y de desviaciones estándar para los valores de potenciales de 
acción, en la ventana usual de $500 \mathrm{~ms}$ de tiempo [76], para ocho registros considerados, correspondientes a experimentos con una estimulación previa $(07,10,13 \mathrm{y} 16), \mathrm{y}$ aquellos sin estimulación $(05,08,11$ y 14$)$.

Se aplicó el test de Kolmogorov-Smirnov (K-S test) a los datos de los ocho experimentos para comprobar si los datos encajaban en una distribución normal, lo que es una condición requerida en la mayoría de los tests estadísticos. El valor para este test fue de $\mathrm{z}=17.044$ con un nivel de significación $\mathrm{p}=0.000$, por lo que esta hipótesis puede ser descartada.

El cálculo de una variable aleatoria del número de eventos independientes, en un intervalo de tiempo fijo, que ocurren con una frecuencia constante, sigue el modelo de Poisson, como ocurre en muchos fenómenos aleatorios [77]. Este es nuestro caso, a excepción de la condición de independencia. Se aplicó el test K-S para la distribución de Poisson y se obtuvo un resultado de $\mathrm{z}=10.075$ con un nivel de significación $\mathrm{p}=$ 0.000 , por lo que la completa aleatoriedad también puede ser descartada.

Posteriormente, se procedió a realizar comparaciones empleado el conjunto completo de los datos de interés. Los dos factores de variabilidad, experimento y electrodo, fueron tomados en cuenta para el análisis. Para comprobar la varianza se empleó el test de Levene porque no depende de una distribución de datos normal [78]. El resultado de homogeneidad estadístico fue de $\mathrm{F}=2.360$ con un nivel de significación $\mathrm{p}=0.000$. Este resultado fue el esperado debido a la probable falta de homogeneidad del crecimiento del cultivo en los diferentes electrodos.

Para comprobar la homogeneidad de los experimentos se realizaron los tests que se resumen en la Tabla 2.2.

\begin{tabular}{llcccc}
\hline \multirow{2}{*}{ Tests de Homogeneidad } & \multicolumn{2}{c}{ Todos los exps. } & \multicolumn{2}{c}{ Sin exp. 05 } \\
\cline { 3 - 6 } & & Estadística & Nivel sig. & Estadística & Nivel sig. \\
\hline \multirow{2}{*}{ Medias } & ANOVA & 5.567 & 0.000 & 0.550 & 0.771 \\
& Kruskal-Wallis & 27.898 & 0.012 & 3.556 & 0.736 \\
& Mediana & 18.013 & 0.000 & 1.459 & 0.962 \\
\hline Varianzas & Levene & 3.903 & 0.000 & 0.590 & 0.739 \\
& Brown-Forsythe & 5.564 & 0.000 & 0.550 & 0.770 \\
\hline
\end{tabular}

Tabla 2.2: Tests de homogeneidad para medias y varianzas del número total de potenciales de acción en la matriz de microelectrodos, calculados en ventanas de 500 ms, en cada experimento.

Los resultados de todos los experimentos tienen un nivel de significación de 0.000 , a excepción de la mediana cuyo nivel es cercano a 0.01. Por tanto, podemos descartar homogeneidad en los valores de varianza y media entre los ocho experimentos. Sin embargo, si se omite el primer experimento de los no estimulados (05), los valores de significación son muy altos, por lo que la igualdad en varianza y media de los valores puede ser sustentada entre el resto de experimentos.

\section{Normalización}

Una vez que se ha establecido que existe un nivel base de actividad espontánea, que es independiente de la estimulación previa después de un tiempo suficiente, y que la actividad no se encuentra homogéneamente distribuida en el MEA, se procedió 
entonces a normalizar cada canal basándose en la actividad espontánea en el periodo de estabilización tras el final de cualquier estimulación.
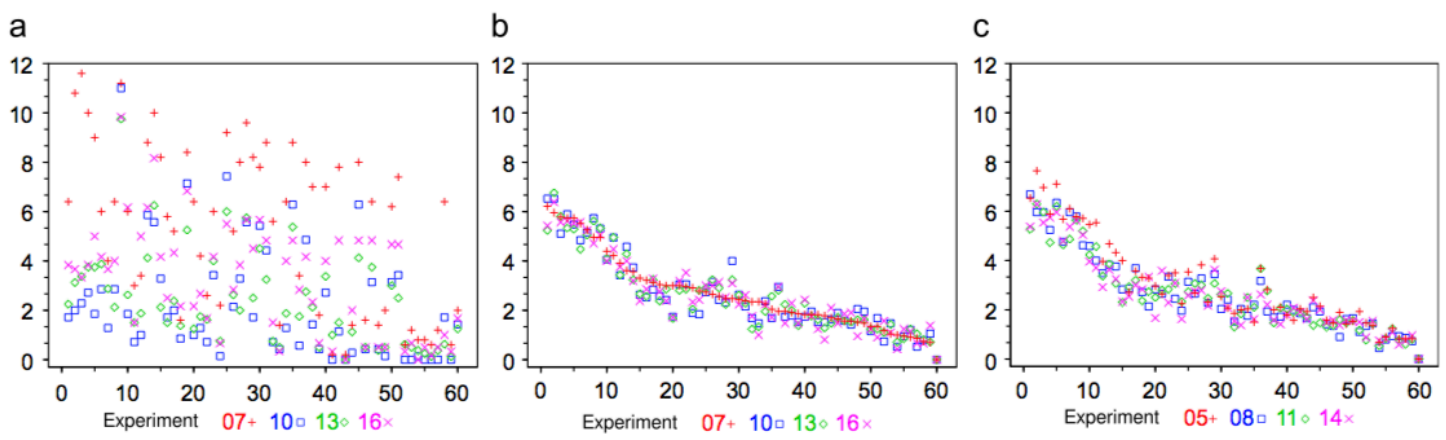

Figura 2.10: Valores medios de actividad por canal en los experimentos. Los canales fueron clasificados de mayor a menor media de actividad en los últimos $10 \mathrm{~s}$ del experimento 7. (a) Sólo durante 3s justo después de la estimulación. (b) Sólo durante los últimos $10 \mathrm{~s}$ de los experimentos estimulados. (c) Sólo durante los últimos $10 \mathrm{~s}$ en los experimentos sin estimulación.

La Figura 2.10 muestra los valores medios de actividad de cada canal en cada experimento. Los canales fueron clasificados desde la máxima a la mínima actividad media en los últimos $10 \mathrm{~s}$ del primer experimento de estimulación. Empleando estos valores medios se propone que el valor de normalización de actividad para el canal i es:

$$
n_{i}(t)=\frac{a_{i}(t)-r_{i}}{s_{i}},(1)
$$

Donde:

- $\mathrm{a}_{\mathrm{i}}(\mathrm{t})$ es la actividad (potenciales de acción) en el instante $\mathrm{t}$ (ventana) para el electrodo $\mathrm{i}$.

- $r_{i}$ es el valor medio en reposo para el canal $i$.

- $\mathrm{s}_{\mathrm{i}}$ es la correspondiente desviación estándar.

Tras aplicar la ecuación (1) a los datos de nuestros experimentos, los valores medios normalizados de actividad para cada canal se pueden observar en la Figura 2.11.
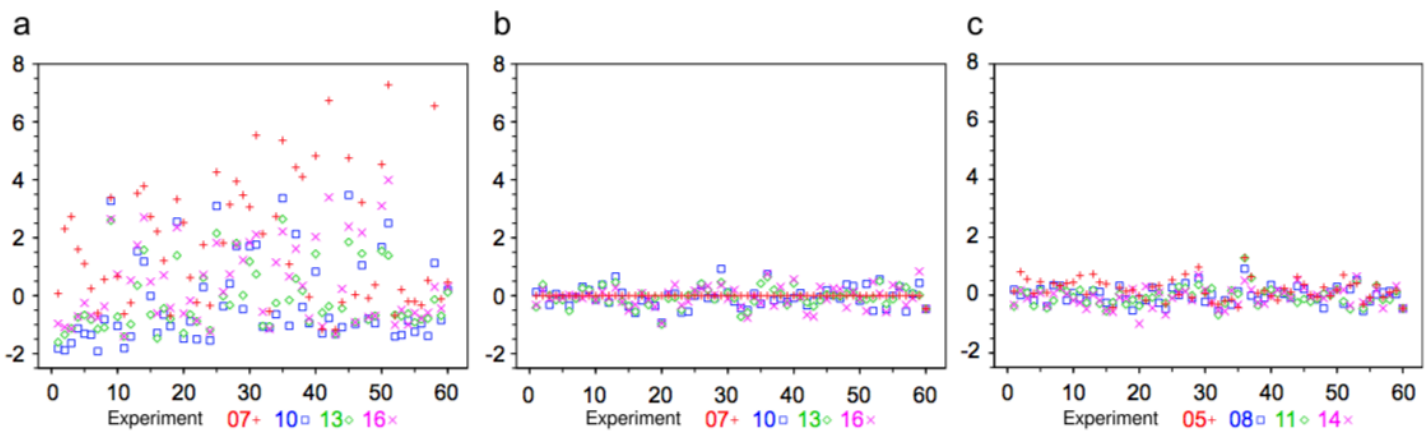

Figura 2.11: Valores medios de actividad normalizada por canal en los experimentos. Los canales fueron clasificados de mayor a menor media de actividad en los últimos 10s del experimento 7. (a) Sólo durante 3s justo después de la estimulación. (b) Sólo durante los últimos 10s de los experimentos estimulados. (c) Sólo durante los últimos 10 s en los experimentos sin estimulación. 
Como se esperaba, las gráficas de los experimentos no estimulados y las correspondientes a los últimos 10 s de los estimulados son prácticamente planas, pero la media de la actividad normalizada en los experimentos analizados justo después de la estimulación permanece significativa para los canales que presentan respuesta.

Algunos de los resultados de la normalización se ilustran en las Figuras 2.12 y 2.13, correspondientes, respectivamente, al experimento con estimulación 07 (últimos 15s), y al experimento sin estimulación 08 (20s). Cada figura comprende la evolución en el tiempo de los valores de actividad por cada canal en la misma posición que se encuentran en la matriz. En cada caso, la subfigura (a) representa la actividad $a_{i}(t)$, la subfigura (b) representa la actividad normalizada y la subfigura (c) representa la actividad normalizada y filtrada.
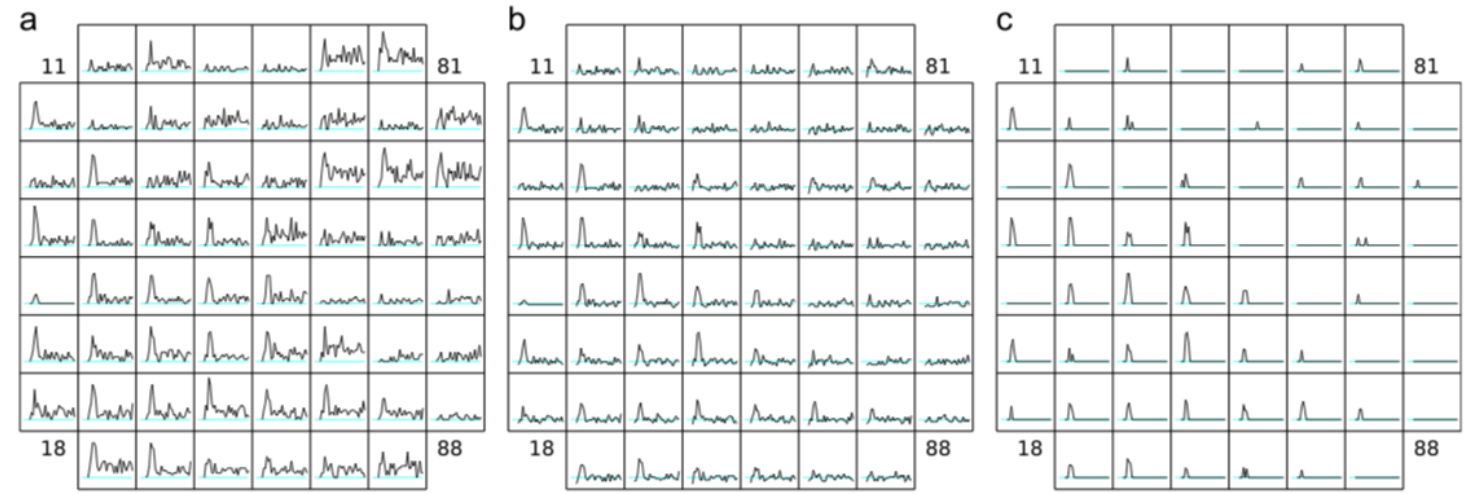

Figura 2.12: Normalización del experimento con estimulación 07.
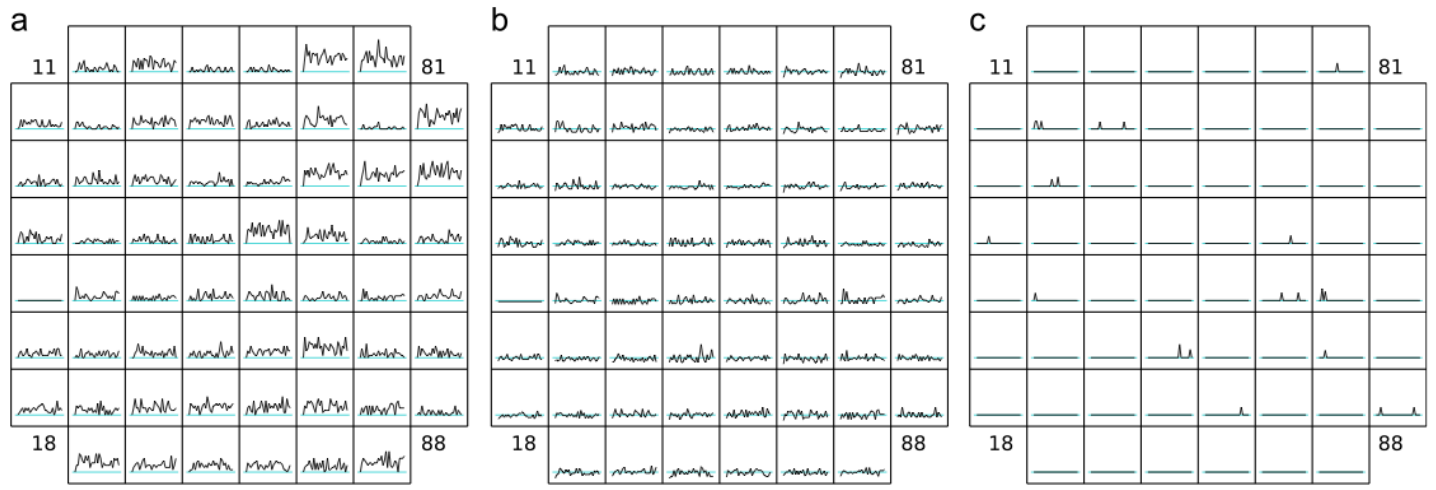

Figura 2.13: Normalización del experimento con estimulación 08.

En las gráficas anteriores podemos distinguir que hay algunos canales muy activos (ruidosos) pero no están respondiendo al estímulo, y, por otro lado, hay canales con actividad espontánea que responden al estímulo. También, se puede ver como hay partes de la matriz más activas respondiendo a estímulos y que podemos identificar con algunas áreas con alta densidad de células. 


\section{Conclusiones}

Los cultivos de neuroblastoma humano pueden ser empleados para circuitos híbridos, como controlar robots, pero el nivel señal a ruido es muy bajo, por lo que cada cultivo debe ser calibrado antes de una sesión para normalizar la respuesta a cada canal. Por ello, se ha realizado un análisis estadístico para comprobar la posibilidad de esta normalización.

Los resultados del análisis apoyan la existencia de un nivel base de actividad espontánea que es independiente de una estimulación previa cuando ha pasado un tiempo suficiente para estabilizarse. También los resultados indican que la actividad espontánea no está homogéneamente distribuida en el MEA, como se esperaba de las características del cultivo, por lo que debe realizarse una normalización para cada canal.

Basándonos en la naturaleza representativa de la media de la actividad espontánea en reposo y su correspondiente desviación estándar, se ha propuesto y comprobado un simple proceso de normalización con datos experimentales. Este proceso remarca claramente qué canales presentan actividad espontánea y están respondiendo a un estímulo y cuales no. 


\subsection{Training biological neural cultures: Towards Hebbian learning}

\section{Introducción}

Diferentes autores han propuesto muy diversas técnicas de aprendizaje para conseguir plasticidad neuronal. Sin embargo, es necesario proporcionar una metodología formal para verificar la plasticidad inducida y validar este paradigma de programación biohíbrida. En este estudio se emplea estimulación a baja frecuencia en cultivos disociados de células de hipocampo para estudiar cómo los cultivos neuronales pueden ser entrenados con este tipo de estimulación. Se muestra que una estimulación persistente y sincronizada de electrodos adyacentes puede emplearse para la creación de conexiones adyacentes físicas o lógicas en diagramas de conectividad que siguen la ley de Hebb.

\section{Métodos}

\section{Cultivo celular}

En este estudio, se emplean células de hipocampo disociadas procedentes de cerebros de ratas embrionarias. Estas células son cultivadas en matrices de microelectrodos planas, también conocidas como MEAs.

Cada MEA se rellena de un medio de cultivo convencional que contiene nutrientes, hormonas de crecimiento y antibióticos, y es reemplazado cada semana. En las primeras horas tras el cultivo, las neuronas empiezan a extender conexiones a las células cercanas y, en 24 horas, una fina capa de extensiones neuronales se hace visible en el área cultivada. La conectividad entre las células cultivadas se incrementa rápidamente en los días siguientes. Tras una semana, puede observarse actividad electrofisiológica espontánea en forma de potenciales de acción, que se convierte en ráfagas densas de actividad eléctrica simultánea a lo largo de toda la red en la siguiente semana. Esta actividad en forma de ráfagas continua a lo largo de la fase de maduración (más allá de 20 días in vitro).

Los cultivos permanecen activos hasta unos 40 días in-vitro, pero pueden permanecer hasta 3 meses bajo las condiciones adecuadas. Durante este periodo, se mantienen en una incubadora humidificada a $37^{\circ} \mathrm{C}$ y $5 \%$ de $\mathrm{CO}_{2}$ para preservar sus propiedades electrofisiológicas.

\section{Aprendizaje y validación}

El aprendizaje es un proceso natural que necesita de la creación y modulación de un conjunto de asociaciones entre estímulos y respuestas. Gran cantidad de autores han empleado diferentes protocolos de estimulación para inducir cambios en la actividad electrofisiológica de cultivos neuronales con este fin [58-65]. Para normalizar la heterogeneidad de estos procesos de aprendizaje es necesario proponer una metodología formal con la que validar el aprendizaje conseguido.

La validación de aprendizaje en redes neuronales artificiales se consigue habitualmente calculando la curva de aprendizaje, es decir, el error producido por la red durante la fase de aprendizaje. Esta curva necesita converger a un mínimo global tras un cierto número de épocas y evitar mínimos locales para validar el proceso de aprendizaje. Una curva 
típica muestra el número de estímulos requeridos para conseguir la respuesta deseada en cada ciclo de estimulación. Cuando se consigue el aprendizaje, la curva de aprendizaje se estabiliza bajo el criterio de convergencia indicando que la respuesta deseada se ha conseguido con el menor número de estímulos. Corregir este criterio de convergencia es crítico para evitar el sobreaprendizaje y proporcionar generalización. En este artículo se propone la siguiente metodología:

1. Imponer un paradigma de aprendizaje sobre la estructura neuronal hasta que se consigue el criterio de convergencia.

2. Comprobar que la red muestra la función deseada sobre su estructura funcional y que este cambio es persistente.

3. Validar las n-respuestas temporales del cambio de las neuronas desde el proceso inicial de disparos espontáneos a un patrón de disparo temporal controlado inducido por las conexiones funcionales.

Para conseguir esta validación se hace uso de técnicas como la conectividad funcional, los histogramas post-estímulo (PSTHs) y el índice de potenciación.

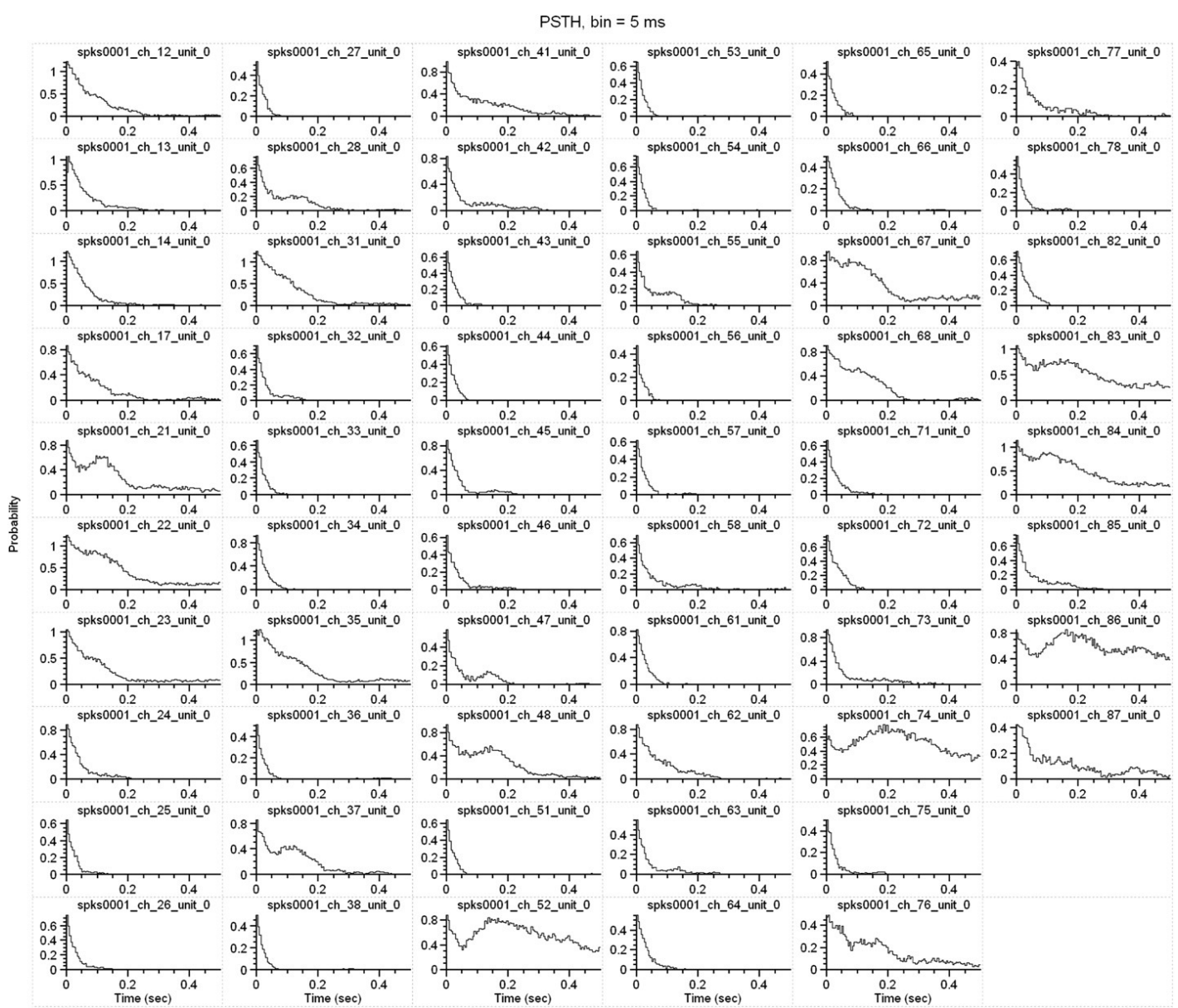

Figura 2.14: PSTHs con intervalos de $5 \mathrm{~ms}$.

La conectividad funcional $[79,80]$ captura patrones de desviaciones de independencia estadística entre unidades de neuronas distribuidas midiendo su correlación/covarianza, coherencia espectral o su fase.

La correlación y los métodos basados en la teoría de la información se utilizan para estimar la conectividad funcional de redes neuronales in vitro: correlación-cruzada, 
información mutua, entropía. Estos métodos han de ser aplicados a cada posible par de electrodos que muestran actividad electrofisiológica espontánea. Para cada par de electrodos, los métodos estiman la fuerza de la conexión a través de matrices de conectividad (CM).

Por su parte, los PSTHs dan información de la actividad neuronal evocada por la estimulación. Representan el impulso de respuesta a la estimulación para cada lugar de la preparación experimental. Los PSTHs se calculan considerando ventanas temporales de los registros tras cada estímulo. Cada ventana se divide en intervalos y se cuenta el número de potenciales de acción que ocurre en cada uno de ellos. Finalmente, el histograma obtenido se normaliza dividiendo el número de potenciales de acción por el número de estímulos y tamaño del intervalo. La Figura 2.14 muestra los PSTH de todos los electrodos de uno de nuestros experimentos. En este caso, se puede observar una respuesta temprana de algunos electrodos, mientras que otros presentan una respuesta tardía de acuerdo a su conectividad intrínseca.

Con el fin de comprobar si un estímulo ha sido capaz de inducir algún tipo de potenciación, se emplea un parámetro conocido como índice de potenciación (PI), relacionado con cambios en el área del PSTH, para cada canal de registro y dos condiciones experimentales: pre- y post-estimulación. Una respuesta potenciada indica un incremento en el área del PSTH a un valor igual o superior de un umbral establecido. Para la validación el índice de potenciación debe exceder un umbral definido empleando la respuesta electrofisiológica del cultivo.

\section{Resultados}

Con el fin de hacer uso de esta metodología se realizó un experimento de aprendizaje Hebbiano. Este tipo de aprendizaje describe un mecanismo básico de plasticidad sináptica donde un incremento en la eficacia sináptica de la célula pre-sináptica proviene de una estimulación repetida y sincronizada de la célula post-sináptica.

Previamente a la realización del experimento, se realizaron diagramas de conectividad funcional de los electrodos basados en correlación cruzada y se seleccionaron dos pares de electrodos que no poseían conexiones lógicas entre ellos. En cada sesión de estimulación se siguieron los siguientes pasos:

1. Registro de la actividad espontánea durante 2 minutos tras un periodo de recuperación.

2. Estimulación de los cultivos a través de dos pares de electrodos empleando un tren de 5 pulsos bifásicos comenzando en catódico $(50 \mu \mathrm{A}$ de pico, $100 \mu \mathrm{s}$ fase, $50 \mathrm{~ms}$ ISI), enviado cada $3 \mathrm{~s}$ durante $10 \mathrm{~min}$.

3. Registro de la actividad de la red durante 2 minutos tras la estimulación.

La actividad espontánea de los cultivos fue observada antes y después de la estimulación, así como las respuestas producidas por el estímulo. Se aplicaron además análisis extensivos de ráfagas, PSTHs, y diagramas de conectividad funcional a los datos. 


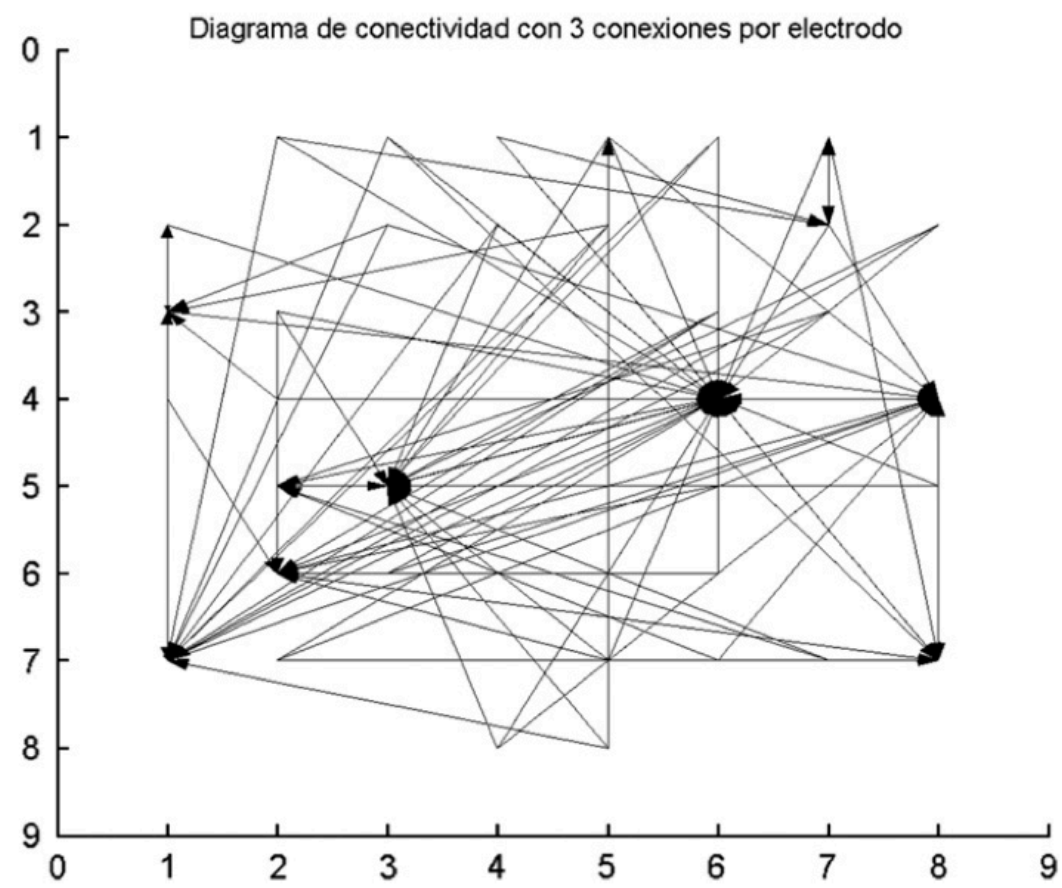

Figura 2.15: Diagrama de conectividad basado en la correlación cruzada entre los electrodos antes de la estimulación. Los electrodos 14, 25, 83 y 84 fueron estimulados. No se observaron conexiones lógicas antes de la estimulación.

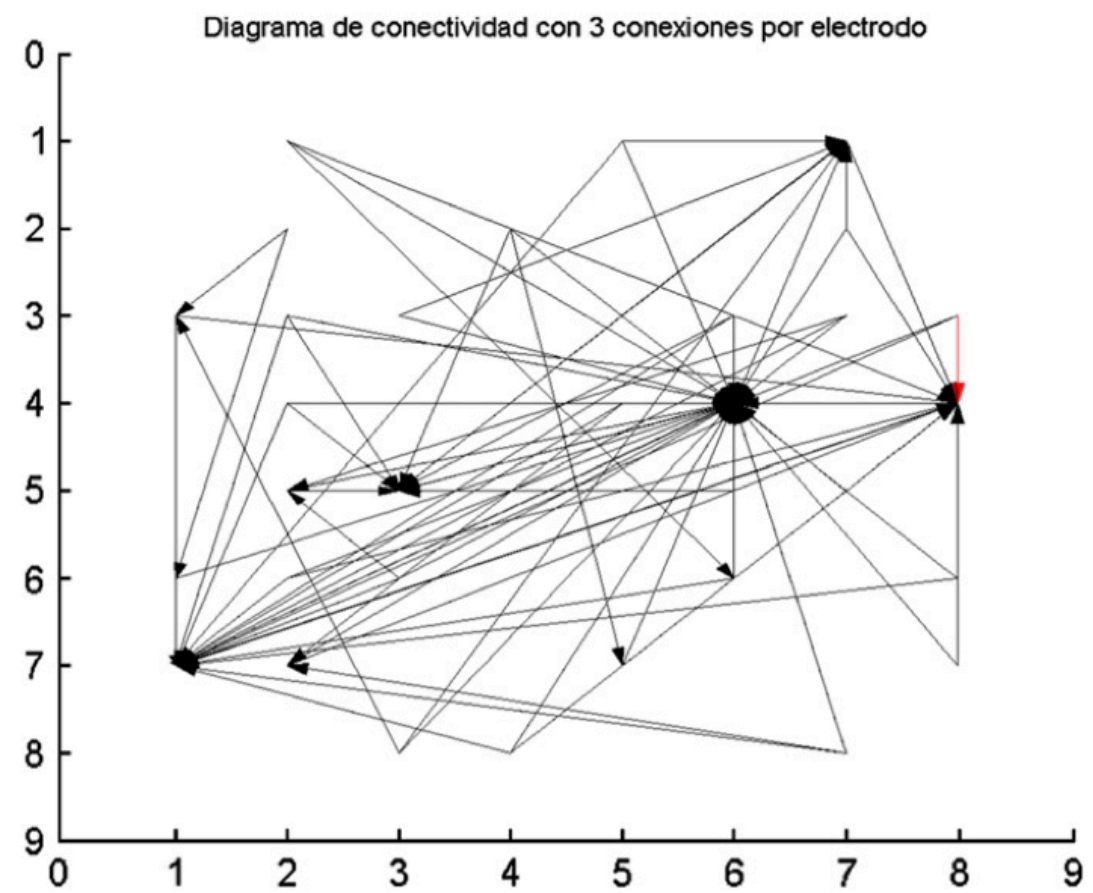

Figura 2.15: Diagrama de conectividad basado en la correlación cruzada entre los electrodos después de la estimulación. Una conexión (flecha roja) entre los electrodos 83 y 84 ha aparecido.

El número de ráfagas y potenciales de acción por ráfaga se incrementó en algunos electrodos tras la estimulación. Además, la respuesta de la red fue mejorada, reduciendo su latencia al estímulo. Los diagramas de conectividad mostraron una especie de reorganización tras la estimulación, concentrando las conexiones lógicas en unos pocos 
electrodos. Adicionalmente, se crearon conexiones lógicas en los diagramas de conectividad que siguen la ley de Hebb, como se muestra en la Figura 2.15. En algunos casos la conexión fue intermitente, durando de uno a varios días. En otros, se creó una conexión persistente. Finalmente, algunos cultivos no crearon ningún tipo de conexión.

En este sentido, la estimulación aplicada creó conexiones lógicas modificando la eficiencia de los caminos entre los electrodos seleccionados. Especulamos que los cultivos fallidos pueden ser causados por un crecimiento no homogéneo entre electrodos o por las propiedades neurobiológicas de las conexiones.

\section{Conclusiones}

El aprendizaje en redes neuronales biológicas cultivadas es una tarea compleja. Diversos autores han propuesto diferentes métodos para inducir una plasticidad deseada y controlada sobre una estructura biológica. Para normalizar la heterogeneidad de estos procesos de aprendizaje es necesario proponer una metodología formal cuyo fin es validar el aprendizaje conseguido.

Además de las curvas de aprendizaje es necesario visualizar la conectividad inicial y final de los cultivos, con el fin de comprobar que la red ha adquirido la función deseada en su estructura biológica. También es esencial que las n-respuestas temporales de las neuronas individuales cambien de un estado inicial a un patrón de disparo controlado inducido por las conexiones funcionales.

La estimulación persistente y sincronizada de electrodos relevantes adyacentes puede ser empleada para fortalecer la eficiencia de las conexiones. Estos procesos pueden ser empleados para imponer un comportamiento deseado sobre la dinámica de la red.

\subsection{Artículos publicados}

Esta sección se compone de los artículos que conforman la tesis por compendio de publicaciones. La documentación referente al índice de impacto de las revistas de publicación se adjunta en el Apéndice A, así como la documentación firmada por todos los co-autores que determina la contribución del candidato, indicando además que la publicación no ha sido previamente utilizada en otra tesis y que no se utilizará en futuras tesis por compendio de publicaciones. 


\title{
Robotics and Autonomous Systems
}

\section{A client-server architecture for remotely controlling a robot using a closed-loop system with a biological neuroprocessor}

\author{
Daniel de Santos ${ }^{c}$, Víctor Lorente ${ }^{b}$, Félix de la Paz ${ }^{c}$, José Manuel Cuadra ${ }^{c}$, José R. Álvarez-Sánchez ${ }^{c}$, \\ Eduardo Fernández ${ }^{\mathrm{a}}$, José M. Ferrández ${ }^{\mathrm{a}, \mathrm{b}, *}$
}

a Instituto de Bioingeniería, Universidad Miguel Hernández, Elche, Spain

${ }^{\mathrm{b}}$ Dept. Electrónica y Tecnología de Computadores, Universidad Politécnica de Cartagena, Spain

${ }^{\mathrm{c}}$ Dept. Inteligencia Artificial, UNED, Spain

\section{A R T I C L E I N F O}

\section{Article history:}

Available online 16 September 2010

\section{Keywords:}

Remote robotic control

Neuroprocessor

Cultured neural network

Client-server architecture

\begin{abstract}
A B S T R A C T
This paper introduces an open-source real-time system that remotely controls a robot using human neuroblastoma cultures and a client-server architecture. Multielectrode array set-ups have been designed for direct culturing of neural cells over silicon or glass substrates, providing the capability simultaneously to stimulate and record populations of neural cells. However, it is very difficult to attach these neural cells to the robot structure due to the special conditions of the biological material. The main objective of this research is to build a client-server system for remotely connecting a robot to a neural culture in a closed-loop experimentation. The robot sensors will feed the biological neuroprocessor, while the neural activity will be used for guiding the robot, controlling in this way the robotic behaviour.

C 2010 Elsevier B.V. All rights reserved.
\end{abstract}

\section{Introduction}

Mammalian nervous systems exhibit complex computational functions including sensory functions, motor function and, in humans, abstract thought. In particular, pattern recognition exhibited in our olfactory, visual and auditory functions are of particular interest to the electronic and computing communities. Meanwhile, several approaches are attempting to mimic/substitute sensory or neural elements (missing because of congenital state or due to pathological processes) in order to enable/restore functions by establishing neuro-electronic interfaces.

Classical computational paradigms consist in serial and supervised processing computations with high-frequency clock silicon processors, with moderate power consumption, and fixed circuit structure. In contrast, the brain uses millions of biological processors, with dynamic structure, slow commutations compared with silicon circuits, low power consumption and unsupervised learning. There have been numerous approaches to creating bioinspired parallel processing [1]. However, silicon provides a fundamentally different technological platform to that of neurobiology. Neurons - the core technology component - have a huge number of interconnections compared to the three in traditional transistors. This provides considerably more computational power. Furthermore,

\footnotetext{
* Corresponding author at: Instituto de Bioingeniería, Universidad Miguel Hernández, Elche, Spain.

E-mail address: jm.ferrandez@upct.es (J.M. Ferrández).
}

0921-8890/\$ - see front matter C 2010 Elsevier B.V. All rights reserved

doi:10.1016/j.robot.2010.09.003 this extraordinary connectivity is coupled with natural unsupervised learning based on varying connective efficiency, and it has been used for robotic guidance [2-4]

This paper introduces an open-source real-time system that remotely controls a robot using human neuroblastoma cultures and a client-server architecture. Multielectrode array set-ups have been designed for direct culturing of neural cells over silicon or glass substrates, providing the capability simultaneously to stimulate and record populations of neural cells. However, it is very difficult to attach these neural cells to the robot structure due to the special conditions of the biological material. The main objective of this research is to build a client-server system for remotely connecting a robot to a neural culture in a closedloop experimentation. The robot sensors will feed the biological neuroprocessor, while the neural activity will be used for guiding the robot, controlling in this way the robotic behaviour.

\section{Learning in human neuroblastoma cultures}

\subsection{Experimental procedures}

The physiological function of neural cells is modulated by the underlying mechanisms of adaptation and reconfiguration in response to neural activity. Hebbian learning describes a basic mechanism for synaptic plasticity wherein an increase in synaptic efficacy arises from the presynaptic cell's repeated and persistent stimulation of the postsynaptic cell. The theory is commonly 


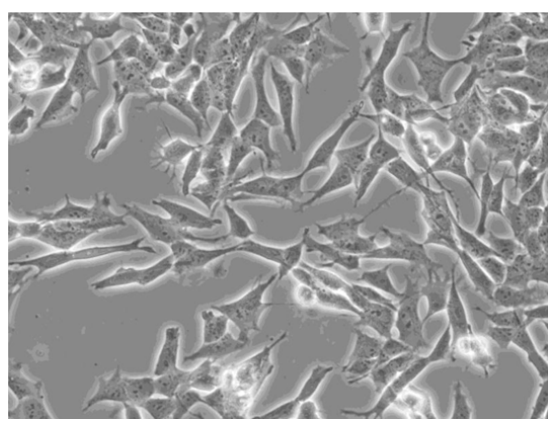

Fig. 1. Human neuroblastoma cells.

evoked to explain some types of associative learning in which simultaneous activation of cells leads to pronounced increases in synaptic strength. The N-methyl-D-aspartate (NMDA) receptor, a subtype of the glutamate receptor, has been implicated as playing a key role in synaptic plasticity in the central nervous system (CNS) [5], whereas dopamine receptors are involved in the regulation of motor and cognitive behaviours. For most synaptic ion channels, activation (opening) requires only the binding of neurotransmitters. However, activation of the NMDA channel requires two events: binding of glutamate (a neurotransmitter) and relief of the $\mathrm{Mg}^{2+}$ block. NMDA channels are located at the postsynaptic membrane. When the membrane potential is at rest, the NMDA channels are blocked by the $\mathrm{Mg}^{2+}$ ions. If the membrane potential is depolarized due to excitation of the postsynaptic neuron, the outward depolarizing field may repel $\mathrm{Mg}^{2+}$ out of the channel pore. On the other hand, binding of glutamate may open the gate of NMDA channels (the gating mechanisms of most ion channels are not known). In the normal physiological process, glutamate is released from the presynaptic terminal when the presynaptic neuron is excited. Relief of the $\mathrm{Mg}^{2+}$ block is due to excitation of the postsynaptic neuron. Therefore, excitation of both presynaptic and postsynaptic neurons may open the NMDA channels; this is closely related with Hebbian learning.

Another important feature of the NMDA channel is that it conducts mainly the $\mathrm{Ca}^{2+}$ ion, which may activate various enzymes for synaptic modification; even nitric oxide has been identified as a relevant element in synaptic regulation. The enhancement of synaptic transmission is called long-term potentiation (LTP), and it consists of two components: induction and maintenance. Induction refers to the process which opens NMDA channels for the entry of $\mathrm{Ca}^{2+}$ ions into the postsynaptic neuron. The subsequent synaptic modification by $\mathrm{Ca}^{2+}$ ions is referred to as the maintenance of LTP.

A human neuroblastoma SH-SY5Y cell line, which expresses clonal-specific human dopamine receptors and NMDA receptors, will be the biological platform for studying learning in cultured cells.

Neuroblastoma SH-SY5Y cells are known to be dopaminergic, acetylcholinergic, glutamatergic and adenosinergic, so in this line they respond to different neurotransmitters. The cells have very different growth phases, as can be seen in Fig. 1. The cells both propagate via mitosis and differentiate by extending neurites to the surrounding area. The dividing cells can form clusters of cells which are reminders of their cancerous nature, but chemicals can force the cells to dendrify and differentiate, in some kind of neuritic growth.

As a consequence, neuroblastoma culture cells show electrophysiological responses similar to standard neurons, as potential action generation sensitive to tetrodotoxin (TTX) and acetylcholyn. They undergo a neurotransmitter synthesis process and are able to undergo neuritic growth in culture medium.

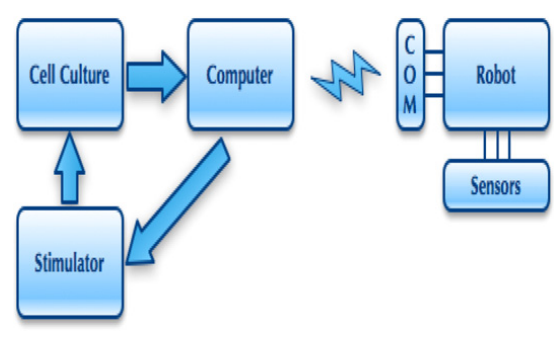

Fig. 2. Experimental set-up.

\section{Experimental set-up}

The neurophysiology set-up provides a complete solution for stimulation, heating, recording, and data acquisition from 64 channels. The MEA (microelectrode array) system is intended for extracellular electrophysiological recordings in vitro of different applications that include acute brain, heart, and retina slices; cultured slices; and dissociated neuronal cell cultures.

The basic components of the proposed system are shown in Fig. 2. These components are as follows.

1. A microelectrode array (MEA), which is an arrangement of 60 electrodes that allows the simultaneous targeting of several sites for extracellular stimulation and recording. Cell lines or tissue slices are placed directly on the MEA and can be cultivated for up to several months. Almost all excitable or spontaneously active cells and tissues can be used.

2. Raw data from the MEA electrodes are amplified by MultiChannel Systems (MCS; MultiChannel Systems, Reutlingen, Germany) filter amplifiers with custom bandwidth and gain, which are built very small and compact using SMD (surface-mounted device) technology. The small-sized amplifier combines the interface to the MEA probe with the signal filtering and the amplification of the signal. The compact design reduces line pick up and keeps the noise level down. The amplifiers are mounted over an inverted microscope.

3. The analog input signals are then acquired and digitized by the MC_Card from MCS that is preinstalled in the data acquisition computer, and which supplies the power for the amplifiers, and the pattern stimuli to the stimulators.

4. The robot sends information about the environment - the obstacles detected by its infrared range sensors - to the computer using a remote link.

Recording from large numbers of electrodes has become increasingly common in neuroscience over the last 30 years. MEAs [6-8] with 60 or more electrodes have been used to study many in vitro preparations including cortical cultures and spinal cord cultures, as well as retinal tissue. Several tools are available for electrophysiological data acquisition and analysis, but two of them are more frequently used: MC_RACK (MultiChannel Systems, Reutlingen, Germany) and MEABENCH (Daniel Wagenaar, California Institute of Technology).

\section{1. $M C_{-} R A C K$}

MC_RACK is a data acquisition and analysis software for Windows operating systems. It works only with MultiChannel Systems the hardware called 'MC_Card'. It has been designed especially for use with an MEA system, but is also ideally suited to work with other experimental set-ups. MC RACK provides recording, graphing, and analyzing in real-time extracellular activities of excitable cells, for in vitro and in vivo preparations. 


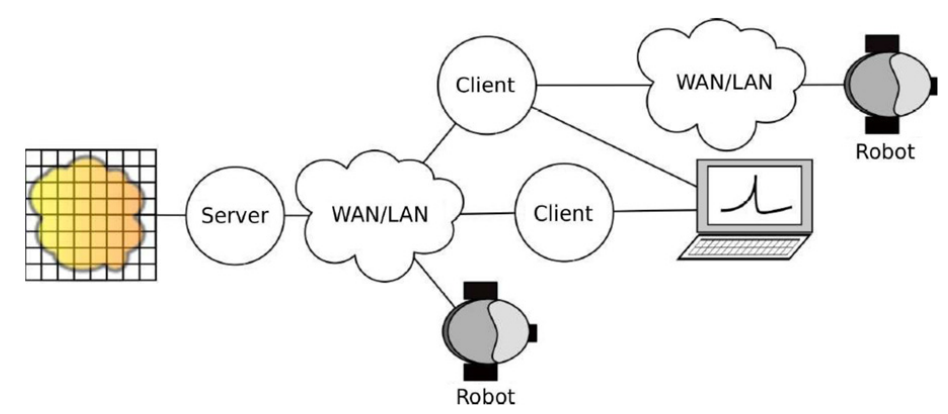

Fig. 3. Remote client-server robot communication architecture.

Features include a virtual oscilloscope, a filter, an event detector, a spike sorter, automatic feedback, sound, and various analysis tools.

The main drawback of MC_RACK is that this software is not user-extendible, and it is not well suited for real-time applications involving bidirectional communications between computers and biological tissue. For our research on a biological processor for robotics using neuroblastoma cultures, these are essential prerequisites, as mentioned before.

\section{2. $M E A B E N C H$}

MEABENCH is a free, open-source, set of programs designed primarily in Linux for multielectrode data acquisition (DAQ) and online analysis [6]. MEABENCH directly communicates with DAQ hardware as well as providing real-time visualization. Thanks to its ability to communicate in real time with stimulator hardware, it can be used in closed-loop stimulation experiments.

MEABENCH was programmed as a set of semi-independent programs sharing a common library. These programs communicate through standard Linux inter-process communication (IPC) facilities such as pipes and shared memory. MEABENCH programs use a client-server model to transfer data. A server creates a shared memory block with a header describing its contents. Clients can then independently read from this memory. Servers notify clients through pipes when new data become available, and when a run starts or ends. This model is used to transfer both electrode voltage data and neural spike information. This modular approach makes it easily maintainable. It also makes it easy for third parties to add their own MEABENCH programs, e.g. to add new visualization or data processing methods. The core of MEABENCH was coded in $\mathrm{C}++$. Some utility programs were written in perl, and several additional data analysis tools were written for Matlab.

The main features of MEABENCH are as follows.

- Data acquisition. MEABENCH has a modular interface for communication with data acquisition (DAQ) cards. Currently, a module to acquire data from the 'MC_Card' hardware (MultiChannel Systems, Reutlingen, Germany) is well supported.

- Inter-process communication. MEABENCH programs use a clientserver model to transfer data. A server creates a shared memory block with a header describing its contents. Clients can then independently read from this memory. Servers notify clients through pipes when new data become available, and when a run starts or ends. This model is used to transfer both electrode voltage data and spike information.

- Multicomputer set-up. MEABENCH provides the option of using one dedicated computer just for data acquisition, and a second computer for all the analysis tasks.

- Visualization. Online data visualization is a main feature of MEABENCH. To show acquired voltage traces and spike rasters online, a set of widgets was written for use with the opensource Qt library (Trolltech, Oslo, Norway).

- Data streaming. MEABENCH provides an interface for external programs to read data directly from MEABENCH shared memory.

- Algorithms. MEABENCH includes programs for the suppression of line noise and stimulation artifacts, as well as for spike detection.

MEABENCH consists of the following main programs.

- Rawsrv - The main server. It reads voltage traces from the hardware and makes them available to other MEABENCH programs.

- Spikedet - A threshold-based spike detector. It reads from a voltage-trace stream, and publishes a spike information stream. Includes algorithms to adapt to fluctuating noise levels.

- Salpa - Stimulation artifact filter.

- Record - Records voltage or spike data to disk.

- Replay - Replays files created by Record.

- Scope - GUI program for online display of voltage and spike data.

- Spikesound - GUI program for online sonification of spike data.

- Flexraster - GUI program for online generation of spike raster plots.

- Neurosock and Nssrv - An alternative to Rawsrv that allows one to dedicate one computer to data acquisition and another to online analysis.

\section{A client-server architecture for remote robotic control}

A client-server architecture has been developed for the remote connection between the robot and the biological neuroprocessor. The server communicates directly with the neural culture through the MC_Card, while the client sends commands remotely to the server, receiving the neural data from it. These neural data are used for controlling the robot and for visualizing the culture activity for debugging purposes. The main functionalities have been implemented in a library set in order that any client task could communicate with the server. The proposed architecture is shown in Fig. 3. It can be seen the three different possibilities for communicating with the server. In the first one (top figure), the client application is used as a bridge between the robot and the server, allowing the user to visualize the data flow between each agent. The middle figure represents the case of preliminarily studying the biological neuroprocessor behaviour before connecting the robot to the culture. Finally, in the bottom figure, the robot control uses the client library directly.

The developed libraries are able to use the different programs that MEABENCH provides, to configure the MC_Card, and to select the electrodes for stimulation. Three different libraries have 


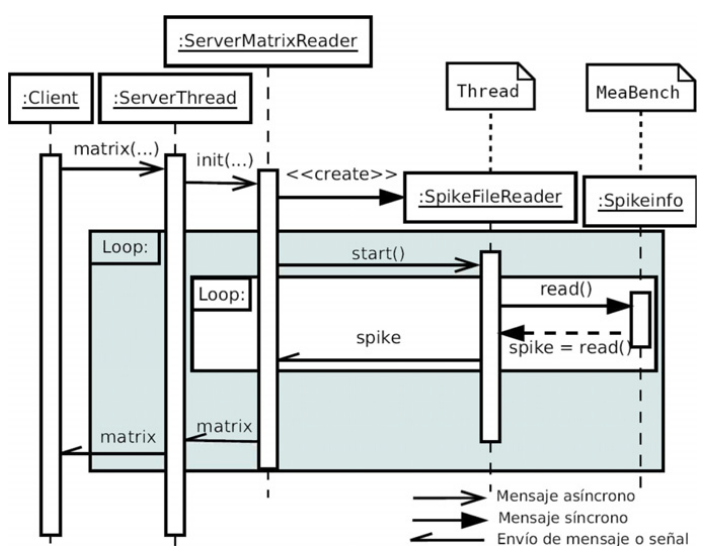

Fig. 4. Client matrix data communication.

been designed: LinkLib, LibPulseGenerator and LibPolar2Script, with some client-server application implemented over them, called Bulture (derived from the term 'biological culture') using $\mathrm{C}++$ and the graphic library Qt4. The data transmission chosen in this previous implementation is asynchronous in order to study the culture behaviour in response to artificial stimulations.

\subsection{LinkLib}

This library, used by Bulture, is responsible for the communication between the client and the server. The main objective is that a developer could use a tool for communicating with the MEA, without knowing the details of the implemented communication. Linklib can program the server for configuring the MC_Card, and use the server-installed programs.

There exist four main functions: (1) selecting the data source, (2) asking for data, (3) executing programs and (4) configuring the stimulator.

\section{(1) Selecting the data source}

This library permits using two different data sources: online and offline. If an online source is used, the data directly received from the culture will be used, while if an offline source is selected, a SPIKE file with previous neural activity registered by MEABENCH will be the source.

(2) Asking for data

The neural data to be transmitted use the SPIKE format developed by MEABENCH. The neural data can be raw data, or dimensional data, using a matrix configuration. If raw data are selected, the server will just send the neural data read by the MC Card. If matrix data are selected the server will read spikes from the culture, building a matrix with the number of spikes detected in each electrode during a defined time window. In both cases it is mandatory to define the timing of the transmission and the number of packet to transmit, called the burst.

Fig. 4 shows the procedure for asking a matrix to the server when the communication is established. The server transmits the online or offline solicitude to the process responsible for reading the neural data, creating a new thread for such task which will build the matrix message. When the time set up by the client is over, the server sends the matrix message to the client. This process is repeated in a bursting way, until the number of packets to transmit is reached. Initially this is an asynchronous communication.

\section{(3) Executing programs}

The client LinkLib can execute commands in the server. This is useful for running some MEABENCH tools while acquiring neural data.

(4) Configuring the stimulator

The pulse waveform defined by the user is transmitted to the server for injecting current to the selected electrodes of the biological culture.

\subsection{LibPulseGenerator}

LibPulseGenerator permits the configuration of the pulse sequences to be delivered to the neural culture. The parameters are the initial and final voltages, and the pulse duration. The configuration is achieved through an ASCII string, showing the pulse evolution every 20 microseconds.

The neural stimulator used, MultiChannel Systems STG1002, allows two different waveforms for all channels. LibPulseGenerator can also load and save predefined pulse waveforms, easing its use for the developer. The library can also compact this waveform configuration in order to save space, saving the data in XML format.

\subsection{LibPolar2Script}

LibPolar2Script library is responsible for coding the free space around the robot captured by its sensors to an equivalent representation in the multielectrode array. This limited representation is necessary because the free space around the robot is a circular area of around $180^{\circ}$ or $360^{\circ}$, while the MEA is just a squared $8 \times 8$ representation. The sensor representation should be included in this limited grating, scaling the free area to the $8 \times 8$ matrix. The system will distinguish between cells occupied by an obstacle, coded zero, or free cells, coded with the distance to the robot; this will be used for the stimulation (see Figs. 5 and 6 ).

This library is implemented on both the client side and the server side. On the client side, it provides the coded matrix pulses, to be sent to the MEA, while on the server side, it creates the script to be sent to the stimulator STG-1002 (see Fig. 7).

\section{Applications: Bulture}

The application Bulture has been built as a front-end for the LinkLib library for studying the neural activity of the culture when a

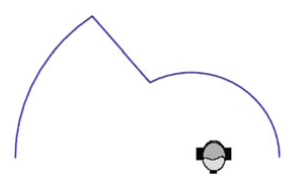

b. . . . . .

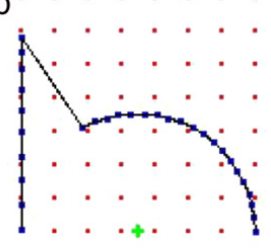

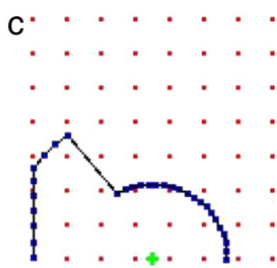

,

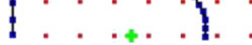

Fig. 5. (a) Free space sensed by the robot. (b) Non-scaled area representation. (c) Scaled area representation with respect to the maximum range sensed. 


\begin{tabular}{|c|c|c|c|c|c|c|c|}
\hline 0 & 0 & 0 & 0 & 0 & 0 & 0 & 0 \\
\hline 12 & 0 & 0 & 0 & 0 & 0 & 0 & 0 \\
\hline 10 & 0 & 0 & 0 & 0 & 0 & 0 & 0 \\
\hline 8 & 8 & 0 & 0 & 0 & 0 & 0 & 0 \\
\hline 8 & 6 & 6 & 6 & 6 & 6 & 0 & 0 \\
\hline 8 & 6 & 4 & 4 & 4 & 4 & 6 & 0 \\
\hline 8 & 6 & 4 & 2 & 2 & 4 & 6 & 8 \\
\hline 8 & 6 & 4 & 2 & 2 & 4 & 6 & 8 \\
\hline
\end{tabular}

Fig. 6. Representation of the free space over an MEA.

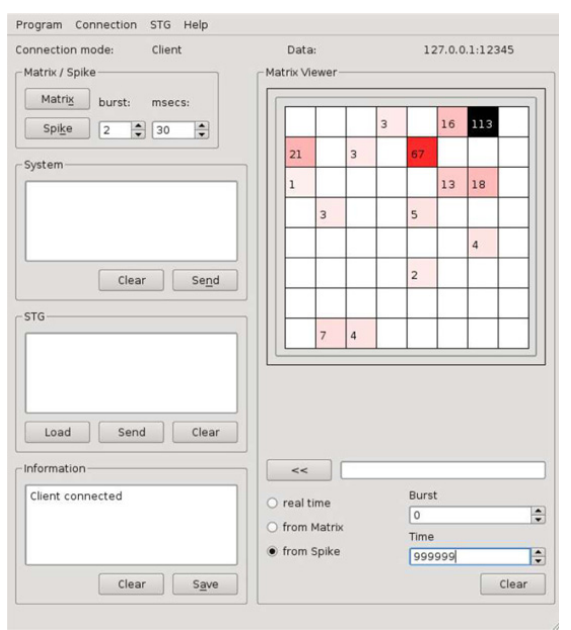

Fig. 7. Graphical user interface of client Bulture application visualizing spike data.

stimulated. It uses two different interfaces: graphic and console. It is recommended to use the graphic mode on the client side and the console interface on the server side. Bulture is composed of three tools.

(1) PulseGenerator, which creates the pulses to be sent to the stimulator according to STG-1002 protocol.

(2) Polar2Script, which generates the pulse sequences to be delivered by the stimulator, selecting the electrodes according to the free space detected by the sensor around the robot.

(3) The main client-server application, which includes the previous ones, and implements the main functions, called Bulture.

Bulture allows several simultaneous client connections to the server, setting some permissions over the clients; for instance, the stimulator can only be configured by the client that is allowed to do so, but only one at a time. The access permissions for administration and configuration are emitted in a FIFO structure. The server creates an execution thread for each client connected, this thread being responsible for communicating with its client. Fig. 7 shows the graphical user interface (GUI) for Bulture. The left side of the window represents the connection parameters, and the console windows with the system, stimulator, and a log window, while the right side is used for matrix data visualization. Each cell represent the number of spikes detected by the corresponding $8 \times 8$ electrode code also with grey levels.

The application PulseGenerator also provides a graphical interface for visually defining the train of pulses to use for the stimulation. Fig. 8 shows the PulseGenerator GUI with two defined

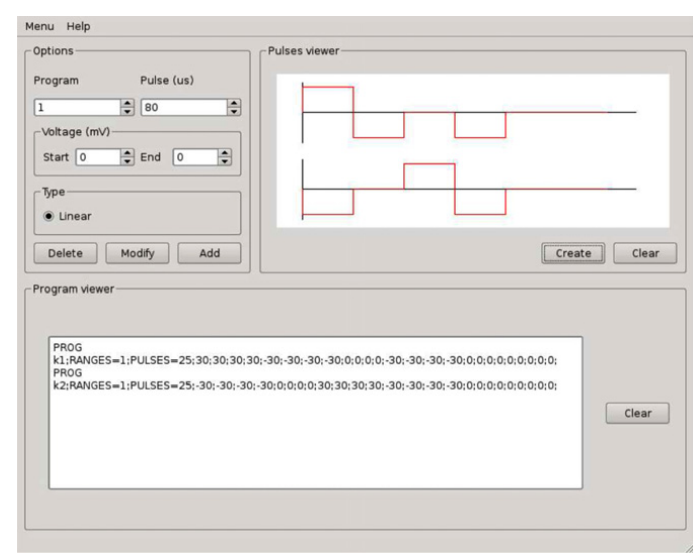

Fig. 8. Graphical user interface of a PulseGenerator application visualizing two train pulses.

train pulses. The visual waveforms are represented on top, while the STG1002 string syntax for the configuration is printed on the console window.

Finally, the Polar2Script application provides a graphical interface for representing the free space around the robot and its conversion to the $8 \times 8$ representation of the neural culture, limited by the number of electrodes. Fig. 9 shows three different areas.

(1) In the left side, polar coordinates of the free space around the robot are represented.

(2) The electrode representation is shown in the right part, with the conversion of the free space area of the robot to the limited $8 \times 8$ matrix, defined by the number of the culture electrodes. Each cell provides the number of train pulses to deliver to the electrode in order to internally represent the robot scenario.

(3) The generated script to be sent to the STG1002 neural stimulator is printed in the lower console window.

\section{Robotic control system}

We have developed a system that provides a complete robotic control platform over neuroblastoma cultures. The system includes five free, open-source, console-based programs written in $\mathrm{C} / \mathrm{C}++$ for real-time robotic applications with embodied cultures. All of this software has been developed for the Linux operating system and MCS hardware (MultiChannel Systems, Reutlingen, Germany). Using this software in conjunction with MEABENCH is specially intended for closed-loop experiments.

The software developed consists of the following programs.

- Cult2Robot: The main program. It has been developed as a MEABENCH module, so it can access to all of the data streams that MEABENCH provides. Cult2Robot read spike information from the MEABENCH spike detector and compute a direction vector based on the MEA neural activity. The direction vector is calculated based on the number of spikes per electrode in $t$ seconds and it can be weighted by the height and width of the spikes. This direction vector could be sent to a robot to control its movement.

- Stg_control: This program controls a general-purpose stimulus generator for current and voltage-driven electrical stimulation, STG 1000 series (MultiChannel Systems, Reutlingen, Germany). The STG may be connected to a PC via an RS232 port or via a USB port. Stg control makes it possible to program and download custom functions to the STG, start/stop the stimulation, reset the device or send any command described in the STG100x RS232 Communication Manual. 


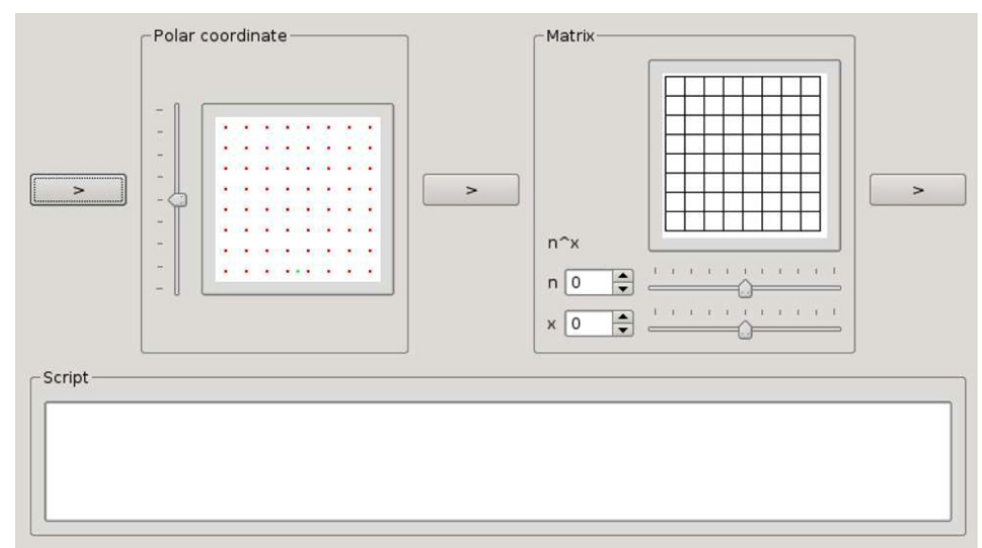

Fig. 9. Graphical user interface of a Polar2Script application

- Electrode_select: This module allows configuring the MEA1060BC amplifier following the MEA protocol from MCS [7]. With the Electrode_select program, it is easy to change the electrode selection during the experiment, e.g. to use stimulating electrodes for recording, and vice versa. It also has almost all the features of its Windows counterpart, 'MEA_select', such as blanking electrodes, changing MEA, using wait for optimizing the electrode's behaviour or resetting the device.

- BT_server: Receiving environmental information from the robot is a primary objective. BT server is a non-blocking Bluetooth server that uses RFCOMM protocol to receive characters from a specific MAC, process the information and do some action, e.g. it can be used to call another program when an obstacle is detected (an 'O' has been received).

- BT_client: Sending information to the robot is also important in order to establish a bidirectional link and transmit the outputs to the robot. BT_client sends ASCII characters via Bluetooth using RFCOMM protocol. In our research, BT_client sends the direction vector calculated by Cult2Robot to change the movement of the robot.

\section{Results}

It is very important to check that the acquisition system is working properly with the hardware set-up before doing more specific tests. Three different signals were simulated by placing an MCS signal generator in the MEA1060BC preamplifier. The signals generated with the MCS signal generator have two possible amplitude values that depend on the electrode.

The first signal was a basic sine wave, with a frequency of $1.25 \mathrm{~Hz}$ and peak values 12 and $24 \mu \mathrm{V}$. Fig. 1 shows the MEABENCH. The 'MC_Card' driver used in MEABENCH for acquiring data with the MultiChannel Systems hardware has a $4 \times$ scaling, so the peak values shown are 48 and $96 \mu \mathrm{V}$ (see Fig. 10).

The MCS signal generator also generated spikes from retinal cells and from hippocampal cells. Retinal cells showed peak values of 35 and $80 \mu \mathrm{V}$, depending on the electrode (Figs. 11 and 12).

Fig. 11 shows a magnification of a retinal spike detected in electrode 42 in MEABENCH. The peak value in MEABENCH was about $140 \mu \mathrm{V}$ with $4 \times$ scaling and the signal-to-noise ratio (snr) was 3.5:1. The noise is a crucial factor in electrophysiological recordings; it limits data analysis because the data signals are usually very near the noise levels.

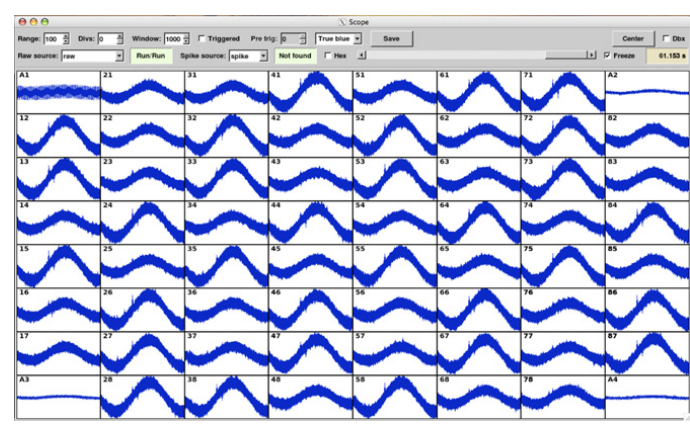

Fig. 10. Sine wave $4 \times$ scaling $-\mathrm{MEABENCH}$.

\subsection{Neuroblastoma cultures}

The cultured neuroblastoma cells establish synaptic connections. Differentiated and non-differentiated neuroblastoma cell bodies can be seen growing around the whole electrode population. The dendritic arborescence is more evident in the magnification shown in Fig. 12, where differentiated neural cells surround the four electrodes while the rest of the cells are in their growing process. This figure corresponds to 80,000 neuroblastoma cells seeded in a no-PEI MEA on the second days in vitro (div).

The electrophysiological properties of the neuroblastoma cultures were analyzed by recording the spontaneous activity of the network. The time course of experiments was over 15 days; recordings were done using two MCS MEAs with two neuroblastoma cell cultures (but only in one of them did the cells survive till day 15). In vitro neuroblastoma networks show spontaneously firing. The firing rates change during the culture development with marked day differences and the global rate is closely related to the age of the network.

The physiological recordings correspond to neuroblastoma cultures in the range of 1-7 div. They show bursting and spiking activity, with usually negative depolarizations. Fig. 4 shows the spiking activity of the neural population with an automatic detection level for each electrode. This is very convenient if you have multiple channels for extracting spikes (see Fig. 13).

The standard deviation of each data trace is used to estimate its spike threshold. A time interval of $500 \mathrm{~ms}$ is used to calculate the standard deviation. By fixing the factor, by which the standard 


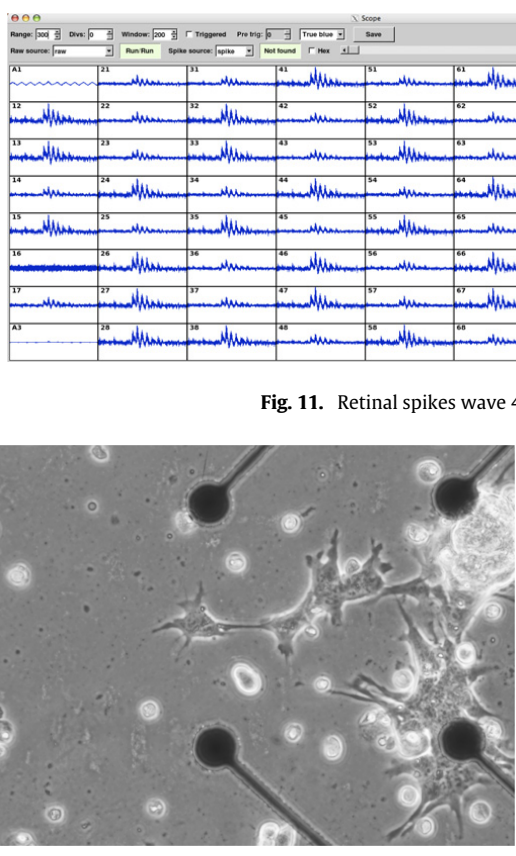

Fig. 12. Biological neural network over a multielectrode array.

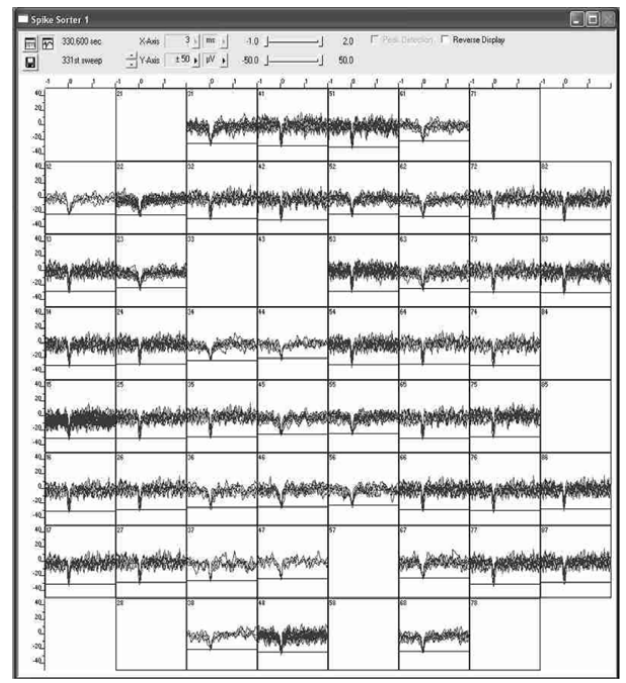

Fig. 13. Spontaneus neural activity detected by the multielectrode array.

deviation is multiplied, the sign of the factor determines whether the spike detection level is positive or negative; only values above this will be extracted as spiking activity. A value between -1 and -4 is appropriate for most applications. The threshold was fixed at standard deviation equal to -3 with respect to the electrode activity in order to identify spikes embedded in the noisy signals.

During the neuroblastoma development, a wide range of population bursting or synchronized activity has been observed, according to some studies in neural cultures preparations [6]. The

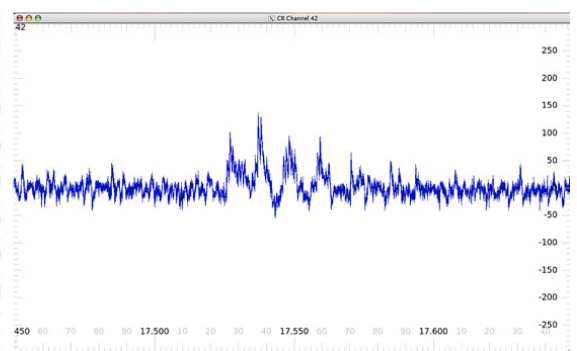

burst usually contains a large number of spikes at many channels, with variable duration, from milliseconds to seconds.

\section{Robotic guiding}

In Mechanics, the branch of Physics which studies the movement of bodies according to causes that produce it, there exists a concept called the centre of mass. For a discrete system, the position of the centre of mass is the weighted mean of particle coordinates in the system, the weights being the relative contributions of each particle to the system's total mass. This centre of mass concept can be applied to robot environment modelling, by replacing the mass with the accessible area detected. Note that this centre of area concept is a construction that emerges from the visual perception of the robot.

For controlling the direction of the robot, we propose to compute the winner neurons (that is, the ones that increase its firing characteristics more) resulting from neural activity recorded in the human neuroblastoma culture stimulated using a centre of area method. The experimental centre of area method [9] has proven to be an efficient mechanism for robotic control. It was inspired by human orientation in a complex and dynamic scenario, producing the robot to move to the nearest centre of area of free space perceived by its sensors. By using this concept and the biological neural topology - a neuron is connected to all its neighbourhood - it is expected that, if we stimulate a limited area, the neuron that receives more activity from its neighbours will be the one that increase its firing rate more [10].

This process is equivalent to applying the artificial centre of area method to the biological neuroprocessor, assuming that the free space around the robot is coded in the biological culture with the appropriate stimulation, which consists basically in stimulating the represented free space, while the occupied space receives no electrical inputs. This process means inducing a representation of the robot surroundings over the neural culture, as has been found in hippocampus in rats [11-13]. The robotic guiding strategy is explained in detail in $[14,15,10,9]$.

\section{Conclusion}

A new remote client-server architecture for robotic control has been presented. The system comprises the following.

- A bio-hybrid robot control: This includes the development of a whole bio-hybrid hardware/software platform for robotic guidance.

- A remote communication system with the neural culture: A remote environment has been developed for the robot to communicate with any bio-hybrid control platform through TCP-IP links.

- Creation of a bio-hybrid robotic control: Design of the neuromorphic processes, e.g. obstacle avoidance tasks, implemented over the bio-hybrid system.

The system will permit the development of new strategies for robotic guidance based on remote biological cultures. 
Future work consists in determining the optimal stimulation to apply for inducing permanent firing changes in the culture, and a normalized representation with real-time implementation, once the asynchronous system is completely adjusted, and the culture calibrated for different experiments.

\section{Acknowledgements}

This work was supported by the Spanish Government through grants TIN2008-06893-C03, TIN-2007-67586-C02-01, TEC200614186-C02-02 and SAF2008-03694, Cátedra Bidons Egara, Fundación Séneca 08788/PI/08, CIBER-BBN and by the European Commission through the project “'NEUROPROBES”' IST-027017.

\section{References}

[1] J.A. Anderson, E. Rosenfeld, Neurocomputing: Foundations of Research, MIT Press Cambridge, MA, USA, 1998

[2] Douglas J. Bakkum, Er C. Shkolnik, Guy Ben-ary, Phil Gamblen, B. Demarse, Steve M. Potter, Removing some 'A' from AI: embodied cultured networks, in: LNAI, vol. 3139, Springer, 2004, pp. 130-145.

[3] Daniel A. Wagenaar, MEABENCH, December 2006. http://www.its.caltech.edu/ daw/meabench/.

[4] Thomas B. Demarse, Daniel A. Wagenaar, Axel W. Blau, S.M. Potter, The neurally controlled animat: biological brains acting with simulated bodies, Autonomous Robots 11 (2001) 305-310.

[5] H. Bading, M.E. Greenberg, Stimulation of protein tyrosine phosphorylation by NMDA receptor activation, Science 253 (5022) (1991) 912-914.

[6] D.A. Wagenaar, J. Pine, S.M. Potter, An extremely rich repertoire of bursting patterns during the development of cortical cultures, BMC Neuro-science 7 (2006) 11

[7] I. Antonov, I. Antonova, E.R. Kandel, Activity-dependent presynaptic facilitation and Hebbian LTP are both required and interact during classical conditioning in aplysia, Neuron 37 (1) (2003) 135-147.

[8] Y. Jimbo, H.P. Robinson, A. Kawana, Strengthening of synchronized activity by tetanic stimulation in cortical cultures: application of planar electrode arrays, IEEE Transactions on Biomedical Engineering 45 (11) (1998) 1297-1304

[9] J.R. Álvarez-Sánchez, J. Mira Mira, F. de la Paz López, J.M. Cuadra Troncoso, The centre of area method as a basic mechanism for representation and navigation, Robotics and Autonomous Systems 55 (12) (2007) 860-869.

[10] J.M. Ferrández, V. Lorente, J.M. Cuadra, F. de la Paz, J.R. Álvarez-Sánchez, . Fernández, A biological neuroprocessor for robotic guidance using a center of area method, Neurocomputing (2010) (in press).

11] P.P. Lenck-Santini, E. Save, B. Poucet, Evidence for a relationship between place-cell spatial firing and spatial memory performance, Hippocampus 11

[12] J. O'Keefe, D.H. Conway, Hippocampal place units in the freely moving rat: why they fire where they fire, Experimental Brain Research 31 (1978) 573-590.

[13] J. O'Keefe, J. Dostrovsky, The hippocampus as a spatial map. Preliminary evidence from unit activity in the freely moving rat Brain Research 34 (1971) $171-175$.

[14] J.M. Ferrández, V. Lorente, J.M. Cuadra, F. de la Paz, J.R. Álvarez-Sánchez, E. Fernández, A Hybrid Robotic Control System using Neuroblastoma Cultures, in: LNAI, vol. 7066, Springer, 2010, pp. 245-254.

[15] J.M. Ferrández, V. Lorente, G. Díaz, F. de la Paz, E. Fernández, An open-source real-time system for remote robotic control using neuroblastoma cultures, IEEE IJCNN (2010) 901-908.

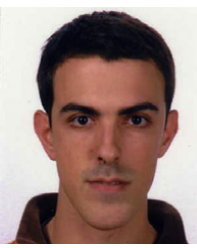

Daniel de Santos received his B.Sc. Degree in Computer Spain. He is an M.Sc. student at the Artificial Intelligence Department of Universidad Nacional de Educación a Distancia, Spain. His main research interests include navigation and representation tasks in mobile robots.

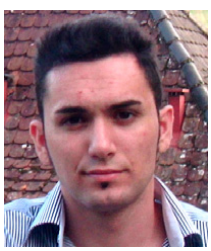

ctor Lorente received his Telecommunications degree rom the Polytechnic University of Cartagena, Spain, in 2008 and his Master's Degree in Commanications and Information Technology in 2009. He is currently studying towards his Ph.D. at the Polytechnic University of Cartagena. In recent years he has been studying the computing capabilities of human neuroblastoma cultured cells to define stimulation patters able to modulate the neural activity in response to external stimuli for controlling an autonomous robot.

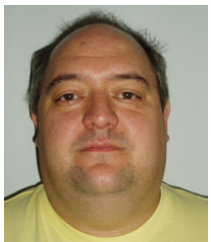

elix de la Paz received his B.Sc. and M.Sc. Degrees in Physics (1995) from Universidad Complutense de Madrid, Spain, and his Ph.D. Degree in Physics (2003) from Universidad Nacional de Educación a Distancia, Madrid, Spain. He is an Associate Professor at the Artificial Intelligence Department of Universidad Nacional de Educación a Distancia, Spain. His main research interests include navigation and representation tasks in mobile robots.

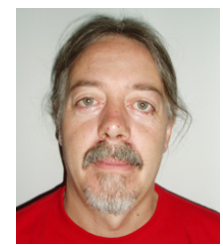

José Manuel Cuadra received his B.Sc. and M.Sc. Degrees in Mathematics (2000) from Universidad Nacional de Educación a Distancia, Spain, and he is now working on his Ph.D. thesis. He is an Assistant Professor in the Artificial Intelligence Department of Universidad Nacional de Educación a Distancia, Spain. His main research interests include artificial neural networks and mobile robotics.

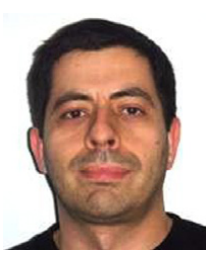

José R. Álvarez-Sánchez received his B.Sc. and M.Sc degrees in Physics (1988) from Universidad Complutense de Madrid, Spain, and his Ph.D. Degree in Physics (1997) from Universidad Nacional de Educación a Distancia, Madrid, Spain. He is an Associate Professor in the Artificial Intelligence Department of Universidad Nacional de Educación a Distancia, Spain. His main research interests include artificial neural networks and mobile robotics.

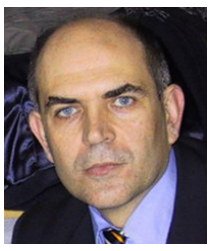
Eduardo Fernández received his M.D. Degree from the University of Alicante, Spain, in 1986 and his Ph.D. Degree Professor in the University Miguel Hernánd an Spain, ande Pirector of the Artificial Vision Laboratory at the and Direction of the Arute Spain. In recent years he has been using histological as well as electrophysiological techniques to nistological as well as electrophysiological techniques to understand how mammalian retinal cells and the circuitry within the retina working on the development of a visual neuroprosthesis for the profoundly blind.

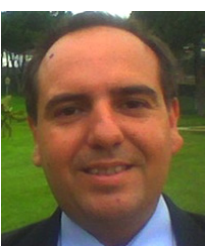

José M. Ferrández was born in Elche, Spain in 1969. He received his M.Sc. Degree in Computer Science in 1995 and his Ph.D. Degree in 1998, both from the Universidad Politécnica de Madrid, Spain. He is currently an Associate Professor in the Department of Electronics, Computer Technology and Projects at the Universidad Politécnica de Cartagena and Head of the Electronic Design and Signal Processing Research Group at the same University. His research interests include bioinspired processing, neuromorphic engineering and low vision prosthesis. 


\title{
A biological neuroprocessor for robotic guidance using a center of area method
}

\author{
J.M. Ferrández ${ }^{\mathrm{a}, \mathrm{b}}$, V. Lorente $^{\mathrm{b}}$, F. delaPaz ${ }^{\mathrm{d}}$, J.M. Cuadra ${ }^{\mathrm{d}, *}$, José Ramón Álvarez-Sánchez ${ }^{\mathrm{d}}$, E. Fernández ${ }^{\mathrm{c}}$ \\ a Instituto de Bioingeniería, Universidad Miguel Hernández, Alicante, Spain \\ ${ }^{\mathrm{b}}$ Departamento de Electrónica, Tecnología de Computadoras y Proyectos, Universidad Politécnica de Cartagena, Spain \\ ${ }^{c}$ CIBER-BBN, Spain \\ d Departamento de Inteligencia Artificial, UNED, Spain
}

A R T I C L E I N F O

Available online 23 October 2010

Keywords:

Neuroprocessor

Cultured neural network

Induced plasticity

Multielectrode recordings

Robotic control

\begin{abstract}
A B S T R A C T
This paper introduces a neuroinformatic system using human neuroblastoma cultures and centre of area learning for basic robotic guidance. Multielectrode Arrays Setups have been designed for direct culturing neural cells over silicon or glass substrates, providing the capability to stimulate and record simultaneously populations of neural cells. The main objective of this work will be to control a robot using this biological neuroprocessor and a simple centre of area learning scheme. The final system could be applied for testing how chemicals affect the behaviour of the robot or to establish the basis for new hybrid optogenetic learning.
\end{abstract}

(c) 2010 Elsevier B.V. All rights reserved.

\section{Introduction}

Mammalian nervous systems exhibit complex computational functions including sensory functions, motor function and in humans, abstract thought. In particular, pattern recognition exhibited in our olfactory, visual and auditory functions are of particular interest to the electronic and computing communities. Meanwhile several approaches attempt to mimic/substitute sensory or neural elements (missing by congenital state or due to pathological processes) in order to enable/restore function by establishing neuro-electronic interfaces.

Classical computational paradigms consist in serial and supervised processing computations with high-frequency clocks silicon processors, with moderate power consumption, and fixed circuits structure. In contrast, the brain uses millions of biological processors, with dynamic structure, slow commutations compared with silicon circuits, low power consumption and unsupervised learning. There have been numerous approaches to creating bioinspired parallel processing. However, silicon provides a fundamentally different technological platform to that of neurobiology. Neuronsthe core technology component has a huge number of interconnections compared to 3 in traditional transistors. This provides considerably more computational power. Furthermore, this extraordinary connectivity is coupled with natural unsupervised learning based on varying connective efficiency.

Our learning experiments were performed in neural cultures containing 120.000 human neuroblastoma SY 5Y, under the assumption that this kind of cells are able to respond electrically

\footnotetext{
* Corresponding author.

E-mail address: jmcuadra@dia.uned.es (J.M. Cuadra).

0925-2312/\$-see front matter @ 2010 Elsevier B.V. All rights reserved. doi:10.1016/j.neucom.2010.07.018
}

to external stimuli and modulate their neural firing by changing the stimulation parameters. Such cultured neuroblastoma networks have shown dynamical configurations, being able to grow and adapt functionally in response to external stimuli over different configuration patterns. We are especially interested in analyzing if populations of neuroblastoma cells are able to process and store information, and if learning can be implemented over this biological structure. The main objective of this work will be to control a robot using this biological neuroprocessor and a simple centre of area learning scheme. The final system could be applied for testing how chemicals affect the behaviour of the robot or to establish the basis for new hybrid optogenetic neuroprostheses.

\section{Learning in human neuroblastoma cultures}

\subsection{Experimental procedures}

The physiological function of neural cells is modulated by the underlying mechanisms of adaptation and reconfiguration in response to neural activity. Hebbian learning describes a basic mechanism for synaptic plasticity wherein an increase in synaptic efficacy arises from the presynaptic cell's repeated and persistent stimulation of the postsynaptic cell. The theory is commonly evoked to explain some types of associative learning in which simultaneous activation of cells leads to pronounced increases in synaptic strength. The N-methyl-D-aspartate (NMDA) receptor, a subtype of the glutamate receptor, has been implicated as playing a key role in synaptic plasticity in the CNS [1], where as dopamine receptors are involved in the regulation of motor and cognitive behaviours. For most synaptic ion channels, activation (opening) 
requires only the binding of neurotransmitters. However, activation of the NMDA channel requires two events: binding of glutamate (a neurotransmitter) and relief of $\mathrm{Mg}^{*}$ block. NMDA channels are located at the postsynaptic membrane. When the membrane potential is at rest, the NMDA channels are blocked by the $\mathrm{Mg}^{*}$ ions. If the membrane potential is depolarized due to excitation of the postsynaptic neuron, the outward depolarizing field may repel $\mathrm{Mg}^{*}$ out of the channel pore. On the other hand, binding of glutamate may open the gate of NMDA channels (the gating mechanisms of most ion channels are not known). In the normal physiological process, glutamate is released from the presynaptic terminal when the presynaptic neuron is excited. Relief of $\mathrm{Mg}^{*}$ block is due to excitation of the postsynaptic neuron. Therefore, excitation of both presynaptic and postsynaptic neurons may open the NMDA channels, this is closely related with Hebbian learning.

Another important feature of the NMDA channel is that it conducts mainly the $\mathrm{Ca}^{*}$ ion which may activate various enzymes for synaptic modification, even nitric oxide has been identified as a relevant element in synaptic regulation. The enhancement of synaptic transmission is called the long-term potentiation (LTP), which involves two parts: the induction and the maintenance. The induction refers to the process, which opens NMDA channels for the entry of $\mathrm{Ca}^{*}$ ions into the postsynaptic neuron. The subsequent synaptic modification by $\mathrm{Ca}^{*}$ ions is referred to as the maintenance of LTP.

A human neuroblastoma SY5Y cell line, that express clonal specific human dopamine receptors, and also NMDA receptors, will be the biological platform for studying learning in cultured cells.

Neuroblastoma SH-SY5Y cells are known to be dopaminergc acetylcholinergic, glutamatergic and adenosinergic, so in this line they respond to different neurotransmitters. The cells have very different growth phases, as it can be seen in Fig. 1(b). The cells both propagate via mitosis and differentiate by extending neurites to the surrounding area. The dividing cells can form clusters of cells which are reminders of their cancerous nature, but chemicals can force the cells to dendrify and differentiate, in some kind of neuritic growth. Extracellular recordings were obtained from ganglion cell populations in isolated superfused albino rabbit (Oryctolagus cuniculus) retina using a rectangular array of $100,1.5 \mathrm{~mm}$ long electrodes, as reported previously [2 5]. Briefly, after enucleation of the eye, the eyeball was hemisected with a razor blade, and the cornea and lens were separated from the posterior half. The retinas were then carefully removed from the remaining eyecup with the pigment epithelium, mounted on a glass slide ganglion cell side up and covered with a Milipore filter. This preparation was then mounted on a recording chamber and superfused with bicarbonate-buffered Ames medium at $35{ }^{\circ} \mathrm{C}$

As conclusion, neuroblastoma culture cells show electrophysiological responses similar to standard neurons, as potential

a

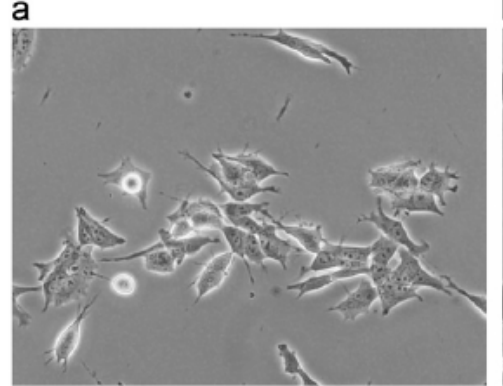

b

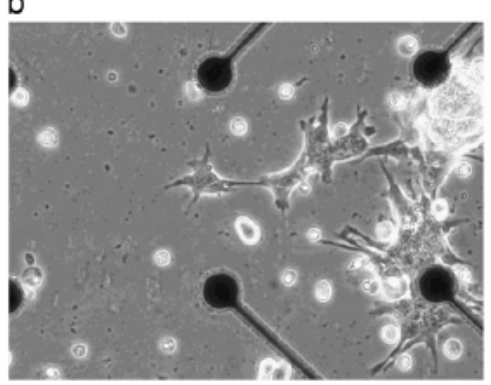
inverted microscopes.

Fig. 1. (a) Human neuroblastoma cells and (b) neuroblastoma cells over multielectrode array.

actions generation sensible to tetrodotoxin (TTX) and acetylcholyn. They have neurotransmitters synthesis process and are able to neuritic growth in culture medium.

\section{Experimental setup}

The neuro-physiology setup provides a complete solution for stimulation, heating, recording, and data acquisition from 64 channels. The MEA (microelectrode array) system is intended for extracellular electrophysiological recordings in vitro of different applications that include acute brain, heart, and retina slices; cultured slices; and dissociated neuronal cell cultures.

The basic components of the proposed system are shown in Fig. 2. These components are:

1. A microelectrode array is an arrangement of 60 electrodes that allows the simultaneous targeting of several sites for extracellular stimulation and recording. Cell lines or tissue slices are placed directly on the MEA and can be cultivated for up to several months. Almost all excitable or spontaneously active cells and tissues can be used.

2. Raw data from the MEA electrodes are amplified by MCS filter amplifiers with custom bandwidth and gain, which are built very small and compact using SMD (Surface Mounted Devices) technology. The small-sized amplifier combines the interface to the MEA probe with the signal filtering and the amplification of the signal. The compact design reduces line pick up and keeps the noise level down. The amplifiers are mounted over an

3. The analog input signals are then acquired and digitized by the MC-Card that is preinstalled on the data acquisition computer, that supplies the power for the amplifiers, and the pattern stimuli to the stimulators.

4. The robot sends information about the environment to the computer using a bluetooth link. The sensor consists in infrared sensors for detecting obstacles.

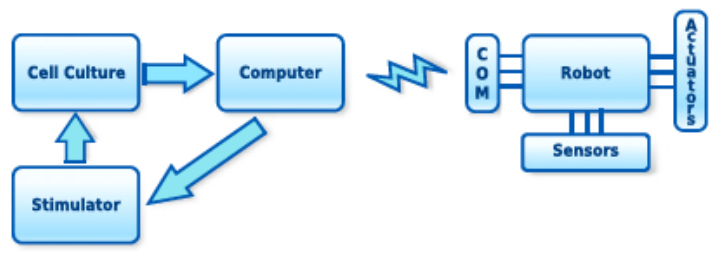

Fig. 2. Experimental setup. 


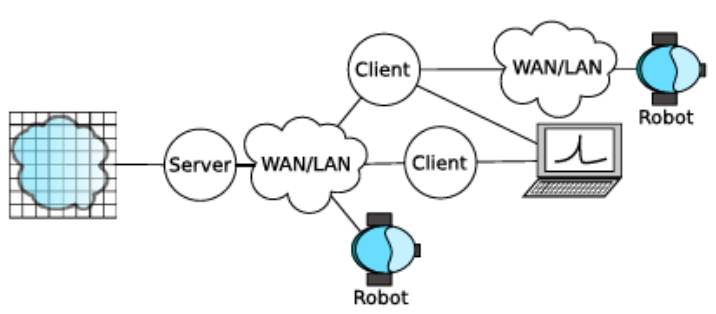

Fig. 3. Remote robot communication architecture.

It has been developed a system that provides a complete robotic control platform over remote neural cultures. The system includes free, open-source, console-based programs written in $\mathrm{C} / \mathrm{C}+$ for realtime robotic applications with embodied cultures. All of this software has been developed for the Linux Operating System and MCS hardware (MultiChannel Systems, Reutlingen, Germany). Using this software in conjunction with MEABENCH is specially intended for close-loop experiments.

The software developed consists of the following programs:

1. Cult2Robot: The main program. It has been developed as a MEABENCH module, so it can read spikes information from MEABENCH spike detector and compute a direction vector based on MEA neural activity. The direction vector is calculated based on the number of spikes per electrode in $t$ seconds and it can be weighted by the height and width of the spikes. This direction vector can be sent to a robot to control its movement.

2. Stg_control: This program controls a general-purpose two channel stimulus generator.

3. BT_server: Non-blocking Bluetooth server that uses RFCOMM protocol to receive characters from a specific MAC, process the information and do some action, this protocol is used for remote controlling the robot.

4. Remote environment: the computer that is communicating directly with the robot include TCP-IP facilities for reading/ sending information to the bio-hybrid platform, wherever it is located (Fig. 3).

Bluetooth client and server will be used with a humanoid robot (Robonova, Hitec Robotics) and a two-wheeled robot (e-puck, www.epuck,org) to send and receive information about obstacles. The system comprises:

1. A bio-hybrid robot control: It includes the development of a whole bio-hybrid hardware/software platform with for robotic guidance.

2. A remote communication system with the neural culture: It has been developed a remote environment for communicating the robot with any bio-hybrid control platform through TCPIP links.

3. Creation of a bio-hybrid robotic control: Design the neuromorphic processes, e.g. obstacle avoidance tasks, implemented over the bio-hybrid system.

\section{Methods}

Human neuroblastoma cultures were produced using the commercial line SH/SY5Y. Neural cells were then plated on Micro-Electrode Arrays - MEAs (MultiChannel Systems, Reutlingen, Germany). Initially the nitrogen frozen cells, was immersed in a $37^{\circ}$ bath, and centrifuged at $1000 \mathrm{rpm}$ during $5 \mathrm{~min}$. When cells have grown in a uniform mono-layer process, they are washed three time with buffer Phosphate-buffered saline (PBS) for keeping the $\mathrm{pH}$ approximately constant. $0.5 \%$ trypsin was added to the solution in order to re-suspend cells adherent to the cell culture dish wall during the process of harvesting cells. The cells were kept in the incubator for $5 \mathrm{~min}$ and passed through a $40 \mu \mathrm{m}$. cell strainer (Falcon, Bedford, MA) to remove large debris. Finally the cells are transferred to a specific medium in order to inactivate trypsin, and centrifugated again during $5 \mathrm{~min}$ at $1000 \mathrm{rpm}$.

For seeding the plate cells are stained with trypan blue, (because cells that lose their permeability get colored with this solution) and counted with a Neubauer chamber. Finally, 80.000 or 120.000 total neuroblastoma cells have been placed over the MEA substrate.

Maintaining cells in culture is essential for studying their physiological properties. Cell culturing is dependent on the growth surfaces and cells must adhere to the electrode substrate in order to establish the best connection with the electrodes material. For most cultures coated tissue culture plates are prerequisite for seeding. The most commonly used coatings are positively charged polymers. In this work, the insulation layer (silicon nitride) of some of the plates was pre-treated with polyethyleneimine (PEI), showing no advantages compared with no covered plates.

The neuroblastoma cultures are maintained in a $37^{\circ}$ humidified incubator with $5 \% \mathrm{CO}_{2}$ and $95 \% \mathrm{O}_{2}$ with serum-free Neurobasal medium. Under the aforementioned conditions we were able to record stable electrophysiological signals over different days in vitro (Div). The medium was replaced one-half of the medium every 5 days.

\section{Results}

The cultured neuroblastoma cells establish synaptic connections. It can be seen differentiated and non-differentiated neuroblastoma cell bodies growing around the whole electrode population. The dendritic arborescence is more evident in the magnification Fig. 1(b) where differentiated neural cells surround the four electrodes while the rest of the cells are in their growing process. This figure corresponds to 80.000 neuroblastoma cells seeded in a no-PEI MEA at 2nd day in vitro (div).

The electrophysiological properties of the neuroblastoma cultures were analized by recording the spontaneous activity of the network. Time course of experiments was over 15 days; recordings were done using two MCS-Meas with two neuroblastoma cell cultures (but only in one the cells survived till day 15). In vitro neuroblastoma networks show spontaneously firing. This firing rates change during the culture development with marked day differences and the global rate is closely related to the age of the network.

The physiological recordings correspond to neuroblastoma cultures in the range of $17 \mathrm{div}$. They show bursting and spiking activity, with usually negative depolarizations. Fig. 4(a) show the spiking activity of the neural population with an automatic detection level for each electrode. This is very convenient if you have multiple channels for extracting spikes.

The standard deviation of each data trace is used to estimate its spike threshold. A time interval of $500 \mathrm{~ms}$ is used to calculate the standard deviation. By fixing the factor, by which the standard deviation is multiplied, the sign of the factor determines whether the spike detection level is positive or negative, only values above this will be extracted as spiking activity. A value between -1 and -4 is appropriate for most applications the threshold was fixed at standard deviation equal to -3 with respect to the electrode activity in order to identify spikes embedded in the noisy signals. 
Estudio y realización de un neuroprocesador biológico: métodos de aprendizaje
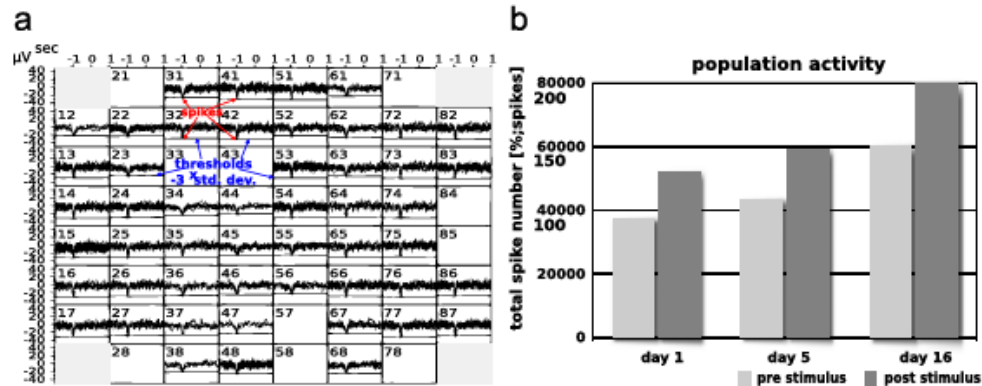

Fig. 4. (a) Spontaneous neural activity detected by the multielectrode array and (b) induced neural activity by tetanization stimuli.

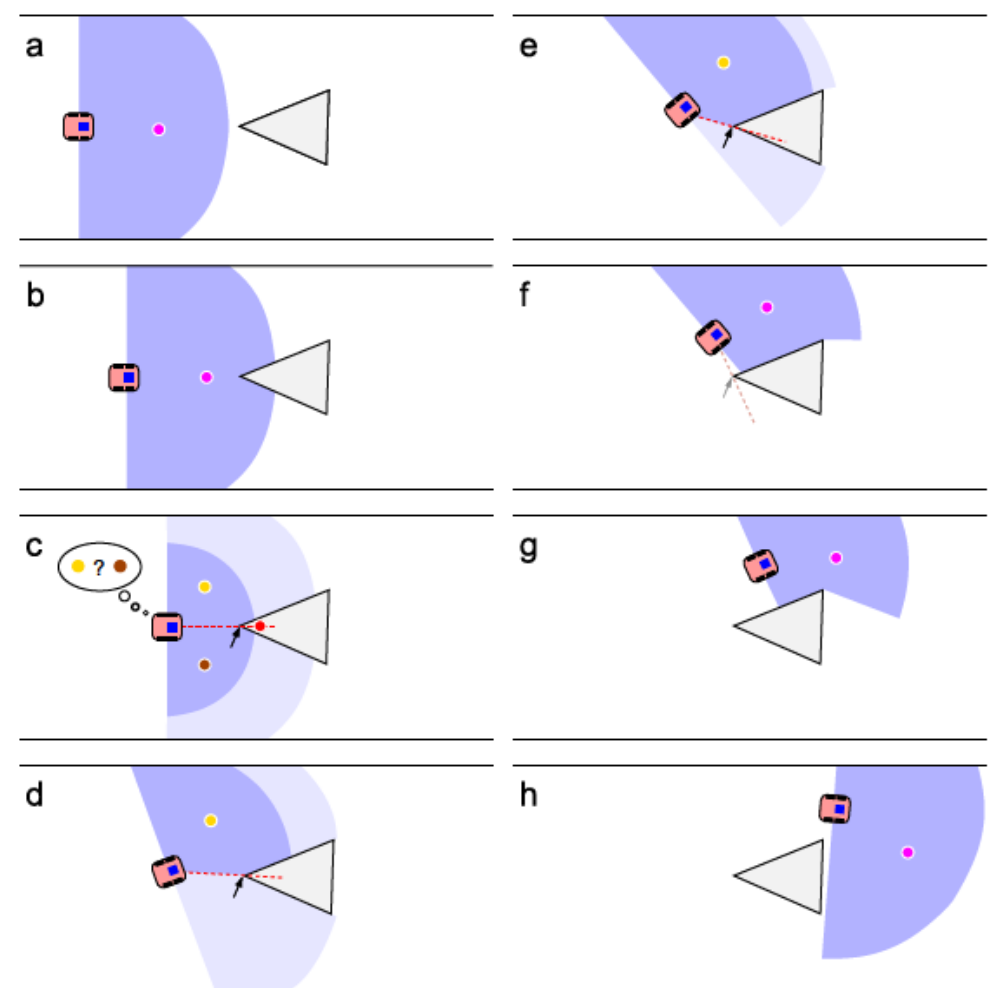

Fig. 5. Obstacles avoidance using area center. These pictures form a sequence showing how a robot overcomes an obstacle using the center of area method. The current advance sector is the dark blue area, discarded sectors are in light blue.(a)Area center (magenta/dark circle) is accessible: followit (using full advance sector). (b) Area center is still accessible: follow it (using full advance sector). (c) Area center became inaccessible (red/dark circle): shrink and split the advance sector, choose one side and turn to its area center (yellow/lighter or brown/darker circles), remember (local coordinates) the split point (marked with arrow). (d) Left side has been chosen: as you turn expand the sector to the right to cover the split point and increase restricted advance sector radius as function of sector amplitude increment, followsector area center (yellow/light circle). (e) You are going past the split point: continue expanding the sector, continue following sector area center (using restricted advance sector). (f) Split point has been gone past, the advance sector has been expanded to its initial radius and amplitude: forget split point, continue following sector area center (magenta/dark), the full advance sector has been recovered. (g) Area center is accessible: follow it (using full advance sector). (h) Robot has overcome the obstacle, area center is accessible: follow it. (For inter pretation of the references to color in this figure legend, the reader is referred to the web version of this article.)

During the neuroblastoma development, a wide range of population bursting or synchronized activity has been observed, according to some studies in neural cultures preparations [6]. The burst usually contains a large number of spikes at many channels, with variable duration, from milliseconds to seconds.

\subsection{Tetanic stimulation}

Spontaneous activity was recorded for intervals of $3 \mathrm{~min}$ before stimulation (PRE-data), and the total number of spikes extracted was counted. The biphasic stimulus consists in a 10 trains of a 100 
anodic-first waveform with 1 Volt amplitude delivered to all 60 electrodes in order to propagate a tetanization stimulus to the neuroblastoma culture.

In neurobiology, a tetanic stimulation consists of a highfrequency sequence of individual stimulations of a neuron. It is associated with long-term potentiation, the objective of this work. High-frequency stimulation causes an increase in transmitter release called post-tetanic potentiation [7]. This presynaptic event is caused by calcium influx. Calcium-protein interactions then produce a change in vesicle exocytosis. Some studies [8] use repetitive stimulation for training neural cultures, achieving activity potentiation or depression.

Once the tetanization stimulus was applied to the whole population $5 \mathrm{~min}$ after the stimulation a $3 \mathrm{~min}$ interval was recorded (POST-data). Only neuronal signals which had at least a 2:1 signal:noise ration were valued as "spikes". Again, the total number of spikes extracted was counted. This process was made for cultures at 1 day in vitro (div), 5 and 16 div. Fig. 4(b) represents

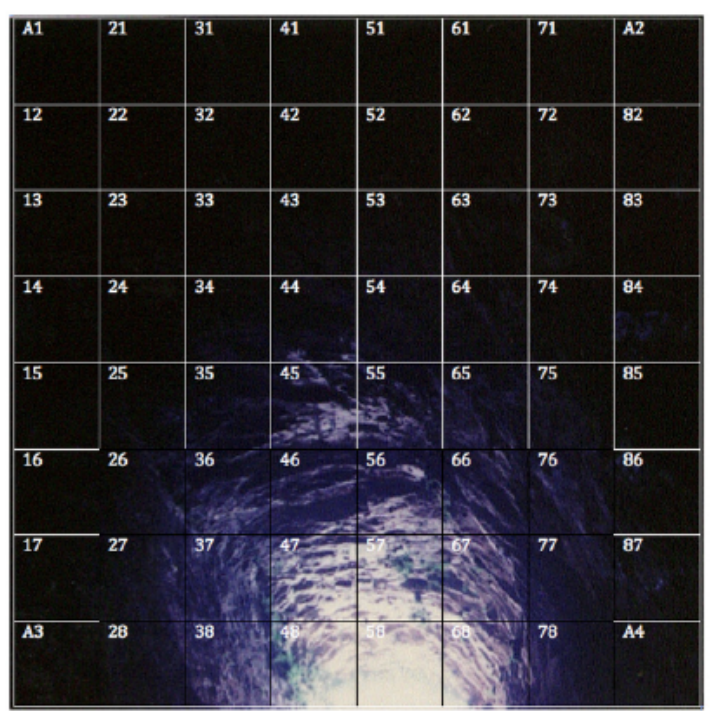

Fig. 6. Image acquired by a robot over MEA.

a

\begin{tabular}{|l|l|l|l|l|l|l|l|}
\cline { 2 - 8 } \multicolumn{1}{c|}{} & 21 & 31 & 41 & 51 & 61 & 71 & \\
\hline 12 & 22 & 32 & 42 & 52 & 62 & 72 & 82 \\
\hline 13 & 23 & 33 & 43 & 53 & 63 & 73 & 83 \\
\hline 14 & 24 & 34 & 44 & 54 & 64 & 74 & 84 \\
\hline 15 & 25 & 35 & 45 & 55 & 65 & 75 & 85 \\
\hline 16 & 26 & 36 & 46 & 56 & 66 & 76 & 86 \\
\hline 17 & 27 & 37 & 47 & 57 & 67 & 77 & 87 \\
\cline { 2 - 8 } & 28 & 38 & 48 & 58 & 68 & 78 & \multicolumn{1}{c}{} \\
\cline { 2 - 7 } & & & & \multicolumn{3}{c|}{}
\end{tabular}

the counted spikes with bar charts for the different recordings. The conclusion from this figure is:

1. While the neuroblastoma culture is growing new connections are created, and the number of spikes increases as the culture expands over the MEA

2. After a tetanic stimulation the cells continue with their increased spiking rate, providing a persistent change in the culture behaviour. When this change in the network response lasts, these changes can be called learning.

In all the experimentation performed, tetanic stimulation was applied as training method, and the electrophysiological properties of the neuroblastoma culture change, getting a potentiation effect on the spontaneous firing, modulating in this way the culture neural activity.

\subsection{Robotic control}

For controlling the direction of the robot we propose to compute the winner neurons (that is the ones that increase more its firing characteristics) resulting from neural activity recorded in the human neuroblastoma culture stimulated using a centre of area method $[9,10]$.

This method is a new brand of navigation methods, at this time a reactive version has been developed. The method computes the center of area of a frontal sector, the advance sector, of the robot free perceived area and use its position for robot driving. The robot approximately follows the center of area path, see Fig. 5 . The idea is that the center of area is normally a safe place to go, but when an obstacle lies near robot path, the center of area could became inaccessible inside the obstacle, so there is no way to follow it. In this case the advance sector is split in two shorter sectors using a point of the obstacle as a reference. If the centers of area of both sectors are accessible one of them is chosen, randomly or by some external preference. If only one center is accessible it is selected. If both centers are inaccessible, no way, then the method determines the center of area of the robot shrunk rear area and robot turns to it as an escape manoeuvre. Successive splits may be done, if needed, so robot can drive through complex configuration of obstacles in a safe way, even passing through narrow places and following smooth paths.

A modification of the method makes it capable of goal reaching avoiding obstacles, still being, at least at these preliminary stages of its development, a reactive method.

b

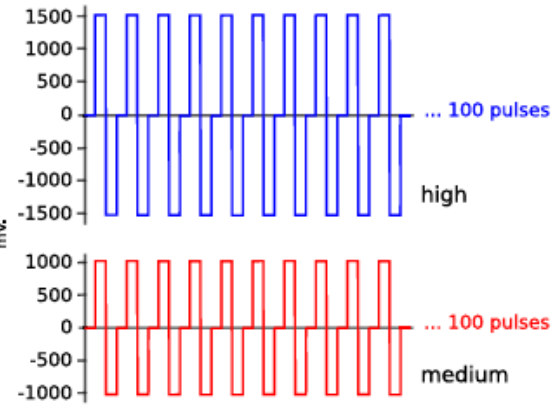

Fig. 7. Selective electrode tetanization. (a) MEA representation showing three groups of electrodes, white ones are not stimulated, light blue ones are stimulated with high tetanization and red (darker) ones are stimulated with medium tetanization. (b) High and medium tetanization pulses train, anodic first waveform. (For interpretation of the references to color in this figure legend, the reader is referred to the web version of this article.) 
Note that this centre of area concept is a construction that emerges from the visual or ranging perception of the robot. In Fig. 6, it can be seen a simulation of a robot walking through a cave. This image will be digitized in three grey levels, black, white and grey, in order to provide three different stimulations to the neural culture, no stimulation, high tetanization, and medium stimulation, respectively.

The resulting stimulation configuration is shown in Fig. 7(a). White boxes correspond to no-stimulation, red boxes correspond to medium tetanization, while blue electrodes will deliver high tetanization according with the acquired cave image. Medium tetanization will consist in five trains of a hundred anodic first pulses with $1 \mathrm{~V}$ amplitude, while high tetanization will provide $1.5 \mathrm{~V}$ anodic first pulses, Fig. 7(b). From this example, it is expected that electrodes that cover the centre of area of the grey and white image, that is the electrodes centered at the bottom of the image, electrodes 48 and 58, will increase more their activity. This winner
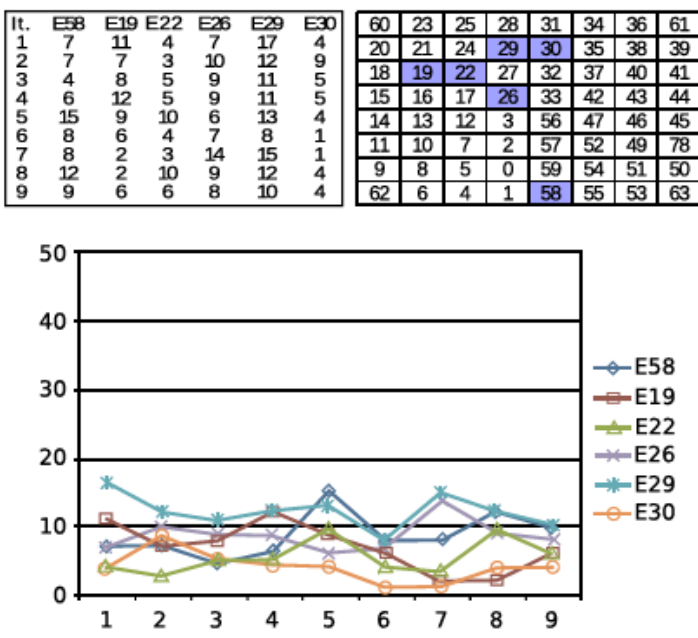

Fig. 8. Spontaneous neural activity detected previous to tetanization. Spikes number ( $y$-axis) from six electrodes were recorded 9 times ( $x$-axis). Left table shows data in numeric format, right table shows a MEA representation with selected electrodes marked out. Spikes number is always below 20 .

a

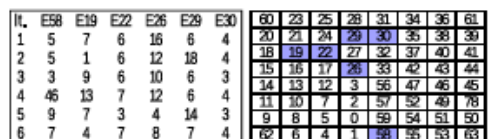

neuron coordinates will be provided to the robot in order to guide its movement. In the new robot position the camera will send a new image, and the information will be passed to the computer in order to induce a selective tetanization of the biological neural network for changing the resulting direction vector.

Again, human neuroblastoma cultures were produced using the commercial line SH/SY5Y. Cell culture of SH SY5Y was grown in DMEM (Gibco) completed with $10 \%$ of fetal bovine serum at $37^{\circ} \mathrm{C}$ in $5 \% \mathrm{CO}_{2}$ and humidify atmosphere. The electrophysiological properties of the neuroblastoma cultures were analyzed by recording the spontaneous activity of the network. In vitro neuroblastoma networks show spontaneously firing. This firing rates change during the culture development with marked day differences and the global rate is closely related to the age of the network. Recordings of Neuroblastoma SH SY5Y has the disadvantage of having a very low signal to noise ratio. As we have shown in previous papers, the electrophysiological properties of the culture change with the age of the culture, getting a potentiation effect in the spontaneous firing. A young neuroblastoma culture ( 15 div) has a low spontaneous firing activity, with a signal to noise ratio barely higher than 1:1. A mature neuroblastoma culture ( 115 div) have a higher spontaneous firing activity and its snr may be higher than 2:1, but still is lower than snr of other cells. The physiological recordings correspond to neuroblastoma cultures in the range of $17 \mathrm{div}$. They show bursting and spiking activity, with usually negative depolarizations. It was used also an automatic detection level for each electrode. This is very convenient if you have multiple channels for extracting spikes.

The standard deviation of each data trace is used to estimate its spike threshold and computing the spikes per channel. A time interval of $500 \mathrm{~ms}$ is used to calculate the standard deviation. The threshold was fixed at standard deviation equal to -4 with respect to the electrode activity in order to identify spikes embedded in the noisy signals. Spontaneous activity was recorded for intervals of $5 \mathrm{~s}$ before stimulation, and the total number of spikes extracted was counted for each channel. Fig. 8 shows the total number of spikes per channel, and a graphic visualization of this data for six different electrodes located at different positions at the neural culture.

When the tetanization configuration shown in Fig. 7 was applied, the spiking characteristics of the neuroblastoma culture changed. The computed spikes per channel is shown in Fig. 9(a) during the tetanization process. It can be seen that the most significant increment registered is at electrode 58 , that matches the centre of area of the provided image, guiding in this way the robot

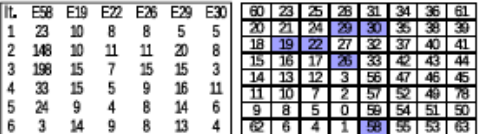

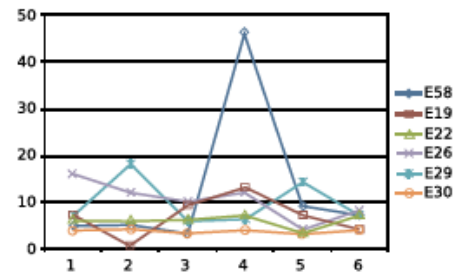

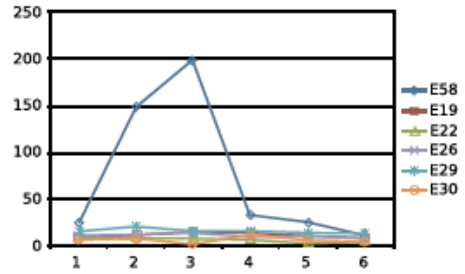

Fig. 9. Spontaneous neural activity detected during (a)and after (b) selective tetanization. In (b) wasused the same selective stimulation as in (a). Note the difference between $y$-axes scales in (a) and (b), it shows a considerable increase in activation at electrode 58. See Fig. 8 foot for more explanations, 
to the light. When the image of the cave was presented once again, that is the same selective stimulation was provided, the registered activity was again modified. In Fig. 9(b) it can be seen a clearly potentiation effect in electrode 58 about 4 times, while the rest of the electrodes did not show any significant increase.

\section{Discussion}

Learning in cultured neuroblastoma networks by a stimulation process requires identifying the correct stimuli to provide to the neurons maintained ex vivo. These neuroblastoma networks form a large culture covering the whole electrode array and generating a rich dendritic configuration. The connectivity can be modulated by external stimulation as has been described in many studies, but also the activity of the network can be modulated with the appropriate stimulation scheme.

Tetanization consists in high-frequency stimulation to the culture, in order to cause an increase in transmitter release called post-tetanic potentiation. The results illustrate the existence of qualitatively different responses to stimulation. Our results indicate the existence of a clear facilitation mechanism in response to the tetanization stimuli at different stages of cell development. Since this kind of stimulation has been used in attempts to induce plasticity in neuroblastoma, refining some crucial aspects of the stimulation is still indispensable.

It is very important to adjust the frequency of the train pulses of the stimulation for suppressing bursting in the culture. While in vivo networks suppress bursting naturally with the tissue development and sensory inputs, ex vivo cultures need to reduce this synchronized activity by adjusting the stimulation parameters. Also, for superimposing a desired behaviour on the biological networks it is necessary to stimulate locally some part of the culture in order to facilitate some parts of the networks, or achieve some kind of electrical stimulation that depress the local activity of a restricted location. With this local potentiation inhibition scheme the culture global behaviour could be controlled.

Future work consists in determining the optimal stimulation to apply for inducing permanent firing changes in the culture. These aspects will then constitute the basis for analyzing the behaviour change by adding chemicals to the culture, and for designing new optogenetic hybrid learning schemes.

\section{Acknowledgements}

This work was supported by the Spanish Government through Grants TIN2008-06893-C03, TEC2006-14186-C02-02 and SAF2008 -03694, Cátedra Bidons Egara, Fundación Séneca 08788/PI/08, CIBER-BBN and by the European Commission through the Project "NEUROPROBES" IST-027017.

\section{References}

[1] H. Bading, M. Greenberg, Stimulation of protein tyrosine phosphorylation by NMDA receptor activation, Science 253 (5022) (1991) 912-914.

[2] E. Fernandez, J. Ferrandez, J. Ammermuller, R.A. Normann, Population coding in spike trains of simultaneously recorded retinal ganglion cells, Brain Research 887 (1) (2000) 222-229.

[3] R.A. Normann, D. Warren, J. Ammermuller, E. Fernandez, S. Guillory, Highresolution spatio-temporal mapping of visual pathways using multi-electrode arrays, Vision Research 41 (10-11) (2000) 1261-1275.

[4] G. Ortega, M. Bongard, E. Louis, E. Fernandez, Conditioned spikes: a simple and fast method to represent rates and temporal patterns in multielectrode recordings, Journal of Neuroscience Methods 133 (1-2) (2004) 135-141.

[5] M.P. Bonomini, J.M. Ferrandez, J.A. Bolea, E. Fernandez, DATA-MEAns: an open source tool for the classification and management of neura ensemb

6] D.A. Wagenar. J. Pine, S.M. Potter, An extremely rich repertoire of bursting patterns during the development of cortical cultures, BMC Neuro-science 7 (11) (2006)

[7] I. Antonov, I. Antonova, E. Kandel, Activity-dependent presynaptic facilitation and Hebbian LTP are both required and interact during classical conditioning in aplysia, Neuron 37 (1) (2003) 135-147.

[8] Y. Jimbo, H. Robinson, A. Kawana, Strengthening of synchronized activity by tetanic stimulation in cortical cultures: application of planar electrode arrays, IEEE Transactions on Biomedical Engineering 45 (11) (1998) 1297-1304.

[9] J.R. Álvarez Sánchez, F. de la Paz López, J.M. Cuadra Troncoso, D. de Santos Sierra, reactive navigation in real environments using partial center of are method, Robotics and Autonomous Systems, in press, doi:10.1016/j.robot. 2010.05.009.

[10] J.R. Álvarez Sánchez, F. de la Paz López, J.M. Cuadra Troncoso, J.I. Rosado Sánchez, Partial center of area method used for reactive autonomous robot navigation, in: J. Mira, J.M. Ferrández, J.R. Alvarez, F. de la Paz, F.J. Toledo (Eds.), Bioinspired Applications in Artificial and Natural Computation, Lecture Notes in Computer Science, vol. 5602, Springer Verlag2009, pp. 408-418.

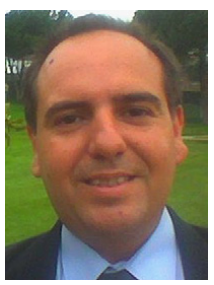

J.M. Ferrández was born in Elche, Spain. He received the M.Sc. degree in Computer Science in 1995, and the Ph.D. Polite in 1908 , all of them from the Universida Politecnica de Madrid, Spain. He is currently Associate Professor at the Department of Electronics, Compute Technology and Projects at the Universidad Politécnica de Cartagena and Head of the Electronic Design and Signal Processing Research Group at the same Univer-
sity. He is the Coordinator of the Spanish and the sity. He is the Coordinator of the Spanish and the
Iberoamerican Network on Naturan and Artificial ComIberoamerican Network on Naturan and Artificial Com-
putation. His research interests include bioinspired processing, neuromorphic engineering and low vision prosthesis.

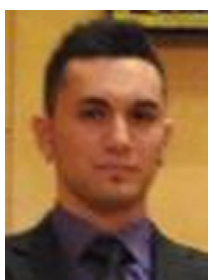

V. Lorente received the Telecommunications degree from the Polytechnic University of Cartagena, Spain, i 2008 and the Master's Degree in Communications an Information Technology in 2009. He is currently study Cartawa in the last years he has been studying of Cartagena. In the last years he has been studying the

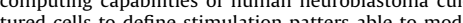
ulate the neural activity in response to extele to modfor controlling an autonomous robot.

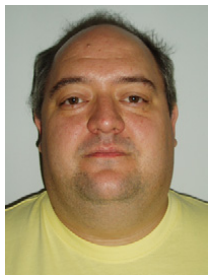

F. delaPaz received his B.Sc. and M.Sc. degrees in Physics (1995) from Univ. Complutense de Madrid, Spain, and his Ph.D. degree in Physics (2003) from Univ. Nacional de Educación a Distancia, Madrid, Spain. He is Associate Professor at the Artificial Intelligence Spain. His main research interests include navigation and representation tasks in mobile robots.

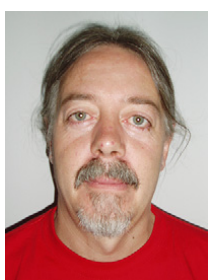

J.M. Cuadra received his B.Sc. and M.Sc. degrees in Mathematics (2000) from Univ. Nacional de Educación a Distancia, Spain he is now working in his Ph. thesis. He is assistant professor at the Artificial Intelligence Department of Univ. Nacional de Educación a Distancia Spain His main research interests include artificial neural networks and mobile robotics. 
Estudio y realización de un neuroprocesador biológico: métodos de aprendizaje

1236

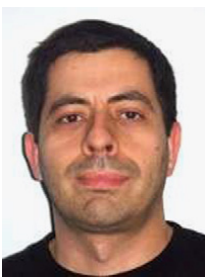

J.M. Ferrández et al. / Neurocomputing 74 (2011) 1229-1236

José Ramón Álvarez-Sánchez received his B.Sc. and de Madrid, Spain, and his Ph.D. degree in Physics (1997) from Univ. Nacional de Educación a Distancia, Madrid, Spain. He is Associate Professor at the Artificial Intelligence Department of Univ. Nacional de Educación a Distancia, Spain. His main research interests include artificial neural networks and mobile robotics.

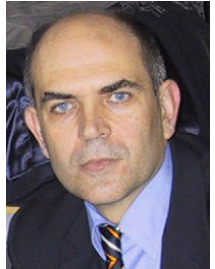

E. Fernandez Jover received the M.D. degree from the University of Alicante, Spain, in 1986 and the Ph.D. degree in Neurosciences in 1990. He is currently Associate Professor at the University Miguel Hernández, Spain, and Director of the Artificial Vision Laboratory at the Bioengineering Institute of the University Miguel Hernández, Spain. In the last years he has been using histological as well as electrophysiological techniques to understand how mammalian retinal cells and the circuitry within the retina can manage and code visual information. He is actively working on the development of a visual neuroprosthesis for the profoundly blind. 


\title{
Response calibration in neuroblastoma cultures over multielectrode array
}

\author{
J.M. Cuadraa ${ }^{\text {a J.R. Álvarez-Sánchez }}{ }^{\text {a,* }}$, D. de Santos ${ }^{a}$, V. Lorente ${ }^{b}$, J.M. Ferrández ${ }^{\text {c,b }}$, \\ F. de la Paz ${ }^{\mathrm{a}}$, E. Fernández ${ }^{\mathrm{c}, \mathrm{d}}$ \\ a Departamento de Inteligencia Artificial, UNED, Spain \\ ${ }^{\mathrm{b}}$ Departamento de Electrónica, Tecnología de Computadoras y Proyectos, Universidad Politécnica de Cartagena, Spain \\ ' Instituto de Bioingeniería, Universidad Miguel Hernández, Alicante, Spain \\ ${ }^{\mathrm{d}}$ CIBER-BBN, Spain
}

\section{A R T I C L E I N F O}

\section{Available online 3 August 2011}

\section{Keywords:}

Hybrid systems

Cultured neural network

Neuroblastoma cultures

Calibration

Normalization

\begin{abstract}
A B S T R A C T
Multielectrode Array (MEA) setups have been designed for direct culturing neural cells over silicon or glass substrates, providing the capability to stimulate and record simultaneously populations of neural cells. Neuroblastoma cultures over MEA have a very low signal/noise ratio response to stimulation, so it is difficult to detect small changes in spike activity in the culture during experiments. The main objective of this work is to study and to assess the statistical relevance of the response capabilities, with corresponding calibration or normalization, of neuroblastoma cultures to be used for hybrid systems. (c) 2011 Elsevier B.V. All rights reserved.
\end{abstract}

\section{Introduction}

Human neuroblastoma networks cultured over Multielectrode Array (MEA) setups have been used with success in hybrid systems. MEA setups have been designed for direct culturing neural cells over silicon or glass substrates, providing the capability to stimulate and record simultaneously populations of neural cells. In previous works [1,2], experiments were performed in neural cultures containing hundred thousands of human neuroblastoma SH-SY5Y cells, under the assumption that this kind of cells are able to respond electrically to external stimuli and modulate their neural firing by changing the stimulation parameters. Such cultured neuroblastoma networks show dynamical configurations, being able to develop and adapt functionally in response to external stimuli over a broad range of configuration patterns. The main interest in those experiments was to analyze if populations of neuroblastoma cells are able to process and store information, and if learning can be implemented over this biological structure. The objective was to build a hybrid system integrating biological and electronic systems to achieve a new computational structure able, for example, of robotic guidance in an obstacle avoidance task.

After the experiments referred in previous paragraph, and using the tools developed for them, it can be seen that the spike activity response in neuroblastoma cultures have a low signal/

\footnotetext{
* Corresponding author.

E-mail addresses: jmcuadra@dia.uned.es (J.M. Cuadra), jras@dia.uned.es (J.R. Álvarez-Sánchez), jm.ferrandez@upct.es (J.M. Ferrández), delapaz@dia.uned.es (F. de la Paz).
}

0925-2312/\$-see front matter $\odot 2011$ Elsevier B.V. All rights reserved. doi:10.1016/j.neucom.2011.04.038 noise ratio. Also, the cell population near each electrode can have different densities, so, although almost all channels (electrodes) in a culture respond to a stimulus, they can have very different level of activation. In order to use a biological culture of neuroblastoma in connection with other computational structures, it is necessary to obtain repeatable responses with the same meaning from any channel in different cultures in any growing stage. This could be obtained through calibration, to detect differences in signal/noise ratio, and through normalization to obtain similar levels of response for similar stimulations in different channels. It seems natural that the next step is to study and assess if the capabilities of response and learning of neuroblastoma cultures are really significant in statistical sense and if there exists a way for calibration and normalization of a culture response. This is the main purpose of this work.

Section 2 describes the biological cultures characteristics and the stimulation and activity recording of the experimental setup. Section 3 describes the statistical studies and the proposed normalization for calibration of neuroblastoma cultures, including some results with experiments. Finally, Section 4 summarizes the conclusions and the future work.

\section{Neuroblastoma cultures for hybrid system}

\subsection{Biological cultures characteristics and preparation}

As in our previous work [1], the biological platform for studying learning in cultured cells was a human neuroblastoma SH-SY5Y cell line, that express clonal specific human dopamine receptors, and also NMDA receptors that play an important role for long-term 
potentiation induced applying a few trains of high-frequency stimuli. Neuroblastoma SH-SY5Y cells are known to be dopaminergic, acetylcholinergic, glutamatergic and adenosinergic, so in this line they respond to different neurotransmitters. The cells both propagate via mitosis and differentiate by extending neurites to the surrounding area. The dividing cells can form clusters of cells which are reminders of their cancerous nature, but chemicals can force the cells to dendrify and differentiate, in some kind of neuritic growth The neuroblastoma cultures must be maintained in a $37^{\circ} \mathrm{C}$ humidified incubator with $5 \% \mathrm{CO}_{2}$ and $95 \% \mathrm{O}_{2}$ with serum-free Neurobasal ${ }^{\mathrm{TM}}$ medium. Under the aforementioned conditions it is possible to record stable electrophysiological signals over different days in vitro (div). The medium was replaced one-half of the medium every 5 days. At 10 div, the cells decrease their adhesion to the plate, so more of the population lost their contact with the metal elements and after 15 div, they get an embryonic configuration. So, the same neuroblastoma cells where seeded in polyethyleneimine (PEI) covered MEAs, see Fig. 1. The main drawback of this covering is that only few electrodes are covered with cells, because it stops the growing process, so we will get very limited responses from the whole electrode matrix. The choice is to have a lot of cells with strong adhesion to the electrodes a few days, or few covered electrodes with longer survival times.

\subsection{Stimulation and activity recording}

The substrate-embedded multielectrode array technology, from MultiChannel Systems (MCS, Reutlingen, Germany), was used. It includes arrays of $60 \mathrm{Ti} / \mathrm{Au} / \mathrm{TiN}$ electrodes, $30 \mu \mathrm{m}$ in diameter, and spaced $200 \mu \mathrm{m}$ from each other. A commercial 60 channel amplifier (B-MEA-1060; MCS) with frequency limits of $103000 \mathrm{~Hz}$ and a gain of $1024 \mathrm{X}$ was used. Stimulation through the MEA is performed using a dedicated two channel stimulus generator (MCS) able of time multiplexing the signals for stimulating the 60 electrodes in a nearly parallel process. The microincubation environment was arranged to support long-term recordings from MEA dishes by electrically heating the MEA platform to $37^{\circ} \mathrm{C}$. Data were digitized using MCS analog-to-digital boards. Each channel is sampled at a frequency of 50,000 samples/s and prepared for analysis using the MC-RACK software provided also by MultiChannel Systems.

Neural spike events, embedded in the noisy signals, are detected by comparing the instantaneous electrode signals to a level threshold computed for each data channel. The spike detection threshold is set as a multiple, expressed as a factor, of the standard deviation for each data trace. Only values crossing beyond the threshold will be detected as spiking activity. The sign of the factor determines whether the spike detection level is positive or negative. A value between -1 and -4 is appropriate for most

a

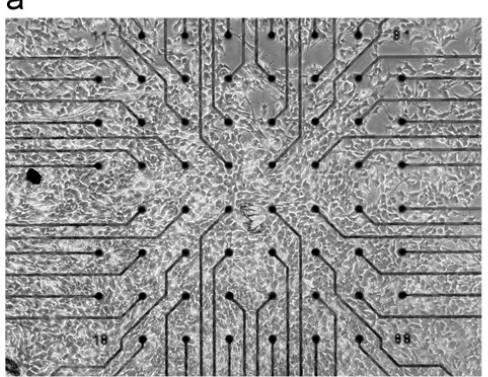

$\mathrm{b}$

applications, in this work the threshold factor was set to -3 . When a supra-threshold event occurs, the signal window surrounding the event was time-stamped and stored together with the state of the visual stimulus for later, offline analysis. For spike sorting we used a free program, NEV2lkit, which has been recently developed by our group and runs under Windows, Mac-OSX and Linux (source code and documentation is freely available [3]). NEV2lkit loads multielectrode data files in various formats (ASCII based formats, LabView formats, Neural Event Files, etc.) and is able to sort extracted spikes from large sets of data. The sorting was done using principal component analysis (PCA) and performed simultaneously on many records from the same experiment.

\section{Calibration of culture response to stimulus}

The electrophysiological properties of the neuroblastoma cultures were analyzed by recording the spontaneous activity of the network. In vitro neuroblastoma networks show spontaneously firing. The firing rates change during the culture development with marked day differences and the global rate is closely related to the age of the network [1].

The physiological recordings from neuroblastoma cultures in the range of 17 div show bursting and spiking activity, with usually negative depolarizations. During the neuroblastoma development, a wide range of population bursting or showing synchronized activity has been observed, according to some studies in neural cultures preparations [4]. The burst usually contains a large number of spikes at many channels, with variable duration, from milliseconds to seconds.

The use of neuroblastoma cultures in hybrid robot controller was based on the response to stimulus from cells in different areas of the culture representing detected obstacles from the robot. The response was measured in terms of the spike activity in corresponding areas after appropriate stimulus trains but, as said above, the cells density and quality in the culture is not homogeneous, so the responses in different electrodes must be analyzed previously to obtain a normalization.

The following tests were applied over data recorded from a series of experiments consisting of tetanic stimulation alternated with rest periods (electrodes to ground). The biphasic stimulus consists in a 10 trains of a 100 anodic-first waveform with $1 \mathrm{~V}$ amplitude delivered to all 60 electrodes in order to propagate a tetanization stimulus to the neuroblastoma culture. Voltage level in each electrode was recorded in sequences of $5 \mathrm{~s}$ before stimulus and $15 \mathrm{~s}$ after them. Every electrode activity was extracted by counting spikes that were above the noise level as explained in Section 2.2. Some of the recordings (labels 0104 ) were discarded because a failure in stimulation control and other

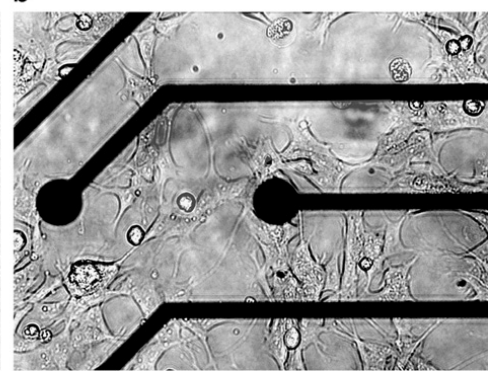

Fig. 1. (a) Human neuroblastoma culture over multielectrode array and (b) detail image of two electrodes with some neuroblastoma cells. 
recordings (labels 06, 09, 12 and 15) were also discarded due to errors in synchronization of recordings with stimulation.

\subsection{Statistical analysis of spontaneous activity in rest state}

First, we must identify the spontaneous activity in each channel, measured time enough after any stimulus to reach the normal activity in rest state. We are going to statistically analyze the last $10 \mathrm{~s}$ of each recording ( 9860 values). Table 1 summarizes the mean values and standard deviations of spikes counts, in the usual $500 \mathrm{~ms}$ time window [5], for the eight considered recordings, corresponding to experiments with a previous stimulation $(07$, 10,13 and 16), and those without stimulation $(05,08,11$ and 14).

The Kolmogorov Smirnov test (K S test) was applied to the data in the eight experiments together in order to check if it fits to a normal distribution, that is a condition required by many statistical tests. The value obtained for the Kolmogorov Smirnov statistic was $z 17.044$ with a significance of $p \quad 0.000$, so the hypothesis of data fitting in a normal distribution can be discarded. The bar-plot for spike count distribution in the 8 experiments, shown in Fig. 2, contributes to the same result.

A random variable counting, in a fixed time or space interval, the number of independent events, occurring with constant frequency, follows the Poison model, as it occurs in many random phenomena [6]. This is our case, except for the independence condition. The K S test for the Poison distribution was applied with a result of $z \quad 10.075$ corresponding to a significance level of $p 0.000$, so the event (spikes production) fully randomness can also be discarded.

Comparisons two by two are not adequate when comparing characters between more than two groups, because test statistical power decreases along with groups number increment. Thus we

Table 1

Mean value and standard deviation of spike count in $500 \mathrm{~ms}$ windows per electrode in all MEA for each considered experiment.

\begin{tabular}{lllll}
\hline & Exp. 05 & Exp. 08 & Exp. 11 & Exp. 14 \\
\hline No stimulation & & & & \\
Mean & 3.03 & 2.66 & 2.61 & 2.55 \\
St. dev. & 2.45 & 2.20 & 2.17 & 2.13 \\
& Exp. 07 & Exp. 10 & Exp. 13 & Exp. 16 \\
Stimulation & & & & \\
Mean & 2.69 & 2.63 & 2.61 & 2.61 \\
St. dev. & 2.18 & 2.19 & 2.17 & 2.18 \\
\hline
\end{tabular}

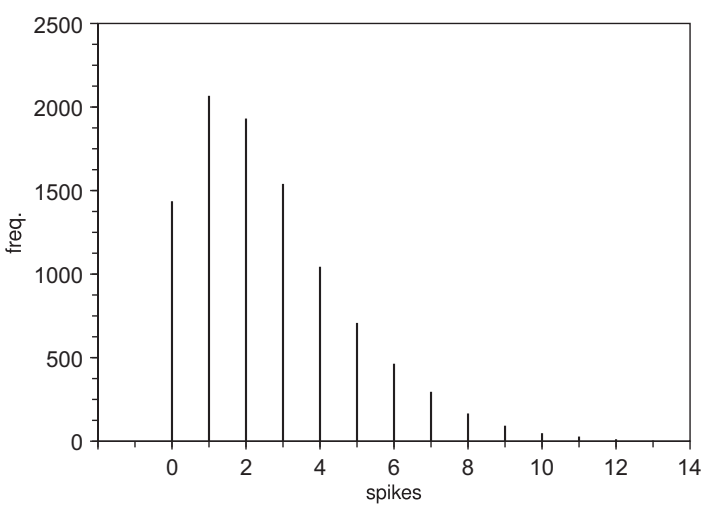

Fig. 2. Bar-plot for spike count (in $500 \mathrm{~ms}$ windows) distribution in the eight experiments. are going to perform tests that make comparisons using the whole data set of interest.

The two variability factors, experiment and electrode, must be taken into account in our analysis. First we will make statistical analysis of both factors at the same time. The lack of normality in the data gives less validity to the ANOVA test, but the big size of sample data allow us to use the central limit theorem to support to some degree the validity of the test. The dependent variable analyzed was the spike count in $500 \mathrm{~ms}$ windows per electrode with both variability factors. The tested hypotheses were:

$H_{0}: \begin{array}{llll}\mu_{1} & \mu_{2} & \cdots & \mu_{k}\end{array}$,

$H_{1}: \mu_{i} \neq \mu_{j}$ for at least one pair $(i, j)$.

Variance homogeneity is another condition for ANOVA tests application. The tested hypotheses are:

$H_{0}: \sigma_{1} \quad \sigma_{2} \quad \cdots \quad \sigma_{k}$,

$H_{1}: \sigma_{i} \neq \sigma_{j}$ for at least one pair $(i, j)$

In order to test variance homogeneity we used the Levene test because it does not depend on data normal distribution [7]. The statistic homogeneity result was $F \quad 2.360$ with a significance of $p 0.000$. This result was expected due to the probable lack of homogeneity of the culture grow over different electrodes in the MEA. It would be interesting to find some homogeneity between experiments. The results for homogeneity test, $F$ with significance $p$, were the following: for the experiment factor, $F \quad 0.919$ with $p$ 0.057; for electrode factor, $F 96.623$ with $p \quad 0.000$; and for the interaction of both factors, $F \quad 0.937$ with $p \quad 0.935$. So, with due reserves about lack of normality, we can conclude that respect to both variability factors there are no significant differences in the spike count due to the experiment, but there are differences due to the electrode, and there is no interaction between both factors.

Given that differences due to electrodes were expected, and we need to test the homogeneity between experiments, we applied more tests for mean and variance equality respect to the experiment factor without grouping data by electrode. Levene and Brown Forsythe [8] tests were used to check variance equality. For the equality in the mean values ANOVA test was used first, but given the inconclusive results due to the lack of normality and inhomogeneity in variances, the robust test of Kruskal Wallis [9] and the median test [10] were used. If we look in Table 1 the results for experiment 05, it seems to be different from the rest (it was the first measurement before any stimulation in the series), so the tests were repeated without experiment 05 .

All the results in the homogeneity tests with the corresponding significance levels are shown in Table 2 . The results for all the experiments at a time show significance levels of 0.000 , except in the median test where the significance is near 0.01 . So we should discard homogeneity in variance and mean values between the eight experiments. However, if the first non-stimulated

Table 2

Homogeneity tests for means and variances for the total number of spikes in the MEA, counted along $500 \mathrm{~ms}$ time windows, in each experiment.

\begin{tabular}{llrllll}
\hline \multirow{2}{*}{ Homogeneity tests } & \multicolumn{2}{c}{ All exps. } & & & \multicolumn{2}{l}{ Without exp. 05 } \\
\cline { 3 - 4 } \cline { 6 - 7 } \cline { 6 - 7 } & & Statistic & Sig. level & & Statistic & \multirow{2}{*}{ Sig. level } \\
\hline \multirow{2}{*}{ Means } & ANOVA & 5.567 & 0.000 & & 0.550 & 0.771 \\
& Kruskal-Wallis & 27.898 & 0.000 & & 3.556 & 0.736 \\
\multirow{2}{*}{ Variances } & Median & 18.013 & 0.012 & & 1.459 & 0.962 \\
& Levene & 3.903 & 0.000 & & 0.590 & 0.739 \\
& Brown-Forsythe & 5.564 & 0.000 & & 0.550 & 0.770 \\
\hline
\end{tabular}


experiment (05) is omitted, then the significance levels are very high, so the equality in variance and mean values can be supported between the rest of experiments.

a

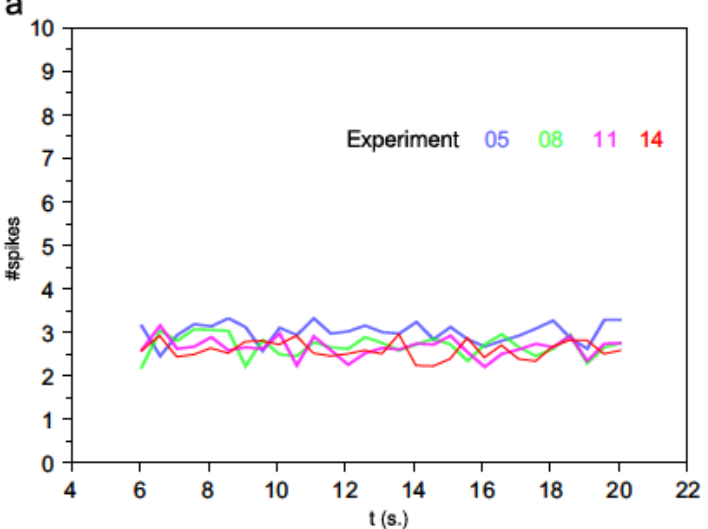

b

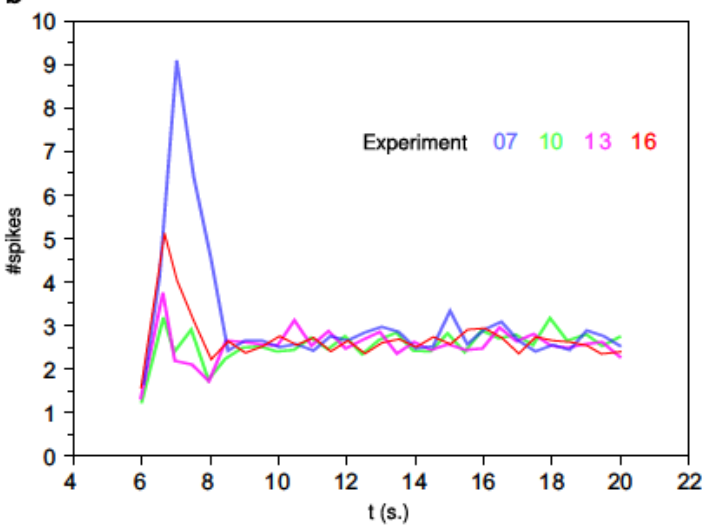

Fig. 3. Temporal evolution of average activity, in all channels in the MEA, starting just after stimulation phase: (a) for experiments without pulse trains (no stimulation) and (b) for experiments with stimulation

\subsection{Normalization}

Once we have established that there is a base level of spontaneous activity, that is independent of the previous stimulation history after some time enough to stabilize, and that this activity is not homogeneously distributed in the MEA, then we will normalize each channel based on its spontaneous activity in the stabilized period starting some time after the end of any stimulation (active or inactive). In Fig. 3, temporal evolution of mean activity starting just after stimulation phase is represented. Each curve is the moving average ( $500 \mathrm{~ms}$ window) of the activity in all channels in the MEA for each experiment. In upper part of Fig. 3 the results for experiments without pulse trains (no stimulation) is represented, while in the lower part shows the results for stimulated experiments. For the normalization purposes, we are interested to find a way to distinguish the flat part at the end of both cases from the high peak just after stimulation.

From Fig. 3, it is evident that there is a short period were the activity is increased due to stimulation, and then the culture returns to its usual spontaneous activity. In Fig. 4, mean values of activity for each channel in the experiments is represented. The channels were sorted from highest to lowest mean activity in the last $10 \mathrm{~s}$ of the first stimulated experiment (07). The mean activity using only the first $3 \mathrm{~s}$ just after the stimulus in stimulated experiments is represented in a graph separated from the mean using the last $10 \mathrm{~s}$, and also from the mean for the non-stimulated experiments.

We can use those averages to try a normalization for each channel in the MEA. Lets call $r_{i}$ to the mean value in rest for channel $i$. It can be measured in any rest period after some time enough elapsed from the last stimulus, given that our previous analysis does not show differences. And lets call $s_{i}$ to the corresponding standard deviations. From the previous statistical analysis, we can suppose that the rest state for a channel is characterized by $\left(r_{i}, s_{i}\right)$ and by the central limit theorem the data out of rest state would follow a normal distribution. So, the proposed normalized value of activity for channel $i$ is

$n_{i}(t) \frac{a_{i}(t)-r_{i}}{s_{i}}$,

where $a_{i}(t)$ is the activity (spike count) at time $t$ (window) for electrode $i$.

The proposed formula cannot be applied for a channel without spontaneous activity $\left(a_{i}(t)\right.$ is zero in rest, like channel " 15 " in our experiments), because $s_{i}$ (and $r_{i}$ ) would be null. In this case, the total standard deviation in rest for all the channels can be used instead of $s_{i}$

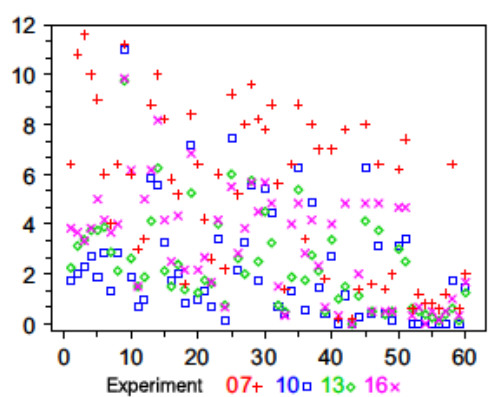

b

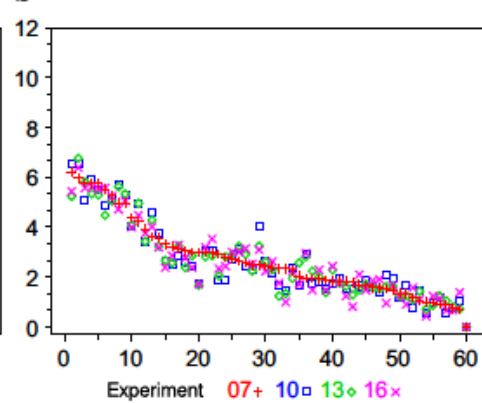

C

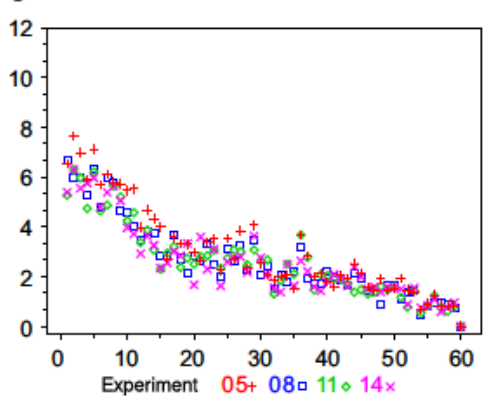

Fig. 4. Mean values of activity for each channel in the experiments. The channels were sorted from highest to lowest average activity in the last $10 \mathrm{~s}$ of experiment 07 (a) only during $3 \mathrm{~s}$ just after the stimulus in stimulated experiments, (b) only during the last $10 \mathrm{~s}$ in stimulated experiments, and (c) only during the last $10 \mathrm{~s}$ in the non-stimulated experiments. 
Estudio y realización de un neuroprocesador biológico: métodos de aprendizaje

We applied Eq. (1) to the data in our experiments. The mean values of normalized activity for each channel in the experiments are shown in Fig. 5 using the same channel ordering as in Fig. 4. As expected the graphs in the non-stimulated experiments and in the last $10 \mathrm{~s}$ of stimulated ones are now almost flat, but the mean normalized activity in the period just after stimulation remains significant for the responsive channels.
The results of normalization are also shown in Figs. 6, 7, 8, 9, and 10 , corresponding, respectively, to experiments $07,10,13$ and 16 with stimulation (last $15 \mathrm{~s}$ ), and one of the experiments without stimulation, $08(20 \mathrm{~s})$. Each figure is composed with the evolution in time of values for each channel in the same position as they are in the MEA. In each case, subfigure (a) represents the activity, $a_{i}(t)$, subfigure (b) represents the normalized activity, a

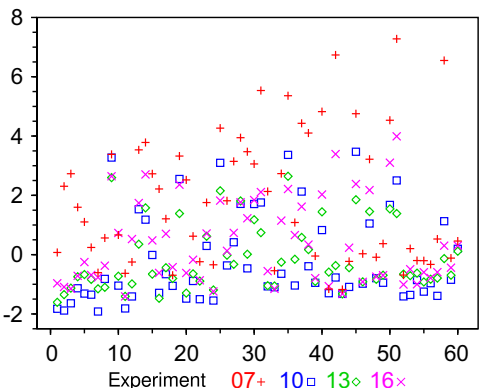

b

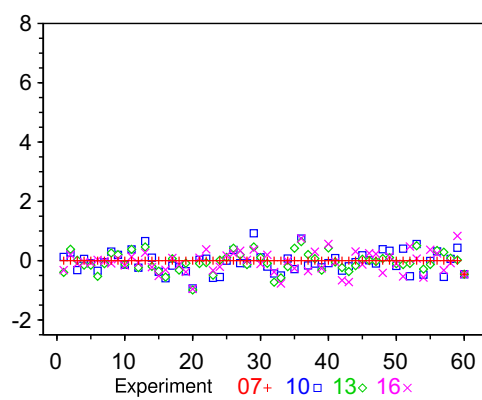

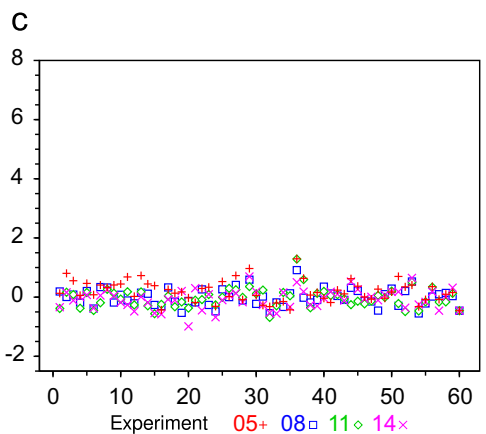

Fig. 5. Mean values of normalized activity for each channel in the experiments. The channels were sorted in the same way as in Fig. 4: (a) only during $3 \mathrm{~s}$ just after the stimulus in stimulated experiments, and (b) only during the last $10 \mathrm{~s}$ in stimulated experiments, (c) only during the last $10 \mathrm{~s}$ in the non-stimulated experiments.

a

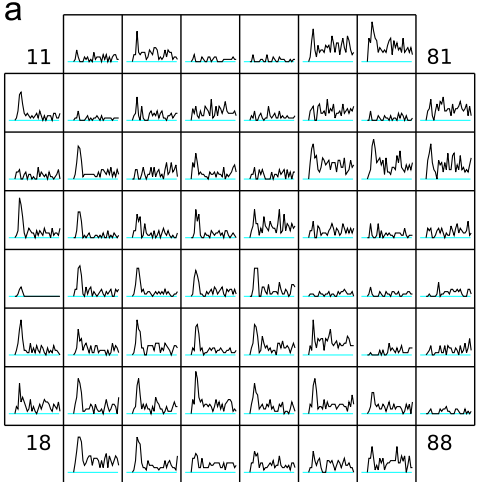

b

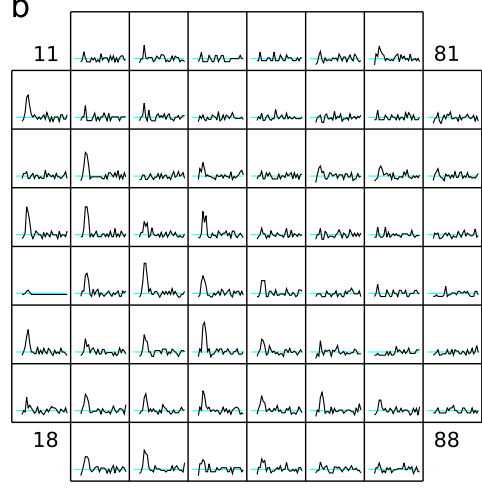

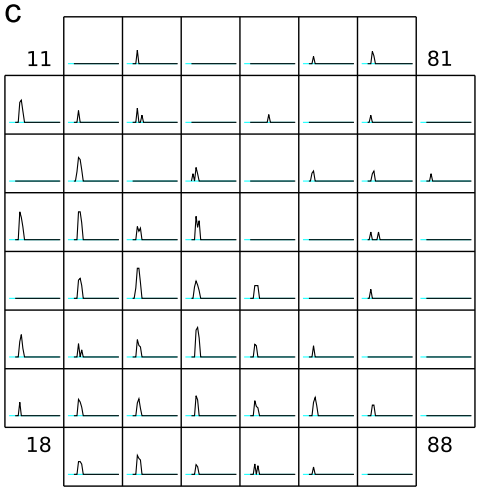

Fig. 6. Normalization of experiment 07 with stimulation: (a) activity, $a_{i}(t)$, (b) normalized activity, $n_{i}(t)$, and (c) normalized and filtered activity, $n_{i}(t) \geq 3$.

a

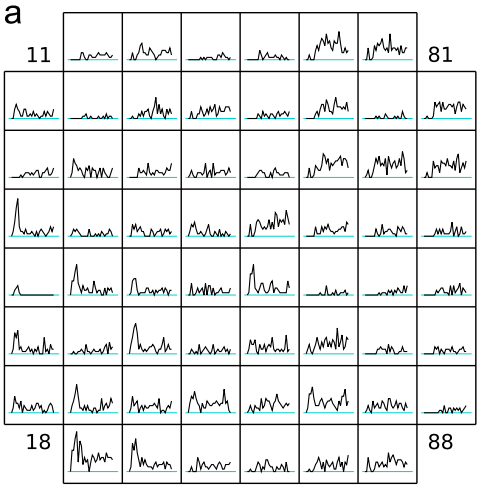

b

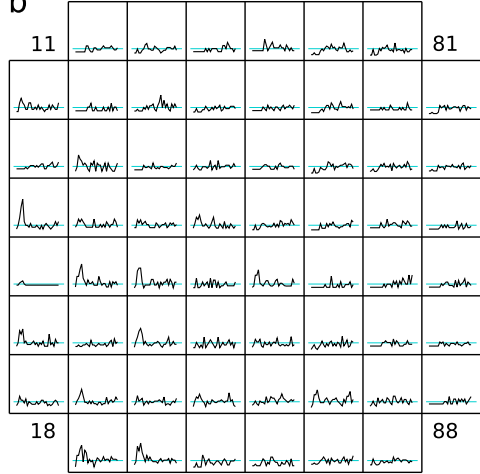

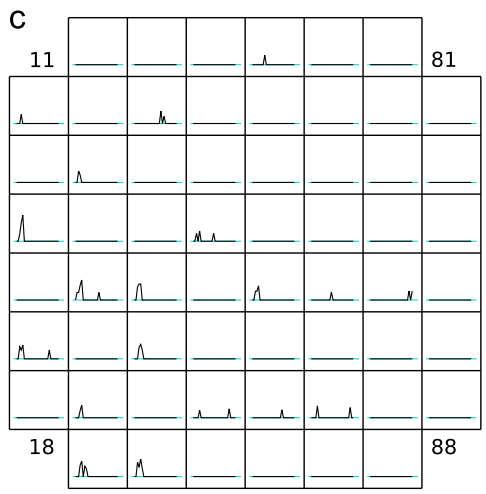

Fig. 7. Normalization of experiment 10 with stimulation: (a) activity, $a_{i}(t)$, (b) normalized activity, $n_{i}(t)$, and (c) normalized and filtered activity, $n_{i}(t) \geq 3$. 
Estudio y realización de un neuroprocesador
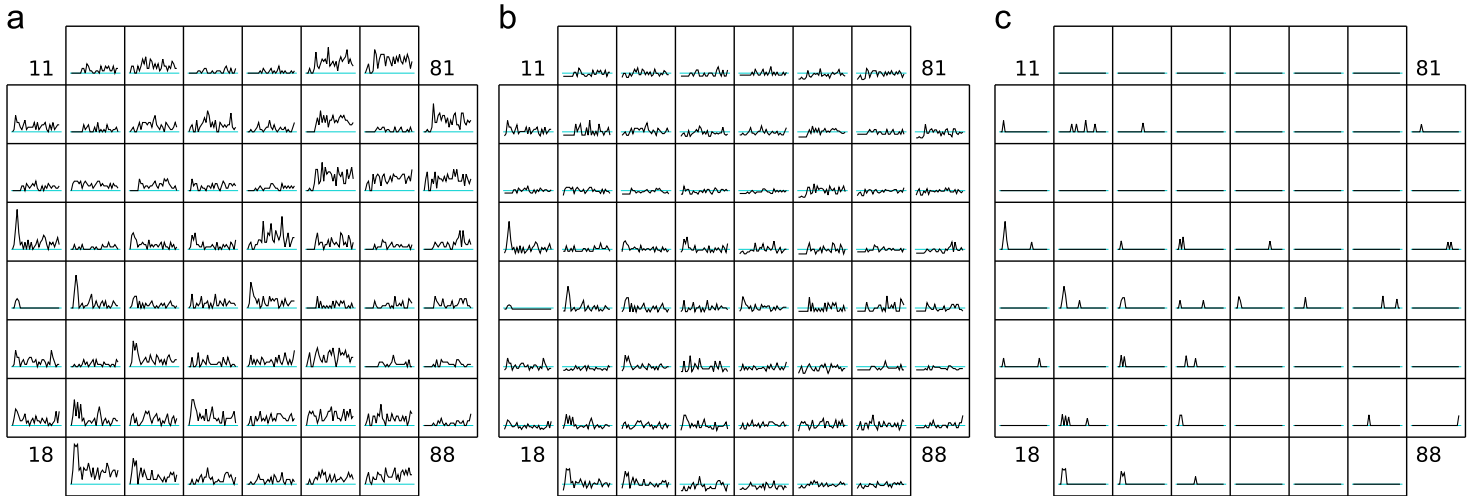

Fig. 8. Normalization of experiment 13 with stimulation: (a) activity, $a_{i}(t)$, (b) normalized activity, $n_{i}(t)$, and (c) normalized and filtered activity, $n_{i}(t) \geq 3$.

a

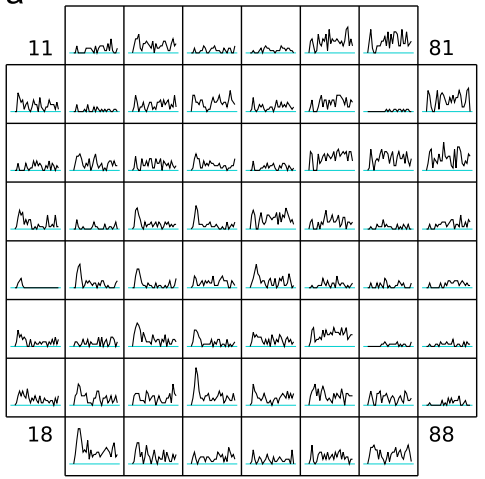

b

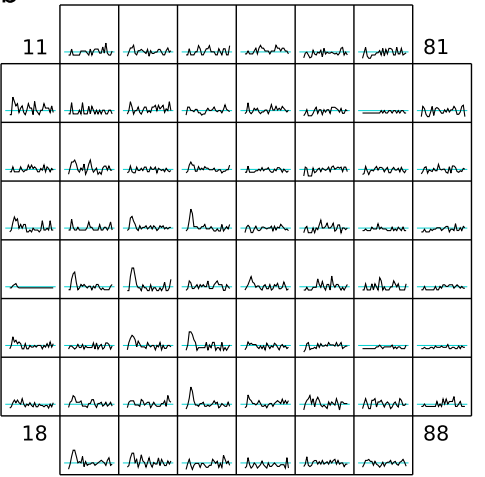

C

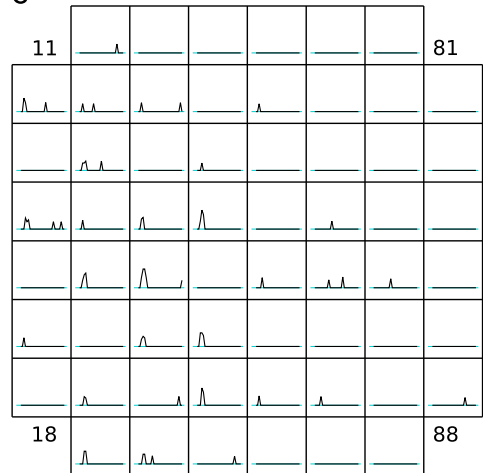

Fig. 9. Normalization of experiment 16 with stimulation: (a) activity, $a_{i}(t)$, (b) normalized activity, $n_{i}(t)$, and (c) normalized and filtered activity, $n_{i}(t) \geq 3$.

a

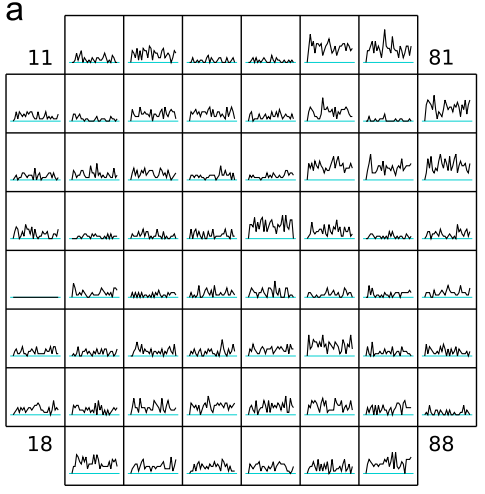

b

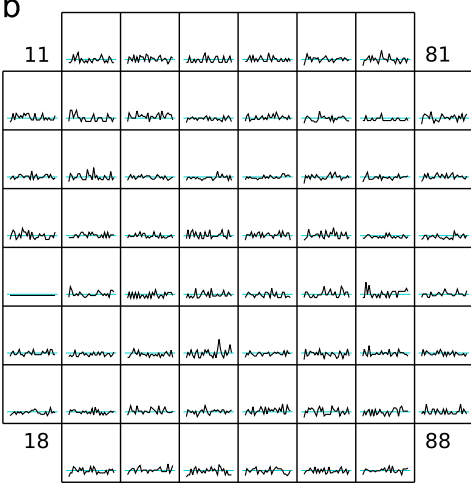

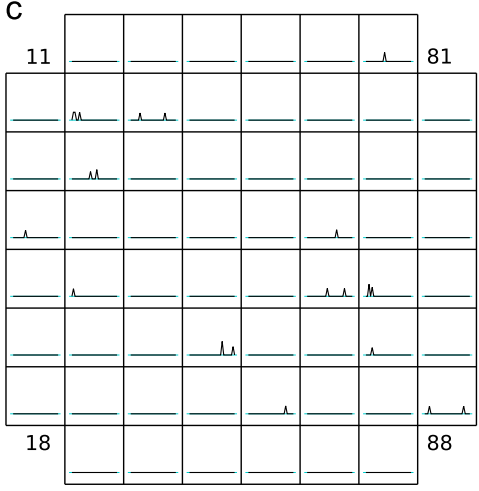

Fig. 10. Normalization of experiment 08 without stimulation: (a) activity, $a_{i}(t)$, (b) normalized activity, $n_{i}(t)$, and (c) normalized and filtered activity, $n_{i}(t) \geq 3$.

$n_{i}(t)$, and subfigure (c) represents only values $a_{i}(t) \geq r_{i}+3 s_{i}$, or equivalently $n_{i}(t) \geq 3$, to enhance the visualization of the channel response to stimulation. In these figures, we can distinguish that some channels are very active (noisy) but are not really responding to stimuli and, on the other hand, there are channels without spontaneous activity that respond to a stimulus. Also, there we can see some parts of the MEA are more active and responding to stimuli (lower-left half) and we can roughly identify them with some areas with higher density of cells (see Fig. 1a). 


\section{Conclusions and future work}

Human neuroblastoma cells cultures can be used for hybrid circuits, for example for controlling robots, but the signal/noise relation is very low, so each culture must be calibrated before a session to normalize the response of each channel. We have done an statistical analysis to asses the possibility of such normalization.

The results from the analysis support the existence of a base level of spontaneous activity that is independent of the previous stimulation history when time enough to stabilize has elapsed. Also the results support that the spontaneous activity is not homogeneously distributed in the MEA, as expected from culture characteristics, so the normalization must be done for each channel independently.

Based on the representative nature of mean spontaneous activity in rest and its corresponding standard deviation, a simple normalization process was proposed and tested with the experimental data. The results are coherent with the expected response in the culture. The normalization highlights clearly which channels have some spontaneous activity and are responding to stimulus and which channels are not responding to stimulus independently of their high or low spontaneous activity in rest.

In the process to obtain the data it was necessary to make some adjustments due to the difficulties found in recordings timing and in events identification (stimulation, rest, etc.) from the recordings. Also some of the experiments recordings were rejected for the same reason. To calibrate a culture before using it for hybrid system of control, some systematic process to synchronize and program the sequences of stimuli and recordings is needed. Also the computation of normalization for each channel must be automatic to allow comparisons of responses in different channels in the same session and to allow the detection and measurements of activities variations over different sessions (habituation, learning, etc.).

The development of a software application to allow that automatic processing is a future work being carried in our group. The objective is to build a program that allow the user to describe the test and calibration session with exact timing, by defining the stimulation type and sequence, and producing the corresponding recordings automatically. The program must receive the results from the measurements and compute the corresponding normalization values for each channel to be applied in the rest of the session.

Also we are expanding the statistical analysis line in our works to enhance spike detection and counting, to define a spatial distribution calibration in responses to stimulus, and to extract the maximum information available from measurements with the low signal/noise ratio found in neuroblastoma cultures.

\section{Acknowledgments}

This work was supported by the Spanish Government through Projects TIN2008-06893-C03, TEC2006-14186-C02-02 and SAF200803694, Cátedra Bidons Egara, Fundación Séneca 08788/PI/08, CIBER-BBN and by the European Commission through the project “NEUROPROBES” IST-027017.

\section{References}

[1] J.M. Ferrández, V. Lorente, F. de la Paz, J.M. Cuadra, J.R. Álvarez-Sánchez, E. Fernández, A biological neuroprocessor for robotic guidance using a center of area method, Neurocomputing 74 (8) (2011) 1229-1236. doi:10.1016/j. neucom.2010.07.018.

[2] J. Ferrández, V. Lorente, J. Cuadra, F. de la Paz, J. Álvarez-Sánchez, . Fernández, A hybrid robotic control system using neuroblastoma cultures, in: M. Graña Romay, E. Corchado, M.T. Garcia Sebastian (Eds.), Hybrid Artificial Intelligence Systems of 6076, Springer, 2010, pp. 245-253. doi:10.1007/978-3-642-13769-3 30
[3] D. Micol, Nev2lkit a preprocessor for intra- and extra-cellular neuronal recordings distributed under GPL, $2006<$ http://nev2lkit.source forge.net/>

[4] D.A. Wagenaar, J. Pine, S.M. Potter, An extremely rich repertoire of bursting patterns during the development of cortical cultures, BMC Neuro-science 7 (11) (2006). doi:10.1186/1471-2202-7-11.

[5] Multi Channel Systems MCS GmbH, MC Rack Tutorial: MEA Application Examples, 2010 〈http://www.multichannelsystems.com/uploads/media/ MC Rack Tutorial MEA Appl 05.pdf

[6] G. Canavos, Applied Probability and Statistical Methods, first ed., Little, Brown and Company, 1984.

[7] H. Levene, Robust tests for equality of variances, in: I. Olkin, S.G. Ghurye W. Hoeffding, W.G. Madow, H.B. Mann (Eds.), Contributions to Probability and Statistics, Vol. 2, Stanford University Press, 1960, pp. 278-292.

[8] M.B. Brown, A.B. Forsythe, Robust tests for equality of variances, Journal of the American Statistical Association 69 (346) (1974) 364-367.

[9] W.H. Kruskal, W.A. Wallis, Use of ranks in one-criterion variance analysis, Journal of the American Statistical Association 47 (260) (1952) 583-621 http://www.jstor.org/stable/2280779.

[10] G.W. Brown, A.M. Mood, On median tests for linear hypotheses, in: J. Neyman (Ed.), Proceedings of the Second Berkeley Symposium on Mathematical Statistics and Probability, University of California Press, 1951, pp. 159-166 http://projecteuclid.org/euclid.bsmsp/1200500226.

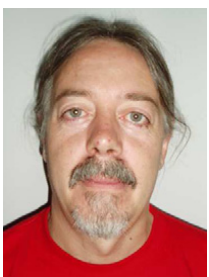

José Manuel Cuadra Troncoso received his B.Sc. and M.Sc. degrees in Mathematics (2000) from Univ. Nacional de Educación a Distancia, Spain, he is now working in his Ph.D. thesis. He is Assistant Professor a de Educación a Distancia, Spain. His main research interests include artificial neural networks and mobile robotics.

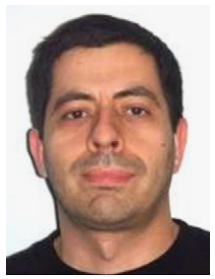

José Ramón Álvarez Sánchez received his B.Sc. and M.Sc. degrees in Physics (1988) from Univ. Complutense de Madrid, Spain, and his Ph.D. degree in Physics (1997) from Univ. Nacional de Educación a Distancia, Madrid, Spain. He is Associate Professor at the Artificial Intelligence Department of Univ. Nacional de Educación a Distancia, Spain. His main research interests (

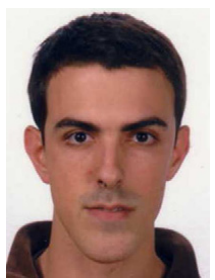
Daniel de Santos Sierra received his B.Sc. degrees in Madrid, Spain. He is M.Sc. student at the Artificial Intelligence Department of Univ. Nacional de Educación a Distancia, Spain. His main research interests include navigation and representation tasks in mobile robots.

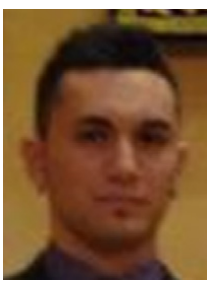

Víctor Lorente Sánchez received the Telecommunications degree from the Polytechnic University of Cartagena, Spain, in 2008 and the Master's Degree in Communications and Information Technology in 2009. He is currently studying towards his Ph.D. at the Polytechnic University of Cartagena. In the last years he has been studying the computing capabilities of human neuroblastoma cultured cells to define stimulation patters able to modulate the neural activity in response to external stimuli for controlling an autonomous robot. 


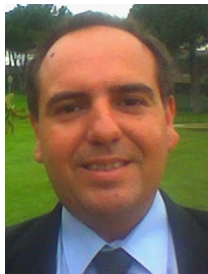

José Manuel Ferrández Vicente was born in Elche, Spain. He received the M.Sc. degree in Compute Science in 1995,and the Ph.D. degree in 1998, all of them from the Universidad Politécnica de Madrid, Spain. He is currently Associate Professor at the Department of Electronics, Computer Technology and Cartagena and Head of the Electronic Design and Signal Processing Research Group at the same University. He is the Coordinator of the Spanish and the Iberoamerica Network on Naturan and Artificial Computation. His research interests include bioinspired processing, neuromorphic engineering and low vision prosthesis.

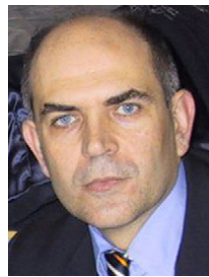

Eduardo Fernández Jover received the M.D. degre from the University of Alicante, Spain, in 1986 and the Ph.D. degree in Neurosciences in 1990. He is currently Associate Professor at the University Miguel Hernández, Spain, and Director of the Artificial Vision Laboratory at the Bioengneering Instute of the University Miguel Hernández, Spain. In the last years he has been using histological as well as electrophysiological techniques to understand how mammalian retinal cells and the circuitry within the retina can manage and code visual information. He is actively working on the development of a visual neuroprosthesis for the profoundly blind.

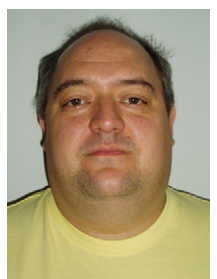

Félix de la Paz López received his B.Sc. and M.Sc. degrees in Physics (1995) from Univ. Complutense de Madrid, Spain, and his Ph.D. degree in Physics (2003) from Univ. Nacional de Educación a Distancia, Madrid, Spain. He is Associate Professor at the Artificial Intelligence Department of Univ. Nacional de Educacion a
Distancia, Spain. His main research interests include navigation and representation tasks in mobile robots. 


\title{
Training biological neural cultures: Towards Hebbian learning
}

\author{
J.M. Ferrández ${ }^{\text {a,b,*, V. Lorente }}{ }^{\text {b }}$, F. de la Paz ${ }^{c}$, E. Fernández ${ }^{a}$ \\ a Instituto de Bioingeniería, Universidad Miguel Hernández, Alicante, Spain \\ b Departamento de Electrónica, Tecnología de Computadores y Proyectos, Universidad Politécnica de Cartagena, Spain \\ c Departamento de Inteligencia Artificial, UNED, Spain
}

\section{A R T I C L E I N F O}

Available online 26 October 2012

Keywords:

Hebbian Law

Cultured neural network

Induced plasticity

Learning.

\begin{abstract}
A B S T R A C T
In this paper a bio-hybrid system based on neural cultured is described and the learning processes for programming this biological neuroprocessor are revised. Different authors proposed many different learning techniques for managing neural plasticity, however it is necessary to provide a formal methodology for verifying this induced plasticity and validating this bio-hybrid programming paradigm. We used low-frequency current stimulation on dissociated cultures of hippocampal cells to study how neuronal cultures could be trained with this kind of stimulation. We show that persistent and synchronous stimulation of adjacent electrodes may be used for creating adjacent physical or logical connections in the connectivity graph following Hebb's Law.
\end{abstract}

(c) 2012 Elsevier B.V. All rights reserved.

\section{Introduction}

Using biological nervous systems as conventional computer elements is a fascinating problem that permits the hybridization between neuroscience and computer science. This synergic approach can provide a deeper understanding of natural perception and may be used for the design of new computing devices based on natural computational paradigms. Classical computational paradigms consist of serial and supervised processing computations with high-frequency clocks silicon processors, with moderate power consumption, and fixed circuits structure. However the brain uses millions of biological processors, with dynamic structure, slow commutations compared with silicon circuits, low power consumption and unsupervised learning. This kind of computation is more related to perceptual recognition, due to the natural variance of the perceptive patterns and the a priori lack of knowledge about the perceptual domain.

A wetware computer may be built from leech neurons, capable of performing simple arithmetic operations and simple pattern recognition tasks. Another wetware computation is based on cellular cultures. Cells could be neurons from dissociated hippocampus or cortical tissue, or even neuroblastoma cells. Some problems to solve within this subgroup are: What are the requirements for wetware computations? Which are the new programming paradigms or learning techniques for wetware computing? What are the methods for validating learning in neural cultures?

In this paper a bio-hybrid system based on neural cultured is described and the learning processes for programming this

\footnotetext{
* Corresponding author at: Instituto de Bioingeniería, Universidad Migue Hernández, Alicante, Spain. Tel.: + 3496832 6516; fax: + 34068326400. E-mail address: jm.ferrandez@upct.es (J.M. Ferrández).
}

0925-2312/\$ - see front matter $\odot 2012$ Elsevier B.V. All rights reserved. http://dx.doi.org/10.1016/j.neucom.2012.09.031 biological neuroprocessor are revised. Different authors proposed many different learning techniques for managing neural plasticity; however it is necessary to provide a formal methodology for verifying this induced plasticity and validating this bio-hybrid programming paradigm. We used low-frequency current stimulation on dissociated cultures of hippocampal cells to study how neuronal cultures could be trained with this kind of stimulation. We show that persistent and synchronous stimulation of adjacent electrodes may be used for creating adjacent physical or logical connections in the connectivity graph following the Hebb's Law.

\section{Learning in neural cultures}

Hippocampal cells are dissociated from the brains of embryonic rats and seeding onto planar Multi-Electrode Arrays (MEAs). The MEA is filled with a conventional cell culture medium containing nutrients, growth hormones and antibiotics, which is replaced weekly. Within the first hour after seeding, neurons start to extend connections no nearby cells and, within $24 \mathrm{~h}$, a thick layer of neuronal extensions is visible across the seeded area. The connectivity between seeded cells increases rapidly over subsequent days. After a week, electrophysiological spontaneous activity is observed in form of actions potentials, which transform into dense bursts of simultaneous electrical activity across the entire network over the following week. This bursting activity continues through the maturation phase (towards 20 days in vitro).

Cultures usually remain active until 40 days approximately, but they may be active until 3 months of age if they are maintain in proper conditions (e.g. with Potter rings). During this period they are maintained in a humidified, $37{ }^{\circ} \mathrm{C}, 5 \% \mathrm{CO}_{2}$ incubator to preserve its electrophysiological properties. 
Table 1

Overview of studies on changes in network activity by electrical stimulation. Tetani are trains of stimuli. A volley is like a train in which a different electrode is stimulated with each pulse.

\begin{tabular}{|c|c|c|c|c|}
\hline Study & $\begin{array}{l}\text { Number of } \\
\text { electrons }\end{array}$ & Stimulation parameters & Evaluated aspect & Effect \\
\hline $\begin{array}{l}\text { Maeda et al. } \\
\text { (1998)[1] }\end{array}$ & 5 & $\begin{array}{l}\text { Tetani: }(20 \times, 20 \mathrm{~Hz} \text {; ITI } 10-15 \mathrm{~s}) \\
5-10 \times\end{array}$ & $\begin{array}{l}\text { Burst rate and size, spontaneous and } \\
\text { induced by test stimuli. }\end{array}$ & $\begin{array}{l}\text { Increase in burst rate and spikes per } \\
\text { burst. Both spontaneous and as } \\
\text { induced by test stimuli. }\end{array}$ \\
\hline $\begin{array}{l}\text { Jimbo et al. } \\
\text { (1998) [2] }\end{array}$ & 1 or 8 & Tetani: $(11 \times, 20 \mathrm{~Hz}$; ITI $5 \mathrm{~s}) 10 \times$ & Cell voltage & Increase in EPSC currents. \\
\hline $\begin{array}{l}\text { Jimbo et al. } \\
\text { (1999) [3] }\end{array}$ & 1 & Tetani: $(11 \times, 20 \mathrm{~Hz}$; ITI $5 \mathrm{~s}) 10 \times$ & $\begin{array}{l}\text { Number and timing of spikes induced } \\
\text { per neuron in response to test stimuli. }\end{array}$ & $\begin{array}{l}\text { Increase or decrease of EPSC's and } \\
\text { number of induced spikes depending } \\
\text { on pathway. }\end{array}$ \\
\hline $\begin{array}{r}\text { Tateno et al. } \\
\text { (1999) [3] }\end{array}$ & 1 or 2 & $100 \mu$ s pulses & $\begin{array}{l}\text { Reliability of action potentials after } \\
\text { test stimuli, time between test stimuli } \\
\text { and first spike. }\end{array}$ & $\begin{array}{l}\text { Shortening of latency and reduction } \\
\text { of jitter of first spike in some } \\
\text { neurons. Increase of effect from } 1 \text { to } \\
2 \text { electrodes. }\end{array}$ \\
\hline $\begin{array}{r}\text { Shahaf et al. } \\
\text { (2001) [5] }\end{array}$ & 2 & $\begin{array}{l}\text { Bipolar stimulation, ISI } 1-3 \mathrm{~s} \text { until } \\
\text { desired response, } 10 \mathrm{~min} \text { max. }\end{array}$ & $\begin{array}{l}\text { Increase in number of spikes on } \\
1 \text { evaluation electrode. }\end{array}$ & $\begin{array}{l}\text { Increase in spikes induced in } \\
\text { window. }\end{array}$ \\
\hline $\begin{array}{l}\text { Ruaro et al. } \\
\text { (2005) [6] }\end{array}$ & 15 & Tetani: $(100 \times, 250 \mathrm{~Hz}$, ITI $2 \mathrm{~s}) 40 \times$ & Responses to test stimuli. & $\begin{array}{l}\text { Increase inset FR between } 1 \text { and } \\
50 \mathrm{~ms} \text {. }\end{array}$ \\
\hline $\begin{array}{l}\text { Wagenaar et al. } \\
\text { (2006) [7] }\end{array}$ & 2 & $\begin{array}{l}\text { Tetani: } 20 \times, 20 \mathrm{~Hz} \text {; ITI } 6 \mathrm{~s}, 150 \times \text {, } \\
\text { shift } 5 \mathrm{~ms}\end{array}$ & $\begin{array}{l}\text { Responses to test stimuli, } 10-50 \mathrm{~ms} \text {. } \\
\text { after test stimuli. }\end{array}$ & $\begin{array}{l}\text { Increase in number of spikes induced } \\
\text { by leading electrode; decrease for } \\
\text { following electrode. }\end{array}$ \\
\hline $\begin{array}{l}\text { Madhavan et al. } \\
\text { (2007) [8] }\end{array}$ & 2 & $\begin{array}{l}\text { Tetani: } 18,000 \times, 20 \mathrm{~Hz}(15 \mathrm{~min}) \text {, } \\
\text { shift } 10 \mathrm{~ms}\end{array}$ & $\begin{array}{l}\text { Spontaneous expression rate of burst } \\
\text { types (BT). }\end{array}$ & $\begin{array}{l}\text { Generation of new BTs, increase or } \\
\text { decrease in expression rate of BTs. }\end{array}$ \\
\hline $\begin{array}{l}\text { Chao et al. (2007) } \\
\text { [9] }\end{array}$ & 2 & $\begin{array}{l}\text { Tetani: } 18,000 \times, 20 \mathrm{~Hz}(15 \mathrm{~min}) \text {, } \\
\text { shift } 10 \mathrm{~ms}\end{array}$ & $\begin{array}{l}\text { Center of Activity Trajectory (CAT) of } \\
\text { evoked activity. }\end{array}$ & $\begin{array}{l}\text { CAT's change significantly on some } \\
\text { of the test electrodes. }\end{array}$ \\
\hline $\begin{array}{l}\text { Brewer et al. } \\
\text { (2010) [10] }\end{array}$ & 30 & $\begin{array}{l}\text { Biphasic paired pulses, 50ms ISI, } 5 \mathrm{~s} \\
\text { ITI, } 0-3 \mathrm{~h} 30 \mu \mathrm{A}, 100 \mu \mathrm{s} \text { phase }\end{array}$ & Evoked responses, spike activity. & $\begin{array}{l}\text { Increase of evoked responses and in } \\
\text { spike frequency. }\end{array}$ \\
\hline $\begin{array}{l}\text { Martinoia et al. } \\
\text { (2010) [11] }\end{array}$ & 8 & $\begin{array}{l}\text { Biphasic pulse } 36 \times, 0.2 \mathrm{~Hz} \\
\text { sequentially to each electrode, } \\
200 \mu \mathrm{s} / \text { phase, } 1.5 \mathrm{Vpp}\end{array}$ & Spontaneous firing rate, burst rate. & $\begin{array}{l}\text { Stimulation significantly changes the } \\
\text { mean firing rate of the networks. }\end{array}$ \\
\hline
\end{tabular}

The first studies demonstrating functional plasticity in cultured networks began 1990s. The research group of Akio Kawana at NTT in Japan reported that tetanic stimulation through one or several electrodes resulted in plasticity [1]. They observed a change in the probability of evoking bursts by test pulses, as well as a change in the rate of spontaneous bursting, as a result of repeated evoking bursts using strong tetanic stimulation. Jimbo et al. reported similar results with a different tetanic stimulation and used voltage clamp to observe inward currents associated with evoked bursts [2]. The following year, Jimbo et al. reported that tetanizing a single electrode resulted in changes in the responses to test pulses to other electrodes [3]. The responses along the culture to a particular stimulation electrode were either all up-regulated or all down-regulated, a phenomenon they called 'pathway-dependent plasticity'. Individual responses throughout the array to stimuli on one particular electrode or pathways were upregulated or down-regulated depending on the correlation between responses to stimuli applied to the test electrode and to the tetanization electrode. In another paper, Jimbo et al. used simultaneous tetanization through a pair of electrodes to induce more precise forms of plasticity, expressed in detailed spike patterns evoked by electrical (probe) pulses [4]. Since then, a few other groups have reported on other forms of plasticity in MEA neural cultures.

Typically, these later papers have focused on more abstract plasticity results, more related to the network level than to the synaptic level. For instance, Shahaf and Marom reported that networks could learn to respond in specific ways to test pulses, by repeated stimulating until the desired response was obtained [5], while Ruaro et al. reported that cultured networks could learn to extract a specific pattern from a complex image that had been presented repeatedly as spatial patterns of multi-electrode stimulation [6].
In the following years, researchers have tried using more complex stimulation patterns in order to induce plasticity in neural cultures. Wagenaar et al. [7] looked for plasticity expressed in changes in spontaneous burst patterns, and in array-wide response patterns to electrical stimuli, following several induction protocols related to the previous ones, as well as some novel ones. Madhavan et al. [8] investigated patterns of spontaneous multisingle-unit activity to study the potential role of bursts of action potentials in memory mechanisms. Their analysis revealed spatio-temporal diverse bursts occurring in well-defined patterns, which remained stable for several hours. Chao et al. [9] compared five established statistical methods to one of their own design, called Center of Activity Trajectory (CAT), to quantify functional plasticity at the network level. Stegenga studied the possibility of changing the spatio-temporal structure of spontaneous bursts using different configurations of tetanic stimulation. They obtained a profile of the array-wide spiking rate, a burst profile (BP) and also calculated the per-electrode spiking rate profile, the phase profiles (PPs). None of their stimulation methods had a measurable effect on of the specific burst statistics (peak firing rate, rise and fall times). However, they found many PP changes in their experiments, which can be seen as a confirmation that the analysis is sensitive to changes in the network.

Other researchers have focused in changing some stimulation parameters (voltage vs. current, frequency, amplitude...) to achieve learning. Brewer et al. [10] used chronic stimulation for getting an increase in evoked spike counts per stimulus and in spiking rate. The results obtained suggested that plastic network changes induced by chronic stimulation enhance the reliability of information transmission and the efficiency of multi-synaptic network communication. In turn, Martinoia et al. [11] applied low-frequency stimulation constantly over weeks. They found that the stimulation had a delayed effect modulating response 
capability of the network without directly affecting its intrinsic in vitro development. Table 1 summarizes an overview of these protocols and the principal results achieved by each of the abovementioned studies on neural cultures.

\section{A methodology for learning validation in neural cultures}

Learning validation in Artificial Neural Networks is usually achieved by computing the learning curve that is the error produced by the network during the learning phase. This curve needs to converge below a global minimum over certain number of epochs, avoiding local minimum in order to validate the learning process. A typical learning curve shows the number of stimuli required to evoke the desired response in every stimulation cycle. When learning is achieved, the learning curve is stabilized below the convergence criterion indicating that the desired response is elicited with a less number of stimuli. Fixing this convergence criterion is critical for avoiding overlearning and providing generalization. We propose the following methodology:

1) Impose a learning paradigm over the neural culture until a convergence criteria is reached.

2) Check that the network has impressed the desired function over its functional structure and this change is persistent.

3) Validate that the temporal $n$-responses from the individual neurons change from the initial spontaneous firing to a controlled temporal firing pattern induced by the functional connections.

The first step is necessary for the cells behavior programming, while the second one is essential for analyzing the subjacent neural structure and checking that from an original and random connectivity matrix, a controlled and desired stabilized matrix is reached. The third step is related with the functional response of aisle cells to the provided stimuli. Initially, each neuron has a temporal spiking response elicit by the provided stimulation. The whole network has unique and original $n$-temporal responses to the stimuli. For validating the modified structure in the network, a contrasted change in the $n$-temporal unit responses is also required. These changes capture the induced connectivity matrix observed in the prior procedure.

\subsection{Functional connectivity}

Functional connectivity [12,13] captures patterns of deviation from statistical independence between distributed neurons units, measuring their correlation/covariance, spectral coherence or phase locking. Functional connectivity is often evaluated among all the elements of a system, regardless whether these elements are connected by direct structural links; moreover, it is highly time-dependent (hundreds of milliseconds) and model-free, and it measures statistical interdependence (e.g. mutual information) without explicit reference to causal effects.

Correlation and information theory-based methods are used to estimate the functional connectivity of in vitro neural networks: Cross-correlation, Mutual Information, Transfer Entropy and Joint Entropy. Such methods need to be applied to each possible pai of electrodes, which shows spontaneous electrophysiological activity. For each pair of neurons, the connectivity method provides an estimation of the connection strength (one for each direction). The connection strength is supposed to be proportional to the value yielded by the method. Thus, each method is associated to a matrix, the Connectivity Matrix (CM), whose elements $(X, Y)$ correspond to the estimated connection strength between neuron $X$ and $Y$.

High and low values in the CM are expected to correspond to strong and weak connections. By using such approach, inhibitory connections could not be detected because they would be mixed with small connection values. However, non-zero $\mathrm{CM}$ values were also obtained when no apparent causal effects were evident, or no direct connections were present among the considered neurons.

In our experiments Connectivity maps (Fig. 1) offered a visualization of the connectivity changes that occur in the culture. Connectivity maps were generated using the connectivity matrix (CM) obtained after applying the analysis and Cross-Correlation or Mutual Information. By setting thresholds in the CM (Fig. 1 right), it is possible to filter out some small values that may correspond to noise or very weak connections. In consequence, these maps show the strongest synaptic pathways, and can be used for visualizing the neural weights dynamics, and validate the achieved learning.

\subsection{Post-stimulus time histogram (PSTH) and potentiation} index $(P I)$

To investigate the neuronal activity evoked by stimulation, the PSTH needs also to be computed. It represents the impulse response of each site of the experimental preparation to the electrical stimulation. The PSTH is calculated by considering time windows from the recordings that follow each stimulus. Each time window is divided into bins and then counted the number of spikes occurring in each time bin. Finally, the histogram obtained is normalized dividing the computed number of spikes by the number of stimuli times the bin size. Fig. 2 shows the PSTH of the overall units from one of our experiments. In this case, an early response to a test stimulus is obtained in some neurons, while others have a delayed response according with their intrinsic connectivity.
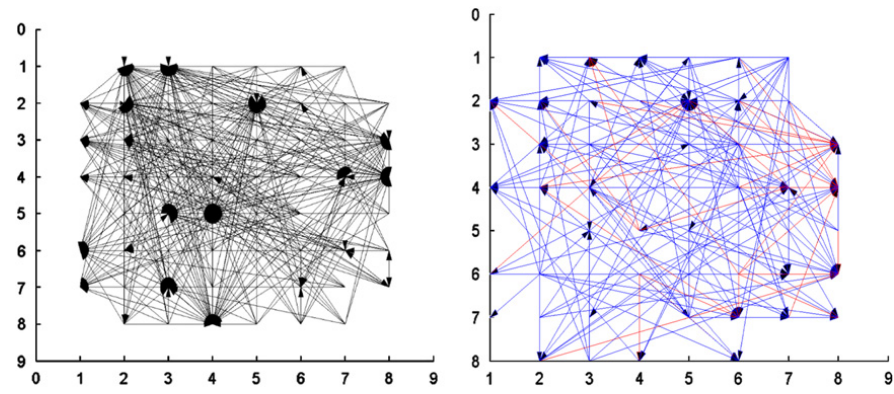

Fig. 1. Initial and final connectivity maps with thresholds. 


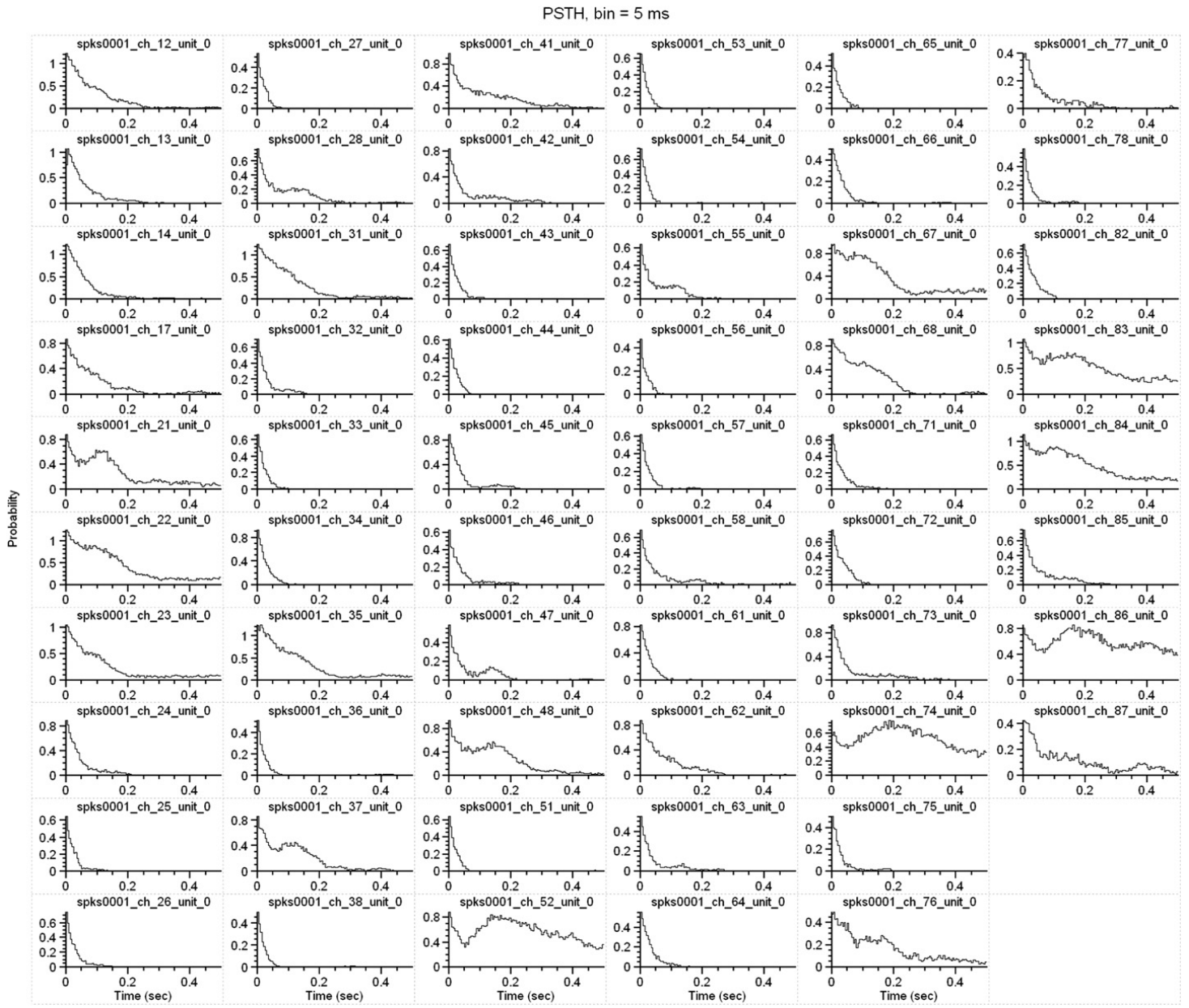

Fig. 2. PSTH with $5 \mathrm{~ms}$ bins. An early response to the stimuli is observed in some units.

If an electrode presented a PSTH with an area below '1', that channel must be eliminated from the statistics because it is considered to be inactive (i.e. not able to evoke a minimal response to stimulation).

One of the problems in dealing with multi-unit extracellular recordings is to give a clear definition of 'potentiation' at a specific recording site. A long-term change in the excitatory post-synaptic potential amplitude (usually recognized as the evident sign that a change in connectivity has occurred) must produce a change also in the evoked firing rate or in the number of evoked spikes in a single or in a group of cells. Thus, to check if a stimulus was able to induce potentiation, a parameter, potentiation index (PI), related to changes in the PSTH area (i.e. number of evoked spikes) for each recording channel in two experimental conditions: pre- and post-stimulus is used. A 'potentiated response' means an increase of the PSTH area (given as a percentage) to a value equal or higher than a settled threshold. In this way, we are able to ensure as significant, only those changes actually due to the application of the stimulation and not to the spontaneous fluctuations of the activity level. The PI was simply calculated as the ratio between the number of electrodes belonging to the stimulating session $\mathrm{S} \rightarrow \mathrm{A}$ presenting a change of the PSTH area above the threshold and the total number of active electrodes in the same session. For validating the learning the Potentiation index must exceed a threshold defined using the culture physiologic response.

\section{Hebbian learning in neural cultures}

Hebbian learning describes a basic mechanism for synaptic plasticity wherein an increase in synaptic efficacy arises from the presynaptic cell's repeated and persistent stimulation of the postsynaptic cell. The theory is commonly evoked to explain some types of associative learning in which simultaneous activation of cells leads to pronounced increases in synaptic strength. Basically the efficiency of a synaptic connection is increased when presynaptic activity is synchronous with post-synaptic activity. In this work we use this kind of stimulation, synchronous stimulation of a pair of electrodes, to create adjacent physical or logical connections in the connectivity graphs using Hebb's Law. 


\subsection{Experimental protocol}

Previously, two pairs of electrodes with no logical connections between them were selected using connectivity diagrams based on cross-correlation as explained in previous section. In every stimulation session these steps were followed:

1 Spontaneous activity was recorded for 2 min after a recovery period.

2 Cultures were then stimulated through the two pairs of electrodes. A train of 5 biphasic pulses cathodic-first $(50 \mu \mathrm{A}$ peak, $100 \mu$ s phase, $50 \mathrm{~ms}$ ISI) was delivered every $3 \mathrm{~s}$ for $10 \mathrm{~min}$.

3 Spontaneous activity was recorded for 2 min after the stimulation.

\subsection{Analysis performed}

We observed the spontaneous activity of the cultures before and after the stimulation experiments, as well as their evoked response to the applied stimulus. Extensive burst analysis, post-stimulus time histograms and connectivity diagrams based on cross-correlation between electrodes were the main analysis performed to the registered data (Fig. 3). The physiological function of neural cells is modulated by the underlying mechanisms of adaptation and reconfiguration in response to neural activity.

\subsection{Validation}

The number of bursts and spikes per burst increased in some electrodes after stimulation. Also, the responsiveness of the network was enhanced, reducing its response latency to the stimulus.

Connectivity diagrams based on cross-correlation between electrodes showed some kind of reorganization of connections after stimulations, concentrating them in a few electrodes. Furthermore, adjacent physical or logical connections in the connectivity graph following the Hebb's law appeared in some pairs of stimulated electrodes (Fig. 4). In some cases, the connection was intermittent, lasting one to several days. In others, a

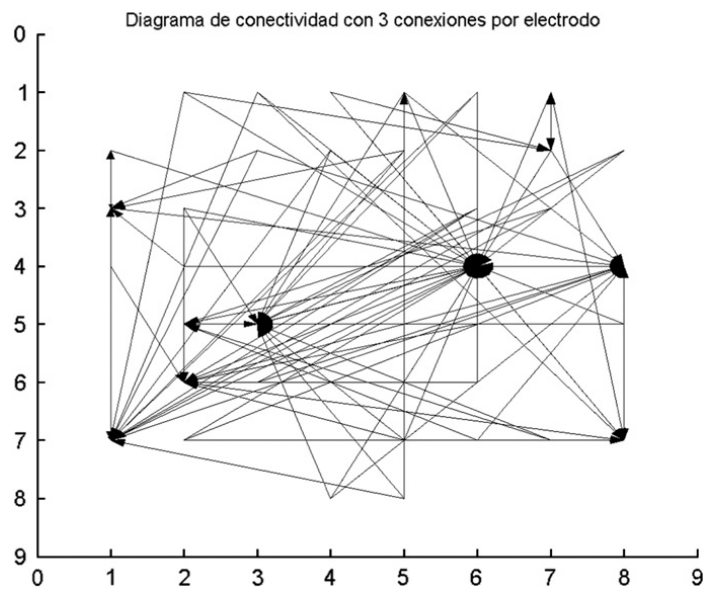

Fig. 3. Connectivity graph based on cross-correlation between electrodes befor stimulation. Electrodes $14,25,83$ and 84 were stimulated. No logical connections were observed before stimulation.

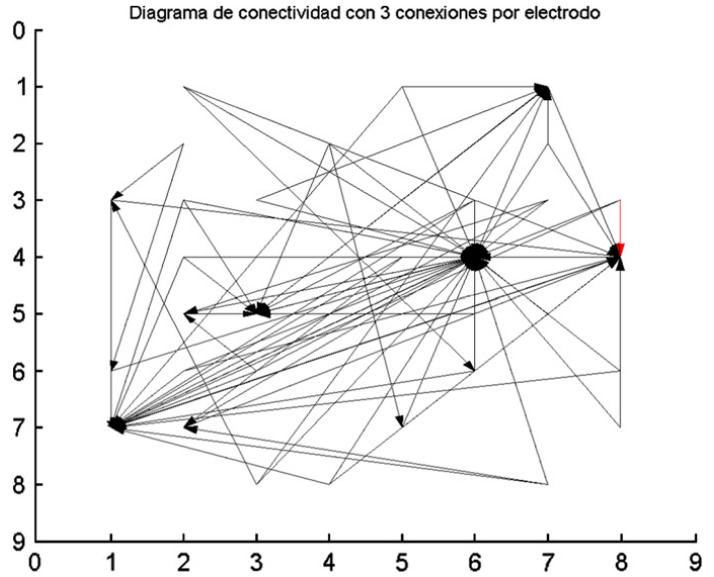

Fig. 4. Connectivity graph based on cross-correlation between electrodes. A connection (red arrow) between electrodes 83 and 84 has appeared. (For interpretation of the reference to color in this figure, the reader is referred to the web version of this article.)

persistent connection was created. Finally, some cultures did not create any kind of connections. In this way, the Hebbian tetanization created ad-hoc permanent or transient logical connections by modifying the efficiency of the paths between the selected electrodes. We speculate that the failed cultures may be caused by a not-homogeneous culture growth between the electrodes or by the neurobiological properties of the connections as will be confirmed using histological techniques in future works.

\section{Conclusions}

Learning in biological neural cultures is a complex task Different authors have proposed different methods for inducing a desired and controlled plasticity over the biological neural structure. For normalizing the heterogeneity of these learning procedures it is necessary to propose a formal methodology for validating the achieved learning.

In addition to the learning curve for determining the convergence criterion it is necessary to visualize the initial connectivity matrix, and the final neural connections for checking that the network has impress the desired function over its functional structure. It is also essential that the temporal $n$-responses from the individual neurons change from the initial spontaneous firing to a controlled temporal firing pattern induced by the functional connections. Validating the temporal stability of the network, how last the induced functional structure, or determining the plasticity required for normal operation are still open question that need to be addressed for using neural cultures as bio-hybrid computing elements.

Persistent and synchronous stimulation of relevant adjacent electrodes may be used for strengthening the efficiency of their connectivity graph. These processes may be used for imposing a desired behavior over the network dynamics. In this work a stimulation procedure is described in order to achieve the desired plasticity over the neural cultures, and shaping in this way the functional connectivity of the neural culture. In future works these induced connections will be used for driving a robot using Braitenberg's principles. 
Estudio y realización de un neuroprocesador biológico: métodos de aprendizaje

\section{Acknowledgments}

This work is being funded by grant 12361/FPI/09 from the Séneca Foundation, Science and Technology Agency from the region of Murcia and by the project 2010 V/PUNED/0011 from the Universidad Nacional de Educación a Distancia.

\section{References}

[1] E. Maeda, Y. Kuroda, H.P. Robinson, A. Kawana, Modification of parallel activity elicited by propagating bursts in developing networks of rat cortical neurones, Eur. J. Neurosci. 10 (2) (1998) 488-496.

[2] Y. Jimbo, H.P. Robinson, A. Kawana, Strengthening of synchronized activity by tetanic stimulation in cortical cultures: application of planar electrode arrays, IEEE Trans. Biomed. Eng. 45 (11) (1998) 1297-1304.

[3] Y. Jimbo, T. Tateno, H.P.C. Robinson, Simultaneous induction of pathway specific potetiation and depression in networks of cortical neurons, Biophys. J. 76 (2) (1999) 670-678

[4] T. Tateno, Y. Jimbo, Activity-dependent enhancement in the reliability of correlated spike timings in cultured cortical neurons, Biol. Cybern. 80 (1) (1999) 45-55.

[5] G. Shahaf, S. Marom, Learning in networks of cortical neurons, J. Neurosci. 21 (22) (2001) 8782-8788.

[6] M.E. Ruaro, P. Bonifazi, V. Torre, Toward the neurocomputer: image processing and pattern recognition with neuronal cultures, IEEE Trans. Biomed. Eng. 52 (3) (2005) 371-383.

[7] D.A. Wagenaar, J. Pine, S.M. Potter, Searching for plasticity in dissociated cortical cultures on multi-electrode arrays, J. negative results in Biomed. 5 (2006) 16.

[8] R. Madhavan, Z.C. Chao, S.M. Potter, Plasticity of recurring spatiotemporal activity patterns in cortical networks, Phys. Biol. 4 (3) (2007) 181-193.

[9] Z.C. Chao, D.J. Bakkum, S.M. Potter, Region-specific network plasticity in simulated and living cortical networks: comparison of the center of activity trajectory (CAT) with other statistics, J. Neural. Eng. 4 (3) (2007) 294-308.

[10] A.N. Ide, A. Andruska, M. Boehler, B.C. Wheeler, G.J. Brewer, Chronic network timulation enhances evoked action potentials, J Neural Eng. 7 (1) (2010)

[11] L.L. Bologna, T. Nieus, M. Tedesco, M. Chiappalone, F. Benfenati, S. Martinoia, Low-frequency stimulation enhances burst activity in cortical cultures during (2010)692-704.

[12] O. Sporns, G. Tononi, Classes of network connectivity and dynamics, Com-

[13] K.J. Friston, C. Frith, R. Frackowiak, Time-dependent changes in effective connectivity measured with PET, Hum. Brain Mapp. 1 (1993) 69-79.

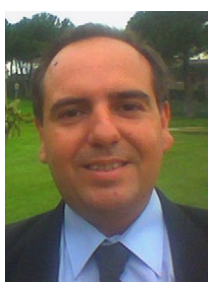

osé Manuel Ferrández Vicente was born in Elche, Spain. He received the M.Sc. degree in Computer Science in 1995,and the Ph.D. degree in 1998, all of them from the Universidad Politécnica de Madrid, Spain. He is currently Associate Professor at the Department of Electronics, Computer Technology and Projects at the Universidad Politécnica de Cartagena, Head of the Electronic Design and Signal Processing Research Group, and Internationalization Vice-rector at the same University. He is the coordinator of the Spanish and the Iberoamerican Network on Natural and Artificial Computation. His research interests include bioinspired processing, neuromorphic engineering and low vision prosthesis.

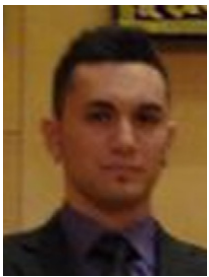

Víctor Lorente Sánchez received the Telecommunications degree from the Polytechnic University of Cartagena, Spain, in 2008 and the Masters Degree in Communications and Information Technology in 2009. $\mathrm{He}$ is currently studying towards his $\mathrm{PhD}$ at the Polytechic University of Cartagena. In the last years he has been studying the computing capabilities of human neuroblastoma cultured cells to define stimulation patters able to modulate the neural activity in response to external stimuli for controlling an autonomous robot.

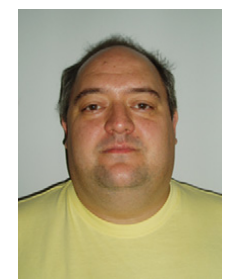

Félix de la Paz López received his B.Sc and M.Sc degrees in Physics (1995) from Univ. Complutense de Madrid, Spain, and his Ph.D degree in Physics (2003) from Univ. Nacional de Educación a Distancia, Madrid, Spain. He is associate professor at the Artificial Intelligence Department of Univ. Nacional de Educación a Dista

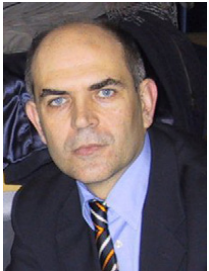

Eduardo Fernández Jover received the M.D. degree from the University of Alicante, Spain, in 1986 and the Ph.D. degree in Neurosciences in 1990 . He is currently Associate Professor at the University Miguel Hernández, Spain, and Director of the Artificial Vision Laboratory at the Bioengineering Institute of the University Miguel Hernández, Spain. In the last years he has been using histological as well as electrophysiological techniques to understand how mammalian retinal cells and the circuitry within the retina can manage and code visual information. He is actively working on the development of a visual neuroprosthesis for the profoundly blind. 


\section{Capítulo 3 \\ Trabajo complementario}

Las contribuciones descritas en los artículos que componen esta tesis por publicaciones cubren en su totalidad el objetivo global de la misma a través del cumplimiento de cada uno de sus sub-objetivos. No obstante, se ha profundizado en estos sub-objetivos por medio de diversas contribuciones que no se incluyen como artículos publicados en esta tesis por compendio de publicaciones al ser contribuciones a diferentes congresos nacionales e internacionales. En este capítulo, se describen brevemente las contribuciones más relevantes y, en el Apéndice B, se incluye una copia íntegra de cada una de ellas.

El objetivo (1), descrito como "Definición y construcción de una plataforma para el soporte en tiempo real de los sistemas de adquisición de registros neuronales, y estimulación eléctrica de los mismos, que se comunique remotamente con un dispositivo robótico" pretende disponer de una plataforma que permita la unificación del hardware empleado para el estudio de cultivos biológicos cultivados y el hardware robótico, con el fin de servir de base para el resto de objetivos. En este sentido, parte de la plataforma descrita en el artículo (1) se encuentra ampliamente detallada en el artículo "An Open-Source Real-Time System for Remote Robotic Control using Neuroblastoma Cultures" publicado en el "IEEE World Congress on Computational Intelligence", que se puede encontrar en el Apéndice B.

El objetivo (2), definido como "Estudio y propuesta de un método de guiado robótico basado en una plataforma de lazo cerrado que integre la información de los sensores del robot en el neuroprocesador y, en función de la respuesta de éste, direccione el sistema robótico", se ve ampliado respecto al artículo presentado en esta tesis por un método de guiado basado en los vehículos de Braitenberg [81]. Valentino Braitenberg describe diferentes comportamientos en circuitos motores originados por simples sensores neuronales. En su investigación experimental, descubrió que simples estructuras neuronales pueden llevar a cabo muy complejos comportamientos. Estos comportamientos, independientemente de su estructura neuronal subyacente, son conocidos como miedo, ira, etc. El sistema de control robótico propuesto en el artículo "A Hybrid Robotic Control System Using Neuroblastoma Cultures", publicado en el congreso "Hybrid Artificial Intelligence Systems", trata de implementar los vehículos de Braitenberg a través de un sistema de evasión de obstáculos basado en la actividad neuronal. Este artículo se incluye en el Apéndice B.

Por otro lado, el artículo (2) presentado en esta tesis, ve su arquitectura de control robótico basada en el método de centro de área ampliada, por medio de un software llamado im2MEA que transforma las imágenes capturadas por una cámara robótica a una estimulación de matriz de electrodos según los principios de centro de área. Este software fue presentado, junto a otros resultados, en la revista "Majlesi Journal of 
Electrical Engineering” con el artículo "Image Coding for Robotic Guidance Using Neuroblastoma Cultures", que se puede encontrar en el Apéndice B.

Finalmente, son varias las contribuciones que amplían el objetivo (4), definido como "Estudio y definición de técnicas de aprendizaje en cultivos neuronales para la realización de conectividad funcional dirigida con objeto de proporcionar nuevos paradigmas de programación en neuroprocesadores biológicos", entre las que destacamos el artículo "Enhancing Hebbian Learning in Biological Neural Cultures Through Electrical Stimulation", publicado en el congreso "Future Computational Technologies and Applications", y galardonado con el "Premio a mejor artículo del congreso". Esta contribución detalla como una estimulación específica de baja frecuencia basada en corriente puede emplearse para entrenar células disociadas de hipocampo sobre matrices de microelectrodos. De esta investigación, se obtuvieron importantes e interesantes resultados, como el hecho de que usando la estimulación mencionada es posible crear conexiones lógicas en la conectividad neuronal siguiendo la ley de Hebb, y que estas conexiones inducen cambios en la respuesta electrofisiológica de las células de los cultivos, que pueden ser observados a través de diferentes parámetros y análisis. 


\section{Capítulo 4}

\section{Conclusiones, aportaciones y líneas futuras}

\subsection{Conclusiones}

El empleo de sistemas nerviosos biológicos como elementos de cómputo convencional es uno de los principales retos actualmente. Esta sinergia permitiría combinar Neurociencia y Computación, consiguiendo una mayor compresión de los procesos de percepción humana, así como su utilización en el diseño de nuevos dispositivos basados en paradigmas computacionales naturales. Estos nuevos dispositivos estarían compuestos por millones de procesadores biológicos, con una estructura dinámica, un bajo consumo de energía y sin aprendizaje supervisado. Sus principales aplicaciones serían aquellas relacionadas con la percepción y el reconocimiento, debido a la variación natural de los patrones perceptivos y a la falta de conocimiento a priori acerca del dominio a percibir.

El logro del objetivo global de esta tesis, "la realización de un neuroprocesador biológico empleando como plataforma redes neuronales biológicas cultivadas sobre matrices de microelectrodos", nos acerca un poco más al escenario ideal de poder emplear sistemas nerviosos biológicos como elementos de cómputo convencional. Sin embargo, para poder llegar a este escenario se han de resolver un gran número de problemas tanto a nivel biológico como a nivel de computación. Los sub-objetivos definidos para esta tesis, completados a través de sus respectivos artículos $\mathrm{y}$ contribuciones adicionales, tratan de solucionar parte de estos problemas.

En primer lugar, se hace necesaria una plataforma que permita controlar tanto el entorno biológico como el robótico, de forma que actúe como nexo de comunicación y control de todos los elementos del sistema. La definición del primer sub-objetivo "Definición y construcción de una plataforma para el soporte en tiempo real de los sistemas de adquisición de registros neuronales, y estimulación eléctrica de los mismos, que se comunique remotamente con un dispositivo robótico" tenía por fin suplir esta carencia para poder disponer de una base de estudio y experimentación bio-híbrida. Por ello, se ha desarrollado todo un sistema de experimentación bio-híbrida a través de la unión de hardware y software, proporcionando así todas las funciones necesarias para la visualización, adquisición, filtrado, procesamiento y estimulación de cultivos celulares sobre matrices de microelectrodos. Esta plataforma va más allá de la mera consecución del objetivo, pues consta de una arquitectura cliente-servidor en tiempo real que hace posible el control robótico en la nube. 
En segundo lugar, la plataforma desarrollada deja patente la falta de un mecanismo de guiado robótico que permita no sólo controlar a un robot, sino que éste sea capaz de moverse en una variedad de escenarios. En la segunda publicación, se adaptó el concepto físico de centro de masas a robótica como mecanismo de guiado robótico, pasando a denominarse, centro de área. Este sistema consigue que un robot sea capaz de moverse por un escenario con obstáculos por medio de las respuestas electrofisiológicas de un cultivo neuronal. La detección de un obstáculo provoca el envío de un patrón de estimulación específico que resultará en un vector de dirección a través de la identificación de las neuronas que incrementan en mayor medida sus respuestas y haciendo uso del algoritmo de centro de área.

Diversos estudios y experimentos con la plataforma y mecanismos de guiado arrojaron la existencia de una nueva problemática, la no-homogeneidad de los cultivos tanto en densidad de cultivo, como en las propiedades eléctricas de los distintos electrodos, lo que podría derivar en comportamientos incorrectos cuando alguno de estos hechos destacara. Para evitar este problema, en el tercer artículo se realizó un estudio en el que se proporcionaron técnicas de calibración y normalización estadística de los registros de poblaciones de neuronas. Estas técnicas conseguían suprimir la variabilidad intrínseca de las poblaciones neuronales y las características de no-homogeneidad presentes tanto en la densidad de cultivo como en las propiedades eléctricas de los distintos electrodos.

Finalmente, una de las características principales y deseables de un neuroprocesador biológico, es la existencia de una asociación entre los estímulos y las respuestas, lo que comúnmente se le denomina aprendizaje. Este proceso requiere la modulación de las respuestas electrofisiológicas del cultivo para adaptarlas a la función a implementar. En este sentido, en el cuarto artículo se propuso y aplicó un paradigma de aprendizaje natural, el aprendizaje Hebbiano, con el que fue posible lograr conexiones funcionales entre electrodos que no se encontraban previamente enlazados a través de una estimulación en corriente de baja frecuencia. Además, se observó que dichas conexiones inducían cambios en la respuesta electrofisiológica de los cultivos. Estos procesos podían ser empleados para imponer un comportamiento deseado sobre la dinámica de la red.

Es necesario resaltar que el aprendizaje en cultivos biológicos neuronales es una tarea muy compleja. Diferentes autores han propuesto diversos métodos para inducir una plasticidad deseada y controlada sobre la estructura biológica neuronal. A lo largo de esta tesis, hemos podido comprobar que la estimulación de baja frecuencia y la estimulación tetánica han proporcionado buenos resultados en la investigación, mejorando la actividad de ráfagas en cultivos corticales. En esta tesis se ha mostrado que empleando estas estimulaciones es posible modelar la actividad de los cultivos a través de la creación y el fortalecimiento de conexiones lógicas siguiendo la Ley de Hebb. En el resto de contribuciones, se han descrito diferentes procedimientos de estimulación para conseguir una plasticidad deseada y profundizar de esta manera en el último de los sub-objetivos. 


\subsection{Aportaciones}

La presente tesis doctoral ha sido el resultado del trabajo y el esfuerzo realizado durante los últimos cuatro años. Este esfuerzo se ha plasmado en la gran cantidad de aportaciones y actividad investigadora realizada. Se han publicado un total de 26 artículos de investigación, citados a continuación en base a su categoría:

Publicaciones en revistas impactadas:

1. Daniel de Santos, Víctor Lorente, Félix de la Paz, José Manuel Cuadra, José R. Álvarez-Sánchez, Eduardo Fernández, José M. Ferrández. A client-server architecture for remotely controlling a robot using a closed-loop system with a biological neuroprocessor. Robotics and Autonomous Systems, 58:12231230, 2010. (JCR-ISI, IF 1.313, Q2).

2. J.M. Ferrández, V. Lorente, F. de la Paz, J.M. Cuadra, José Ramón ÁlvarezSánchez, E. Fernández. A biological neuroprocessor for robotic guidance using a center of area method. Neurocomputing 74:1229-1236, 2011. (JCRISI, IF 1.580, Q2).

3. J.M. Cuadra, J.R. Álvarez-Sánchez, D. De Santos, V. Lorente, J.M. Ferrández, F. de la Paz, E. Fernández. Response calibration in neuroblastoma cultures over multielectrode array. Neurocomputing 75:98-105, 2012. (JCR-ISI, IF 1.634, Q2).

4. J.M. Ferrández, V. Lorente, F. de la Paz, E. Fernández. Training biological neural cultures: Towards Hebbian learning. Neurocomputing 114:3-8, 2013. (JCR-ISI, IF 1.634, Q2).

Publicaciones en revistas no impactadas:

5. J.M. Ferrández, V. Lorente, J. Garrigós, E. Fernández. Image Coding for Robotic Guidance Using Neuroblastoma Cultures. Majlesi Journal of Electrical Engineering. Special Issue on Cognitive Information Processing, March 2011, pp. 11-20.

6. V. Lorente. Sistema de Tiempo-Real de Código Abierto para Control Robótico usando Cultivos de Neuroblastoma. III Jornada de Introducción a la Investigación, pp. 59-61, 2010.

7. V. Lorente. Análisis y detección automática de potenciales de acción en cultivos neuronales. IV Jornada de Introducción a la Investigación, pp. 82-83, 2011.

8. V. Lorente, J.M. Ferrández. Programación de Neuroprocesadores Biológicos mediante Estimulación Hebbiana. VI Jornada de Introducción a la Investigación de la UPCT, 2013. 
Capítulos de libro:

9. J.M. Ferrández, M. Bongard, V. Lorente, J. Abarca, R. Villa and E. Fernández. Activity Modulation in Human Neuroblastoma Cultured Cells: Towards a Biological Neuroprocessor. IWINAC 2009, Part I, LNCS 5601, pp. 142-154, 2009. DOI: $10.1007 / 978-3-642-02264-7 \_16$

10. J.M. Ferrández, V. Lorente, J.M. Cuadra, F. delaPaz, J.R. Álvarez-Sánchez and E. Fernández. A Hybrid Robotic Control System Using Neuroblastoma Cultures. HAIS 2010, Part I, LNAI 6076, pp. 245-253, 2010. DOI: 10.1007/978-3-642-13769-3_30

11. D. de Santos, J.M. Cuadra, F. de la Paz, V. Lorente, J.R. Álvarez, J.M. Ferrández. Tools for Controlled Experiments and Calibration on Living Tissues Cultures. IWINAC 2011, Lecture Notes in Computer Science, Vol. 6687, pp. 472-481, 2011. DOI: 10.1007/978-3-642-21326-7_51

12. V. Lorente, F. de la Paz, E. Fernández y J.M. Ferrández. A Methodology for Learning Validation in Neural Cultures. Distributed Computing and Artificial Intelligence Advances in Intelligent and Soft Computing, Volume 151, 2012, pp 421-428. DOI: 10.1007/978-3-642-28765-7_50

13. V. Lorente, J.M. Ferrández, F.J. Garrigós, F. de la Paz, J.M. Cuadra, J. R. Álvarez y E. Fernández. Neural Spike Activation in Hippocampal Cultures Using Hebbian Electrical Stimulation. Natural and Artificial Models in Computation and Biology Lecture Notes in Computer Science, Volume 7930, 2013, pp 37-47. DOI: 10.1007/978-3-642-38637-4_5

Contribuciones a congresos internacionales:

14. J.M. Ferrández, V. Lorente, F.J. Garrigós, and E. Fernández. A Biological Neural Network for Robotic Control - Towards a Human Neuroprocessor. IJCCI 2009, pp. 508-513, 2009.

15. J.M. Ferrández, V. Lorente, G. Díaz, F. delaPaz and E. Fernández. An OpenSource Real-Time System for Remote Robotic Control using Neuroblastoma Cultures. WCCI 2010, pp. 901-908, 2010. DOI: 10.1109/IJCNN.2010.5596696

16. J.M. Ferrández, V. Lorente, M. Bongard, G. Díaz, F. delaPaz and E. Fernández. Tetanization Dynamics in Human Neuroblastoma Cultures. MEA Meeting 2010, pp. 223-224, 2010.

17. J.M. Ferrández, V. Lorente, M. Bongard, G. Díaz, F. delaPaz and E. Fernández. A Closed-Loop System for Robotic Control using Human Neuroblastoma Cultures. MEA Meeting 2010, pp. 224-225, 2010. 
18. J.M. Ferrández, V. Lorente, F.D.L. Paz, J.M.C. Troncoso, J.R.Á. Sánchez, and E. Fernández. Learning in Biological Neuroprocessors using a Center of Area Method. IJCCI (ICFC-ICNC), 2010, pp.336-343.

19. J.M. Ferrández, V. Lorente, E. Fernández. Real-Time Spike Detection For Robotic Control. Neuroinformatics 2011, pp. 128-129, 2011. DOI: 10.3389/conf.fninf.2011.08.00087

20. J.M. Ferrández, V. Lorente, D. de Santos, J.M. Cuadra, F. de la Paz, J.R. Álvarez y E. Fernández. Human Neuroblastoma Cultures for Biorobotics. EMBC 2011, pp. 6672-6675, 2011. DOI: 10.1109/IEMBS.2011.6091645.

21. V. Lorente, J.M. Ferrández, F. de la Paz y E. Fernández. Training hippocampal cultures using low-frequency stimulation: Towards Hebbian Learning. MEA Meeting 2012, pp. 90-91, 2012.

22. V. Lorente, J.M. Ferrández, F. de la Paz y E. Fernández. Using Braitenberg's principles for stimulate and re-cord simultaneously populations of hippocampal cells: a biorobotic approach. MEA Meeting 2012, pp. 208-209, 2012.

23. V. Lorente, J.M. Ferrández, E. Fernández y F. de la Paz. Enhancing Hebbian Learning in Biological Neural Cultures Through Electrical Stimulation. Future Computing 2013, pp. 20-25, 2013.

24. V. Lorente, J.M. Ferrández y E. Fernández. Spike Synchronization in Hippocampal Cultures Using Hebbian Learning. Neuroinformatics 2013. DOI: 10.3389/conf.fninf.2013.09.00115

Contribuciones a congresos nacionales:

25. V. Lorente. An Open-Source Real Time System for Remote Robotic Control using Neuroblastoma Cultures. Simposio de la TICBioMed, 2010.

26. D. de Santos, V. Lorente, J.M. Cuadra, F. delaPaz, J.R. Álvarez-Sánchez and J.M. Ferrández. Bulture: Un Software Cliente-Servidor para la conexión remota con Cultivos de Células. CEDI 2010, pp. 23-31, 2010.

Además de las publicaciones en revistas impactadas, cabe destacar la contribución "Enhancing Hebbian Learning in Biological Neural Cultures Through Electrical Stimulation", publicada en el congreso internacional "Fifth International Conference on Future Computational Technologies and Applications", celebrado en Valencia en 2013, por la obtención del "Premio mejor artículo del congreso".

Se ha de mencionar también que, actualmente, se encuentran en revisión dos publicaciones en revistas impactadas y se han enviado dos contribuciones a congresos internacionales. 
Como actividad investigadora adicional, se han realizado tres estancias de cuatro meses cada una en el Instituto de Bioingeniería de la Universidad Miguel Hernández de Elche, donde se han adquirido conocimientos de técnicas de laboratorio, especialmente técnicas de electrofisiología y cultivo celular, y se ha participado en diversos estudios relacionados con el aprendizaje de células nerviosas mediante neuroestimulación eléctrica y su aplicación al control de dispositivos robóticos. Además, se ha asistido a un total de ocho congresos, de los cuales siete son congresos internacionales de gran impacto en la temática tratada en la tesis. De estas aportaciones, cuatro de ellas han sido representadas mediante presentación oral.

A esta actividad investigadora se une la participación en la organización de la III y IV Jornada de Introducción a la Investigación, y del congreso internacional "International Work-conference on the Interplay between Natural and Artificial Computation" en sus ediciones de 2011 y 2013, la partición en diferentes seminarios, y la impartición del seminario Learning in Neural Cultures" dentro del Workshop "Neural interfaces: Novel possibilities for neurorehabilation", incluido en el programa del "Summer School on Neurorehabilitation" en 2013.

\subsection{Líneas futuras}

En futuras investigaciones, son abundantes y diversas las líneas que se pueden abordar al ser la temática una unión de campos muy amplios, biología y computación.

A nivel biológico, es necesario y conveniente refinar los parámetros óptimos de estimulación que inducen cambios permanentes en las redes cultivadas, lo cual mejoraría enormemente la capacidad de estos cultivos de funcionar en sistemas biohíbridos.

Sería interesante además experimentar con diferentes formas de estimulación, como la optogenética, que combina métodos genéticos y ópticos para controlar eventos específicos en cultivos con una mayor precisión, necesaria para mantener el ritmo de funcionamiento de los sistemas biológicos intacto, empleando la luz como agente inductor, y con posibilidad de inhibición.

La aplicación de diferentes sustancias en los cultivos y la comprobación de su efecto sobre el control robótico promete ser una línea también de gran interés.

A nivel de computación, sería de gran interés profundizar en la optimización de la arquitectura para el control robótico, estudiando posibilidades como el empleo de varios ordenadores, o la posibilidad de emplear una FPGA y acoplar el cultivo a un robot, consiguiendo así un sistema autónomo. Experimentar con estrategias cooperativas podría ser también otra línea, en la que se examinaría el comportamiento de varios robots con cultivos de neuronas.

Finalmente, se ha de mencionar que, a nivel de hardware y computación, los avances se suceden con gran rapidez, por lo que emplear nuevos elementos a nivel técnico tendría un gran atractivo. Estos elementos pueden ser el uso de nuevas plataformas de registro y estimulación de mayor eficiencia en su funcionalidad, que permitan una mayor variabilidad de parámetros y nuevas posibilidades, como uso de matrices con un mayor 
número de electrodos o de varias matrices de electrodos al mismo tiempo, estimulaciones más complejas o nuevos sistemas de cultivo tridimensional. 
Estudio y realización de un neuroprocesador biológico: métodos de aprendizaje

Víctor Lorente Sánchez 


\section{Bibliografía}

[1] Anderson, J.A., Rosenfeld, E., "Neurocomputing: Foundations of research". MIT Press, Cambridge, 1988.

[2] The FACETS Project, http://facets.kip.uni-heidelberg.de/

[3] Ammermuller, J., Kolb, H, "The organization of the turtle inner retina. I. ON- and OFF-center pathways”. J. Comp. Neurol. 358(1), pp. 1-34, 1995.

[4] Ammermuller, J., Weiler, R., Perlman, I., "Short-term effects of dopamine on photoreceptors, luminosity and chromaticity horizontal cells in the turtle retina. Vis. Neurosci. 12(3), pp. 403-412, 1995.

[5] Berry, M.J., Warland, D.K., Meister, M., "The Structure and Precision of Retinal Spike Trains”. Proc. Natl. Acad. Sci. USA 94(10), pp. 5411-5416, 1997.

[6] Secker, H., Searle, C., "Time Domain Analysis of Auditory-Nerve Fibers Firing Rates". J. Acoust. Soc. Am. 88(3), pp. 1427-1436, 1990.

[7] Chrobak, J.J. and G. Buzsaki, "Gamma oscillations in the entorhinal cortex of the freely behaving rat”. Journal of Neuroscience, 1998. 18(1): p. 388-98.

[8] Hasselmo, M.E., C. Bodelon, and B.P. Wyble, "A proposed function for hippocampal theta rhythm: separate phases of encoding and retrieval enhance reversal of prior learning". Neural Comput, 2002. 14(4): p. 793-817.

[9] Huerta, P.T. and J.E. Lisma, "Bidirectional synaptic plasticity induced by a single burst during cholinergic theta oscillation in CA1 in vitro". Neuron, 1995. 15(5): p. 1053-63.

[10] Levy, W.B. and O. Steward, "Temporal contiguity requirements for long-term associative potentiation/depression in the hippocampus". Neuroscience, 1983. 8(4): p. $791-7$.

[11] Bliss, T.V. and T. Lomo, "Long-lasting potentiation of synaptic transmission in the dentate area of the anaesthetized rabbit following stimulation of the perforant path". $J$ Physiol, 1973. 232(2): p. 331-56.

[12] Raymond, C.R., "LTP forms 1, 2 and 3: different mechanisms for the "long" in long-term potentiation". Trends Neurosci, 2007. 30(4): p. 167-75. 
[13] Holscher, C., R. Anwyl, and M.J. Rowan, "Stimulation on the positive phase of hippocampal theta rhythm induces long-term potentiation that can be depotentiated by stimulation on the negative phase in area CA1 in vivo". Journal of Neuroscience, 1997. 17(16): p. 6470-7.

[14] Markram, H., J. Lubke, M. Frotscher, and B. Sakmann, "Regulation of synaptic efficacy by coincidence of postsynaptic APs and EPSPs”. Science, 1997. 275(5297): p. 213-5.

[15] Zhang, L.I., H.W. Tao, C.E. Holt, W.A. Harris, and M. Poo, “A critical window for cooperation and competition among developing retinotectal synapses". Nature, 1998. 395(6697): p. 37-44.

[16] Baras, D. and R. Meir, "Reinforcement learning, spike-time-dependent plasticity, and the BCM rule". Neural Comput, 2007. 19(8): p. 2245-79.

[17] Bear, M.F. and R.C. Malenka, "Synaptic plasticity: LTP and LTD”. Curr Opin Neurobiol, 1994. 4(3): p. 389-99.

[18] Bi, G.Q. and M.M. Poo, "Synaptic modifications in cultured hippocampal neurons: dependence on spike timing, synaptic strength, and postsynaptic cell type". J Neuroscience, 1998. 18(24): p. 10464-72.

[19] Hebb, D.O., "The Organization of Behavior". 1949, New York: John Wiley and Sons. 335.

[20] Le Feber, J., W.L.C. Rutten, J. Stegenga, P.S. Wolters, G.J.A. Ramakers, and J. van Pelt, "Conditional firing probabilities in cultured neuronal networks: a stable underlying structure in widely varying spontaneous patterns". J. Neural Eng., 2007. 4: p. 54-67.

[21] Marom, S. and D. Eytan, "Learning in ex-vivo developing networks of cortical neurons”. Prog Brain Res, 2005. 147: p. 189-99.

[22] Marom, S. and G. Shahaf, "Development, learning and memory in large random networks of cortical neurons: lessons beyond anatomy". Q Rev Biophys, 2002. 35(1): p. 63-87.

[23] Barria, A. and R. Malinow, "NMDA receptor subunit composition controls synaptic plasticity by regulating binding to CaMKII". Neuron, 2005. 48(2): p. 289-301.

[24] Lemon, R., "Methods for Neuronal Recording in Conscious Animals". 1984, New York: Wiley.

[25] Lewicki, M.S. (1998) "A review of methods for spike sorting: the detection and classification of neural action potentials". Network: Computation in Neural Systems. 9(4): R53-R78, 1998.

[26] MultiChannel Systems, Microelectrode Array (MEA) Manual. 
http://www.multichannelsystems.com/sites/multichannelsystems.com/files/documents/ manuals/MEA_Manual.pdf

[27] Y. Jimbo, T. Tateno, and H. P. C. Robinson, "Simultaneous induction of pathwayspecific potentiation and depression in networks of cortical neurons". Biophys. J., vol. 76, no. 2, pp. 670-678,1999.

[28] S. M. Potter, "Distributed processing in cultured neuronal networks". Progress in Brain Research, M. A. L. Nicolelis, Ed., vol. 130, pp. 49-62. Elsevier Science, 2001.

[29] G. Shahaf and S. Marom, "Learning in networks of cortical neurons". J. Neurosci., vol. 21, no. 22, pp. 8782-8788, 2001.

[30] Wagenaar, D.A., R. Madhavan, J. Pine, and S.M. Potter, "Controlling bursting in cortical cultures with closed-loop multi-electrode stimulation”. J Neurosci, 2005. 25(3): p. $680-8$.

[31] G. W. Gross and J. M. Kowalski, "Origins of activity patterns in self-organizing neuronal networks in vitro”. J. Intell. Mater. Syst. Struct., vol. 10, no. 7, pp. 558-564, 1999.

[32] M. Meister, J. Pine, and D. A. Baylor, "Multi-neuronal signals from the retina acquisition and analysis". J. Neurosci. Methods, vol. 51, no. 1, pp. 95-106, 1994.

[33] Z. Bashir, N. Berretta, Z. Bortolotto, K. Clark, C. Davis, B. G. Freguelli, J. Harvey, B. Potier, and G. L. Collingridge, "NMDA receptors and long-term potentiation in the hippocampus," in The NMDA Receptor, G. L. Collingridge and J. C. Watkins Eds. Cambridge, U.K.: Oxford Univ. Press, 1994, pp. 295-312.

[34] A. Artola and W. Singer, "Long-term potentiation and NMDA receptors in rat visual cortex”. Nature, vol. 330, pp. 649-652, 1987.

[35] Y. Komatsu, K. Fujii, J., H. Sakaguchi, and K. Toyama, "Long-term potentiation of synaptic transmission in kitten visual cortex". J. Neurophysiol., vol. 59, pp. 124-141, 1988.

[36] Y. Yoshimura and T. Tsumoto, "Dependence of LTP induction on postsynaptic depolarization: A perforated patch-clamp study in visual cortical slices of young rats". J. Neurophysiol., vol. 71, pp. 1638-1645, 1994.

[37] Y. Kuroda, K. Muramoto, M. Kawahara, M. Kobayashi, Y. Sekino, E. Maeda, and A. Kawana, "Spatial and temporal changes of patterns of synchronous oscillation in cultured cortical neuronal network by stimulation". Abst. Soc. Neurosci., vol. 173, no. 13, 1993.

[38] E. Maeda, H. P. C. Robinson, Y. Kuroda, and A. Kawana, "Synaptic potentiation in cultured cortical neurons: Long-lasting modification of spontaneous synchronized periodic firing by patterned electrical stimulation". Abst. Soc. Neurosci., vol. 546, no. 6, 1993. 
[39] Y. Jimbo, H. P. Robinson and A. Kawana, "Strengthening of synchronized activity by tetanic stimulation in cortical cultures: application of planar electrode arrays". IEEE Transactions on Biomedical Engineering 45(11), pp. 1297-1304, Nov. 1998.

[40] Bologna, L. L; ., M; Chiappalone, N.; Nieus, T and Martinoia, S., "Constant low frequency stimulation shows changes in response of in-vitro cortical cultures during development". Molecular Mechanisms in Neuroscience, 19-20 June 2008, Milan (Italy), 2008 .

[41] Brewer, G.J., Boehler, M.D., Ide, A.N., Wheeler, B.C., "Chronic electrical stimulation of cultured hippocampal networks increases spontaneous spike rates". J. Neurosci. Meth. 184: 104-109, 2009.

[42] [35] Wagenaar, D. A., Pine, J. and Potter, S. M., "Effective parameters for stimulation of dissociated cultures using multi-electrode arrays". Journal of Neuroscience Methods 138: 27-37, 2004.

[43] Buitenweg, Jan Reinoud and Rutten, Wim L.C. and Marani, Enrico, "Extracellular stimulation window explained by a geometry-based model of the neuron-electrode contact". IEEE Transactions on Biomedical Engineering, 49 (12). pp. 1591-1599, 2002.

[44] Van Pelt, J., P.S. Wolters, M.A. Corner, W.L. Rutten, and G.J. Ramakers, "Longterm characterization of firing dynamics of spontaneous bursts in cultured neural networks". IEEE Trans Biomed Eng, 2004. 51(11): p. 2051-62.

[45] Wagenaar, D.A., J. Pine, and S.M. Potter, "An extremely rich repertoire of bursting patterns during the development of cortical cultures". BMC Neurosci, 2006. 7: p. 11.

[46] Stegenga, J. and le Feber, J. and Marani, E. and Rutten, W.L.C., "Analysis of cultured neuronal networks using intraburst firing characteristics". IEEE transactions on biomedical engineering, 55 (4). pp. 1382-1390, 2008. ISSN 0018-9294.

[47] Stegenga, J. and le Feber, J. and Marani, E. and Rutten, W.L.C., "The Effect of Learning on Bursting". IEEE transactions on biomedical engineering, 56 (4). pp. 12201227, 2009. ISSN 0018-9294

[48] Stegenga J., leFeber J., Marani E., Rutten, W.L.C., "Theta rhythm stimulation in cultured networks",.European Journal of Neuroscience, submitted.

[49] Bakkum, D.J., Z.C. Chao, and S.M. Potter, "Spatio-temporal electrical stimuli shape behavior of an embodied cortical network in a goal-directed learning task". J Neural Eng, 2008. 5(3): p. 310-323.

[50] Madhavan, R., Z.C. Chao, and S.M. Potter. "Artificial background sensory input aids functional plasticity in cultured cortical networks". 6th international meeting on substrate-integrated micro electrode arrays. 2008. Reutlingen, Germany: BIOPRO Baden-Würtemberg GmbH.

[51] Bakkum, D. J., Shkolnik, A. C., Ben-Ary, G., Gamblen, P., DeMarse, T. B. and Potter, S. M. 'Removing some 'A' from AI: Embodied Cultured Networks. Embodied 
Artificial Intelligence". Iida, F., Pfeifer, R., Steels, L. and Kuniyoshi, Y. New York, Springer. 3139: 130-145, 2004.

[52] Meyer, J. A. \& Wilson, S. W., "From Animals to Animats". Proceedings of the First International Conference on Simulation of Adaptive Behavior. MIT Press, Cambridge, 1991.

[53] Potter, S. M., Fraser, S. E. \& Pine, J., "Animat in a Petri Dish: Cultured Neural Networks for Studying Neural Computation". Proc. 4th Joint Symposium on Neural Computation, UCSD (1997) 167-174.

[54] DeMarse, T. B., Wagenaar, D. A., Blau, A. W. \& Potter, S. M., "The Neurally Controlled Animat: Biological Brains Acting with Simulated Bodies". Autonomous Robots 11 (2001) 305-310

[55] DeMarse, T. B., Wagenaar, D. A. \& Potter, S. M., "The neurally-controlled artificial animal: A neural-computer interface between cultured neural networks and a robotic body". Society for Neuroscience Abstracts 28 (2002) 347.1

[56] Reger, B. D., Fleming, K. M., Sanguineti, V., Alford, S. \& Mussa-Ivaldi, F. A. "Connecting brains to robots: The development of a hybrid system for the study of learning in neural tissues". Proceedings of the 7th Intl. Conf. on Artificial Life, pp. 263$272,2000$.

[57] Chao, Z. C., Bakkum, D. J., \& Potter, S. M., "Shaping Embodied Neural Networks for Adaptive Goal-directed Behavior". PLoS Computational Biology, 4(3): e1000042, 2008.

[58] Maeda, E., Y. Kuroda, H.P. Robinson, and A. Kawana, "Modification of parallel activity elicited by propagating bursts in developing networks of rat cortical neurones". Eur J Neurosci, 1998. 10(2): p. 488-96.

[59] Tateno, T. and Y. Jimbo, "Activity-dependent enhancement in the reliability of correlated spike timings in cultured cortical neurons". Biol Cybern, 1999. 80(1): p. 4555 .

[60] Ruaro, M.E., P. Bonifazi, and V. Torre, "Toward the neurocomputer: image processing and pattern recognition with neuronal cultures". IEEE Trans Biomed Eng, 2005. 52(3): p. 371-83.

[61] Wagenaar, D.A., J. Pine, and S.M. Potter, "Searching for plasticity in dissociated cortical cultures on multi-electrode arrays". Journal of negative results in biomedicine, 2006. 5(16).

[62] Madhavan, R., Z.C. Chao, and S.M. Potter, "Plasticity of recurring spatiotemporal activity patterns in cortical networks". Phys Biol, 2007. 4(3): p. 181-93.

[63] Chao, Z.C., D.J. Bakkum, and S.M. Potter, "Region-specific network plasticity in simulated and living cortical networks: comparison of the center of activity trajectory (CAT) with other statistics". J Neural Eng, 2007. 4(3): p. 294-308. 
[64] Ide AN, Andruska A, Boehler M, Wheeler BC, Brewer GJ, "Chronic network stimulation enhances evoked action potentials". J Neural Eng. 2010 Feb;7(1):16008.

[65] Bologna LL., Nieus T., Tedesco M., Chiappalone M., Benfenati F., Martinoia S., "Low-frequency stimulation enhances burst activity in cortical cultures during development”. Neuroscience 165:692-704, 2010.

[66] Wagenaar, D. A., DeMarse, T. B., \& Potter, S. M., "MeaBench: A toolset for multi-electrode data acquisition and on-line analysis". 2nd Intl. IEEE EMBS Conference on Neural Engineering, pp. 518-521, 2005.

[67] J.R. Álvarez-Sánchez, J. Mira Mira, F. delaPaz López, J.M. Cuadra Troncoso, "The centre of area method as a basic mechanism for representation and navigation". Robotics and Autonomous Systems 55 (12) 860-869, 2007.

[68] J.R. Álvarez Sánchez, F. de la Paz López, J.M. Cuadra Troncoso, D. de Santos Sierra, "Reactive navigation in real environments using partial center of area method". Robotics and Autonomous Systems Vol. 58 (12), pp. 1231-1237, 2010. DOI: 10.1016/j.robot. 2010.05.009.

[69] J.R. Álvarez Sánchez, F. de la Paz López, J.M. Cuadra Troncoso, J.I. Rosado Sánchez, "Partial center of area method used for reactive autonomous robot navigation", in: J. Mira, J.M. Ferraández, J.R. Álvarez, F. de la Paz, F.J. Toledo (Eds.). Bioinspired Applications in Artificial and Natural Computation, Lecture Notes in Computer Science, vol. 5602, Springer Verlag2009, pp. 408-418.

[70] I. Antonov, I. Antonova, E. Kandel, “Activity-dependent presynaptic facilitation and Hebbian LTP are both required and interact during classical conditioning in aplysia”. Neuron 37 (1) (2003) 135-147.

[71] J.M. Ferrández, M. Bongard, V. Lorente, J. Abarca, R. Villa and E. Fernández, "Activity Modulation in Human Neuroblastoma Cultured Cells: Towards a Biological Neuroprocessor". IWINAC 2009, Part I, LNCS 5601, pp. 142-154, 2009. DOI: 10.1007/978-3-642-02264-7_16

[72] J.M. Ferrández, V. Lorente, F.J. Garrigós, and E. Fernández, "A Biological Neural Network for Robotic Control - Towards a Human Neuroprocessor". IJCCI 2009, pp. 508-513, 2009.

[73] J.M. Ferrández, V. Lorente, F. DelaPaz, J.M. Cuadra, J.R. Alvarez, E.Fernandez, "A Biological Neuroprocessor for Robotic Guidance using a Center of Area Method". Neurocomputing, Volume 74, Issue 8, 15 March 2011, pp. 1229-1236. DOI: 10.1016/j.neucom.2010.07.018

[74] J.M. Ferrández, V. Lorente, J.M. Cuadra, F. delaPaz, J.R. Álvarez-Sánchez and E. Fernández, "A Hybrid Robotic Control System Using Neuroblastoma Cultures", HAIS 2010, Part I, LNAI 6076, pp. 245-253, 2010. DOI: 10.1007/978-3-642-13769-3_30 
[75] D. Micol, "Nev2lkit - a preprocessor for intra- and extra-cellular neuronal recordings distributed under GPL", $2006 / \mathrm{http}: / /$ nev2lkit.source forge.net/S.

[76] MultiChannel Systems MCS GmbH, "MC_Rack Tutorial: MEA Application Examples", $\quad 2010 \quad$ http://www.multichannelsystems.com/uploads/media/ MC_Rack_Tutorial_MEA_Appl_05.pdfS.

[77] G. Canavos, “Applied Probability and Statistical Methods”. First ed., Little, Brown and Company, 1984.

[78] H. Levene, "Robust tests for equality of variances", in: I. Olkin, S.G. Ghurye, W. Hoeffding, W.G. Madow, H.B. Mann (Eds.), Contributions to Probability and Statistics, Vol. 2, Stanford University Press, 1960, pp. 278-292.

[79] O. Sporns, G. Tononi, "Classes of network connectivity and dynamics". Complexity 7 (2002) 28-38.

[80] K.J. Friston, C. Frith, R. Frackowiak, "Time-dependent changes in effective connectivity measured with PET”. Hum. Brain Mapp. 1, pp. 69-79, 1993.

[81] Braitenberg, V., "Vehicles: Experiments in Synthetic Psichology". MIT Press, Cambridge, 1984. 
Estudio y realización de un neuroprocesador biológico: métodos de aprendizaje

Víctor Lorente Sánchez 


\section{Apéndice A \\ Documentos que sustentan las publicaciones}

Este apéndice recopila toda la documentación que sustenta las publicaciones aportadas para esta tesis. Para cada uno de los artículos que la componen, se incluye en esta sección una declaración de co-autoría, así como la información referente al índice de impacto (IF) y al ranking del Journal Citation Report (JCR), publicado por el Institute for Scientific Information (ISI) para cada uno de los artículos publicados, que son los que se citan a continuación:

a. Daniel de Santos, Víctor Lorente, Félix de la Paz, José Manuel Cuadra, José R. Álvarez-Sánchez, Eduardo Fernández, José M. Ferrández. A client-server architecture for remotely controlling a robot using a closed-loop system with a biological neuroprocessor. Robotics and Autonomous Systems, 58:12231230, 2010. (JCR-ISI, IF 1.313, Q2).

b. J.M. Ferrández, V. Lorente, F. de la Paz, J.M. Cuadra, José Ramón ÁlvarezSánchez, E. Fernández. A biological neuroprocessor for robotic guidance using a center of area method. Neurocomputing 74:1229-1236, 2011. (JCRISI, IF 1.580, Q2).

c. J.M. Cuadra, J.R. Álvarez-Sánchez, D. De Santos, V. Lorente, J.M. Ferrández, F. de la Paz, E. Fernández. Response calibration in neuroblastoma cultures over multielectrode array. Neurocomputing 75:98-105, 2012. (JCR-ISI, IF 1.634, Q2).

d. J.M. Ferrández, V. Lorente, F. de la Paz, E. Fernández. Training biological neural cultures: Towards Hebbian learning. Neurocomputing 114:3-8, 2013. (JCR-ISI, IF 1.634, Q2). 


\section{Declaración de co-autoría}

Nombre completo del estudiante de doctorado: Víctor Lorente Sánchez

Esta declaración concierne al siguiente artículo/manuscrito:

\begin{tabular}{|l|l|}
\hline Título: & $\begin{array}{l}\text { A client-server architecture for remotely controlling a robot using a closed- } \\
\text { loop system with a biological neuroprocessor }\end{array}$ \\
\hline Autores: & $\begin{array}{l}\text { Daniel de Santos, Víctor Lorente, Félix de la Paz, José Manuel Cuadra, José R. } \\
\text { Álvarez-Sánchez, Eduardo Fernández, José M. Ferrández. }\end{array}$ \\
\hline
\end{tabular}

El artículo/manuscrito se encuentra: Publicado $\bigotimes$ Aceptado $\square$ Enviado $\square$ En preparación

Si ha sido publicado, proporcionar referencia complete:

Daniel de Santos, Víctor Lorente, Félix de la Paz, José Manuel Cuadra, José R. ÁlvarezSánchez, Eduardo Fernández, José M. Ferrández. A client-server architecture for remotely controlling a robot using a closed-loop system with a biological neuroprocessor. Robotics and Autonomous Systems, 58:1223-1230, 2010. DOI: 10.1016/j.robot.2010.09.003

Si ha sido aceptado o enviado, proporcionar la revista:

El artículo/manuscrito ha sido previamente empleado en otra tesis doctoral?

No $\bigotimes$, y no será empleado en tesis doctorales futuras, Sí

En caso afirmativo, proporcionar detalles:

El estudiante de doctorado ha contribuido a los elementos del artículo/manuscrito como se indica:
A. Ninguna o pequeña contribución
B. Ha contribuido (10-30 \%)
C. Ha contribuido considerablemente (40-60 \%)
D. Ha realizado la mayor parte del trabajo (70-90 \%)
E. Ha hecho prácticamente todo el trabajo

\begin{tabular}{|l|l|}
\hline Elemento & $\begin{array}{l}\text { Alcance (A- } \\
\text { E) }\end{array}$ \\
\hline 1. Formulación/identificación del problema científico & B \\
\hline 2. Planificación de los experimentos y diseño y desarrollo de la metodología & $\mathrm{B}$ \\
\hline 3. Participación en el trabajo experimental & $\mathrm{C}$ \\
\hline 4. Interpretación de los resultados & $\mathrm{C}$ \\
\hline 5. Escritura del primer borrador del artículo & $\mathrm{C}$ \\
\hline 6. Finalización del artículo y envío & $\mathrm{B}$ \\
\hline Contribución global & $\mathrm{C}$ \\
\hline
\end{tabular}


Firmas de los co-autores

\begin{tabular}{|l|l|l|}
\hline Fecha & Nombre & Firma \\
\hline 21/01/2014 & Daniel de Santos & \\
\hline 21/01/2014 & Félix de la Paz & \\
\hline 21/01/2014 & José Manuel Cuadra & \\
\hline $21 / 01 / 2014$ & José R. Álvarez-Sánchez & Eduardo Fernández \\
\hline
\end{tabular}

Fecha: 23/01/2014

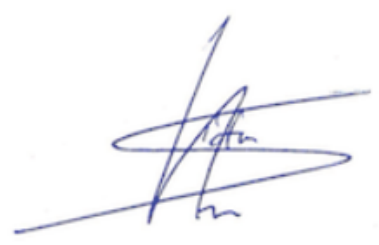

Víctor Lorente Sánchez

Firma del estudiante de doctorado 


\section{ISI Web of Knowledge}

Journal Citation Reports ${ }^{\oplus}$

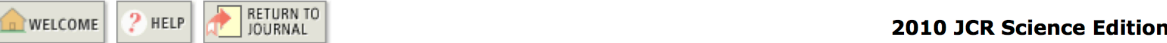 \\ Rank in Category: ROBOTICS AND AUTONOMOUS SYSTEMS}

\section{Journal Ranking i}

For 2010, the journal ROBOTICS AND AUTONOMOUS SYSTEMS has an Impact Factor of 1.313.

This table shows the ranking of this journal in its subject categories based on Impact Factor.

\begin{tabular}{|l|c|c|c|}
\hline \multicolumn{1}{|c|}{ Category Name } & $\begin{array}{c}\text { Total Journals } \\
\text { in Category }\end{array}$ & $\begin{array}{c}\text { Journal Rank } \\
\text { in Category }\end{array}$ & $\begin{array}{c}\text { Quartile } \\
\text { in Category }\end{array}$ \\
\hline AUTOMATION \& CONTROL SYSTEMS & 60 & 24 & Q2 \\
\hline COMPUTER SCIENCE, ARTIFICIAL INTELLIGENCE & 108 & 58 & Q3 \\
\hline ROBOTICS & 17 & 7 & Q2 \\
\hline
\end{tabular}

\section{Category Box Plot i)}

For 2010, the journal ROBOTICS AND AUTONOMOUS SYSTEMS has an Impact Factor of 1.313.

This is a box plot of the subject category or categories to which the journal has been assigned. It provides information about the distribution of journals based on Impact Factor values. It shows median, 25th and 75th percentiles, and the extreme values of the distribution.

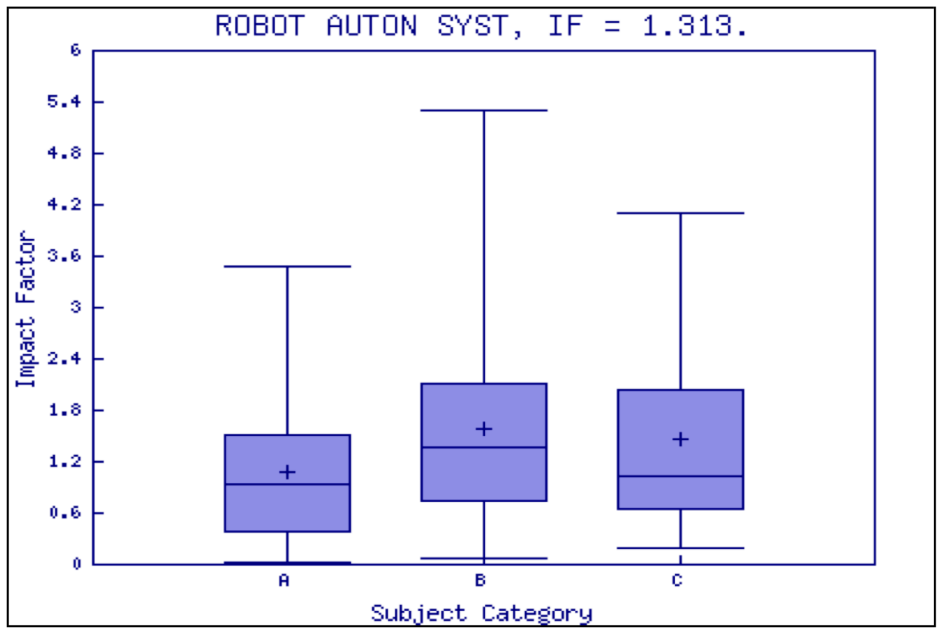

Key

AUTOMATION

A - \& CONTROL SYSTEMS COMPUTER

B - SCIENCE, ARTIFICIAL INTELLIGENCE

Subject Category C - ROBOTICS 


\section{Declaración de co-autoría}

Nombre completo del estudiante de doctorado: Víctor Lorente Sánchez

Esta declaración concierne al siguiente artículo/manuscrito:

\begin{tabular}{|l|l|}
\hline Título: & $\begin{array}{l}\text { A biological neuroprocessor for robotic guidance using a center of área } \\
\text { method }\end{array}$ \\
\hline Autores: & $\begin{array}{l}\text { J.M. Ferrández, V. Lorente, F. de la Paz, J.M. Cuadra, José Ramón Álvarez- } \\
\text { Sánchez, E. Fernández. }\end{array}$ \\
\hline
\end{tabular}

El artículo/manuscrito se encuentra: Publicado $\bigotimes$ Aceptado $\square$ Enviado $\square$ En preparación

Si ha sido publicado, proporcionar referencia complete:

J.M. Ferrández, V. Lorente, F. de la Paz, J.M. Cuadra, José Ramón Álvarez-Sánchez, E. Fernández. A biological neuroprocessor for robotic guidance using a center of área method. Neurocomputing 74:1229-1236, 2011. DOI: 10.1016/j.neucom.2010.07.018

$\mathrm{Si}$ ha sido aceptado o enviado, proporcionar la revista:

El artículo/manuscrito ha sido previamente empleado en otra tesis doctoral?

No $\bigotimes$, y no será empleado en tesis doctorales futuras, Sí $\square$

En caso afirmativo, proporcionar detalles:

El estudiante de doctorado ha contribuido a los elementos del artículo/manuscrito como se indica:
A. Ninguna o pequeña contribución
B. Ha contribuido (10-30 \%)
C. Ha contribuido considerablemente (40-6o \%)
D. Ha realizado la mayor parte del trabajo $(70-90 \%)$
E. Ha hecho prácticamente todo el trabajo

\begin{tabular}{|l|l|}
\hline Elemento & $\begin{array}{l}\text { Alcance (A- } \\
\text { E) }\end{array}$ \\
\hline 1. Formulación/identificación del problema científico & C \\
\hline 2. Planificación de los experimentos y diseño y desarrollo de la metodología & $\mathrm{D}$ \\
\hline 3. Participación en el trabajo experimental & $\mathrm{D}$ \\
\hline 4. Interpretación de los resultados & $\mathrm{D}$ \\
\hline 5. Escritura del primer borrador del artículo & $\mathrm{C}$ \\
\hline 6. Finalización del artículo y envío & $\mathrm{C}$ \\
\hline Contribución global & $\mathrm{D}$ \\
\hline
\end{tabular}




\section{Firmas de los co-autores}

\begin{tabular}{|l|l|l|}
\hline Fecha & Nombre & Firma \\
\hline 21/01/2014 & José M. Ferrández & \\
\hline 21/01/2014 & Félix de la Paz & \\
\hline 21/01/2014 & José Manuel Cuadra & \\
\hline 21/01/2014 & José R. Álvarez-Sánchez & \\
\hline & Eduardo Fernández & \\
\hline
\end{tabular}

Fecha: 23/01/2014

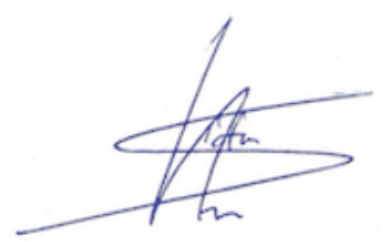

Víctor Lorente Sánchez

Firma del estudiante de doctorado 


\section{ISI Web of Knowledge}

Journal Citation Reports ${ }^{\oplus}$

CINEICOME $?$ HELP $\rightarrow$ RETURN TO

2010 JCR Science Edition

\section{Rank in Category: NEUROCOMPUTING}

\section{Journal Ranking}

For 2010, the journal NEUROCOMPUTING has an Impact Factor of $\mathbf{1 . 4 4 2}$

This table shows the ranking of this journal in its subject categories based on Impact Factor.

\begin{tabular}{|c|c|c|c|}
\hline Category Name & $\begin{array}{c}\text { Total Journals } \\
\text { in Category }\end{array}$ & $\begin{array}{c}\text { Journal Rank } \\
\text { in Category }\end{array}$ & $\begin{array}{c}\text { Quartile } \\
\text { in Category }\end{array}$ \\
\hline COMPUTER SCIENCE, ARTIFICIAL INTELLIGENCE & 108 & 50 & Q2 \\
\hline
\end{tabular}

\section{Category Box Plot i)}

For 2010, the journal NEUROCOMPUTING has an Impact Factor of $\mathbf{1 . 4 4 2 .}$

This is a box plot of the subject category or categories to which the journal has been assigned. It provides information about the distribution of journals based on Impact Factor values. It shows median, 25th and 75th percentiles, and the extreme values of the distribution.

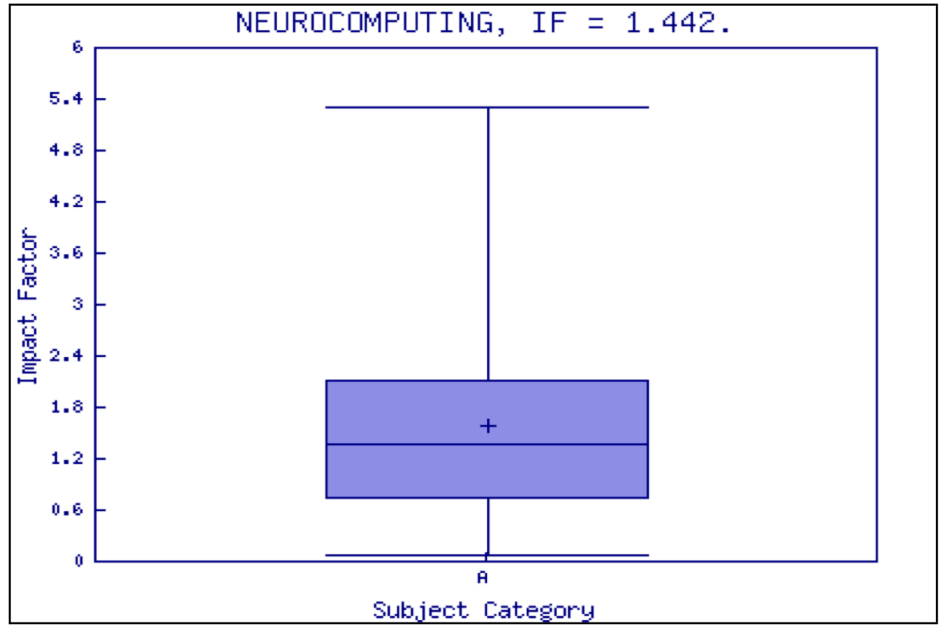




\section{ISI Web of Knowledge}

Journal Citation Reports ${ }^{\oplus}$

II-WELCOME ? HELP $\rightarrow$ RETURN TOO

2011 JCR Science Edition

\section{Rank in Category: NEUROCOMPUTING}

\section{Journal Ranking}

For 2011, the journal NEUROCOMPUTING has an Impact Factor of $\mathbf{1 . 5 8 0}$

This table shows the ranking of this journal in its subject categories based on Impact Factor.

\begin{tabular}{|c|c|c|c|}
\hline Category Name & $\begin{array}{c}\text { Total Journals } \\
\text { in Category }\end{array}$ & $\begin{array}{c}\text { Journal Rank } \\
\text { in Category }\end{array}$ & $\begin{array}{c}\text { Quartile } \\
\text { in Category }\end{array}$ \\
\hline COMPUTER SCIENCE, ARTIFICIAL INTELLIGENCE & 111 & 39 & Q2 \\
\hline
\end{tabular}

\section{Category Box Plot i}

For 2011, the journal NEUROCOMPUTING has an Impact Factor of $\mathbf{1 . 5 8 0}$

This is a box plot of the subject category or categories to which the journal has been assigned. It provides information about the distribution of journals based on Impact Factor values. It shows median, 25th and 75th percentiles, and the extreme values of the distribution.

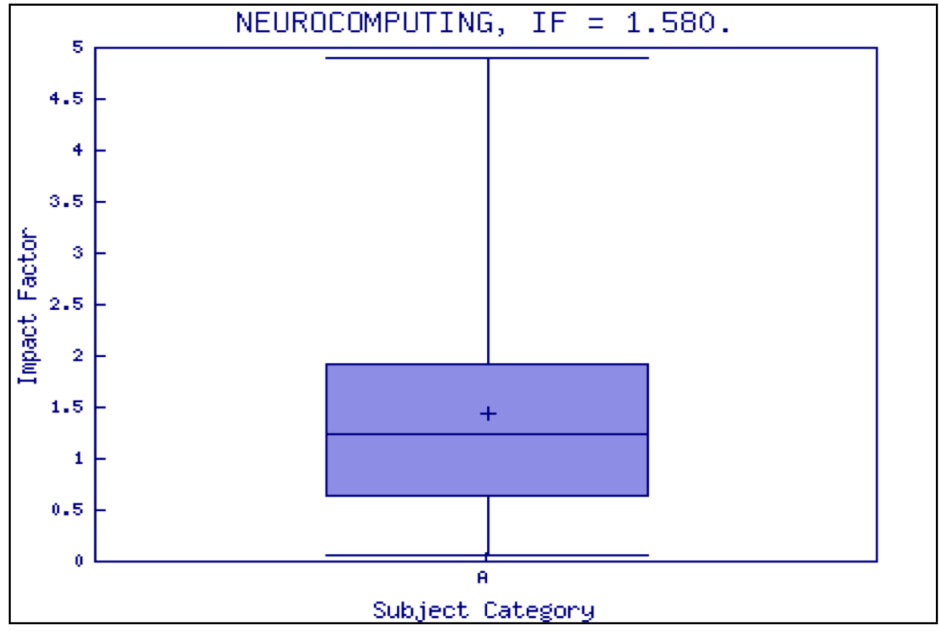




\section{Declaración de co-autoría}

Nombre completo del estudiante de doctorado: Víctor Lorente Sánchez

Esta declaración concierne al siguiente artículo/manuscrito:

\begin{tabular}{|l|l|}
\hline Título: & Response calibration in neuroblastoma cultures over multielectrode array \\
\hline Autores: & $\begin{array}{l}\text { J.M. Cuadra, J.R. Álvarez-Sánchez, D. De Santos, V. Lorente, J.M. Ferrández, } \\
\text { F. de la Paz, E. Fernández }\end{array}$ \\
\hline
\end{tabular}

El artículo/manuscrito se encuentra: Publicado $\bigotimes$ Aceptado $\square$ Enviado $\square$ En preparación

Si ha sido publicado, proporcionar referencia complete:

J.M. Cuadra, J.R. Álvarez-Sánchez, D. De Santos, V. Lorente, J.M. Ferrández, F. de la Paz, E. Fernández. Response calibration in neuroblastoma cultures over multielectrode array. Neurocomputing 75:98-105, 2012. DOI: 10.1016/j.neucom.2011.04.038

Si ha sido aceptado o enviado, proporcionar la revista:

El artículo/manuscrito ha sido previamente empleado en otra tesis doctoral?

No $\bigotimes$, y no será empleado en tesis doctorales futuras, Sí $\square$

En caso afirmativo, proporcionar detalles:

El estudiante de doctorado ha contribuido a los elementos del artículo/manuscrito como se indica:
A. Ninguna o pequeña contribución
B. Ha contribuido (10-30 \%)
C. Ha contribuido considerablemente (40-60\%)
D. Ha realizado la mayor parte del trabajo $(70-90 \%)$
E. Ha hecho prácticamente todo el trabajo

\begin{tabular}{|l|l|}
\hline Elemento & $\begin{array}{l}\text { Alcance (A- } \\
\text { E) }\end{array}$ \\
\hline 1. Formulación/identificación del problema científico & B \\
\hline 2. Planificación de los experimentos y diseño y desarrollo de la metodología & $\mathrm{B}$ \\
\hline 3. Participación en el trabajo experimental & $\mathrm{C}$ \\
\hline 4. Interpretación de los resultados & $\mathrm{C}$ \\
\hline 5. Escritura del primer borrador del artículo & $\mathrm{B}$ \\
\hline 6. Finalización del artículo y envío & $\mathrm{C}$ \\
\hline Contribución global & $\mathrm{C}$ \\
\hline
\end{tabular}




\section{Firmas de los co-autores}

\begin{tabular}{|l|l|l|}
\hline Fecha & Nombre & Firmá \\
\hline $21 / 01 / 2014$ & José Manuel Cuadra & \\
\hline $21 / 01 / 2014$ & José R. Álvarez-Sánchez & \\
\hline $21 / 01 / 2014$ & José M. Ferrández & Daniel de Santos \\
\hline $21 / 01 / 2014$ & Félix de la Paz &
\end{tabular}

Fecha: 23/01/2014

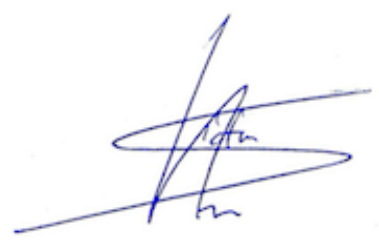

Víctor Lorente Sánchez

Firma del estudiante de doctorado 


\section{ISI Web of Knowledge}

Journal Citation Reports ${ }^{\oplus}$

CINEICOME $?$ HELP $\rightarrow$ RETURN TO

2012 JCR Science Edition

\section{Rank in Category: NEUROCOMPUTING}

\section{Journal Ranking}

For 2012, the journal NEUROCOMPUTING has an Impact Factor of $\mathbf{1 . 6 3 4}$

This table shows the ranking of this journal in its subject categories based on Impact Factor.

\begin{tabular}{|c|c|c|c|}
\hline Category Name & $\begin{array}{c}\text { Total Journals } \\
\text { in Category }\end{array}$ & $\begin{array}{c}\text { Journal Rank } \\
\text { in Category }\end{array}$ & $\begin{array}{c}\text { Quartile } \\
\text { in Category }\end{array}$ \\
\hline COMPUTER SCIENCE, ARTIFICIAL INTELLIGENCE & 114 & 37 & Q2 \\
\hline
\end{tabular}

\section{Category Box Plot i}

For 2012, the journal NEUROCOMPUTING has an Impact Factor of $\mathbf{1 . 6 3 4 .}$

This is a box plot of the subject category or categories to which the journal has been assigned. It provides information about the distribution of journals based on Impact Factor values. It shows median, 25th and 75th percentiles, and the extreme values of the distribution.

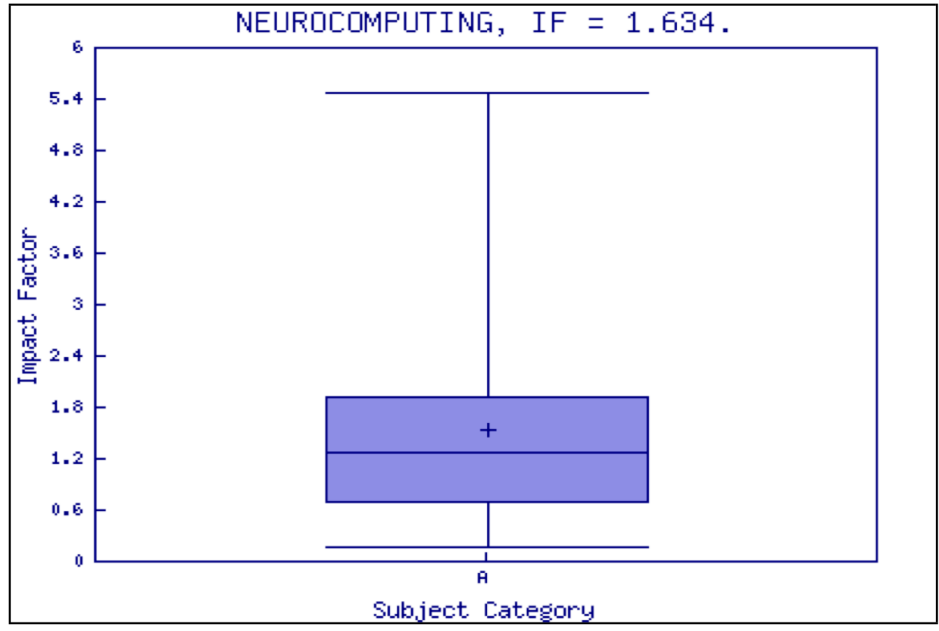

Key COMPUTER SCIENCE, ARTIFICIAL INTELLIGENCE 


\section{Declaración de co-autoría}

Nombre completo del estudiante de doctorado: Víctor Lorente Sánchez

Esta declaración concierne al siguiente artículo/manuscrito:

\begin{tabular}{|l|l|}
\hline Título: & Training biological neural cultures: Towards Hebbian learning \\
\hline Autores: & J.M. Ferrández, $\underline{\text { V. Lorente, F. de la Paz, E. Fernández. }}$ \\
\hline
\end{tabular}

El artículo/manuscrito se encuentra: Publicado $\bigotimes$ Aceptado $\square$ Enviado $\square$ En preparación

Si ha sido publicado, proporcionar referencia complete:

J.M. Ferrández, V. Lorente, F. de la Paz, E. Fernández. Training biological neural cultures: Towards Hebbian learning. Neurocomputing 114:3-8, 2013. DOI:

10.1016/j.neucom.2012.09.031

Si ha sido aceptado o enviado, proporcionar la revista:

El artículo/manuscrito ha sido previamente empleado en otra tesis doctoral?

No $\bigotimes$, y no será empleado en tesis doctorales futuras, Sí

En caso afirmativo, proporcionar detalles:

El estudiante de doctorado ha contribuido a los elementos del artículo/manuscrito como se indica:

A. Ninguna o pequeña contribución

B. Ha contribuido (10-30 \%)

C. Ha contribuido considerablemente (40-6o \%)

D. Ha realizado la mayor parte del trabajo $(70-90 \%)$

E. Ha hecho prácticamente todo el trabajo

\begin{tabular}{|l|l|}
\hline Elemento & $\begin{array}{l}\text { Alcance (A- } \\
\text { E) }\end{array}$ \\
\hline 1. Formulación/identificación del problema científico & $\mathrm{D}$ \\
\hline 2. Planificación de los experimentos y diseño y desarrollo de la metodología & $\mathrm{D}$ \\
\hline 3. Participación en el trabajo experimental & $\mathrm{E}$ \\
\hline 4. Interpretación de los resultados & $\mathrm{D}$ \\
\hline 5. Escritura del primer borrador del artículo & $\mathrm{D}$ \\
\hline 6. Finalización del artículo y envío & $\mathrm{D}$ \\
\hline Contribución global & $\mathrm{D}$ \\
\hline
\end{tabular}




\section{Firmas de los co-autores}

\begin{tabular}{|l|l|l|}
\hline Fecha & Nombre & Firma \\
\hline 21/01/2014 & José M. Ferrández & \\
\hline 21/01/2014 & Félix de la Paz & \\
\hline 21/01/2014 & Eduardo Fernández & \\
\hline
\end{tabular}

Fecha: 23/01/2014

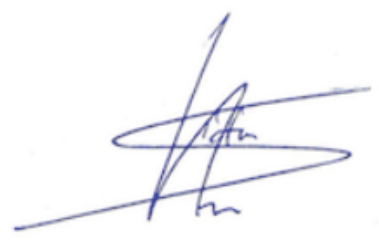

Víctor Lorente Sánchez

Firma del estudiante de doctorado 


\section{ISI Web of Knowledge}

Journal Citation Reports ${ }^{\oplus}$

CINEICOME $?$ HELP $\rightarrow$ RETURN TO

2012 JCR Science Edition

\section{Rank in Category: NEUROCOMPUTING}

\section{Journal Ranking}

For 2012, the journal NEUROCOMPUTING has an Impact Factor of $\mathbf{1 . 6 3 4}$

This table shows the ranking of this journal in its subject categories based on Impact Factor.

\begin{tabular}{|c|c|c|c|}
\hline Category Name & $\begin{array}{c}\text { Total Journals } \\
\text { in Category }\end{array}$ & $\begin{array}{c}\text { Journal Rank } \\
\text { in Category }\end{array}$ & $\begin{array}{c}\text { Quartile } \\
\text { in Category }\end{array}$ \\
\hline COMPUTER SCIENCE, ARTIFICIAL INTELLIGENCE & 114 & 37 & Q2 \\
\hline
\end{tabular}

\section{Category Box Plot i}

For 2012, the journal NEUROCOMPUTING has an Impact Factor of $\mathbf{1 . 6 3 4 .}$

This is a box plot of the subject category or categories to which the journal has been assigned. It provides information about the distribution of journals based on Impact Factor values. It shows median, 25th and 75th percentiles, and the extreme values of the distribution.

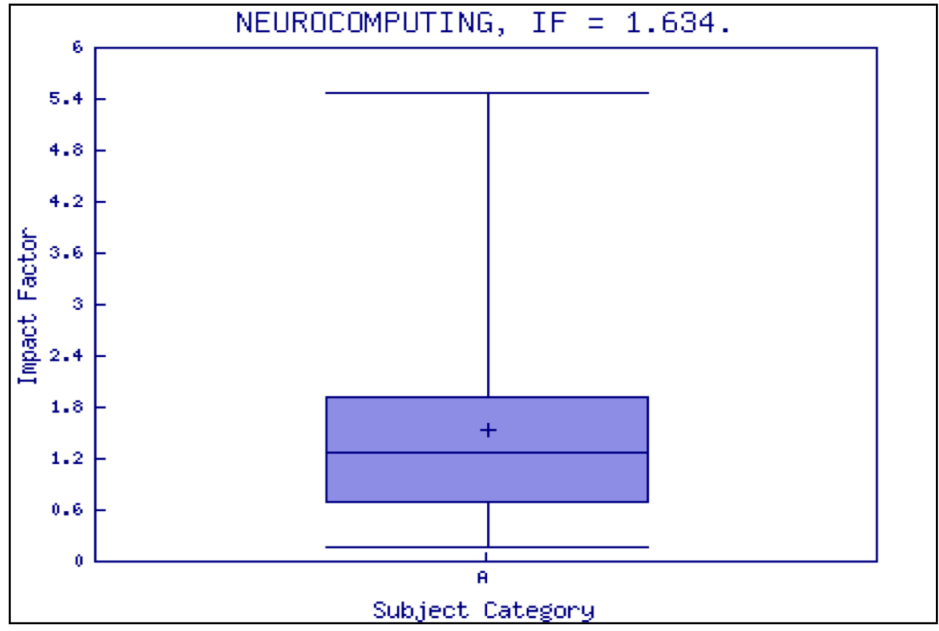

Key COMPUTER SCIENCE, ARTIFICIAL INTELLIGENCE 


\section{Apéndice B \\ Contribuciones complementarias}

Este apéndice contiene los artículos que corresponden a aquellas contribuciones que profundizan en los objetivos de esta tesis pero que no pueden ser incluidas en la misma como artículos publicados. Los artículos contenidos en este apéndice, cuya descripción se encuentra en el Capítulo 3, se citan a continuación:

1. J.M. Ferrández, V. Lorente, G. Díaz, F. delaPaz and E. Fernández. An OpenSource Real-Time System for Remote Robotic Control using Neuroblastoma Cultures. WCCI 2010, pp. 901-908, 2010. DOI: 10.1109/IJCNN.2010.5596696

2. J.M. Ferrández, V. Lorente, J.M. Cuadra, F. delaPaz, J.R. Álvarez-Sánchez and E. Fernández. A Hybrid Robotic Control System Using Neuroblastoma Cultures. HAIS 2010, Part I, LNAI 6076, pp. 245-253, 2010. DOI: 10.1007/978-3-642-13769-3_30

3. J.M. Ferrández, V. Lorente, J. Garrigós, E. Fernández. Image Coding for Robotic Guidance Using Neuroblastoma Cultures. Majlesi Journal of Electrical Engineering. Special Issue on Cognitive Information Processing, March 2011, pp. 11-20.

4. V. Lorente, J.M. Ferrández, E. Fernández y F. de la Paz. Enhancing Hebbian Learning in Biological Neural Cultures Through Electrical Stimulation. Future Computing 2013, pp. 20-25, 2013. 


\title{
An Open-Source Real-Time System for Remote Robotic Control using Neuroblastoma Cultures
}

\author{
Ferrández J. M., Lorente V., Díaz G., delaPaz F., Fernández E.
}

\begin{abstract}
This paper introduces an open-source real-time system that controls remotelly a robot using Human Neuroblastoma cultures and basic Braitenberg principles. Multielectrode Arrays Setups have been designed for direct culturing neural cells over silicon or glass substrates, providing the capability to stimulate and record simultaneously populations of neural cells. The main objective of this research is to modulate the natural physiologic responses of human neural cells by tetanic stimulation of the culture. If the system is able to modify the selective responses of some cells with a external pattern stimuli provided by a robot over different time scales, the neuroblastoma-cultured structure could be trained to process pre-programmed spatio-temporal patterns, controlling in this way the robotic behaviour.
\end{abstract}

\section{INTRODUCTION}

$\mathrm{U}$ SING neural cultures as conventional computer elements is an emerging field that permits the hybridation between Neuroscience and Computer Science. This fascinating approach can provide a deeper understanding of natural processing and may be used for the design of new computing devices based on natural computational paradigms. The brain uses millions of biological processors, with dynamic structure; slow commutations compared with silicon circuits, low power consumption and unsupervised learning. This kind of computation is more related to perceptual recognition, due to the natural variance of the perceptive patterns and the a priori lack of knowledge about the perceptual domain.

There exist different approaches based on mimicking this bioinspired parallel processing, not only from the algorithm perspective [1], but also from the silicon circuits design.

Manuscript received January 30, 2010 This work was supported by the Spanish Government through grants TIN2008-06893-C03, TEC200614186-C02-02 and SAF2008-03694, Cátedra Bidons Egara, Fundación Séneca 08788/PI/08, CIBER-BBN and by the European Comission through the project " NEUROPROBES"' IST-027017

J M Ferrández is with the Electronic and Computer Technology Department at Universidad Politécnica de Cartagena, Spain; e-mail: jm ferrandez@upct es

V Lorente is with the Electronic and Computer Technology Department at Universidad Politécnica de Cartagena, Spain

F delaPaz is with the Artificial Intelligence Department at UNED, Spain

G Díaz, is with Bioengineering Institute at Universidad Miguel Hernandez, Spain

E Fernández, is with Bioengineering Institute at Universidad Miguel Hernandez, Spain
These neuromorphic approaches are useful for pattern recognition applications, like computer vision or robotics, however they are implemented over serial and artificial silicon processors with fixed and static structure. A real biological neuroprocessor with millions of interconnections, would provide much more computational power instead of their low transition rates due to high number of computing elements and the extraordinary network capability of adaptation and reconfiguration to unknown environments.

Our learning experiments were performed in neural cultures containing 120.000 human neuroblastoma SY-5Y, under the assumption that this kind of cells are able to respond electrically to external stimuli and modulate their neural firing by changing the stimulation parameters. Such cultured neuroblastoma networks have shown dynamical configurations, beeing able to grow and adapt functionally in response to external stimuli over different configuration patterns. We are especially interested in analizing if populations of neuroblastoma cells are able to process and store information, and if learning can be implemented over this biological structure. The main objective of this work will be to control a robot using this biological neuroprocessor and a simple Braitenberg [2] learning scheme.

This paper introduces an open-source real-time system that controls remotelly a robot using Human Neuroblastoma cultures and basic Braitenberg principles. Multielectrode Arrays Setups have been designed for direct culturing neural cells over silicon or glass substrates, providing the capability to stimulate and record simultaneously populations of neural cells. This work describes the process of growing human neuroblastoma cells over MEA substrates and tries to change the natural physiologic responses of these cells by external stimulation of the culture provided by the robot sensors. Modifying the global responses of some cells with a external pattern stimuli means adjusting the biological network behaviour due to changes in synaptic efficiency or long-term potentiation (LTP). We propose a system for determining that the large neuroblastoma networks developed in cultured MEAs are capable of learning: stablishing numerous and dynamic connections, with modifiability induced by external stimuli, in this case the robot sensors. 


\section{LEARNING IN HUMAN NEUROBLASTOMA CULTURES}

The physiological function of neural cells is modulated by the underlying mechanisms of adaptation and reconfiguration in response to neural activity. Hebbian learning describes a basic mechanism for synaptic plasticity wherein an increase in synaptic efficacy arises from the presynaptic cell's repeated and persistent stimulation of the postsynaptic cell. The theory is commonly evoked to explain some types of associative learning in which simultaneous activation of cells leads to pronounced increases in synaptic strength. The N-methyl-D-aspartate (NMDA) receptor, a subtype of the glutamate receptor, has been implicated as playing a key role in synaptic plasticity in the CNS (Bading and Greenberg, 1991), where as dopamine receptors are involved in the regulation of motor and cognitive behaviors. For most synaptic ion channels, activation (opening) requires only the binding of neurotransmitters. However, activation of the NMDA channel requires two events: binding of glutamate (a neurotransmitter) and relief of $\mathrm{Mg} 2+$ block. NMDA channels are located at the postsynaptic membrane. When the membrane potential is at rest, the NMDA channels are blocked by the $\mathrm{Mg} 2+$ ions. If the membrane potential is depolarized due to excitation of the postsynaptic neuron, the outward depolarizing field may repel $\mathrm{Mg} 2+$ out of the channel pore. On the other hand, binding of glutamate may open the gate of NMDA channels (the gating mechanisms of most ion channels are not known). In the normal physiological process, glutamate is released from the presynaptic terminal when the presynaptic neuron is excited. Relief of $\mathrm{Mg} 2+$ block is due to excitation of the postsynaptic neuron. Therefore, excitation of both presynaptic and postsynaptic neurons may open the NMDA channels, this is closely related with Hebbian learning.

Another important feature of the NMDA channel is that it conducts mainly the $\mathrm{Ca} 2+$ ion which may activate various enzymes for synaptic modification, even nictric oxide has been identified as a relevant element in synaptic regulation. The enhancement of synaptic transmission is called the longterm potentiation (LTP), which involves two parts: the induction and the maintenance. The induction refers to the process, which opens NMDA channels for the entry of $\mathrm{Ca} 2+$ ions into the postsynaptic neuron. The subsequent synaptic modification by $\mathrm{Ca} 2+$ ions is referred to as the maintenance of LTP.

A human neuroblastoma SY5Y cell line, that express clonal specific human dopamine receptors, and also NMDA receptors, will be the biological platform for studying learning in cultured cells

Neuroblastoma SH-SY5Y cells are known to be dopaminergc, acetylcholinergic, glutamatergic and adenosinergic, so in this line they respond to different neurotransmitters. The cells have very different growth phases, as it can be seen in Figure 1. The cells both propagate via mitosis and differentiate by extending neurites to the surrounding area. The dividing cells can form clusters of cells that are reminders of their cancerous nature, but chemicals can force the cells to dendrify and differentiate, in some kind of neuritic growth.

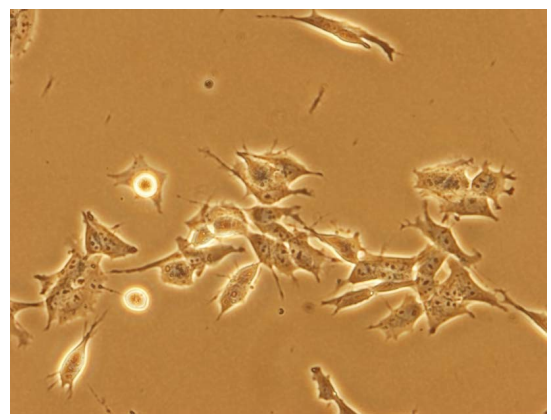

Figure 1: Human neuroblastoma cells

As conclusion, neuroblastoma culture cells show electrophysiological responses similar to standard neurons, as potential actions generation sensible to tetrodotoxin (TTX) and acetylcholyn. They have neurotransmitters synthesis process and are able to neuritic growth in culture medium.

\section{EXPERIMENTAL SETUP}

The neuro-physiology setup provides a complete solution for stimulation, heating, recording, and data acquisition from 64 channels. The MEA (microelectrode array) system is intended for extracellular electrophysiological recordings in vitro of different applications that include acute brain, heart, and retina slices; cultured slices; and dissociated neuronal cell cultures.

The basic components of the proposed system are shown in Figure 2. These components are:

- A microelectrode array is an arrangement of 60 electrodes that allows the simultaneous targeting of several sites for extracellular stimulation and recording. Cell lines or tissue slices are placed directly on the MEA and can be cultivated for up to several months. Almost all excitable or spontaneously active cells and tissues can be used.

- Raw data from the MEA electrodes are amplified by MCS filter amplifiers with custom bandwidth and gain, which are built very small and compact using SMD (Surface Mounted Devices) technology. The small-sized amplifier combines the interface to the MEA probe with the signal 
filtering and the amplification of the signal. The compact design reduces line pick up and keeps the noise level down. The amplifiers are mounted over an inverted microscopes.

- The analog input signals are then acquired and digitized by the MC-Card that is preinstalled on the data acquisition computer, that supplies the power for the amplifiers, and the pattern stimuli to the stimulators.

- The robot sends information about the environment to the computer using a bluetooth link. The sensor consists in infrared sensors for detecting obstacles.

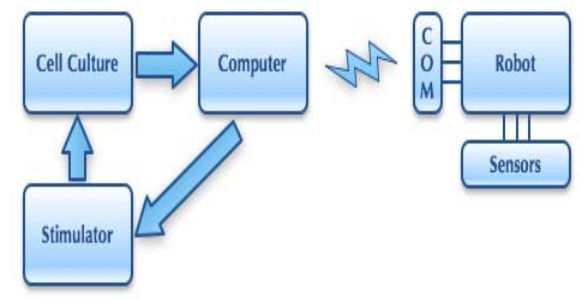

Figure 2: Experimental Setup

\section{CULTURE DATA ACQUISITION SYSTEMS}

Recording from large numbers of electrodes has become increasingly common in neuroscience over the last 30 years. Micro-electrode arrays (MEAs) [3-5] with 60 or more electrodes have been used to study many in vitro preparations including cortical cultures, spinal cord cultures, as well as retinal tissue. For electrophysiological data acquisition and analysis there exist several tools available, but two of them are more frequently used: MC RACK (MultiChannel Systems, Reutlingen, Germany) and MEABENCH (Daniel Wagenaar, California Institute of Technology).

\section{A. MCRACK}

MC RACK is a data acquisition and analysis software for Windows Operating Systems [7]. It works only with the hardware of MultiChannel Systems called 'MC CARD'. It has been designed especially for use with the $\bar{M}$ - and the MEA-System, but is also ideally suited to work with other experimental setups. MC RACK provides recording, graphing, and analyzing in real time extracellular activities of excitable cells, for in vitro and in vivo preparations. Features include a virtual oscilloscope, a filter, an event detector, a spike sorter, automatic feedback, sound, and various analysis tools.

The main drawback of MC_RACK is that this software is not user-extendible, and not well suited for real-time applications involving bidirectional communications between computers and biological tissue. For our research on a biological processor for robotics using neuroblastoma cultures, these are essential pre-rrequisites, as mentioned before.

\section{B. $M E A B E N C H$}

MEABENCH is a free, open-source, set of programs designed primarily for Linux for multi-electrode data acquisition (DAQ) and online analysis [6]. MEABENCH directly communicates with DAQ hardware as well as providing real-time visualization. Thanks to its ability to communicate in real-time with stimulator hardware it can be used in closed-loop stimulation experiments.

MEABENCH was programmed as a set of semiindependent programs sharing a common library. These programs communicate through standard Linux interprocess communication (IPC) facilities such as pipes and shared memory. MEABENCH programs use a client-server model to transfer data. A server creates a shared memory block with a header describing its contents. Clients can then independently read from this memory. Servers notify clients through pipes when new data become available, and when a run starts or ends. This model is used to transfer both electrode voltage data and neural spikes information. This modular approach makes it easily maintainable. It also makes it easy for third parties to add their own MEABENCH programs, e.g. to add new visualization or data processing methods. The core of MEABENCH was coded in $\mathrm{C}++$. Some utility programs were written in perl, and several additional data analysis tools were written for Matlab.

These are the main features of MEABENCH:

- Data acquisition MEABENCH has a modular interface for communication with data acquisition (DAQ) cards. Currently, a module to acquire data from the 'MC Card' hardware (MultiChannel Systems, Reutlingen, Germany) is well-supported.

- Inter-process communication MEABENCH programs use a client-server model to transfer data. A server creates a shared memory block with a header describing its contents. Clients can then independently read from this memory. Servers notify clients through pipes when new data become available, and when a run starts or ends. This model is used to transfer both electrode voltage data and spike information.

- Multi-computer setup MEABENCH provides the option of using one dedicated computer just for data acquisition, and a second computer for all the analysis tasks.

- Visualization Online data visualization is a main feature of MEABENCH. To show acquired voltage traces and spike rasters online, a set of widget was written for use with the open-source Qt library (Trolltech, Oslo, Norway). 
- Data streaming MEABENCH provides an interface for external programs to read data directly from MEABENCH shared memory.

- Algorithms MEABENCH includes programs for the suppression of line noise and stimulation artifacts, as well as for spike detection.

MEABENCH consists of the following main programs:

- Rawsrv - The main server. It reads voltage traces from the hardware and makes them available to other MEABENCH programs.

- Spikedet - A threshold-based spike detector. It reads from a voltage-trace stream, and publishes a spike information stream. Includes algorithms to adapt to fluctuating noise levels.

- Salpa - Stimulation artifact filter [8]

- Record - Records voltage or spike data to disk.

- Replay - Replays files created by Record.

- Scope - GUI program for online display of voltage and spike data.

- Spikesound - GUI program for online sonification of spike data.

- Flexraster - GUI program for online generation of spike raster plots.

- Neurosock and Nssrv - An alternative to Rawsrv that allows one to dedicate one computer to data acquisition and another for online analysis.

\section{ROBOTIC CONTROL SYSTEM.}

We have developed a system that provides a complete robotic control platform over neuroblastoma cultures. The system includes five free, open-source, console-based programs written in $\mathrm{C} / \mathrm{C}++$ for real-time robotic applications with embodied cultures. All of this software has been developed for the Linux Operating System and MCS hardware (MultiChannel Systems, Reutlingen, Germany). Using this software in conjuction with MEABENCH is specially intended for close-loop experiments.

The software developed consists of the following programs:

- Cult2Robot The main program. It has been developed as a MEABENCH module, so it can access to all of the data streams that MEABENCH provides. Cult2Robot read spikes information from MEABENCH spike detector and compute a direction vector based on MEA neural activity. The direction vector is calculated based on the number of spikes per electrode in $t$ seconds and it can be weighted by the height and width of the spikes. This direction vector could be sent to a robot to control its movement.

- Stg_control This program controls a general-purpose stimulus generator for current and voltage-driven electrical stimulation, STG 1000 series (MultiChannel Systems, Reutlingen, Germany). The STG may be connected to a PC via RS232 port or via USB port. Stg_control make possible program and download custom functions to the STG, start/stop the stimulation, reset the device or send any command described in the STG100x RS232 Communication Manual.

- Electrode select This module allows configuring the MEA1060BC amplifier following the MEA protocol from MCS [7]. With the Electrode_select program, it is easy to change the electrode selection during the experiment, e.g. to use stimulating electrodes for recording and vice versa. It also has almost all the features that its Windows counterpart 'MEA_select', such as blanking electrodes, changing MEA, using wait for optimizing the electrode's behaviour or reset the device.

- BT_server Receiving environmental information from the robot is a primary objective. BT server is a non-blocking Bluetooth server that uses RFCOMM protocol to receive characters from a specific MAC, process the information and do some action, e.g. it can be used to call another program when an obstacle is detected ( $\mathrm{An}$ ' $\mathrm{O}$ ' has been received).

- BT_client Sending information to the robot is also important to establish a bidirectional link and transmit the outputs to the robot. BT_client sends ASCII characters via Bluetooth using RFCOMM protocol. In our research BT client sends the direction vector calculated by Cult 2 Robot to change the movement of the robot.

At the moment, we are developing a GUI program for doing remote close-loop experiments that involves data acquisition, stimulation and robot controls. Also, some new utilities are being designed to add more features to this set of software, such as different learning procedures.

\section{RESULTS}

It is very important to check that the acquisition system is working correctly with the hardware setup before doing more specific tests. Three different signals were simulated placing a MCS Signal Generator in the MEA1060BC preamplifier. Signals generated with MCS Signal Generator have two possible amplitude values that depend on the electrode.

The first signal was a basic sine wave, with a frequency of $1,25 \mathrm{~Hz}$ and its peak values $12 \mu \mathrm{V}$ and $24 \mu \mathrm{V}$. Figure 1 shows the MEABENCH. The 'MC_Card' driver used in 
MEABENCH for acquiring data with MultiChannel System's Hardware has a 4x scaling, so the peak values shown are $48 \mu \mathrm{V}$ and $96 \mu \mathrm{V}$.

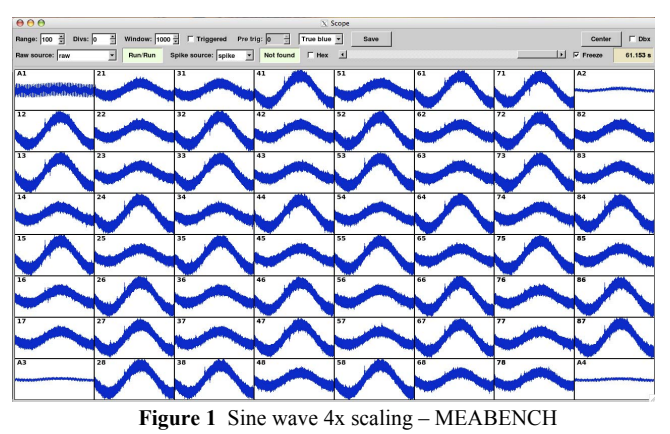

The MCS signal generator also generated spikes from retinal cells and from hippocampal cells. Retinal cells showed peak values of $35 \mu \mathrm{V}$ and $80 \mu \mathrm{V}$, depending on the electrode (Figure 2).

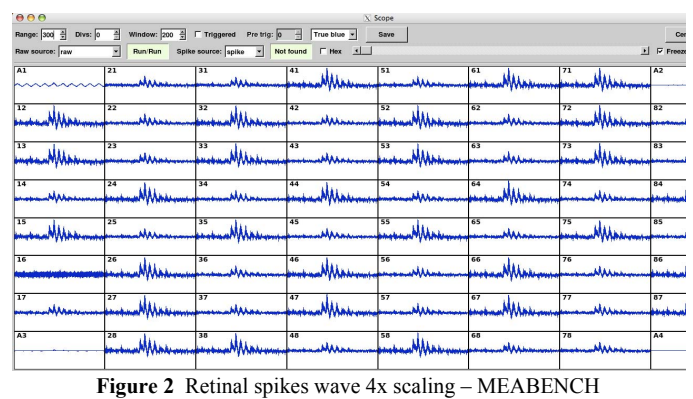

Figure 3 shows a magnification of a retinal spike detected in the electrode 42 in MEABENCH. The peak value in MEABENCH was about $140 \mu \mathrm{V}$ with $4 \mathrm{x}$ scaling and the snr was 3,5:1. The noise is a crucial factor in electrophysiological recordings that limits data analysis due to the electrophysiological data signals usually are enclosed into the noise levels.

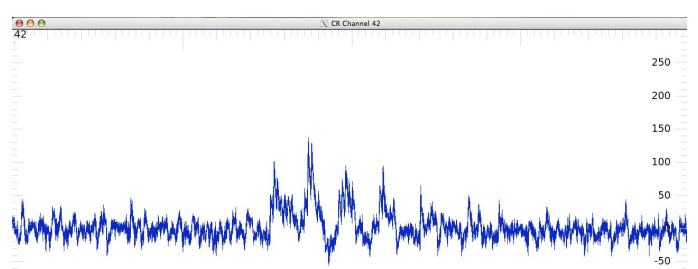

450 17.500 4017.550

Figure 3. Magnification of a retinal spike $4 \mathrm{x}$ scaling
Hippocampal cells showed higher peak and snr values. The peak values were 250 and 500 depending on the electrode and the snr was about 25:1. Figure 4 shows the hippocampal recordings in MEABENCH.

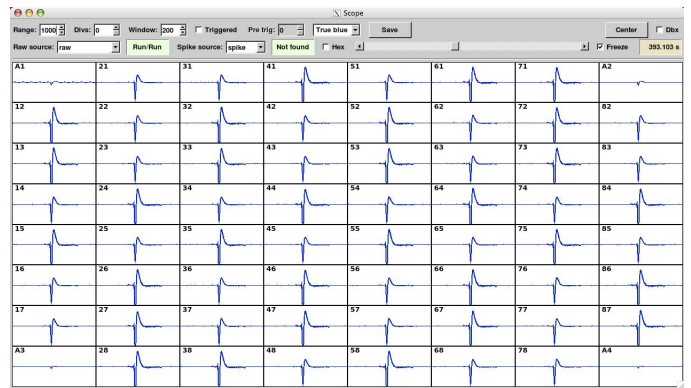

Figure 4. Hippocampal spikes $4 \mathrm{x}$ scaling

VII. NEUROBLASTOMA CULTURES

Human neuroblastoma cultures were produced using the commercial line SH/SY5Y . Cell culture of SH SY5Y was grown in DMEM (Gibco) completed with $10 \%$ of fetal bovine serum at $37 \mathrm{oC}$ in $5 \% \quad \mathrm{CO} 2$ and humidify atmosphere.

On each MEA $100000 \mathrm{cell} / \mathrm{ml}$ where placed in a volume of $2 \mathrm{ml}$ and maintained on the mentioned conditions until experimentation on different days in vitro (div). Neural cells were then plated on Micro-Electrode Arrays -MEAs (MultiChannel Systems, Reutlingen, Germany). Initially the nitrogen frozen cells, was immersed in a 37 degree bath, and centrifuged at $1000 \mathrm{rpm}$ during 5 minutes. When cells have grown in a uniform mono-layer process, they are washed three time with buffer Phosphate-buffered saline (PBS) for keeping the $\mathrm{pH}$ approximately constant. 0,5 per cent trypsin was added to the solution in order to re-suspend cells adherent to the cell culture dish wall during the process of harvesting cells. The cells were kept in the incubator for 5 minutes and passed through a 40 microm. cell strainer (Falcon, Bedford, MA) to remove large debris. Finally the cells are transferred to a specific medium in order to inactivate trypsin, and centrifugated again during 5 minutes at $1000 \mathrm{rpm}$.

For seeding the plate cells are stained with trypan blue, (because cells that loose their permeability get colorred with this solution) and counted with a Neubauer chamber. Finally, 80.000 or 120.000 total neuroblastoma cells have been placed over the MEA substrate.

Maintaining cells in culture is essential for studying their physiological properties. Cell culturing is dependent on the growth surfaces and cells must adhere to the electrode substrate in order to establish the best connection with the electrodes material. For most cultures coated tissue culture 
plates are prerequisite for seeding. The most commonly used coatings are positively charged polymers. In this work, the insulation layer (silicon nitride) of some of the plates was pre-treated with polyethyleneimine (PEI), showing no advantages compared with no covered plates.

The neuroblastoma cultures are maintained in a 37 degree humidified incubator with 5 per cent $\mathrm{CO} 2$ and 95 per cent $\mathrm{O} 2$ with serum-free Neurobasal medium. Under the aforementioned conditions we were able to record stable electrophysiological signals over different days in vitro (Div). The medium was replaced one-half of the medium every 5 days.

\section{NEUROPROCESSOR SIGNALS}

The cultured neuroblastoma cells establish synaptic connections. In Figure 5 it can be seen differentiated and non-differentiated neuroblastoma cell bodies growing around the whole electrode population. The dendritic arborescence is more evident in the magnification Figure 3 where differentiated neural cells surround the four electrodes while the rest of the cells are in their growing process. This Figure corresponds to 80.000 neuroblastoma cells seeded in a no-PEI MEA at 2nd day in vitro (div).

The electrophysiological properties of the neuroblastoma cultures were analized by recording the spontaneous activity of the network. Time course of experiments was over 15 days; recordings were done using two MCS-Meas with two neuroblastoma cell cultures (but only in one the cells survived till day 15). In vitro neuroblastoma networks show spontaneously firing. This firing rates change during the culture development with marked day differences and the global rate is closely related to the age of the network.

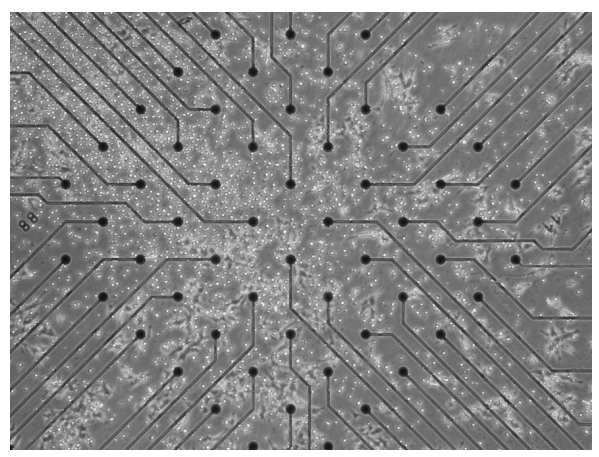

Figure 5: Biological neural network over multielectrode array

Recordings of Neuroblastoma SH-SY5Y has the disadvantage of having a very low signal to noise ratio. As we have shown in previous papers [9, 10], the electrophysiological properties of the culture change with the age of the culture, getting a potentiation effect in the spontaneous firing. A young neuroblastoma culture (1-5 DIV) has a low spontaneous firing activiy, with a signal to noise ratio barely higher than 1:1. A mature neuroblastoma culture (1-15 DIV) have a higher spontaneous firing activity and its snr may be higher than 2:1, but still is lower than snr of other cells. Figure 6 show the electrophysiological recording of a neuroblastoma culture with 4DIV on electrode 42. The recording was acquired with MEABENCH toolset with $4 \mathrm{X}$ scaling. The noise takes values up to $25 \mu \mathrm{V}(4 \mathrm{X})$ and the real signal hides the most of the time beyond the noise. Neuroblastoma peaks have 40 $\mu \mathrm{V}$ and sometimes noise glitches may be mistaken as them.

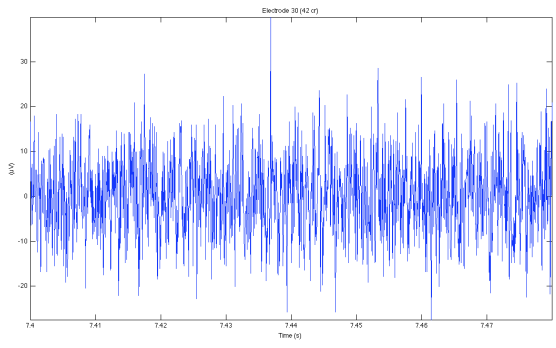

Figure 6 Neuroblastoma recording

The frequency components of neuroblastoma spontaneous activity are primarily low frequency but he noise from equipment and power line and its harmonics are also low frequency. MEABENCH use an adaptive template filter to suppress power line pickup digitally. However, noise is still a common problem in the recordings. It is needed to obtain clean recordings in order to get better results. Regarding the software, we are working on improving MEABENCH modules for reducing noise levels. Also we are trying to isolate noise with other equipment solutions such as a Faraday cage.

The physiological recordings correspond to neuroblastoma cultures in the range of 1-7 div. They show bursting and spiking activity, with usually negative depolarisations. Figure 7 shows the spiking activity of the neural population with an automatic detection level for each electrode. This is very convenient if you have multiple channels for extracting spikes.

The standard deviation of each data trace is used to estimate its spike threshold. A time interval of $500 \mathrm{~ms}$ is used to calculate the standard deviation. By fixing the factor, by which the standard deviation is multiplied, the sign of the factor determines whether the spike detection level is positive or negative, only values above this will be extracted as spiking activity. A value between -1 and -4 is appropriate for most applications the threshold was fixed at standard deviation equal to -3 with respect to the electrode activity in order to identify spikes embedded in the noisy signals.

During the neuroblastoma development, a wide range of population bursting or synchronized activity has been 
observed, according to some studies in neural cultures preparations [11]. The burst usually contains a large number of spikes at many channels, with variable duration, from milliseconds to seconds.

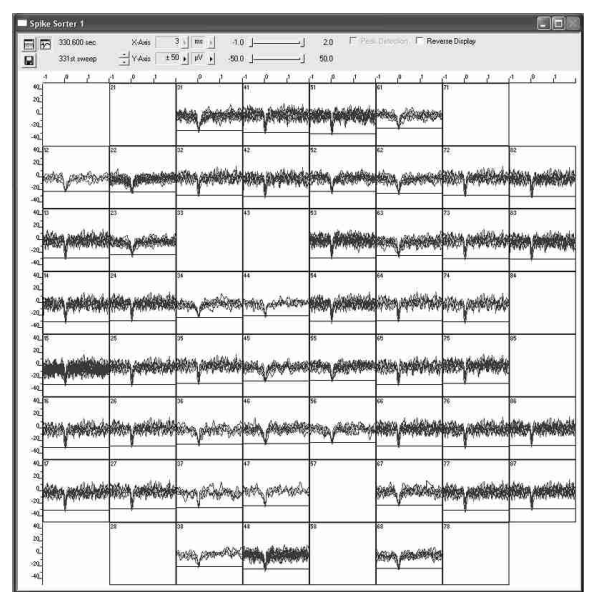

Figure 7: Spontaneus neural activity detected by the multielectrode array

\section{ROBOTIC CONTROL}

For controling the direction of the robot we propose to compute the vector resulting from neural activity recorded in the human neuroblastoma culture. This vector will be provided to the robot in order to guide his movement. The sensors will detect the obstacles, and the information will be passed to the computer in order to induce a selective tetanization of the biological neural network for changing the resulting direction vector. In Figure 8, the selected electrodes for the tetanization are shown in order to selective induce a persistent change in the biological neural network behaviour.
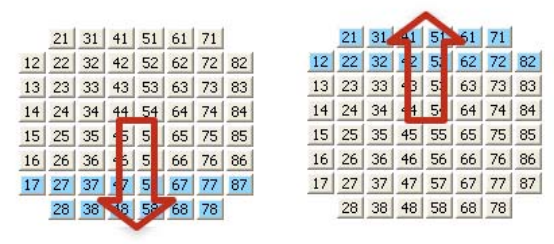

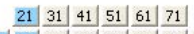
\begin{tabular}{llllllll} 
& 21 & & 41 & 51 & 61 & 71 & \\
\hline
\end{tabular}

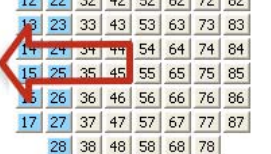

21| $31 \mid$\begin{tabular}{l|l|l|l|l|l|l|l|}
51 & 61 & 71 \\
\hline
\end{tabular}

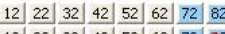
\begin{tabular}{l|l|l|l|l|l|l|l|}
13 & 23 & 33 & 43 & 53 & 63 & 73 & $\mathbf{3}$ \\
\hline 14 & 24 & 34 & 44 & 54 & 63 & 74 &
\end{tabular} \begin{tabular}{l|l|l|l|l|l|l|l|l}
14 & 24 & 34 & 44 & 54 & 64 & 74 & 84 \\
\hline
\end{tabular}

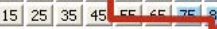

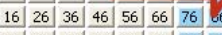
$\begin{array}{llllllllll}17 & 27 & 37 & 47 & 57 & 67 & 77 & 87\end{array}$

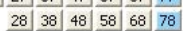

Figure 8: Selective electrode tetanization
When the robot detects an obstacle in his left path, a stimulation signal will be sent to the system for tetanizing the right tissue. By tetaniztion the electrodes of the right part of the array, an increase in the firing rate of the neural cells that lie in the part of the culture will be achieved, and the direction vector will point to the right in this particular case. We expect to apply some basic Braitenberg principles to the system in order to study the biological neural network behaviour induced by a tetanization-learning scheme.

\section{CONCLUSION}

Learning in cultured neuroblastoma networks by a stimulation process controlled by robot sensors requires identifying the correct stimuli to provide to the neurons maintained ex vivo. These neuroblastoma networks form a large culture covering the whole electrode array and generating a rich dendritic configuration. It is needed an open neural acquisition and stimulation system that responses in real time to the information provided by the robot sensors controlling its behaviour.

It is very important to adjust the frequency of the train pulses of the stimulation for suppressing bursting in the culture. While in vivo networks suppress bursting naturally with the tissue development and sensory inputs, ex-vivo cultures need to reduce this synchronized activity by adjusting the stimulation parameters. Also, for superimposing a desired behaviour on the biological networks it is necessary to stimulate locally some part of the culture in order to facilitate some parts of the networks, or achieve some kind of electrical stimulation that depress the local activity of a restricted location. With this local potentiation-inhibition scheme the culture global behaviour could be controlled.

Future work consists in determining the optimal stimulation to apply for inducing permanent firing changes in the culture, and the strategies for connecting the robot sensors to the stimulation patterns. These aspects will then constitute the basis for inducing stable goal-directed plasticity, and hence for designing new biological neuroprocessors applied to robotics.

\section{REFERENCES}

[1] Anderson J A and Rosenfeld E "Neurocomputing: Foundations of research", MIT Press Cambridge, MA, USA, 1998

[2] Braitenberg, V Vehicles: Experiments in synthetic psychology Cambridge, MA: MIT Press, 1984

[3] C A Thomas, Jr, P A Springer, G E Loeb, Y Berwald-Netter, and L M Okun, "A miniature microelectrode array to monitor the bioelectric activity of cultured cells," Exp. Cell. Res., vol 74, pp 6166,1972

[4] G W Gross, "Simultaneous single unit recording in vitro with a photoetched laser deinsulated gold multimicroelectrode surface," IEEE Trans Biomed Eng, vol 26, no 5, pp 273-279, 1979

[5] J Pine, "Recording action potentials from cultured neurons with extracellular microcircuit electrodes," J. Neurosci. Methods, vol 2, no 1, pp $19-31,1980$ 
Estudio y realización de un neuroprocesador

[6] Wagenaar, D A, DeMarse, T B , \& Potter, S M (2005) MeaBench: A toolset for multi-electrode data acquisition and on-line analysis 2 nd Intl IEEE EMBS Conference on Neural Engineering, 518-521

[7] MultiChannel Systems, http://www multichannelsystems com

[8] Ed Robbins, http://www multichannelsystems com/

[9] Ferrández, J M, Bongard, M, Lorente, V, Abarca, J, Villa, R, Fernández, E: "Activity modulation in human neuroblastoma cells: Fernandez, E : "Activity modulation in human neuroblastoma cells:
towards a biological neuroprocessor", LNCS

[10] Ferrández, J M, Lorente, V, Garrigós, J : “A biological neural network for robotic control: towards a biological neuroprocessor", ICNC (2009)

[11] Wagenaar, D A, Pine, J and Potter, S M, 2006 "An extremely rich repertoire of bursting patterns during the development of cortical cultures ", BMC Neuro-science, 7:11 


\title{
A Hybrid Robotic Control System Using Neuroblastoma Cultures
}

\author{
J.M. Ferrández ${ }^{1,2}$, V. Lorente ${ }^{2}$, J.M. Cuadra ${ }^{4}$, F. delaPaz ${ }^{4}$, \\ José Ramón Álvarez-Sánchez ${ }^{4}$, and E. Fernández ${ }^{1,3}$ \\ 1 Instituto de Bioingeniería, Universidad Miguel Hernández, Alicante, Spain \\ 2 Departamento de Electrónica, Tecnología de Computadoras y Proyectos, \\ Universidad Politécnica de Cartagena, Spain \\ 3 CIBER-BBN, Spain \\ 4 Departamento de Inteligencia Artificial, UNED, Spain
}

\begin{abstract}
The main objective of this work is to analyze the computing capabilities of human neuroblastoma cultured cells and to define connection schemes for controlling a robot behavior. Multielectrode Array (MEA) setups have been designed for direct culturing neural cells over silicon or glass substrates, providing the capability to stimulate and record simultaneously populations of neural cells. This paper describes the process of growing human neuroblastoma cells over MEA substrates and tries to modulate the natural physiologic responses of these cells by tetanic stimulation of the culture. We show that the large neuroblastoma networks developed in cultured MEAs are capable of learning: establishing numerous and dynamic connections, with modifiability induced by external stimuli and we propose an hybrid system for controlling a robot to avoid obstacles.
\end{abstract}

Keywords: Hybrid systems, cultured neural network, induced plasticity, robotic control.

\section{Introduction}

Using biological nervous systems as conventional computer elements is a fascinating problem that permits the hybridization between Neuroscience and Computer Science. There exist many research approaches based on mimicking this bioinspired parallel processing, not only from the algorithm perspective [1,5], but also from the silicon circuits design. These bioinspired approaches are useful for pattern recognition applications, like computer vision or robotics, however they are implemented over serial and artificial silicon processors with fixed and static structure. A real biological processor with millions of biological neurons and a huge number of interconnections, would provide much more computational power instead of their low transition rates due to high number of computing elements and the extraordinary network capability of adaptation and reconfiguration to unknown environments. This extraordinary capability is related with natural unsupervised learning.

M. Graña Romay et al. (Eds.): HAIS 2010, Part I, LNAI 6076, pp. 245-253, 2010

(C) Springer-Verlag Berlin Heidelberg 2010 


\section{J.M. Ferrández et al.}

Our learning experiments were performed in neural cultures containing 120.000 human neuroblastoma SH-SY5Y, under the assumption that this kind of cells are able to respond electrically to external stimuli and modulate their neural firing by changing the stimulation parameters. Such cultured neuroblastoma networks showed dynamical configurations, being able to develop and adapt functionally in response to external stimuli over a broad range of configuration patterns. We are especially interested in analyzing if populations of neuroblastoma cells are able to process and store information, and if learning can be implemented over this biological structure.

The main objective is to build a hybrid system integrating biological and electronic systems to achieve a new computational structure, able of robotic guidance in an obstacle avoidance task. MEA setups have been designed for direct culturing neural cells over silicon or glass substrates, providing the capability to stimulate and record simultaneously populations of neural cells. This paper describes the process of growing human neuroblastoma cells over MEA substrates and tries to modulate the natural physiologic responses of these cells by tetanic stimulation of the culture. We show that the large neuroblastoma networks developed in cultured MEAs are capable of learning: establishing numerous and dynamic connections, with modifiability induced by external stimuli and we propose an hybrid system for controlling a robot to avoid obstacles.

\section{Human Neuroblastoma Cultures}

Hebbian learning describes a basic mechanism for synaptic plasticity wherein an increase in synaptic efficacy arises from the presynaptic cells repeated and persistent stimulation of the postsynaptic cell. The theory is commonly evoked to explain some types of associative learning in which simultaneous activation of cells leads to pronounced increases in synaptic strength. The N-methyl-Daspartate (NMDA) receptor, a subtype of the glutamate receptor, has been implicated as playing a key role in synaptic plasticity in the central nervous system [3], where as dopamine receptors are involved in the regulation of motor and cognitive behaviors. For most synaptic ion channels, activation (opening) requires only the binding of neurotransmitters. However, activation of the NMDA channel requires two events: binding of glutamate (a neurotransmitter) and relief of Mg2 + block. NMDA channels are located at the postsynaptic membrane. When the membrane potential is at rest, the NMDA channels are blocked by the $\mathrm{Mg} 2+$ ions. If the membrane potential is depolarized due to excitation of the postsynaptic neuron, the outward depolarizing field may repel $\mathrm{Mg} 2+$ out of the channel pore. On the other hand, binding of glutamate may open the gate of NMDA channels (the gating mechanisms of most ion channels are not known). In the normal physiological process, glutamate is released from the presynaptic terminal when the presynaptic neuron is excited. Relief of $\mathrm{Mg} 2+$ block is due to excitation of the postsynaptic neuron. Therefore, excitation of both presynaptic and postsynaptic neurons may open the NMDA channels, this is closely related with Hebbian learning. 
In neuroscience, long-term potentiation (LTP) is a long-lasting enhancement in signal transmission between two neurons that results from stimulating them synchronously. It is one of several phenomena underlying synaptic plasticity, the ability of chemical synapses to change their strength. As memories are thought to be encoded by modification of synaptic strength, LTP is widely considered one of the major cellular mechanisms that underlies learning and memory. The term long-term potentiation comes from the fact that this increase in synaptic strength, or potentiation, lasts a very long time compared to other processes that affect synaptic strength. Induction of LTP occurs when the concentration of calcium inside the postsynaptic cell exceeds a critical threshold. In many types of LTP, the flow of calcium into the cell requires the NMDA receptor, which is why these types of LTP are considered to be NMDA receptor-dependent. NMDA receptor-dependent LTP can be induced experimentally by applying a few trains of high-frequency stimuli to the connection between two neurons, this is called tetanization, or tetanic stimulation. So, a tetanic stimulation consists of a highfrequency sequence of individual stimulations of a neuron. It is associated with long-term potentiation, the objective of this work. High-frequency stimulation causes an increase in transmitter release called post-tetanic potentiation [2]. This presynaptic event is caused by calcium influx. Calcium-protein interactions then produce a change in vesicle exocytosis. Some studies [6] use repetitive stimulation for training neural cultures, achieving activity potentiatiation or depresion.

A human neuroblastoma SH-SY5Y cell line, that express clonal specific human dopamine receptors, and also NMDA receptors, will be the biological platform for studying learning in cultured cells. Neuroblastoma SH-SY5Y cells are known to be dopaminergic, acetylcholinergic, glutamatergic and adenosinergic, so in this line they respond to different neurotransmitters. The cells have very different growth phases, as it can be seen in Figure 1a). The cells both propagate via mitosis and differentiate by extending neurites to the surrounding area. The dividing cells can form clusters of cells which are reminders of their cancerous nature, but chemicals can force the cells to dendrify and differentiate, in some kind of neuritic growth.
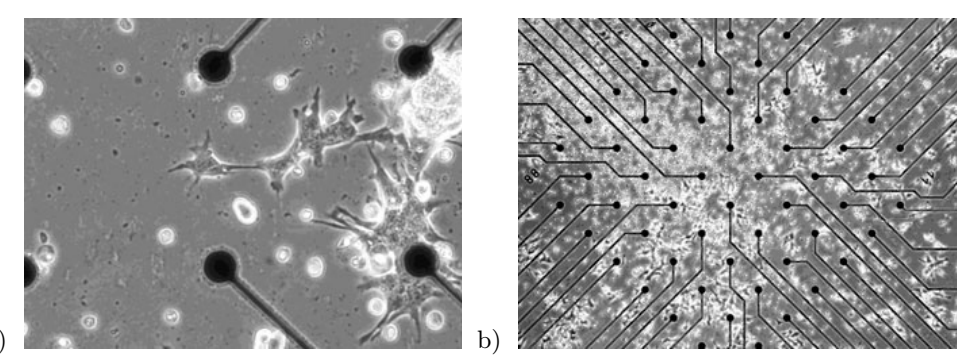

Fig. 1. a) Human neuroblastoma cells over multielectrode array. b)Biological neural network over MEA. 
The neuroblastoma cultures are maintained in a 37 degree humidified incubator with 5\% CO2 and 95\% O2 with serum-free Neurobasal medium. Under the aforementioned conditions we were able to record stable electrophysiological signals over different days in vitro (div). The medium was replaced one-half of the medium every 5 days. At 10 div, the cells decrease their adhesion to the plate, so more of the population lost their contact with the metal elements and after $15 \mathrm{div}$, they get an embryonic configuration. So, the same neuroblastoma cells where seeded in polyethyleneimine (PEI) covered MEAs. The main drawback of this covering is that only few electrodes are covered with cells, because it stops the growing process, so we will get very limited responses from the whole electrode matrix. The choice is to have a lot of cells with strong adhesion to the electrodes a few days, or few covered electrodes with longer survival times.

\section{Experimental Setup}

The basic components of the proposed system are shown in Figure 2.

The substrate-embedded multielectrode array technology was used. It includes arrays of $60 \mathrm{Ti} / \mathrm{Au} / \mathrm{TiN}$ electrodes, 30 microm in diameter, and spaced 200 microm from each other [MultiChannelSystems (MCS), Reutlingen, Germany]. A commercial 60 channel amplifier (B-MEA-1060; MCS) with frequency limits of $10-3000 \mathrm{~Hz}$ and a gain of $1024 \mathrm{X}$ was used. Stimulation through the MEA is performed using a dedicated two channel stimulus generator (MCS) able of time multiplexing the signals for stimulating the 60 electrodes in a nearly parallel process. The microincubation environment was arranged to support long-term recordings from MEA dishes by electrically heating the MEA platform to $37^{\circ} \mathrm{C}$. Data were digitized using MCS analog-to-digital boards. Each channel is sampled at a frequency of 24,000 samples/sec and prepared for analysis using the MCRACK softeware provide also by Multichannel Systems.

We use this system for remote obstacle avoidance, having the neuroblastoma culture mounted in an inverted microscope connected to the control unit, instead of having the cultures attached to the robot in an embedded system, that nowadays has many technical difficulties. The robot sends information about the environment to the computer using a bluetooth link and it has infrared sensors for detecting obstacles.

Neural spike events, embedded in the noisy signals, are detected by comparing the instantaneous electrode signals to level thresholds set for each data channel.

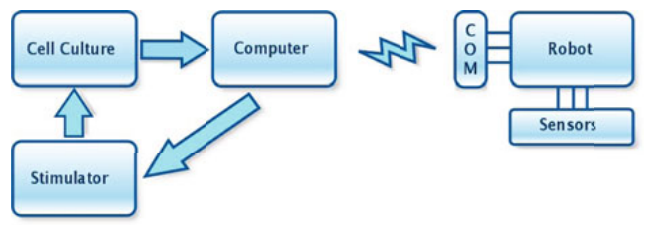

Fig. 2. Experimental Setup 
The standard deviation of each data trace is used to estimate its spike threshold, a time interval of $500 \mathrm{~ms}$ is used to calculate it. The threshold is set as a multiple of the computed deviation, only values above will be extracted as spiking activity. The sign of the factor determines whether the spike detection level is positive or negative. A value between -1 and -4 is appropriate for most applications, in this work the threshold was set to -3 . When a supra-threshold event occurs, the signal window surrounding the event was time-stamped and stored together with the state of the visual stimulus for later, offline analysis. For spike sorting we used a free program, NEV2lkit, which has been recently developed by our group and runs under Windows, MacOSX and Linux (source code and documentation is freely available [7]). NEV2lkit loads multielectrode data files in various formats (ASCII based formats, LabView formats, Neural Event Files, etc) and is able to sort extracted spikes from large sets of data. The sorting was done using principal component analysis (PCA) and performed simultaneously on many records from the same experiment.

\section{Results}

The cultured neuroblastoma cells establish synaptic connections. In Figure 1b) it can be seen differentiated and non-differentiated neuroblastoma cell bodies growing around the whole electrode population. The dendritic arborescence is more evident in the magnification Figure 1a) where differentiated neural cells surround the four electrodes while the rest of the cells are in their growing process. Figure 1b) corresponds to 80.000 neuroblastoma cells seeded in a nopoly-ethylene-imine (no-PEI) MEA at 2 nd day in vitro (div).

The electrophysiological properties of the neuroblastoma cultures were analyzed by recording the spontaneous activity of the network. Time course of experiments was over 15 days; recordings were done using two MCS-Meas with two neuroblastoma cell cultures (but only in one the cells survived till day 15). In vitro neuroblastoma networks show spontaneously firing. The firing rates change during the culture development with marked day differences and the global rate is closely related to the age of the network.

The physiological recordings correspond to neuroblastoma cultures in the range of 1-7 div. They show bursting and spiking activity, with usually negative depolarizations. Figure 3a) shows the spiking activity of the neural population with an automatic detection level for each electrode. This is very convenient if you have multiple channels for extracting spikes.

During the neuroblastoma development, a wide range of population bursting or showing synchronized activity has been observed, according to some studies in neural cultures preparations [8]. The burst usually contains a large number of spikes at many channels, with variable duration, from milliseconds to seconds.

\subsection{Tetanic Stimulation}

Spontaneous activity was recorded for intervals of 3 minutes before stimulation (PRE-data), and the total number of spikes extracted was counted. The biphasic 

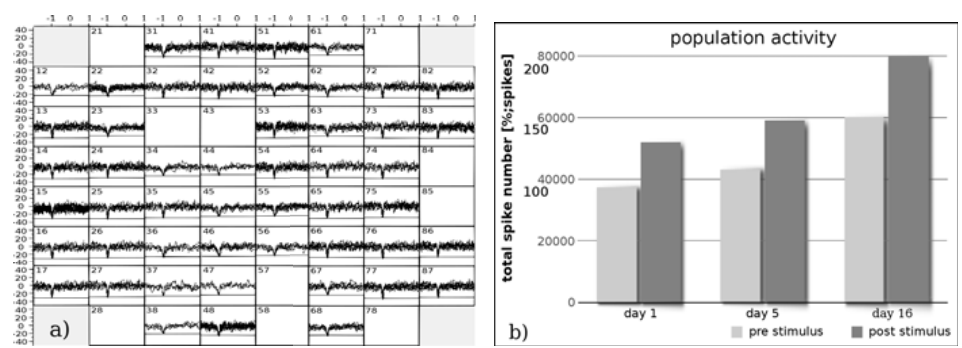

Fig. 3. a) Spontaneous neural activity detected by the multielectrode array. b) Induced neural activity by tetanization stimuli.

stimulus consists in a 10 trains of a 100 anodic-first waveform with 1 Volt amplitude delivered to all 60 electrodes in order to propagate a tetanization stimulus to the neuroblastoma culture.

Once the tetanization stimulus was applied to the whole population 5 minutes after the stimulation a 3 minutes interval was recorded (POST-data). Only neuronal signals which had at least a 2:1 signal:noise ratio were valued as "spikes". Again, the total number of spikes extracted was counted. This process was made for cultures at 1 day in vitro (div), 5 div and 16 div. Figure $3 b$ ) represents the counted spikes with bar charts for the different recordings. The conclusions from this figure are: 1) While the neuroblastoma culture is growing new connections are created, and the number of spikes increases as the culture expands over the MEA. 2) After a tetanic stimulation the cells continue with their increased spiking rate, providing a persistent change in the culture behavior. When a change in the network response lasts, such a change can be called learning.

In all the experimentation performed, tetanic stimulation was applied as training method, and the electrophysiological properties of the neuroblastoma culture change, getting a potentiation effect on the spontaneous firing, modulating in this way the culture neural activity.

\subsection{Robotic Control}

For controlling the direction of the robot we propose to compute the vector resulting from neural activity recorded in the human neuroblastoma culture. This vector will be provided to the robot in order to guide its movement. The sensors will detect the obstacles, and the information will be passed to the computer in order to induce a selective tetanization of the biological neural network for changing the resulting direction vector. In Figure 4a), the selected electrodes for the tetanization are shown in order to selectively induce a persistent change in the biological neural network behavior.

When the robot detects an obstacle at the left of its path, an stimulation signal will be sent to the system for tetanizing the left tissue. By tetanization of 


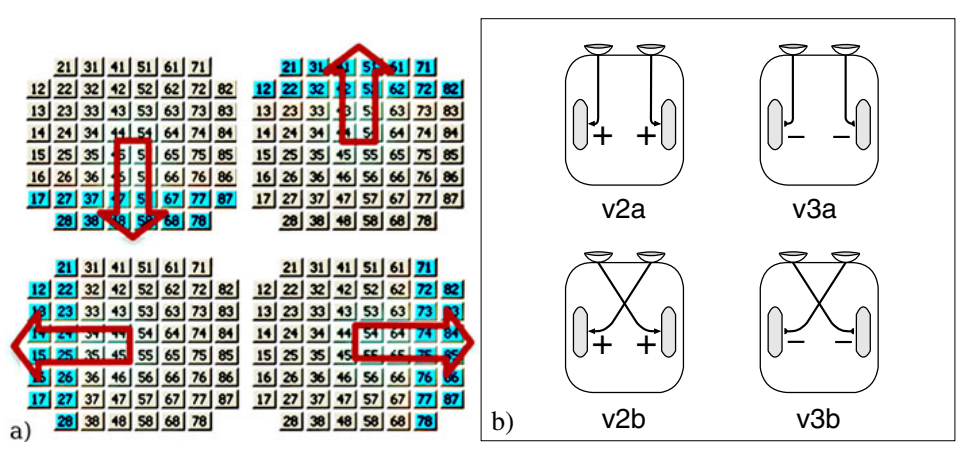

Fig. 4. a) Selective electrode tetanization. b) Simple Braitenberg's vehicles showing sensory motor connections.

the electrodes at the left part of the array, an increase in the firing rate of the neural cells laying in this area of the culture will be achieved. If each culture side is connected to the corresponding robot motor, we get a direction vector for the robot pointing to the right in this particular case.

\section{Discussion}

Valentino Braitenberg [4] describes the different behaviors originated by simple neural sensory motor circuits. In his experimental research, he found that very simple neural structure give rise to very complex and astonishing behaviors. These behaviors, independent from its underlying neural structure, are known as fear, anger... and so on.

The neural robotic control system proposed in this paper aims to implement Braitenberg's vehicles. The proposed system is oriented to obstacle avoidance with the following scheme: an increase in the neural activity of lateral part of the culture will imply an increase of the speed in the corresponding robot motor, Braitenberg's vehicle v2a, see Figures $4 \mathrm{~b}$ ) and 5 . If the scheme is transposed in a cross-modal connection, that is every part of the culture is connected to the opposite lateral motor, the robot behavior changes, orienting its direction to the stimulus source, Braitenberg's vehicle v2b. This behavior could be seen as attacking or pursuing the source.

If we include inhibitory connections instead of excitatory ones, the behavior also changes, Braitenberg's vehicles v3a and v3b. The obstacle-avoiding robot would decrease its speed as it approaches the source, stopping in front of it, while the source attacking robot would also decrease its speed as it reaches the source, but any perturbation on the source intensity would achieve escaping from it.

If we have two different sensory systems, one can be used for an obstacle avoidance task, while the other for detecting the source-goal. The combination 


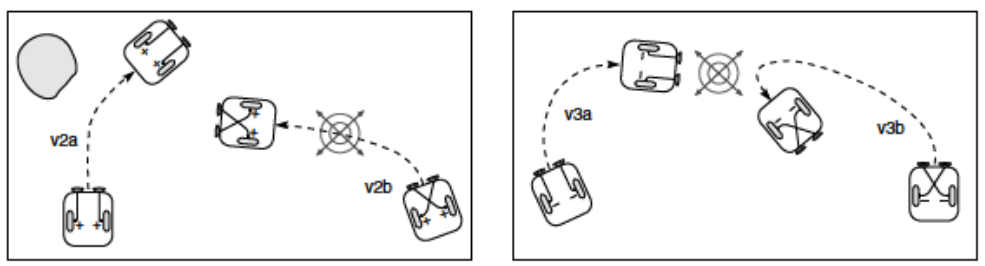

Fig. 5. Braitenberg's vehicles behaviors

of both systems would induce reaching a certain goal while avoiding obstacles, the main objective in autonomous robotics. In such scenario it is essential to define the subsystems priority: if the goal to reach is behind some obstacles, the obstacle avoidance task must impose over the reaching-goal task. This priority can be implemented by inhibiting the goal-reaching task when an obstacle is detected.

In conclusion, the first definition for building the biologically robotic control system is the number of neuroblastoma cultures to use: if two neural cultures are used, one for each sensory system, and hence for each behavior, there must exist some inhibition mechanism for blocking the neural activity of the reaching-goal culture when an obstacle is detected. On the other hand if there exist only one neural culture for both tasks, some inhibitory connections should be induced over the culture in order to define the priority system over the neural subpopulations.

The first solution, two neural cultures, is a very expensive solution, because the 64-channel registering-stimulation system has an elevate cost, and the equipment mounted over an inverted microscope. This solution should be connected to the same computer that must analyze the neural activity of each culture for implementing the inhibition strategies. In addition each culture must be stimulated using different Braitenberg principles in order to define the desired behavior task.

The second solution could be implemented training different parts of the cultures with different Braitenberg paradigms and defining inhibitory connections between both areas. This solution requires culturing, training and reading neural cells in parallel, defining different stimulation paradigms for different neural subpopulations. The main difficulty is that the growing process of the culture is not homogeneous over the Multielectrode Array, evoking distinct neural activity patterns. In this case it is needed a normalizing process for getting homogeneous activity on the electrodes, or improving the growing protocols for seeding and culturing homogeneous biological neuroblastoma networks. A third solution could consist in a hybrid system with one behavior implemented over the biological culture and the other in the hardware that is reading the neural activity, implementing a biological-silicon super-structure. The limitation is the number of electrodes available for reading/stimulating the neural tissue that in our system is 64 bidirectional electrodes. An optical stimulation of the tissue would provide much more spatial resolution, and inhibition procedures, so we are working in 
selective genetic programing the neuroblastoma cultures for optical stimulation, using in this way many visual processes, we call it optogenetic neuroblastoma culture.

\section{References}

1. Anderson, J.A., Rosenfeld, E.: Neurocomputing: Foundations of research. MIT Press, Cambridge (1998)

2. Antonov, I., Antonova, I., Kandel, E.R.: Activity-dependent presynaptic facilitation and hebbian ltp are both required and interact during classical conditioning in aplysia. Neuron 37(1), 135-147 (2003)

3. Bading, H., Greenberg, M.E.: Stimulation of protein tyrosine phosphorylation by nmda receptor activation. Science 253(5022), 912-914 (1991)

4. Braitenberg, V.: Vehicles: Experiments in Synthetic Psichology. MIT Press, Cambridge (1984)

5. Duro, R.J., Graña, M., de Lope, J.: On the potential contributions of hybrid intelligent approaches to multicomponent robotic system development. Information Sciences (2010) (in Press)

6. Jimbo, Y., Robinson, H.P., Kawana, A.: Strengthening of synchronized activity by tetanic stimulation in cortical cultures: application of planar electrode arrays. IEEE Transactions on Biomedical Engineering 45(11), 1297-1304 (1998)

7. Micol, D.: Nev2lkit (2006), http://nev2lkit.sourceforge.net/

8. Wagenaar, D.A., Pine, J., Potter, S.M.: An extremely rich repertoire of bursting patterns during the development of cortical cultures. BMC Neuro-science 7, 11 (2006) 


\title{
Image Coding for Robotic Guidance Using Neuroblastoma Cultures
}

\author{
José M. Ferrández ${ }^{1}$, Víctor Lorente ${ }^{1}$, Javier Garrigós ${ }^{1}$, Eduardo Fernández ${ }^{2}$ \\ 1- Departamento de Electrónica, Tecnología de Computadores y Proyectos, Universidad Politécnica de Cartagena, Spain \\ Email: jm ferrandez@upct es \\ 2- Instituto de Bioingeniería, Universidad Miguel Hernández de Elche, CIBER-BBN, Spain \\ Email: e fernandez@umh es \\ Received: July 2010 \\ Revised: December 2010 \\ Accepted: January 2011
}

\begin{abstract}
:
The main objective of this work is to analyze the computing capabilities of human neuroblastoma cultured cells and to define stimulation patterns able to modulate the neural activity in response to an image for controlling an autonomous robot. Multielectrode Arrays Setups have been designed for direct culturing neural cells over silicon or glass substrates, providing the capability to stimulate and record simultaneously populations of neural cells. If we are able to modify the selective responses of some cells with an external pattern stimuli over different time scales, the neuroblastoma-cultured structure could be trained to process image sequences.
\end{abstract}

KEYWORDS: Biological processing, image coding, multielectrode array, neural learning, robotic guidance.

\section{INTRODUCTION}

Using biological nervous systems as conventional computer elements is a fascinating problem that permits the hybridation between Neuroscience and Computer Science. This synergic approach can provide a deeper understanding of natural perception and may be used for the design of new computing devices based on natural computational paradigms. The brain uses millions of biological processors, with dynamic structure; slow commutations compared with silicon circuits, low power consumption and unsupervised learning. This kind of computation is more related to perceptual recognition, due to the natural variance of the perceptive patterns and a priori lack of knowledge about the perceptual domain.

There exist many research approaches based on mimicking this bioinspired parallel processing, not only from the algorithm perspective [1,2], but also from the silicon circuits design. These bioinspired approaches are useful for pattern recognition applications, like computer vision or robotics, however they are implemented over serial and artificial silicon processors with fixed and static structure. A real biological processor with millions of biological neurons and a huge number of interconnections, would provide much more computational power instead of their low transition rates due to high number of computing elements and the extraordinary network capability of adaptation and reconfiguration to unknown environments. This extraordinary capability is related with natural unsupervised learning.

Our learning experiments were performed in neural cultures containing 120.000 human neuroblastoma SY$5 \mathrm{Y}$, under the assumption that this kind of cells are able to respond electrically to external stimuli and modulate their neural firing by changing the stimulation parameters. Such cultured neuroblastoma networks showed dynamical configurations, being able to develop and adapt functionally in response to external stimuli over a broad range of configuration patterns. We are especially interested in analizing if populations of neuroblastoma cells are able to process and store information, and if learning can be implemented over this biological structure. The main objective of this work is coding images acquired by a robot into a stimulation pattern based on a selective stimulation. This stimulation will be applied to the culture in order to change its neural activity and guide the robot movement.

This work describes the process of growing human neuroblastoma cells over MEA (MultiElectrode Array) substrates and tries to change the natural physiologic responses of these cells by external stimulation of the culture provided by the robot sensors. Modifying the global responses of some cells with an external pattern stimuli means adjusting the biological network behavior due to changes in synaptic efficiency or longterm potentiation (LTP). Several groups have followed the same path studying how information is processed and encoded in living cultured neuronal networks by 


\section{Majlesi Journal of Electrical Engineering}

interfacing them to a robot $[3,4]$. The cells used in these experiments were extracted from cortical or hippocampal tissue of embryonic rats, but none of them have used human neuroblastoma cells, which can grow and replicate so its plasticity will be higher than in previous studies and we can achieve better results in learning experiments.

We propose a system for determining that the large neuroblastoma Networks developed in cultured MEAs are capable of learning: stablishing numerous and dynamic connections, with modifiability induced by external stimuli, in this case an image acquired by a robot through its camera.

\section{HUMAN NEUROBLASTOMA CULTURES}

The physiological function of neural cells is modulated by the underlying mechanisms of adaptation and reconfiguration in response to neural activity. Hebbian learning describes a basic mechanism for synaptic plasticity wherein an increase in synaptic efficacy arises from the presynaptic cell's repeated and persistent stimulation of the postsynaptic cell. The theory is commonly evoked to explain some types of associative learning in which simultaneous activation of cells leads to pronounced increases in synaptic strength. The N-methyl-D-aspartate (NMDA) receptor, a subtype of the glutamate receptor, has been implicated as playing a key role in synaptic plasticity in the central nervous system [5], where as dopamine receptors are involved in the regulation of motor and cognitive behaviors. Excitation of both presynaptic and postsynaptic neurons may open the NMDA channels, that it is closely related with Hebbian learning.

Neuroplasticity refers to the ability of the human brain to change as a result of one's experience, that the brain is 'plastic' and 'malleable'. The brain consists of nerve cells (or "neurons") and glial cells which are interconnected, and learning may happen through change in the strength of the connections, by adding or removing connections, and by the formation of new cells. "Plasticity" relates to learning by adding or removing connections, or adding cells. In this paper, neuroblastoma cultures, able of growing and establish new connections, will be the biological platform for inducing platicity in a directed or supervised process.

In neuroscience, LTP is a long-lasting enhancement in signal transmission between two neurons that results from stimulating them synchronously. It is one of several phenomena underlying synaptic plasticity, the ability of chemical synapses to change their strength (in chemical synapses transmission is mediated through neurotrasmitters, while in electrical synapses it is achieved by electrical currents). As memories are thought to be encoded by modification of synaptic strength, LTP is widely considered one of the major cellular mechanisms that underlie learning and
Vol. 5, No. 1, March 2011

memory. The term long-term potentiation comes from the fact that this increase in synaptic strength, or potentiation, lasts a very long time compared to other processes that affect synaptic strength. Induction of LTP occurs when the concentration of calcium inside the postsynaptic cell exceeds a critical threshold. In many types of LTP, the flow of calcium into the cell requires the NMDA receptor, which is why these types of LTP are considered to be NMDA receptordependent. NMDA receptor-dependent LTP can be induced experimentally by applying a few trains of high-frequency stimuli to the connection between two neurons, this is called tetanization, or tetanic stimulation. So, a tetanic stimulation consists of a highfrequency sequence of individual stimulations of a neuron. It is associated with long-term potentiation, the objective of this work. High-frequency stimulation causes an increase in transmitter release called posttetanic potentiation [6]. This presynaptic event is caused by calcium influx. Calcium-protein interactions then produce a change in vesicle exocytosis. Some studies [7] use repetitive stimulation for training neural cultures, achieving activity potentiation or depression.

Another important feature of the NMDA channel is that it conducts mainly the $\mathrm{Ca} 2+$ ion, which may activate various enzymes for synaptic modification; even nictric oxide has been identified as a relevant element in synaptic regulation. The enhancement of synaptic transmission is called the LTP, which involves two parts: the induction and the maintenance. The induction refers to the process, which opens NMDA channels for the entry of $\mathrm{Ca} 2+$ ions into the postsynaptic neuron. The subsequent synaptic modification by $\mathrm{Ca} 2+$ ions is referred to as the maintenance of LTP

A human neuroblastoma SY5Y cell line, that express clonal specific human dopamine receptors, and also NMDA receptors, will be the biological platform for studying learning in cultured cells.

Neuroblastoma SH-SY5Y cells are known to be dopaminergc, acetylcholinergic, glutamatergic and adenosinergic, so in this line they respond to different neurotransmitters. The cells have very different growth phases, as it can be seen in Fig. 1 b). The cells both propagate via mitosis and differentiate by extending neurites to the surrounding area. The dividing cells can form clusters of cells, which are reminders of their cancerous nature, but chemicals can force the cells to dendrify and differentiate, in some kind of neuritic growth.

As conclusion, neuroblastoma culture cells show electrophysiological responses similar to standard neurons, as potential actions generation sensible to tetrodotoxin (TTX) and acetylcholyn. They have neurotransmitters synthesis process and are able to neuritic growth in culture medium. 
Majlesi Journal of Electrical Engineering

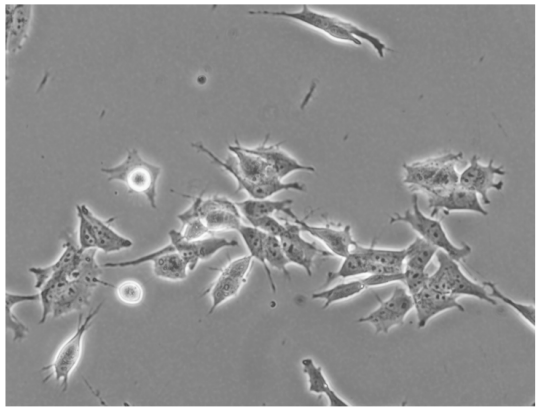

(a)

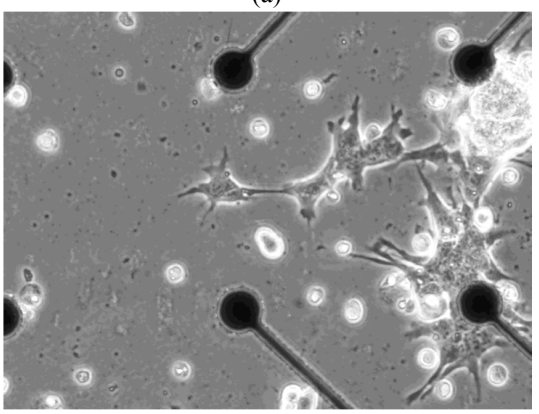

(b)

Fig. 1. (a) Human neuroblastoma cells

(b) Neuroblastoma cells over multielectrode array.

\section{EXPERIMENTAL SETUP}

The neuro-physiological setup provides a complete solution for stimulation, heating, recording, and data acquisition from 64 channels. The MEA system is intended for extracellular electrophysiological recordings in vitro of different applications that include acute brain, heart, and retina slices; cultured slices; and dissociated neuronal cell cultures.

The basic components of the proposed system are shown in Fig. 2. These components are:

- A microelectrode array is an arrangement of 60 electrodes that allows the simultaneous targeting of several sites for extracellular stimulation and recording. Cell lines or tissue slices are placed directly on the MEA and can be cultivated for up to several months. Almost all excitable or spontaneously active cells and tissues can be used.

- Raw data from the MEA electrodes are amplified filter amplifiers from MCS (MultiChannel Systems, Reutlingen, Germany). with custom bandwidth and gain, which are built very small and compact using SMD (Surface Mounted Devices) technology. The small-sized amplifier combines the interface to the MEA

\section{Vol. 5, No. 1, March 2011}

probe with the signal filtering and the amplification of the signal. The compact design reduces line pick up and keeps the noise level down. The amplifiers are mounted over an inverted microscope.

- The analog input signals are then acquired and digitized by the MC-Card that is preinstalled on the data acquisition computer, that supplies the power for the amplifiers, and the pattern stimuli to the stimulators.

- The robot sends information about the environment to the computer using a bluetooth link. The sensor consists in a camera placed on the robot.

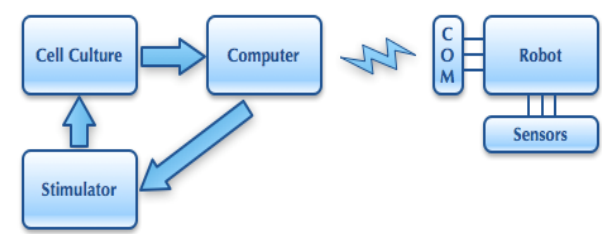

Fig. 2. Experimental Setup.

We have developed a system that provides a complete robotic control platform over neuroblastoma cultures. The system includes five free, open-source, console-based programs written in $\mathrm{C} / \mathrm{C}++$ for real-time robotic applications with embodied cultures. All of this software has been developed for the Linux Operating System and MCS hardware. Using this software in conjunction with MEABENCH is specially intended for close-loop experiments.

The software developed consists of the following programs:

- Cult2Robot The main program. It has been developed as a MEABENCH module, so it can access to all of the data streams that MEABENCH provides. Cult2Robot read spikes information from MEABENCH spike detector and compute a direction vector based on MEA neural activity.

- Stg_control This program controls a generalpurpose stimulus generator for current and voltage-driven electrical stimulation, STG 1000 series (MultiChannel Systems, Reutlingen, Germany). The STG may be connected to a PC via RS232 port or via USB port. Stg_control make possible program and download custom functions to the STG, start/stop the stimulation, reset the device or send any command described in the STG100x RS232 Communication Manual.

- Electrode select This module allows configuring the MEA1060BC amplifier 


\section{Majlesi Journal of Electrical Engineering}

following the MEA protocol from MCS [6]. With the Electrode_select program, it is easy to change the electrode selection during the experiment, e.g. to use stimulating electrodes for recording and vice versa. It also has almost all the features that its Windows counterpart 'MEA_select', such as blanking electrodes, changing MEA, using wait for optimizing the electrode's behaviour or reset the device.

- BTserver Receiving environmental information from the robot is a primary objective. BT_server is a non-blocking Bluetooth server that uses RFCOMM protocol to receive characters from a specific MAC, process the information and do some action, e.g. it can be used to call another program when $p$. eg. an obstacle is detected ( $\mathrm{An}$ ' $\mathrm{O}$ ' has been received).

- BT client Sending information to the robot is also important to establish a bidirectional link and transmit the outputs to the robot. BT_client sends ASCII characters via Bluetooth using RFCOMM protocol.

\section{METHODS}

Human neuroblastoma cultures were produced using the commercial line SH/SY5Y . Neural cells were then plated on Micro-Electrode Arrays - MEAs (MultiChannel Systems, Reutlingen, Germany). Initially the nitrogen frozen cells, was immersed in a 37-degree bath, and centrifuged at $1000 \mathrm{rpm}$ during 5 minutes. When cells have grown in a uniform monolayer process, they are washed three times with buffer Phosphate-buffered saline (PBS) for keeping the $\mathrm{pH}$ approximately constant. 0,5 percent trypsin was added to the solution in order to re-suspend cells adherent to the cell culture dish wall during the process of harvesting cells. The cells were kept in the incubator for 5 minutes and passed through a 40-microm-cell strainer (Falcon, Bedford, MA) to remove large debris. Finally the cells are transferred to a specific medium in order to inactivate trypsin, and centrifuged again during 5 minutes at $1000 \mathrm{rpm}$.

For seeding the plate cells are stained with trypan blue, (because cells that loose their permeability get colored with this solution) and counted with a Neubauer chamber. Finally, 80.000 or 120.000 total neuroblastoma cells have been placed over the MEA substrate.

Maintaining cells in culture is essential for studying their physiological properties. Cell culturing is dependent on the growth surfaces and cells must adhere to the electrode substrate in order to establish the best connection with the electrodes material. For most cultures coated tissue culture plates are prerequisite for seeding. The most commonly used coatings are
Vol. 5, No. 1, March 2011

positively charged polymers. In this work, the insulation layer (silicon nitride) of some of the plates was pre-treated with polyethyleneimine (PEI), showing no advantages compared with no covered plates.

The neuroblastoma cultures are maintained in a 37 degree humidified incubator with 5 per cent $\mathrm{CO} 2$ and 95 per cent $\mathrm{O} 2$ with serum-free Neurobasal medium. Under the aforementioned conditions we were able to record stable electrophysiological signals over different days in vitro (Div). The medium was replaced one-half of the medium every 5 days.

\section{RESULTS}

The cultured neuroblastoma cells establish synaptic connections. In Fig. 3 a) it can be seen differentiated and non-differentiated neuroblastoma cell bodies growing around the whole electrode population. The dendritic arborescence is more evident in the magnification Fig. 3 b) where differentiated neural cells surround the four electrodes while the rest of the cells are in their growing process. This figure corresponds to 80.000 neuroblastoma cells seeded in a no-PEI MEA at 2nd day in vitro (div).

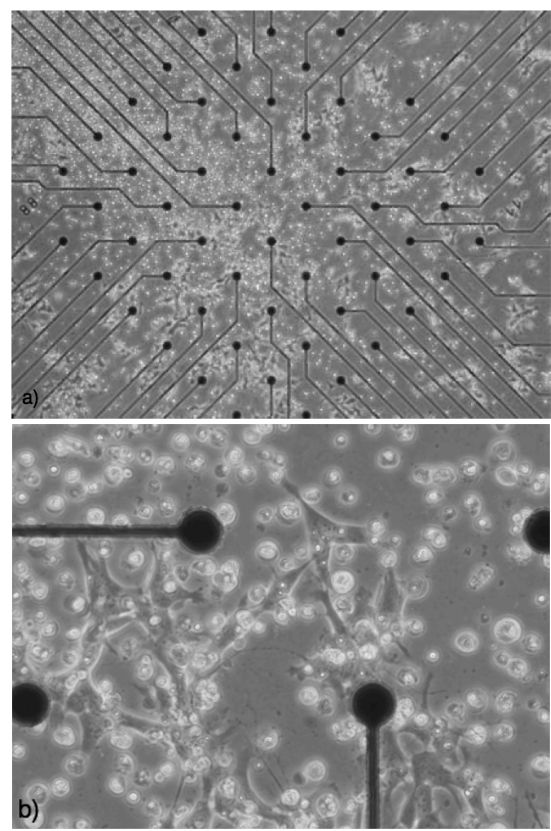

Fig. 3. a) Human Neuroblastoma Culture over Multielectrode Array (80.000 cells). b) Magnification of the culture shown in a).

The electrophysiological properties of the neuroblastoma cultures were analyzed by recording the 


\section{Majlesi Journal of Electrical Engineering}

spontaneous activity of the network. Time course of experiments was over 15 days; recordings were done using two MCS-Meas with two neuroblastoma cell cultures (but only in one the cells survived till day 15). In vitro neuroblastoma networks show spontaneously firing. This firing rates change during the culture development with marked day differences and the global rate is closely related to the age of the network.

The physiological recordings correspond to neuroblastoma cultures in the range of 1-7 div. They show bursting and spiking activity, with usually negative depolarizations. Fig. 4 shows the spiking activity of the neural population with an automatic detection level for each electrode. This is very convenient if you have multiple channels for extracting spikes.

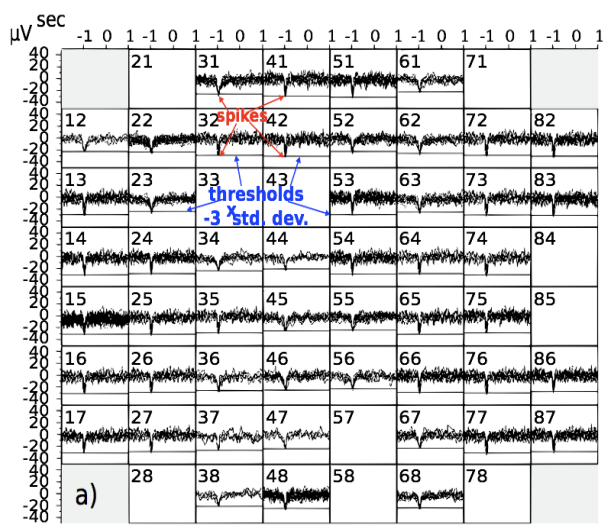

Fig. 4. a) Spontaneous neural activity detected by the multielectrode array.

The standard deviation of each data trace is used to estimate its spike threshold. A time interval of $500 \mathrm{~ms}$ is used to calculate the standard deviation. By fixing the factor, by which the standard deviation is multiplied, the sign of the factor determines whether the spike detection level is positive or negative, only values above this will be extracted as spiking activity. A value between -1 and -4 of the standard deviation is appropriate for most applications the threshold was fixed at standard deviation equal to -3 with respect to the electrode activity in order to identify spikes embedded in the noisy signals. During the neuroblastoma development, a wide range of population bursting or synchronized activity has been observed, according to some studies in neural cultures preparations [9]. The burst usually contains a large number of spikes at many channels, with variable duration, from milliseconds to seconds.

In our first approximation we used tetanic stimulation for programming the culture $[6,7,10]$
Vol. 5, No. 1, March 2011

getting temporal changes in the culture behavior.

\subsection{Robotic Control}

In previous papers $[10,11]$ we proposed to compute the vector resulting from neural activity recorded in the human neuroblastoma culture and this vector was provided to the robot in order to guide its movement. The sensors detected the obstacles, and the information was passed to the computer in order to induce a selective tetanization of the biological neural network for changing the resulting direction vector.
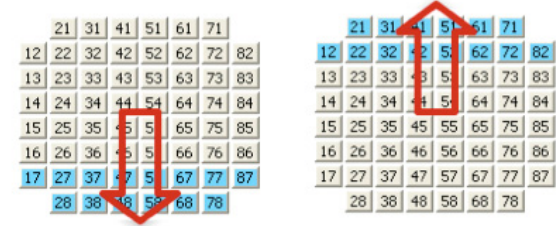

$2131|41| 51|61| 71$

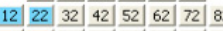

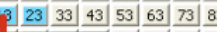

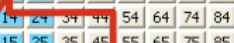

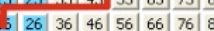

$\begin{array}{lllllllll}17 & 27 & 37 & 47 & 57 & 67 & 77 & 87\end{array}$

28 38 48 |

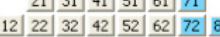

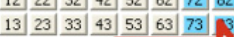

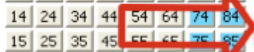

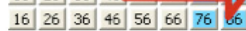

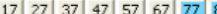

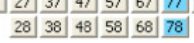

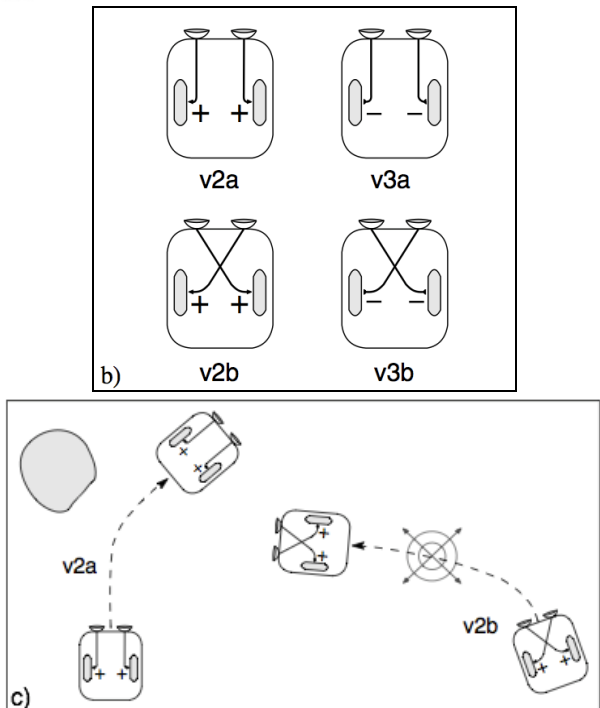

Fig. 5. a) Selective electrode tetanization. b) Simple Braitenberg's vehicles showing sensory motor connections. c) Braitenberg's vehicles behaviors.

In Fig. 4a, the selected electrodes for the tetanization are shown in order to selectively induce a persistent change in the biological neural network 


\section{Majlesi Journal of Electrical Engineering}

behavior. This robotic control system aimed to implement Braitenberg's vehicles [12] with the following scheme: an increase in the neural activity of lateral part of the culture will imply an increase of the speed in the corresponding robot motor, (Braitenberg's vehicle v2a, see Fig. $5 b$ ) and $5 c$ ))

If the scheme is transposed in a cross-modal connection, which is every part of the culture is connected to the opposite lateral motor, the robot behavior changes, orienting its direction to the stimulus source, Braitenberg's vehicle v2b. So, when the robot detected an obstacle in his left path, a stimulation signal was sent to the system for tetanizing the right tissue. By tetanizing the electrodes of the right part of the array, an increase in the firing rate of the neural cells that lie in the part of the culture was achieved, and the direction vector pointed to the right in this particular case.

Coding images for robotic guidance makes it difficult to use the previous scheme. Because of that, we propose to apply a simple centre of area method, presented in earlier papers $[13,14]$. In this method we compute the winner neurons (that is the ones that increase more its firing characteristics) resulting from neural activity recorded in the human neuroblastoma culture stimulated using a centre of area method [15, $16]$.

This centre of area concept is a construction that emerges from the visual or ranging perception of the robot. In Fig. 6, it can be seen a simulation of what robot would see walking through a cave. This image will be digitalized in three grey levels, black, white and grey, in order to provide three different stimulations to the neural culture, no stimulation, high tetanization, and medium stimulation respectively.

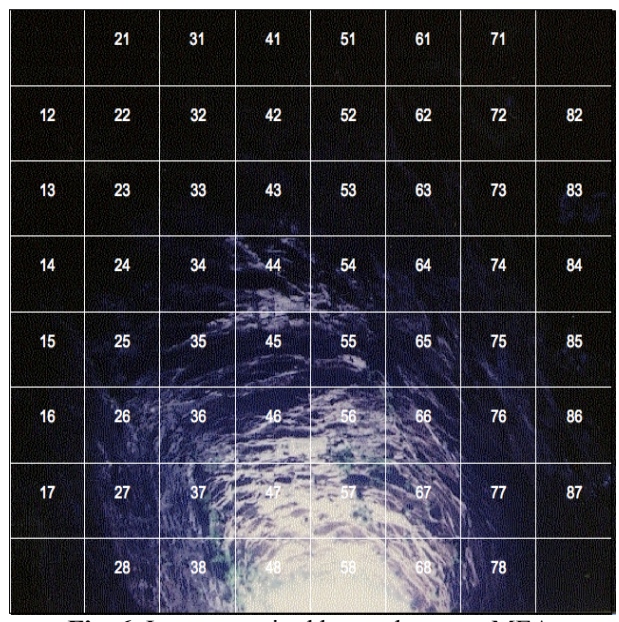

Fig. 6. Image acquired by a robot over MEA.

\section{Vol. 5, No. 1, March 2011}

The resulting stimulation configuration is shown in Fig. 7a. Red boxes correspond to no-stimulation; blue boxes correspond to medium tetanization, while white electrodes will deliver high tetanization according with the acquired cave image. Medium tetanization will consist in five trains of a hundred anodic first pulses with $1 \mathrm{~V}$ amplitude, while high tetanization will provide $1,5 \mathrm{~V}$ anodic first pulses, Fig. $7 \mathrm{~b}$. From this example, it is expected that electrodes that cover the centre of area of the grey and white image, that is the electrodes centered at the bottom of the image, electrodes 48 and 58, will increase more their activity. This winner neuron coordinates will be provided to the robot in order to guide its movement. In the new robot position the camera will send a new image, and the information will be passed to the computer in order to induce a selective tetanization of the biological neural network for changing the resulting direction vector.

$\mathrm{mV}$
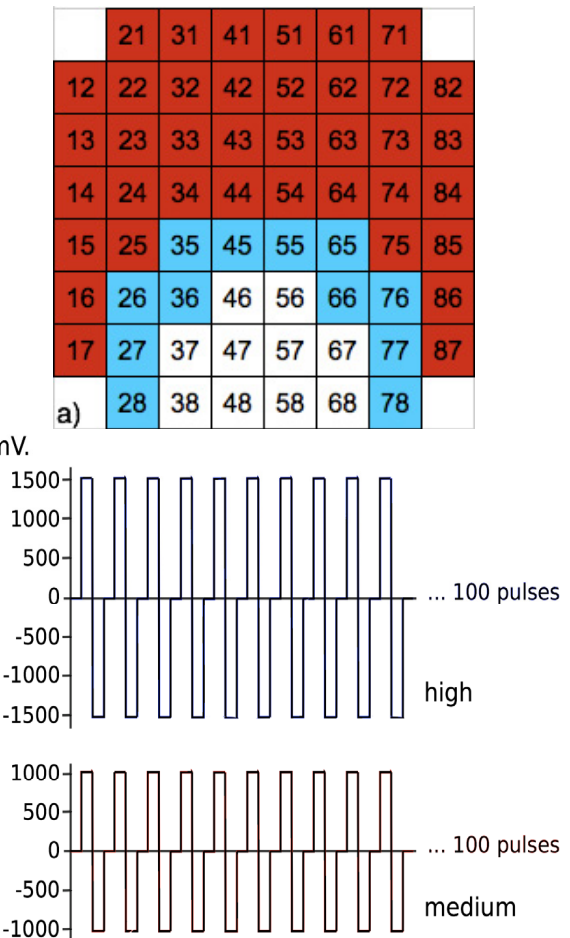

Fig. 7. Selective electrode tetanization. a) MEA representation showing three groups of electrodes, red ones are not stimulated, light blue ones are stimulated with medium tetanization and white ones are stimulated with high tetanization. b) High and medium tetanization pulses train, anodic first waveform. 


\section{Majlesi Journal of Electrical Engineering}

The computer codes the image into a selective tetanization using software developed for us called im2MEA. This software allows loading an image and getting a three gray level image and its corresponding stimulation (see Fig. 8). It allows to specify the gray levels thresholds for selectivity and provides the commands needed to apply such stimulation with a MultiChannel Systems Stimulator STG100x. Im2MEA is still under development and our goal is to achieve with it an autonomous scheme for coding images for robot guidance.

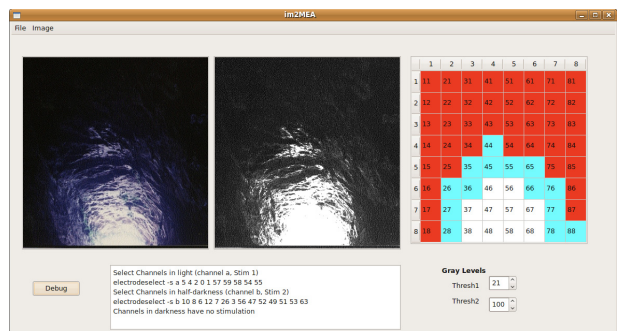

Fig. 8. Screenshot from im2MEA. The image acquired by a robot (left) is transformed into a three gray levels image (centre) and finally transformed into stimulation (right).
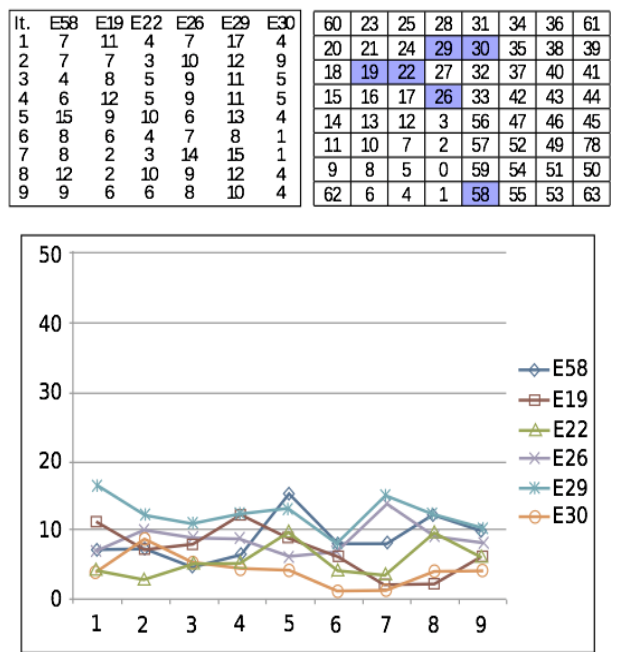

Fig. 9. Spontaneous neural activity detected previous to tetanization. Spikes number (y-axis) from six electrodes were recorded 9 times (x-axis). Left table shows data in numeric format, right table shows a MEA representation with selected electrodes marked out. Spikes number is always below 20 .
Vol. 5, No. 1, March 2011

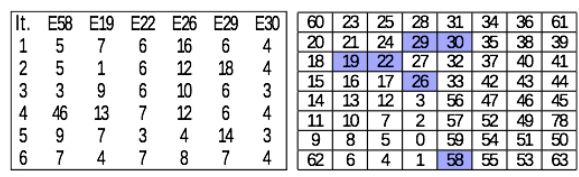

a)
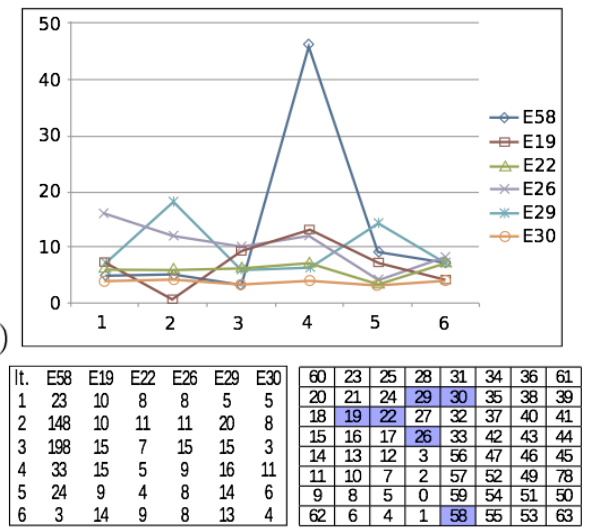

b)

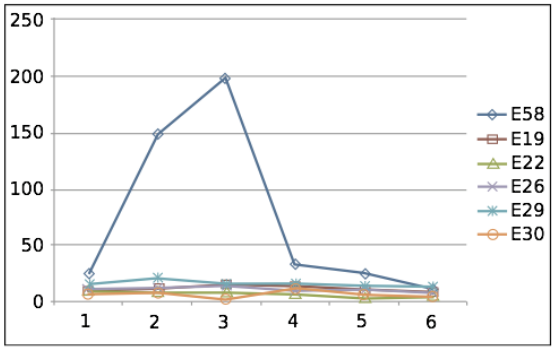

Fig 10. Spontaneous neural activity detected during a) and after b) selective tetanization. In b) was used the same selective stimulation as in a). Note the difference between $y$-axes scales in a) and b), it shows a considerable increase in activation at electrode 58. See Fig. 9 foot for more explanations.

Again, human neuroblastoma cultures were produced using the commercial line SH/SY5Y. Cell culture of SH SY5Y was grown in DMEM (Gibco) completed with $10 \%$ of fetal bovine serum at $37 \mathrm{oC}$ in $5 \% \quad \mathrm{CO} 2$ and humidify atmosphere. The electrophysiological properties of the neuroblastoma cultures were analyzed by recording the spontaneous activity of the network. In vitro neuroblastoma networks show spontaneously firing. This firing rates change during the culture development with marked day differences and the global rate is closely related to the age of the network. Recordings of Neuroblastoma SH-SY5Y has the disadvantage of having a very low signal to noise ratio. As we have shown in previous 


\section{Majlesi Journal of Electrical Engineering}

papers, the electrophysiological properties of the culture change with the age of the culture, getting a potentiation effect in the spontaneous firing. A young neuroblastoma culture (1-5 DIV) has a low spontaneous firing activity, with a signal to noise ratio barely higher than 1:1. A mature neuroblastoma culture (1-15 DIV) has a higher spontaneous firing activity and its SNR may be higher than $2: 1$, but still is lower than SNR of other cells. The physiological recordings correspond to neuroblastoma cultures in the range of 17 div. They show bursting and spiking activity, with usually negative depolarizations. It was used also an automatic detection level for each electrode. This is very convenient if you have multiple channels for extracting spikes.

Spontaneous activity was recorded for intervals of 5 seconds before stimulation, and the total number of spikes extracted was counted for each channel. Fig. 9 shows the total number of spikes per channel, and a graphic visualization of this data for six different electrodes located at different positions at the neural culture.

When the tetanization configuration shown in Fig. 7 was applied, the spiking characteristics of the neuroblastoma culture changed. The computed spikes per channel is shown in Fig. 10a) during the tetanization process. It can be seen that the most significant increment registered is at electrode 58, that matches the centre of area of the provided image, guiding in this way the robot to the light. When the image of the cave was presented once again, that is the same selective stimulation was provided, the registered activity was again modified. In Fig. 10b) it can be seen a clearly potentiation effect in electrode 58 about 4 times, while the rest of the electrodes didn't show any significant increase.

\section{DISCUSSION AND CONCLUSION}

Learning in cultured neuroblastoma networks by a stimulation process, without the involvement of a natural adaptation process to the environment requires identifying the correct stimuli to provide to the neurons maintained ex vivo. These neuroblastoma networks form a large culture covering the whole electrode array and generating a rich dendritic configuration. The connectivity can be modulated by external stimulation as has been described in many studies, but also the activity of the network can be modulated with the appropriate stimulation scheme. We use a stimulation configuration based on the imaged captured by a robot camera. It is very important to adjust the frequency of the train pulses of the stimulation for guiding the robot to the light

Future work consists of determining the optimal stimulation to apply for inducing permanent firing changes in the culture using the image captures, and the

\section{Vol. 5, No. 1, March 2011}

strategies for connecting the robot sensors to the stimulation patterns. These aspects will then constitute the basis for inducing stable goal-directed plasticity, and hence for designing new biological neuroprocessors applied to robotics.

\section{ACKNOWLEDGMENT}

This work was supported by the Spanish Government through grants TIN2008-06893-C03, TEC2006-14186-C02-02 and SAF2008-03694, Cátedra Bidons Egara, Fundación Séneca 08788/PI/08, CIBER$\mathrm{BBN}$ and by the European Comission through the project "'NEUROPROBES"' IST-027017.

\section{REFERENCES}

[1] J A Anderson and E Rosenfeld, Neurocomputing: Foundations of research MIT Press, Cambridge 1998

[2] R J Duro, M Graña and J de Lope, "On the potential contributions of hybrid intelligent approaches to multicomponent robotic system development", Information Sciences 180 (4), pp 2635-2648, Jul 2010

[3] T B DeMarse, D A Wagenaar and S M Potter, "The Neurally Controlled Animat: Biological Brains Acting with Simulated Bodies", Autonomous Robots 11, pp 305-310, 2001

[4] A Novellino, P D'Angelo, L Cozzi, M Chiappalone, V Sanguineti and S Martinoia, "Connecting Neurons to a Mobile Robot: An In Vitro Bidirectional Neural Interface", Computer Intell. Neurosci 2007, pp 1-13, doi: 10 1155/2007/12725

[5] H Bading and M E Greenberg, "Stimulation of protein tyrosine phosphorylation by nmda receptor activation", Science 253 (5022), pp 912-914, Aug 1991

[6] I Antonov, I Antonova and E R Kandel, "Activitydependent presynaptic facilitation and hebbian LTP are both required and interact during classical conditioning in aplysia", Neuron 37(1), pp 135-147, Jan 2003

[7] Y Jimbo, H P Robinson and A Kawana, "Strengthening of synchronized activity by tetanic stimulation in cortical cultures: application of planar electrode arrays", IEEE Transactions on Biomedical Engineering 45(11), pp 1297-1304, Nov Biomedical Engineering 45(11), pp 1297-1304, Nov 1998

[8] E Robbins, MultiChannel Systems Available: www.multichannelsystems.com.

[9] D A Wagenaar, J Pine and S M Potter "An extremely rich repertoire of bursting patterns during the development of cortical cultures", $B M C$ Neuro-science, 7:11, Feb 2006

[10] J M Ferrández, V Lorente, F J Garrigós and E Fernández, "A Biological Neural Network for Robotic Control - Towards a Human Neuroprocessor", IJCCI 2009, pp 508-513, 2009

[11] J M Ferrández, V Lorente, G Díaz, F delaPaz and E Fernández, "An Open-Source Real-Time System for Remote Robotic Control using Neuroblastoma Cultures", WCCI 2010, pp 901-908, 2010 
[12] V Braitenberg, Vehicles: Experiments in Synthetic Psichology MIT Press, Cambridge 1984

[13] J M Ferrández, V Lorente, J M Cuadra, F de la Paz, J R Álvarez-Sánchez and E Fernández, "A Biological Neuroprocessor for Robotic Guidance using a Center of Area Method.”, NeuroComputing (2010), doi: 10 1016/j neucom 201007018

[14] J R Álvarez-Sánchez, J Mira Mira, F de la Paz López and J M Cuadra Troncoso, "The centre of area method as a basic mechanism for representation and navigation", Robotics and Autonomous Systems 55(12), pp 860-869, Dec 2007

[15] J R Álvarez-Sánchez, F delaPaz, J M Cuadra and D de Santos "Reactive Navigation in Real Environments Using Partial Center of Area Method", Robotics and Autonomous Systems (2010), doi: 10 1016/j robot 201009003

[16] J R Álvarez Sánchez, F delaPaz, J M Cuadra and J Rosado, "Partial Center of Area Method Used for Reactive Autonomous Robot Navigation", Bioinspired Applications in Artificial and Natural Computation, 5602, pp 408-418, Jun 2009 


\section{Enhancing Hebbian Learning in Biological Neural Cultures Through Electrical Stimulation}

\author{
Víctor Lorente, Jose Manuel \\ Ferrández \\ Dpto. Electrónica, Tecnología de \\ Computadores y Proyectos, \\ UPCT, Cartagena, Spain \\ \{victor.lorente, jm.ferrandez\}@upct.es
}

\author{
Eduardo Fernández \\ Instituto de Bioingeniería \\ Universidad Miguel Hernández \\ Elche, Spain \\ e.fernandez@umh.es
}

Felix de la Paz

Dpto. de Intelegencia Artificial

UNED

Madrid, Spain

delapaz@dia.uned.es

\begin{abstract}
Electric stimulation has been widely used to induce changes in neuronal cultures coupled to microelectrode arrays (MEAs). In this paper, we used low-frequency current stimulation on dissociated cultures of hippocampal cells to study how neuronal cultures could be trained with this kind of stimulation. We show that persistent and synchronous stimulation of adjacent electrodes may be used for creating adjacent physical or logical connections in the connectivity graph following Hebb's Law.
\end{abstract}

Keywords- Cultured neural networks; Hebbian Law; Induced plasticity; Learning.

\section{INTRODUCTION}

Using biological nervous systems as conventional computer elements is a fascinating problem that permits the hybridization between Neuroscience and Computer Science. This synergic approach can provide a deeper understanding of natural perception and may be used for the design of new computing devices based on natural computational paradigms. Classical computational paradigms consist in serial and supervised processing computations with highfrequency clocks silicon processors, with moderate power consumption, and fixed circuits structure. However the brain uses millions of biological processors, with dynamic structure, slow commutations compared with silicon circuits, low power consumption and unsupervised learning. This kind of computation is more related to perceptual recognition $[1,2]$, due to the natural variance of the perceptive pattern and the a priori lack of knowledge about the perceptual domain.

A real biological processor with millions of biological neurons and a huge number of interconnections would provide much more computational power instead of their low transition rates due to high number of computing elements and the extraordinary network capability of adaptation and reconfiguration to unknown environments. This extraordinary capability is related with natural unsupervised learning.

Microelectrode Arrays (MEAs) have been designed for direct culturing neural cells over silicon or glass substrates, providing the capability to stimulate and record simultaneously populations of neural cells. The use of dissociated cortical neurons cultured onto MEAs represents a useful experimental model to characterize both the spontaneous behaviour of neuronal populations and their activity in response to electrical and pharmacological changes.

Learning is a natural process that needs the creation and modulation of sets of associations between stimuli and responses. Many different stimulation protocols have been used to induced changes in the electrophysiological activity of neural cultures looking for achieve learning [3-13] and low-frequency stimulation has brought good results to researchers enhancing bursting activity in cortical cultures $[10,11]$.

Hebbian learning describes a basic mechanism for synaptic plasticity wherein an increase in synaptic efficacy arises from the presynaptic cell's repeated and persistent stimulation of the postsynaptic cell. The theory is commonly evoked to explain some types of associative learning in which simultaneous activation of cells leads to pronounced increases in synaptic strength. Basically the efficiency of a synaptic connection is increased when presynaptic activity is synchronous with post-synaptic activity. In this work, we use this kind of stimulation to create adjacent physical or logical connections in the connectivity graphs using Hebb's Law.

In previous papers, we used a specific low-frequency current stimulation on dissociated cultures of hippocampal cells to study how neuronal cultures could be trained with this kind of stimulation $[14,15]$. We showed that persistent and synchronous stimulation of adjacent electrodes may be used for creating adjacent physical or logical connections in the connectivity graph following Hebb's Law. In later experiments, we have used different parameters for this stimulation to check if those connections can be created stimulating with different configurations. The results provided in this paper show that low-frequency stimulation can create adjacent connections with different amplitude values. In addition, we present new results explaining when such connections have been established in a dissociated culture of hippocampal neurons grown onto a MEA. 
The outline of the paper is as follows. We first introduce the evolution of the related work on this topic. Next, we present the methods for addressing Hebbian Learning throw electrical stimulation. The following section shows the results obtained using a specific stimulation with our experimental setup on hippocampal cultures to train them. We conclude by discussing some crucial aspects of the research and the remaining challenges.

\section{RELATED WORK}

The first studies demonstrating functional plasticity in cultured networks began 1990s. The research group of Akio Kawana at NTT in Japan reported that tetanic stimulation through one or several electrodes resulted in plasticity [3] They observed a change in the probability of evoking bursts by test pulses, as well as a change in the rate of spontaneous bursting, as a result of repeatedly evoking bursts using strong tetanic stimulation. Jimbo et al. reported similar results with a different tetanic stimulation and used voltage clamp to observe inward currents associated with evoked bursts [4] The following year, Jimbo et al. reported that tetanizing a single electrode resulted in changes in the responses to tes pulses to other electrodes [5]. In another paper, Jimbo et al. used simultaneous tetanization through a pair of electrodes to induce more precise forms of plasticity, expressed in detailed spike patterns evoked by electrical (probe) pulses [6]. Since then, a few other groups have reported on other forms of plasticity in MEA neural cultures.

Typically, these later papers have focused on more abstract plasticity results, more related to the network level than to the synaptic level. For instance, Shahaf and Marom reported that networks could be learn to respond in specific ways to test pulses, by repeatedly stimulating until the desired response was obtained [7], while Ruaro et al. reported that cultured networks could learn to extract a specific pattern from a complex image that had been presented repeatedly as spatial patterns of multielectrode stimulation [8].

In the following years, researchers have tried using more complex stimulation patterns in order to induce plasticity in neural cultures. Wagenaar et al. [9] looked for plasticity expressed in changes in spontaneous burst patterns, and in array-wide response patterns to electrical stimuli, following several induction protocols related to the previous ones, as well as some novel ones. Madhavan et al. [10] investigated patterns of spontaneous multi-single-unit activity to study the potential role of bursts of action potentials in memory mechanisms. Their analysis revealed spatiotemporally diverse bursts occurring in well-defined patterns, which remained stable for several hours. Chao et al. [11] compared five established statistical methods to one of their own design, called center of activity trajectory (CAT), to quantify functional plasticity at the network level. Stegenga studied the possibility of changing the spatio-temporal structure of spontaneous bursts using different configurations of tetanic stimulation. They obtained a profile of the array-wide spiking rate, a burst profile (BP) and also calculated the perelectrode spiking rate profile, the phase profiles (PPs). None of their stimulation methods had a measurable effect on of the specific burst statistics (peak firing rate, rise and fall times). However, they found many PP changes in their experiments, which can be seen as a confirmation that the analysis is sensitive to changes in the network.

Other researchers have focused in changing some stimulation parameters (voltage vs. current, frequency, amplitude...) to achieve learning. Brewer et al. [12] used chronic stimulation for getting an increase in evoked spike counts per stimulus and in spiking rate. The results obtained suggested that plastic network changes induced by chronic stimulation enhance the reliability of information transmission and the efficiency of multi-synaptic network communication. In turn, Martinoia et al. [13] applied lowfrequency stimulation constantly applied over weeks. They found that the stimulation had a delayed effect modulating responsiveness capability of the network without directly affecting its intrinsic in vitro development.

\section{METHODS}

\section{A. Cell Culture Preparation}

Dissociated cultures of hippocampal CA1-CA3 neurons were prepared from E17.5 sibling embryos (Figure 1). During the extraction of the hippocampus a small amount of cortical tissue will have inevitably also been included. Tissue was kept in $2 \mathrm{ml}$ of HBSS. $10 \mathrm{mg} / \mathrm{ml}$ of trypsin was added to the medium and placed in a $37 \mathrm{C}$ water bath for $13 \mathrm{~min}$ for subsequent dissociation. The tissue was then transferred to a $15 \mathrm{ml}$ falcon containing $4 \mathrm{ml}$ of NB/FBS and triturated using combination of fine pore fire polished Pasteur pipettes (Volac). Cells were then transferred onto 12 well plates (Corning Incorporated) containing glass coverslips (Thermo Scientific).

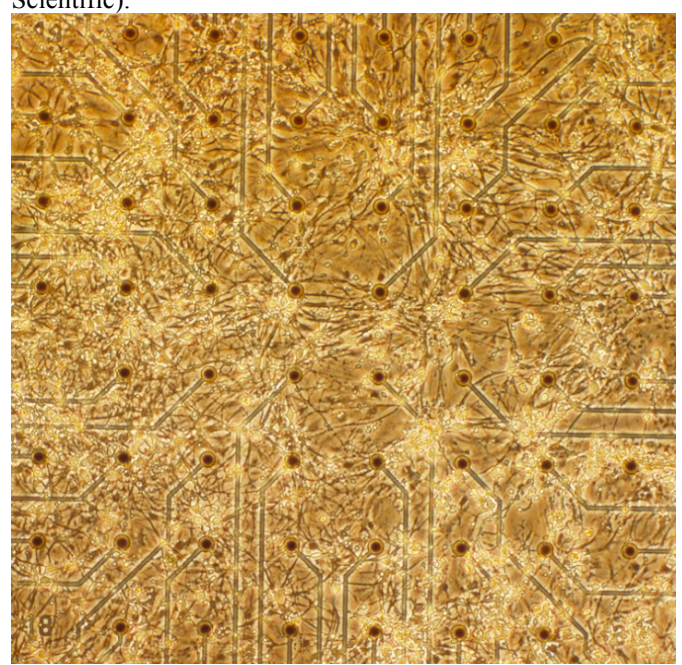

Figure 1 Hippocampal CA1-CA3 culture (21 DIV) on a microelectrodes array 
The coverslips were pre-treated overnight with PDL $(50 \mathrm{mg} / \mathrm{ml})$, a synthetic molecule used as a coating to enhance cell attachment. The PDL was then aspirated away and the coverslips washed twice with PBS. This was then followed by a final coating of laminin $(50 \mu \mathrm{g} / \mathrm{ml})$, a protein found in the extracellular matrix, to further help anchor the dissociated hippocampal cells. The cells were maintained in a mixture of $500 \mathrm{ml} \mathrm{NB} / \mathrm{B} 27$ (promotes neural growth) and $500 \mathrm{ml} \mathrm{NB} / \mathrm{FBS}$ (promotes glial growth), each supplemented with Glutamax and Pen/Strep (dilution 1/100). Glutamax improves cells viability and growth while preventing build up of ammonia and Pen/Strep helps to prevent any infections. Cell density for each coverslip was roughly 200000 cells. Cells were kept in an incubator at $37 \mathrm{C}$ in $6 \%$ $\mathrm{CO} 2$.

\section{B. Expeerimental Setup}

Microelectrode arrays (Multichannel systems, MCS) consisted of $60 \mathrm{TiN} / \mathrm{SiN}$ planar round electrodes $(200 \mu \mathrm{m}$ electrode spacing, $30 \mu \mathrm{m}$ electrode diameter) arrange in a $8 \times 8$ grid were used. Two pairs of electrodes were selected for creating functional connections between them. The activity of all cultures was recorded using a MEA60 System (MCS). After 1200X amplification, signals were sampled at $10 \mathrm{kHz}$ and acquired through the data acquisition card and MCRack software (MCS). Electrical stimuli were delivered through a two-channel stimulator (MCS STG1002) to each pair of electrodes.

\section{Expeerimental Protocol}

Three experiments were carried out using a total of 15 cultures during 2-3 weeks. Five cultures were stimulated in each experiment with a low-frequency electrical stimulation, which differs only on a few parameters. Each experiment started when cultures had 14DIV. The following summarizes the experiments and stimulation applied to the cultures:

1) Experiment1 (E1) Cultures ID48-52

a) Days of experiment 16 .

b) Stimulation 1 train of 5 biphasic pulses cathodicfirst (50 $\mu \mathrm{A}$ peak, $100 \mu$ s phase, $50 \mathrm{~ms}$ ISI) was delivered every $3 \mathrm{~s}$ for $10 \mathrm{~min}$.

2) Experiment2 (E2) Cultures ID68-72

a) Days of experiment 10

b) Stimulation 2 train of 5 biphasic pulses cathodicfirst $(60 \mu \mathrm{A}$ peak, $100 \mu$ s phase, $50 \mathrm{~ms}$ ISI) was delivered every $3 \mathrm{~s}$ for $8 \mathrm{~min}$

3) Experiment3 (E3) Cultures ID73-77

a) Days of experiment 11

b) Stimulation3 train of 5 biphasic pulses cathodicfirst (40 $\mu \mathrm{A}$ peak, $100 \mu$ s phase, $50 \mathrm{~ms}$ ISI) was delivered every $3 \mathrm{~s}$ for $8 \mathrm{~min}$.

In every experiment, two pairs of electrodes with no logical connections between them were selected using connectivity diagrams based on cross-correlation. In every stimulation session these steps were followed:

1) Spontaneous activity was recorded for $2 \mathrm{~min}$ after a recovery period.

2) Cultures were then stimulated through the two pairs of electrodes using the corresponding stimulation protocol.

3) Spontaneous activity was recorded for 2 min after the stimulation.

\section{Analysis Performed}

We observed the spontaneous activity of the cultures before and after the stimulation experiments, as well as their evoked response to the applied stimulus. Extensive burst analysis, post-stimulus time histograms and functional connectivity were the main analysis performed to the registered data.

Correlation and information theory-based methods are used to estimate the functional connectivity $[16,17]$ of invitro neural networks: Cross-correlation, Mutual Information, Transfer Entropy and Joint Entropy. Such methods need to be applied to each possible pair of electrodes, which shows spontaneous electrophysiological activity. For each pair of neurons, the connectivity method provides an estimation of the connection strength (one for each direction). The connection strength is supposed to be proportional to the value yielded by the method. Thus, each method is associated to a matrix, the Connectivity Matrix $(\mathrm{CM})$, whose elements $(\mathrm{X}, \mathrm{Y})$ correspond to the estimated connection strength between neuron $\mathrm{X}$ and $\mathrm{Y}$.

High and low values in the $\mathrm{CM}$ are expected to correspond to strong and weak connections. By using such approach, inhibitory connections could not be detected because they would be mixed with small connection values. However, non-zero CM values were also obtained when no apparent causal effects were evident, or no direct connections were present among the considered neurons.

In our experiments, Connectivity maps offered a visualization of the connectivity changes that occur in the culture. Connectivity maps were generated using the connectivity matrix (CM) obtained after applying the analysis and Cross-Correlation or Mutual Information. By setting thresholds in the CM, it is possible to filter out some small values that may correspond to noise or very weak connections. In consequence, these maps show the strongest synaptic pathways, and can be used for visualizing the neural weights dynamics, and validate the achieved learning.

\section{RESULTS}

The low-frequency current stimulation used in this study had an impact on the electrophysiological responses of the cultures, as previous studies had reported [13]. Raster plots showed that all of the stimulations provided induce changes in the firing frequency of the cultures. 


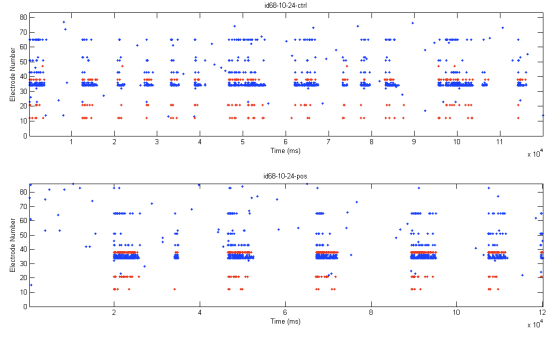

(a)

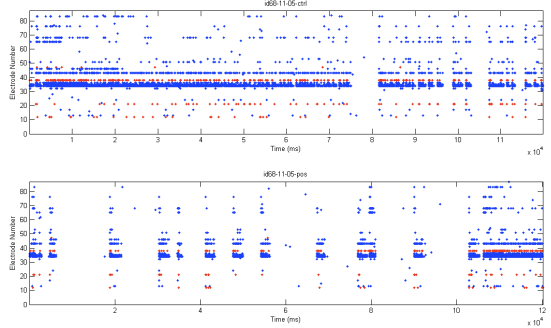

(b)
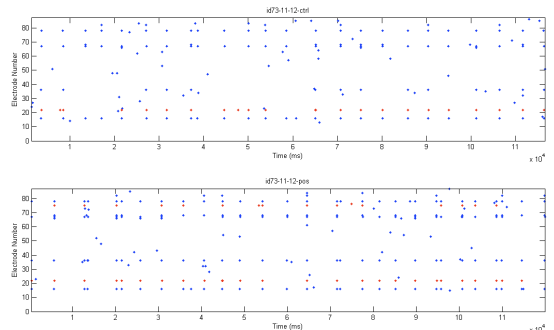

(c)
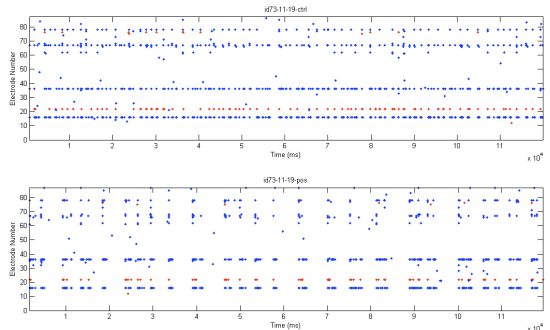

(d)

Figure 2 Raster plots extracted from cultures of experiments E2 and E3 (a) (21DIV) and (b) (32DIV) belong to ID68 from E2, (c) (30DIV) and (d) (37DIV) belong to ID73 from E3 Each figure is divided in two graphs, which show the spiking activity of the culture before and after stimulation Raster plots show a change in the spiking activity, changing from a uniform activity before stimulation to a more concentrated activity after stimulation This result is emphasized after the third week in vitro due to the maturing occurred in the cultures
Furthermore, we can observe some kind of reorganization in the firing activity, from a uniform spiking activity to a discrete spiking activity. After the third week in vitro, the bursting activity becomes more frequent and robust and this effect is much more evident than during the first weeks (Figure 2).

The change on the spiking activity of the cultures can also be seen clearly observing the instantaneous firing frequencies (Figure 3) and the interspike intervals (Figure 4) over the time. Instantaneous firing frequency graphs shows that stimulated electrodes start firing in more separated period of times after stimulation but each firing period last longer.

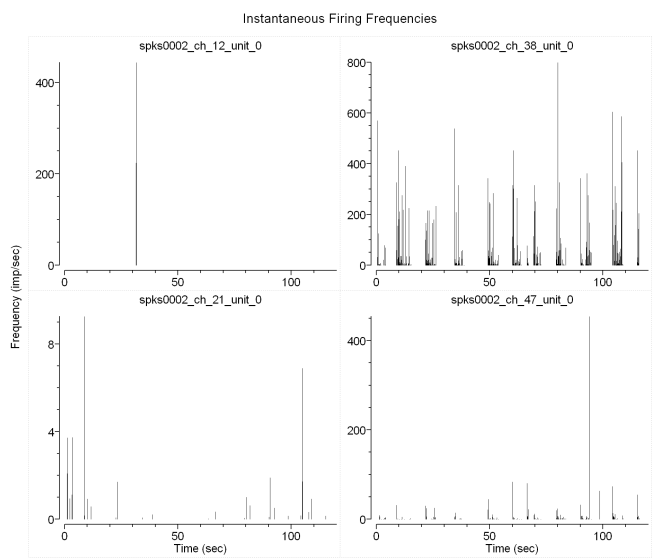

(a)

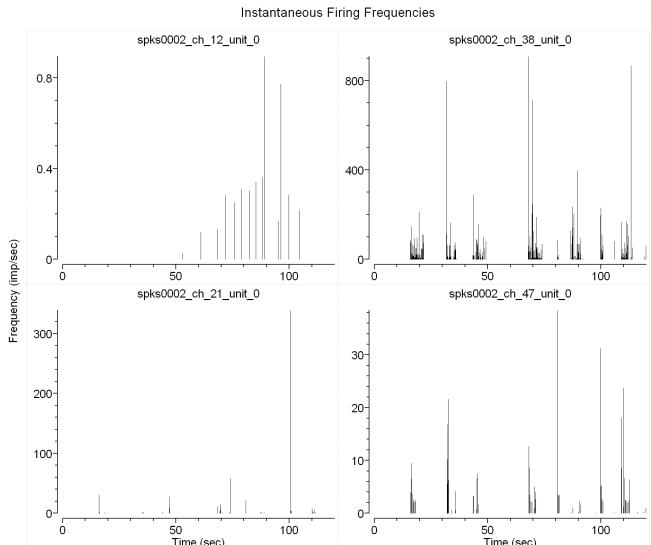

(b)

Figure 3 Instantaneous firing frequencies of stimulated electrodes in the culture ID68 (22DIV) from E2 before (a) and after (b) stimulation A change in the spiking periods can clearly be seen, which are less in quantity and longer in duration This culture only created a connection between the second pair of electrodes $(38,47)$, which had an impact on the instantaneous firing frequencies Connected electrodes fire in the same firing periods, whereas not connected electrodes had no firing relation 
In addition, interspike intervals graphs show the previous results in the spiking periods but also it can be seen that the ISI decrease both in value and dispersion. Both effects are related to the stimulation, which modulates the firing capabilities of the cultures.

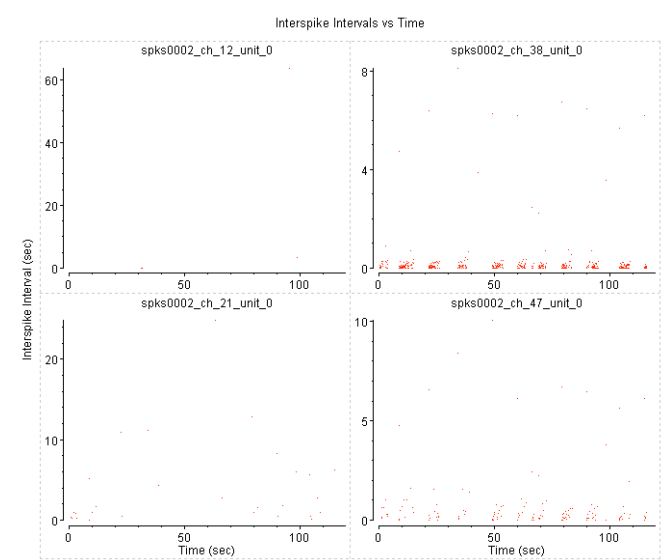

(a)

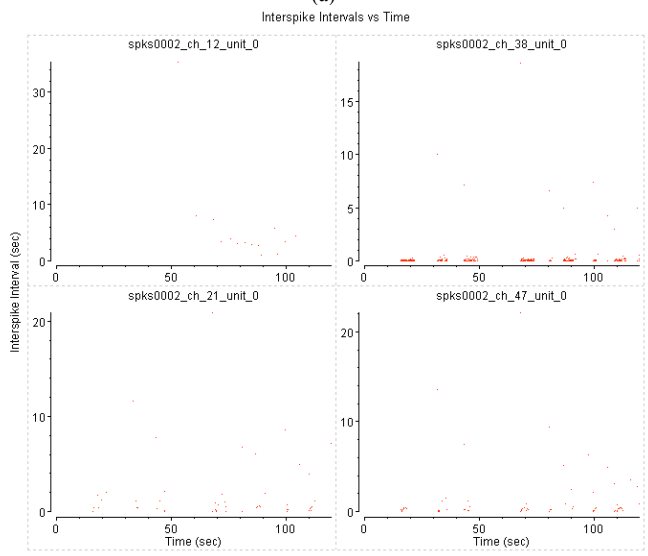

(b)

Figure 4 Interspike intervals on recordings from stimulated electrodes in the culture ID68 (22 DIV) from E2 before (a) and after (b) stimulation Spiking periods have change after stimulation (b) ISI has decreased both in value and dispersion after stimulation

Connectivity diagrams based on cross-correlation between electrodes showed some kind of connections reorganization after stimulations, concentrating them in a few electrodes. Furthermore, adjacent physical or logical connections in the connectivity graph following Hebb's law appeared in some pairs of stimulated electrodes (Figure 5).
Electrodes with created connections between them can distinctly be detected with the instantaneous firing frequencies graphs. Figure 3 showed two pair of stimulated electrodes $(12,21$ and 38, 47) before and after the stimulation session. The firing periods of the electrodes from the second pair follow exactly each other, whereas the firing periods of the first pair of electrodes do not match. Furthermore, the electrodes of the second pair change both the firing periods after stimulation. This features indicates that there exits a strong connection between them.

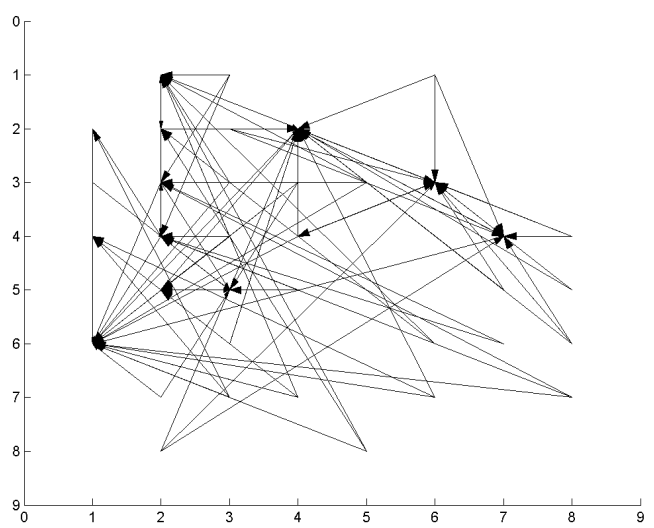

(a)

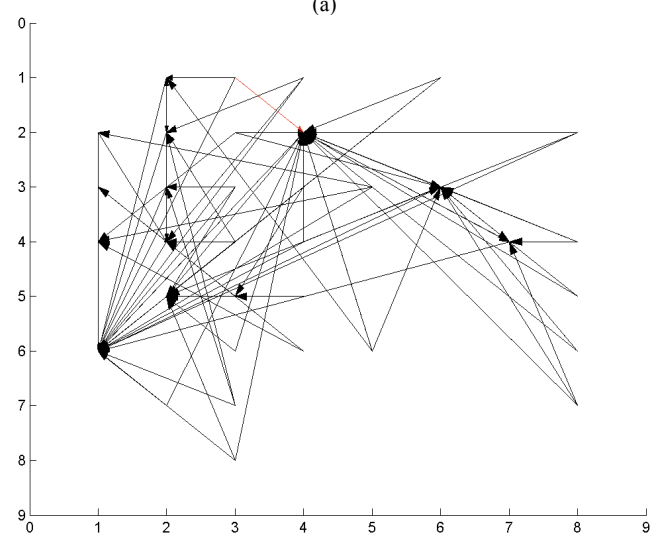

(b)

Figure 5 Connectivity graphs based on cross-correlation between electrodes The graph belong to the culture ID48 (E1) at 25 DIV Pair of electrodes 31,42 and 52,53 were stimulated with low-frequency current stimulation with $50 \mu \mathrm{A}$ biphasic pulses (a) No logical connections were observed before stimulation (b) A connection (red arrow) between electrodes 31 and 42 has appeared 
All of the cultures of E1 created a connection between the paired stimulated electrodes, whereas $60 \%$ of the cultures of E3 and only $20 \%$ of the cultures of E2 showed that connection. In some cases, the connection was intermittent, lasting one to several days. In others, a persistent connection was created. Finally, some cultures did not create any kind of connections. In this way, Hebbian tetanization created ad-hoc permanent or transient logica connections by modifying the efficiency of the paths between the selected electrodes. We speculate that the failed cultures may be caused by a not-homogeneous culture growth between the electrodes or by the neurobiological properties of the connections as will be confirmed using histological techniques in future works. In this case, using low-frequency current stimulation with $50 \mu \mathrm{A}$ biphasic pulses provided the best results for creating connections following Hebb's law.

\section{CONCLUSIONS}

Learning in biological neural cultures is a challenging task. Different authors have proposed different methods for inducing a desired and controlled plasticity over the biological neural structure. Low-frequency stimulation has brought good results to researchers enhancing bursting activity in cortical cultures.

In this paper, we have shown that using this kind of stimulation it is possible to create adjacent physical or logical connections in the connectivity graph following Hebb's Law and such connections induce changes in the electrophysiological response of the cells in the culture, which can be observed in the different analysis performed. Furthermore, low-frequency stimulation induces changes using different values of current amplitude and stimulation time. Persistent and synchronous stimulation of relevant adjacent electrodes may be used for strengthen the efficiency of their connectivity graph. These processes may be used for imposing a desired behaviour over the network dynamics. In this work, a stimulation procedure is described in order to achieve the desired plasticity over the neura cultures, and shaping in this way the functional connectivity of the neural culture.

In future works, we will use different kind of electrical stimulations, such as tetanic stimulation, and try to find what are the optimal parameters of every stimulation that induce persistent changes in the cultured network. These induced connections will be used for driving a robot using Braitenberg's principles.

\section{ACKNOWLEDGMENT}

This work is being funded by grant 12361/FPI/09 from Séneca Foundation, from the region of Murcia and by the project 2010V/PUNED/0011 from UNED.

\section{REFERENCES}

[1] J A Anderson and E Rosenfeld, "Neurocomputing: Foundations of research" MIT Press, Cambridge, 1988

[2] The Facets Project Accessed March 2013 from http://facets kip uni-heidelberg de/

[3] E Maeda, Y Kuroda, H P Robinson and A Kawana, "Modification of parallel activity elicited by propagating bursts in developing networks of rat cortical neurons" European Journal of Neuroscience, vol 10, num 2, 1998, p 488-96

[4] Y Jimbo, H P Robinson and A Kawana, "Strengthening of synchronized activity by tetanic stimulation in cortical cultures: application of planar electrode arrays" IEEE Transactions on Biomedical Engineering, vol 45, num 11, 1998, p 1297-304

[5] Y Jimbo, T Tateno and H PC Robinson, "Simultaneous induction of pathway specific potetiation and depression in induction of pathway specific potetiation and depression in
networks of cortical neurons" Biophysical Journal, vol 76, networks of cortical neur
num 2, 1999, p 670-678

[6] T Tateno and Y Jimbo, "Activity-dependent enhancement in the reliability of correlated spike timings in cultured cortical neurons" Biological Cybernetics, vol 80, num 1, 1999, p 45-55

[7] G Shahaf and S Marom, "Learning in networks of cortical neurons" Journal of Neuroscience, vol 21, num 22, 2001, p 8782-8

[8] ME Ruaro, P Bonifazi, and V Torre, "Toward the neurocomputer: image processing and pattern recognition with neuronal cultures" IEEE Transactions on Biomedical Engineering, vol 52, num 3, 2005, p 371-83

[9] D A Wagenaar, J Pine, and S M Potter, "Searching for plasticity in dissociated cortical cultures on multi-electrode arrays" Journal of negative results in biomedicine, vol 5, num 16, 2006

[10] R Madhavan, ZC Chao, and S M Potter, "Plasticity of recurring spatiotemporal activity patterns in cortical recurring spatiotemporal activity patterns in cortical
networks" Physical Biology, vol 4, num 3,2007, p 181-93

[11] Z C Chao, D J Bakkum, and S M Potter, "Region-specific network plasticity in simulated and living cortical networks: comparison of the center of activity trajectory (CAT) with other statistics" Journal of Neural Engineering, vol 4, num 3, 2007, p 294-308

[12] A N Ide, A Andruska, M Boehler, B C Wheeler, and G J Brewer, "Chronic network stimulation enhances evoked action potentials" Journal of Neural Engineering, vol 7, num 3, February 2010, 16008

[13] L L Bologna, T Nieus, M Tedesco, M Chiappalone, $F$ Benfenati, and S Martinoia, "Low-frequency stimulation enhances burst activity in cortical cultures during enhances burst activity in cortical
development" Neuroscience, vol 165,2010

[14] V Lorente, J M Ferrández, F de la Paz, and E Fernández, "Training hippocampal cultures using low-frequency stimulation: Towards Hebbian Learning" 8th International Meeting on Substrate-Integrated Microelectrodes Arrays, 2012, pp 90-91

[15] J M Ferrández, V Lorente, F de la Paz, and E Fernández, "Training, Biological Neural Cultures: Towards Hebbian Learning" Neurocomputing, 2012 http://dx doi org/10 1016/j neucom 201209031

[16] O Sporns and G Tononi G, "Classes of network connetivity and dynamics" Complexity, vol 7,2002, pp 28-38

[17] K J Friston, C Frith, R Frackowiak, "Time-dependent changes in effective connectivity measured with PET" Human Brain Mapping, vol 1, 1993, pp 69-79 